Illinois State University

ISU ReD: Research and eData

Theses and Dissertations

$1-16-2020$

\title{
The 'dialogic' Of Pedagogical Design: Elementary Teachers Who Consistently Integrate Digital Technologies
}

Aaron R. Gierhart

Illinois State University, aarongierhart@gmail.com

Follow this and additional works at: https://ir.library.illinoisstate.edu/etd

Part of the Curriculum and Instruction Commons, Educational Methods Commons, Elementary and Middle and Secondary Education Administration Commons, Elementary Education and Teaching Commons, and the Instructional Media Design Commons

\section{Recommended Citation}

Gierhart, Aaron R., "The 'dialogic' Of Pedagogical Design: Elementary Teachers Who Consistently Integrate Digital Technologies" (2020). Theses and Dissertations. 1198.

https://ir.library.illinoisstate.edu/etd/1198

This Dissertation is brought to you for free and open access by ISU ReD: Research and eData. It has been accepted for inclusion in Theses and Dissertations by an authorized administrator of ISU ReD: Research and eData. For more information, please contact ISUReD@ilstu.edu. 
THE 'DIALOGIC’ OF PEDAGOGICAL DESIGN: ELEMENTARY TEACHERS WHO CONSISTENTLY INTEGRATE DIGITAL TECHNOLOGIES

\section{AARON R. GIERHART}

\section{Pages}

Despite the pervasiveness of digital technologies in society and educational settings, gaps in digital participation for elementary learners and means-end views of the benefits and effectiveness of digital innovations for teaching and learning persist. The focus on digital technologies at the elementary level must shift to critical pedagogy in order to promote effective teaching and learning and equitable student participation in an increasingly digital society. A teacher's pedagogy continually evolves across their entire life journey and is never fully mastered; therefore, in order to better understand the development of pedagogical design with digital technologies by elementary teachers, it was vital to tell their stories. The purpose of this study was to describe the experiences and life stories of elementary teachers who consistently integrate digital technologies in their instruction. To construct the narratives of five participants, who were fulltime K-5 classroom teachers in Western and Central Illinois, narrative methodology was used. Data collection included an initial life story interview, a focus group and interview about artifacts of teaching, a classroom observation, and a follow-up interview. A critical events approach was used to analyze the data and construct each participant's narrative. The findings were presented within the theoretical lenses of the New London Group's (1996) pedagogy of multiliteracies framework and Britzman's (2003) dialogic theory of teacher practice. In teaching with digital technologies, the participants remained in dialogue with the 
following factors: core beliefs, district curricula, institutional factors, perceived pedagogical affordances of digital technologies, professional development and collaboration, self-efficacy, student needs, and technology access. Of the four pedagogical components of the pedagogy of multiliteracies - situated practice, overt instruction, critical framing, and transformed practice critical framing and transformed practice were the least emphasized by the participants.

Ultimately, it was found that elementary teachers develop their pedagogical design with digital technologies across their careers as well as throughout their lives. These experiences are laden with personal and professional dialogue that each elementary teacher must negotiate and make ongoing meaning of as they continue to develop and enact their digital pedagogical design. To better design of transformative learning experiences for students, teachers must actively reflect on and respond to this dialogue. To support educators in leveraging technology in ways that promote equitable participation and effective, authentic learning, policymakers must pass legislation that reduces restrictions on teachers so they may enact critical digital pedagogical design. Designers of professional development and teacher educators must prepare and support practicing and future elementary teachers in adopting critical pedagogical perspectives and approaches with technologies. Finally, in spite of dialogic factors and challenges they face, the narratives suggest that teachers are ultimately responsible for designing instruction with a critical mindset, leveraging digital technologies to empower students as they engage in socioculturally authentic learning. Recommendations for future research include additional narrative inquiry focused on the life stories of elementary teachers who consistently enact critical digital pedagogy and how this impacts elementary students' digital participation and learning, both in the classroom context and beyond.

KEYWORDS: Educational technology; Pedagogy; Elementary education, Multiliteracies 
THE 'DIALOGIC' OF PEDAGOGICAL DESIGN: ELEMENTARY TEACHERS WHO CONSISTENTLY INTEGRATE DIGITAL TECHNOLOGIES

AARON R. GIERHART

\begin{abstract}
A Dissertation Submitted in Partial
Fulfillment of the Requirements for the Degree of

DOCTOR OF EDUCATION

School of Teaching and Learning

ILLINOIS STATE UNIVERSITY
\end{abstract}


Copyright 2020 Aaron R. Gierhart 
THE 'DIALOGIC' OF PEDAGOGICAL DESIGN: ELEMENTARY TEACHERS WHO CONSISTENTLY INTEGRATE DIGITAL TECHNOLOGIES

AARON R. GIERHART

COMMITTEE MEMBERS:

Robyn Seglem, Chair

Kyle Miller

Anna Smith 


\section{ACKNOWLEDGMENTS}

I would like to thank my wife, Alesha, without whom this research and my pursuit of a doctoral degree would not be possible. Your support, encouragement, patience, and love made all the difference. I am beyond excited for our family's new chapter in Georgia this year.

I want to thank my daughter Eloise and to-be-born second child. Both of you are my inspiration.

I wish to thank my parents, Paul and Susan, for your support during the past four years. I hope I continue to make you proud in the years to come.

I would like to thank Robyn Seglem, my mentor and chairperson of my dissertation committee, for your unyielding support and guidance. You gave so much of your time to answer questions and point me in the right direction. I will be forever grateful for how much you have impacted my life during my time at Illinois State.

Thank you Kyle Miller for sharing your expertise in qualitative research design. You even took time after trick-or-treating to video chat and answer my questions, for which I am ever-grateful!

Thank you Anna Smith for sharing your wisdom as I designed the theoretical and conceptual frameworks for this study. I hope to continue co-authoring with you in the years to come.

Thank you to the professors and staff at the School of Teaching and Learning at Illinois State University, especially Sherry Sanden, Ryan Brown, and Alan Bates. My experience as a student and professor in this department was incredible! 
Finally, I would like to thank the five wonderful educators who participated in this study. Felicity, Iris, Laurel, Nora, and Thea: I am forever indebted for your time, generosity, and willingness to share your lives and teaching practices with me.

A. R. G. 


\section{CONTENTS}

Page

ACKNOWLEDGEMENTS

TABLES Viii

FIGURES

PROLOGUE 1

CHAPTER I: ESTABLISHING THE RESEARCH PROBLEM 6

$\begin{array}{ll}\text { Statement of the Research Problem } & 7\end{array}$

Purpose of the Research Study 9

$\begin{array}{ll}\text { Research Questions } & 10\end{array}$

Operationalizing Key Terms 11

$\begin{array}{ll}\text { Consistently } & 11\end{array}$

Digital Technologies $\quad 11$

$\begin{array}{ll}\text { Pedagogy } & 15\end{array}$

$\begin{array}{ll}\text { Design and Pedagogical Components } & 17\end{array}$

$\begin{array}{ll}\text { Dialogic } & 18\end{array}$

$\begin{array}{ll}\text { Significance of the Research } & 18\end{array}$

Overview of the Study 19

CHAPTER II: REVIEW OF LITERATURE 22

Theoretical Framework: Dialogic Theory of Teacher Practice 23

$\begin{array}{ll}\text { Pedagogical Discourses } & 24\end{array}$

$\begin{array}{ll}\text { Social Nature of Pedagogy } & 26\end{array}$

Biography and Pedagogy 30 
Discourses of Technology in Education 33

Historical Authoritative Discourses $\quad 34$

Internally Persuasive Discourses $\quad 40$

Theoretical Framework: Pedagogy of Multiliteracies Framework 51

Situated Practice $\quad 52$

$\begin{array}{ll}\text { Overt Instruction } & 53\end{array}$

Critical Framing $\quad 55$

$\begin{array}{ll}\text { Transformed Practice } & 57\end{array}$

Conceptual Framework: Bakhtinian Novelness 58

$\begin{array}{lr}\text { Polyphony } & 59\end{array}$

$\begin{array}{lr}\text { Chronotope } & 62\end{array}$

$\begin{array}{ll}\text { Carnival } & 66\end{array}$

$\begin{array}{ll}\text { Conclusion } & 69\end{array}$

$\begin{array}{ll}\text { CHAPTER III: METHODOLOGY } & 70\end{array}$

Restatement of the Research Question $\quad 70$

$\begin{array}{ll}\text { Interpretivist Paradigm } & 71\end{array}$

$\begin{array}{ll}\text { Narrative Methodology } & 72\end{array}$

$\begin{array}{ll}\text { Participant Selection } & 75\end{array}$

$\begin{array}{ll}\text { Research Contexts } & 77\end{array}$

$\begin{array}{ll}\text { Data Collection } & 78\end{array}$

Initial Life Story Interviews $\quad 79$

$\begin{array}{lr}\text { Artifacts and Focus Group } & 80\end{array}$

$\begin{array}{lr}\text { Observations } & 82\end{array}$ 
$\begin{array}{ll}\text { Follow-Up Interviews } & 83\end{array}$

$\begin{array}{ll}\text { Data Analysis } & 85\end{array}$

$\begin{array}{ll}\text { Construction of the Narratives } & 85\end{array}$

$\begin{array}{ll}\text { Analyzing the Narratives } & 88\end{array}$

Rigor and Authenticity $\quad 89$

$\begin{array}{ll}\text { Ethics } & 92\end{array}$

Limitations of the Methodology 94

CHAPTER IV: NARRATIVE FINDINGS 96

$\begin{array}{ll}\text { Felicity } & 96\end{array}$

Felicity’s Classroom: January $2019 \quad 96$

$\begin{array}{ll}\text { Felicity's Journey } & 101\end{array}$

$\begin{array}{ll}\text { Felicity’s Pedagogical Design } & 105\end{array}$

$\begin{array}{ll}\text { Iris } & 130\end{array}$

Iris’s Classroom: March $2019 \quad 130$

$\begin{array}{ll}\text { Iris's Journey } & 137\end{array}$

Iris’s Pedagogical Design 139

$\begin{array}{ll}\text { Laurel } & 156\end{array}$

Laurel's Classroom: February $2019 \quad 156$

$\begin{array}{ll}\text { Laurel's Journey } & 163\end{array}$

$\begin{array}{ll}\text { Laurel's Pedagogical Design } & 168\end{array}$

$\begin{array}{ll}\text { Nora } & 183\end{array}$

Nora’s Classroom: March $2019 \quad 183$

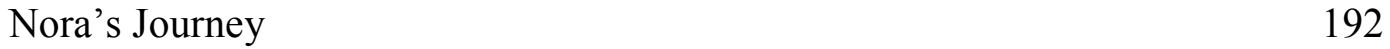


Thea

Thea's Classroom: March 2019

Thea's Journey

Thea's Pedagogical Design

Conclusion

Pedagogy in Dialogue

Core Beliefs

District Curricula

Institutional Factors

Perceived Pedagogical Affordances of Digital Technologies

Professional Development and Collaboration

Self-Efficacy

Student Needs

Technology Access

Pedagogical Components

Situated Practice

Overt Instruction

Critical Framing

Transformed Practice

Conclusion 
Answering the Research Questions 275

$\begin{array}{ll}\text { Biography } & 276\end{array}$

$\begin{array}{ll}\text { Career Experiences } & 278\end{array}$

Transformative Pedagogical Design $\quad 280$

$\begin{array}{ll}\text { Answering the Sub-Questions } & 281\end{array}$

Implications of the Research 286

$\begin{array}{ll}\text { Policymakers } & 286\end{array}$

Teacher Education and Professional Development 288

$\begin{array}{ll}\text { Elementary Teachers } & 290\end{array}$

Recommendations for Future Research $\quad 292$

$\begin{array}{ll}\text { EPILOGUE } & 294\end{array}$

$\begin{array}{ll}\text { REFERENCES } & 296\end{array}$

APPENDIX A: LIFE STORY INTERVIEW PROTOCOL 355

APPENDIX B: ONLINE FOCUS GROUP INTRODUCTION 356

APPENDIX C: OBSERVATION PROTOCOL 357

APPENDIX D: SEMI-STRUCTURED INTERVIEW PROTOCOL 358

APPENDIX E: INFORMED CONSENT FORM 359 


\section{TABLES}

Table

Page

1. Participant demographics 


\section{FIGURES}

Figure

$\begin{array}{ll}\text { 1. Felicity's class recording booth/studio } & 108\end{array}$

2. Felicity's first grade classroom 119

3. Iris's fifth grade classroom $\quad 131$

4. Iris's Native American research guide template 144

5. Iris's Native American tribe Adobe Spark rubric 145

6. Iris's fictional writing rubric developed as part of NBCT work 151

$\begin{array}{ll}\text { 7. Laurel's fourth grade classroom } & 157\end{array}$

8. Excerpt of Laurel's Google Doc expository writing template 178

$\begin{array}{ll}\text { 9. Nora's third grade classroom } & 184\end{array}$

10. Nora's geometry Monster Quiz SMART Board activity 204

11. Excerpt from Nora's fraction unit assessment blueprint 211

12. Thea's kindergarten classroom 217

13. Thea's subtraction SMART Board activity 238

14. SMART Notebook slide from Thea's mathematics pattern lesson 241

15. SMART Notebook slide from Thea's intervention lesson 244 


\section{PROLOGUE}

I have been exploring technology almost my entire life. I was born in 1987, the first of three boys in my family. The initial influx of digital technology, or what has been called the “Third Industrial Revolution” (Stulman, 1974, p. 53), was well underway. I remember sitting down with my father when I was about five years old, asking him to show me how to input commands in our home computer to load games. I sorted through the various five-and-a-half inch floppy disks on our computer desk, looking for applications I could use to color pictures or type stories to print on the continuous form paper of yesteryear.

My family subscribed to a local Internet provider when I was in sixth grade, a bit later compared to when some of my friends had online access at home. I had used the Internet a few times at my cousin's house but found myself completely in awe at the unparalleled access I now had to information and digital resources. I regularly explored the starting lineups of my favorite NFL team: the New England Patriots. I began to dabble in the fandom spaces and insider news websites about pro wrestling; this engagement eventually evolved into a headfirst dive into this digital "affinity space" (Gee, 2009b, p. 223) by co-producing a weekly pro wrestling podcast in my late 20 s with friends from the east coast.

As an adolescent, I created and burned mix CDs of my favorite songs, designing and printing custom sticker labels for each disc. I bought my first digital camera and created folders and subfolders of my photos on my family's home computer. I upgraded from three-and-a-half inch floppy disks to USB flash drives, typing and printing notes from my classes to organize my studies. My digital organization practices as a high school student, in hindsight, were the first time I identified and leveraged the affordances technology can provide - in certain situations - as opposed to traditional or print-based approaches (Jones \& Hafner, 2012). 
In my pre-service teaching education experiences, technology was mainly demonstrated as a means for presenting academic content to students in a more engaging way than just using chalk or paper. Given the limited student-centered models of technology integration I had to draw upon, I entered my first teaching position with 25 first graders in 2009 mimicking the technology uses of more experienced colleagues. Mostly, I created colorful slideshows meant for teacher and student annotation on a Promethean or SMART Board, despite only being equipped with a mobile projector and standard whiteboard. I learned very quickly that despite my uses of and interests in technology in my personal life, a direct transfer to my pedagogy and teaching practices could not be assumed (Greener \& Wakefield, 2015; Lei, 2009).

My use of modern digital technologies increased after my first year of teaching. At the beginning of my second year of teaching, for reasons that were never explained to me, I was chosen to pilot the use of five new devices Apple had released called iPads. I downloaded many fun academic games in which students could practice phonics, basic math operations, reading, handwriting, etc. I also recorded students' parents reading aloud popular books that students could listen to as audio read-alongs during literacy centers.

A few years later, the district purchased enough iPad Mini tablets for all of my first graders to have their own to use. Two district teachers were reassigned to technology coaching positions at the elementary level, and my coach helped me use specific apps (e.g., 30Hands, ShowMe, etc.) to move towards student-centered technology integration in my teaching. The students designed and narrated presentations and products of learning that we printed and displayed in the hallway or posted on my blog for their parents to view.

I requested a grade level reassignment for the 2014-15 school year, which was granted, and I have been teaching third grade ever since. In that time, I replaced flash drives and external 
hard drives with cloud storage. My colleagues and I mapped and revised curriculum digitally, cross-referencing resources we could use with students in specific units and lessons (Gierhart, 2016). I also integrated student-centered applications that supported their development of digital literacies as they published original multimodal compositions. Eventually, I learned that my students wanted to engage in more authentic digital literacy tasks and publish original content online; therefore, I started to incorporate blogging and multimodal composition opportunities moving forward (Gierhart, 2018; Gierhart \& Brown, 2018).

Additionally, I developed a "personal learning network" (Tour, 2016, p. 11), conducting extensive searches and engaging in dialogic learning in specific online spaces (e.g., Twitter). I shared in the experiences of graduate students as they build and share insights from their own personal learning networks through my professional practice and graduate assistantship work in my doctoral program. Online learning that informs pedagogical development must be intentional and specific (Barton, 2012) to the learning needs and competency levels of teachers (Frank, Zhao, Penuel, Ellefson, and Porter, 2011; Freeman, Sugai, Simonsen, \& Everett, 2017), such as engaging in targeted discussions using hashtags on social media (Herbert, 2012).

I do not feel that I was truly confident in effectively teaching elementary students using digital technologies until I developed theoretical understandings of digital pedagogy. In the latter portion of my doctoral coursework sequence, I developed theoretical background knowledge about teaching and learning with digital technologies. I now understand that technology can be effective at making abstract academic content more relatable and comprehensible for students (Hobbs, 2013). It can also help students connect students' learning beyond the walls of the classroom towards more equitable social participation (Ito et al., 2013). 
However, technology is not an elixir for improving educational ends (Warschauer, 2012). Nor is it immune to political influences, having been included as part of educational reforms efforts (Kalmbach, 1996) dating back to the federally-funded content transmission efforts with broadcast radio in the early 20th century (Armstrong, 1929; Cassidy, 1998; Riley, 1940). Political impacts persist in the present day, most recently through state legislation towards digital course offerings in high schools (Archambault, Kennedy, \& Friedhoff, 2016) and the repeal of Obama-era net neutrality regulations by the Federal Communications Commission (Selyuhk, 2018; Snider, 2018).

Likewise, technology is not neutral at the sociocultural level (Cope, Kalantzis, \& Smith, 2018; Luke, 2018). Multimodal media continues to shape information and communication practices in unique ways (Fry, 2015). Friesen (2008) noted that inevitably, stereotypical roles regarding race, age, gender, etc. are reinforced in the digital realm, positioned within "whatever terms and ideologies that are generally taken as 'normal' on the Internet" (para. 44). Despite the opportunities to connect online with digital communication tools, social norms dictate which literacy practices are valued and which are disregarded (Lorimer Leonard, 2013).

Reflecting on my life story allowed me to access my beliefs and motivations for this current research study (Glesne, 2010; Kim, 2015; Spector-Mersel, 2010). Prensky (2001) would classify me as a "digital native" (p. 1), given my age (32 years at the time of this writing) and experience with digital technologies in my personal life; however, the digital native-immigrant distinction oversimplifies the impact of digital technologies on teaching and learning (Bennett, Maton, \& Kervin, 2003). Technological expertise is not a result of age, nor is it synonymous with digital pedagogy. I have worked very hard to develop knowledge of and skills with digital technologies and even harder to integrate them into my instruction with sound pedagogy. My 
development of digital pedagogy did not occur in a vacuum (Britzman, 2003); rather, I collaborated with colleagues who mentored me. I also engaged in additional professional development online and completed many, many hours of graduate coursework.

A few years of working with technology coaches in my district, the initiative was abandoned due to budget constraints. Eventually, after I presented about technology at a handful of my district's teacher institute days, the staff at my school began coming to me to discuss and/or receive support in using technology in their classrooms. Many of my colleagues entered these conversations apologetically, expressing frustration and shame from their struggles, which always made me feel sad.

I began thinking about elementary teachers and the challenges of integrating modern, constantly-evolving digital technologies with young students. Each teacher has their own story to tell - a story of a lifetime of experiences that led them to their current teaching practices and pedagogical approaches with technology (Clandinin \& Connelly, 2000; Mishler, 1999;

Schwandt, 2015). These types of stories must be shared in order to understand how elementary teachers develop their pedagogical design with digital technologies amongst the ongoing dialogue of the teaching profession (Britzman, 2003; Eagleton, 2003). 


\section{CHAPTER I: ESTABLISHING THE RESEARCH PROBLEM}

Digital technologies are being increasingly utilized for teaching and learning purposes, as they can provide a means for modeling, exploring, making meaning of, and communicating about complex content that would otherwise be more difficult without their use (Hobbs, 2013). Digital teaching and learning is recommended by the national teacher councils for all core elementary (K-5) content areas (National Council for the Social Studies, 2013; National Council of Teachers of English, 2013; National Council of Teachers of Mathematics, 2011; National Science Teachers Association, 2016). Additionally, in the Every Student Succeeds Act (ESSA) signed into law during the Obama administration, the federal government stipulated that public schools must dedicate funding towards improving technological infrastructure and implementations as well as digital teaching and learning opportunities (Public Law 114-95, 2015).

Subsequently, technology integration has become a prevalent instructional strategy for today's teachers, due in part to schools' investments toward student access to computers and mobile devices, including at the elementary level (Cristia, Ibarrarán, Cueto, Santiago, \& Severín, 2017; Pereira \& Pereira, 2015). Through the Universal Service Fund, the Federal Communications Commission (2018) has implemented the E-rate program to offset the costs of implementing digital technologies and Internet connectivity for schools and libraries in need. In recent years, school applications to the E-rate program have greatly increased due to the expectations for digital learning in all U.S. schools (Herold, 2016).

By facilitating elementary students' active use of constructing and designing digital texts and media, schools and educators can promote their development of 'digital literacies.' Lankshear and Knobel (2003, 2007) defined digital literacies as the abilities and dispositions 
needed to fully participate in the social practices and construction of meaning in digital contexts. Literacies in a plural sense, refer to the "distinct discourses and multiple modes of communication of various disciplines" (p. 7) broadening the concept of literacy beyond the English language arts curricular scope (Cope, Kalantzis, \& Smith, 2018). Language was reframed in social terms, not just as a cognitive practice, by the 'New Literacy Studies,' or NLS (Gee, 2009a, 2015c; Street, 1993, 2003). Modern digital tools can mediate authentic and situated social practices centered around language (Jones \& Hafner, 2012; Steffen, Gaskin, Meservy, Jenkins, \& Wolman, 2019). These social practices can take place in physical and/or digital locales, or "affinity spaces" (Gee, 2009b, p. 223), which are built around shared content, symbols, and situated language.

\section{Statement of the Research Problem}

While digital technologies offer many affordances for socioculturally-authentic teaching and learning, means-end views about the benefits of technology for the purposes of teaching and learning, or "technological determinism" (Chandler, 2012, p. 256) persist in public discourse and news media (Pereira \& Pereira, 2015) and unilateral one-size-fits-all school implementations (Cristia et al., 2017). Furthermore, current technology implementations in schools may perpetuate digital participation gaps related to race, parental education, socioeconomic status, and linguistic diversity (Hollingworth, Mansaray, Allen, \& Rose, 2011; Li, Snow, \& White, 2015; Vigdor, Ladd, \& Martinez, 2014).

Digital technologies remain central to how Kalantzis, Cope, and Harvey (2003) conceptualized the "new economy," (p. 16) of which symbols are at the forefront. Students who lack the ability to engage in current digital social practices, when viewed through Bourdieu's (1986) concept of convertible social capital, may face future economic and employment 
disadvantages. Issues of access may be compounded for elementary students, who may be less likely to own or control their own devices compared to their older counterparts (Li et al., 2015; O'Hara, 2011). Critical pedagogical practices with digital technologies must become a greater focus within and across the elementary content areas; technology, in and of itself, without critical, pedagogy-driven consideration for individual learners, remains futile (Friesen, 2008).

Public dialogue about how to utilize digital technologies in elementary classrooms must begin to center around effective pedagogy (Pereira \& Pereira, 2015). Truly focusing on the countless needs and challenges students experience can prove challenging for teachers, given the instructional demands imposed explicitly or implicitly by authoritative discourses (Britzman, 2003), such as improving standardized testing results (Cope, Kalantzis, \& Smith, 2018). Freire (1970/2014) called for oppression to be fought through transformative action, and simply providing access to tablets or laptop computers does little to overcome disadvantages and missed educational opportunities. Without effective, pedagogically-driven practices implemented by reflective and responsive teachers, technology does little to impact students' learning, growth, motivation, or empowerment (Tabb, 2008). Educational technology implementations can become more effective if they are coupled with pedagogical practices that increase student learning, digital participation, and equity for all students (Eng, 2016).

If critical digital pedagogy is to be understood holistically, knowledge-based concepts of teaching with technologies must be transcended. Teachers do not develop pedagogy only during a pre-service coursework experience (Holquist, 2002), nor is it immune from dialogue with educational discourses, social milieu (Britzman, 2003), or a life lived (Greene, 1995; Wertz et al., 2011). Depicting and understanding the nature of digital pedagogical design narratively can illuminate the dynamic, evolving nature of pedagogy (Bakhtin, 1981b; Bruner, 1986). In this 
study, I sought to tell the stories of elementary teachers in order to better understand their development of pedagogical design with digital technologies.

\section{Purpose of the Research Study}

In ruminating on Dostoevsky's development of characters in his novels, Bakhtin $(1963 / 1999 a ; 1981 a)$ recognized the power of social inquiry and dialogue in revealing the true essences of others. In his view, any attempt to describe the identities and tell the narratives of others without first sharing dialogue results in a failure of constructing valid knowledge. Narratives should reveal the essences and identities of others, not just what 'happened' or what was depicted in an interview (Andrews, Sclater, Squire, \& Tamboukou, 2004; Clandinin \& Connelly, 2000).

The purpose of this study was to describe the experiences and life stories of elementary teachers who integrate digital technologies in their instruction as a consistent teaching approach. Pedagogy, in the most realistic and practical sense, is never fully mastered, but continually developed through self-driven learning and reflection (Schein, 1972). This must include considerations for how the life history of a teacher impacts their perceptions of present and future scenarios (Alsup, 2006; Kim, 2015; Mahiri, 2004).

Teachers do not just develop pedagogy during their pre-service teacher education programs and career experiences. Rather, pedagogy is developed across the entire life journey. As will be discussed in Chapter II as part of the theoretical framing of this study, pedagogy can be viewed in terms of the cacophonous dialogue in which a teacher engages as part of designing instruction (Britzman, 2003; Dressman, 2004). Pedagogical design is formed and evolves socially, rather than in an isolated fashion (Holquist, 2002). They dialogue with the experiences from their biographical past that shape their views of teaching and learning with or without 
technologies in the present (Clandinin \& Connelly, 1988; Dall'Alba, 2009; Greene, 1995).

Likewise, they engage in dialogue with matters of the present, such as mandated standards and curricula, institutional authorities, student needs, and their core beliefs about effective digital pedagogical design.

As pedagogical design is constantly evolving, it is best conveyed through narration. Coconstructing and analyzing the narrative meaning the five participants shared in this study through stories of living and practice provided greater understanding of pedagogy with digital technologies at the elementary level (Clandinin \& Connelly, 2000; Hays \& Singh, 2012; Lemley \& Mitchell, 2012). Ultimately, my goal was to present the narratives as shared by the participants and, subsequently, how it applied to my research questions, in addition to the implications it had for policymakers, teacher education, professional development, and practicing elementary teachers (Geertz, 1973).

\section{Research Questions}

This study was guided by the following question: How do elementary teachers who consistently integrate digital technologies develop their pedagogical design across their careers?

I also posed the following sub-questions: a) What pedagogical components do elementary teachers emphasize when teaching with digital technologies?, and b) What can be learned about the dialogic nature of pedagogy from the life stories of elementary teachers who consistently integrate digital technologies?

The main question was carefully worded in the tradition of narrative inquiry. Research questions for narrative research must remain somewhat broad in order to allow for a variety of 
stories and voices (Mishler, 1999), accounting for a lifetime of stories rather than constricting participants' narration towards expected ends (Kim, 2015).

On the other hand, the sub-questions targeted aspects of the theoretical frameworks of this study - Britzman's (2003) dialogic theory of teacher practice and the New London Group's (1996) pedagogy of multiliteracies - and were influenced by my Weltanschauung (Checkland, 1981; Sylvester, Tate, \& Johnstone, 2013) about how pedagogy and technology are developed and function within the contexts of teaching and learning.

Utilizing narrative inquiry in this fashion embodied the spirit of the transliteracies-driven research called for by Stornaiuolo, Smith, and Phillips (2017). Through narrative research, I was able to find and present different ways of understanding the how elementary teachers are taking up and developing digital teaching approaches.

\section{Operationalizing Key Terms}

\section{Consistently}

I was primarily interested in co-constructing the narratives of elementary teachers who consistently integrate digital technologies in their instructional practices. These teachers shared examples of digital pedagogy from their personal and professional practices across a lifetime of experiences. For the purposes of this study, I considered teachers to be integrating digital technologies consistently if they used them within their classroom contexts for teaching and/or student learning purposes at least three days per school week.

\section{Digital Technologies}

Debates over how to define the use of technology in educational settings for the purposes of teaching and learning has hinged on the selection of key terms and how they depict power relations (Davies \& Schwen, 1971). In the mid-1900s, technological innovations in education fell 
within the field of audiovisual communications, a field which Finn (1953) noted was in a state of flux and was not fully defined as a profession at the time. Historically, technologies were used as a means for facilitating and optimizing the transmission of academic content (Cassidy, 1998).

Approaches that objectified students (Freire, 2009) fit within Ely's (1963) then-popular definition of audiovisual communications as the "branch of educational theory and practice primarily concerned with design and use of messages which control the learning process" (p. D21). The word 'control' was of great importance to Ely (1972) over less authoritative terms such as 'facilitate' (Li, Chu, Ki, \& Woo, 2012). However, Januszewski (2001) pointed out that conceptualizations like Ely's did move discourse about educational technologies past a sole focus on products and into theoretical discussions of teaching and learning processes. It should also be acknowledged that Ely (1972) later advocated for the term 'educational technology' to be defined separately from audiovisual communications.

Essentially, Ely's $(1963,1976)$ definition of educational technology focused on the work of designers and authoritative decision-makers (i.e., teachers, librarians, administrators, etc.), rather than students. In 1977, the Association for Educational Communications and Technology (AECT) published a lengthy revised definition of educational technology in an attempt to encompass what was evolving into a multifaceted field: "Educational technology is a complex, integrated process involving people, procedures, ideas, devices, and organization, for analyzing problems and devising, implementing, evaluating, and managing solutions to those problems, involved in all aspects of human learning" (p. 1). AECT's 16-component definition featured Learning Resources for problem-solving, Educational Development Functions of technological solutions to problems of practice and application, and Educational Management Functions 
related to administrative tasks in educational settings. Saettler (1990) characterized AECT's definition as "too broad [with] little relevance to the real world of the public school" (p. 6).

In the 1990s, as the Internet and email became more commonly used within professional and social contexts, Seels and Richey (1994) observed that technology in educational settings had grown into a professional practice with a burgeoning knowledge and research base. Therefore, they labeled the field as "instructional technology" - while acknowledging that this term could be used interchangeably with 'educational technology' - and defined it as "the theory and practice of design, development, utilization, management, and evaluation of processes and resources for learning" (p. 1).

In their 2017 updates to the National Education Technology Plan, the U.S. Department of Education's Office of Educational Technology (2017) defined technology as a "powerful tool for transforming learning" (p. 3) that "can accelerate, amplify, and expand...effective teaching practices" (p. 5). The plan goes on to situate effective learning with digital technologies within the symbiotic structure of leadership, instruction, and assessment. It also stipulated that teaching and learning with technology requires digital infrastructure, including reliable devices and Internet connectivity (Demski, 2012), which is not far removed from historical conceptions of technology based on whether or not devices were powered by electricity (Januszewski, 2001); however, Hunter (2015) recognized that students can also use technologies while being disconnected from the Internet.

The Office of Educational Technology (2017) also recognized that technology is not ubiquitous across society and that many students and schools still lack equitable access to reliable, modern digital technologies (Joan Ganz Cooney Center, 2016; Robinson, 2009). Furthermore, Jenkins (2006) delineated between digital access and participation gaps. Certain 
populations in society have less access to financial resources than others, impacting the types of technology they can access as well as the ways they can utilize them (Luke, Sefton-Green, Graham, Kellner, \& Ladwig, 2018; Van Dijk, 2012, 2017). Those who lack access cannot engage in digitally-mediated social practices as fully as others, perpetuating unequal access to online resources (Hargittai, 2002; Jesson, McNaughton, \& Wilson, 2015) and/or achievement of desired outcomes (van Deurson \& Helsper, 2015).

Considering the modern digital nature of technological innovations (Milman, CarlsonBancroft, \& Vanden Boogart, 2014; Office of Educational Technology, 2017) as well as the focus of this study on the stories of elementary teachers' pedagogical approaches with technology, it made sense to define digital technologies broadly as an overarching term for the technological innovations used in teaching and learning. It was also necessary to operationalize digital technologies practically in order to co-construct and situate teachers' stories (Kim, 2015; Lemley \& Mitchell, 2012) within the academic discourse of pedagogy and practice (Scheffler, 1960/1964). Teachers or students may also appropriate technologies in ways that were unintended when they were initially designed (Eglash, 2004), so the technical design emphases of definitions such as Ely's (1963) did not fit within the scope of this study.

Therefore, I defined digital technologies as the electronic devices, applications, and digital resources used for constructing and/or communicating meaning online or offline. By remaining broad and incorporating a variety of technologies, uses, and options for connectivity (Jones \& Bennett, 2017; Sassen, 2002), this definition did not impose stringent preconceptions or limitations on how other teachers' pedagogical approaches could be interpreted in the field (Anyon, 1994; Clandinin \& Connelly, 2000; Kim, 2008, 2015). 


\section{Pedagogy}

Pedagogy, in the most realistic and practical sense, is never fully mastered, but is continually developed through self-driven learning and reflection (Schein, 1972). In defining pedagogy for this study, it was important to consider its nature and implications for teaching and learning. Teaching has long been viewed as an artistic profession due to the pedagogical spontaneity and responsiveness required in meeting students' learning needs in real time (Eisner, 1979). Shulman (1986) defined pedagogical knowledge (PK) as a form that encompasses "the ways of representing and formulating the subject that make it comprehensible to others" (p. 9). Mishra and Koehler (2006) extended the notion of pedagogy as knowledge in their technological pedagogical content knowledge (TPACK) framework, linking pedagogical understanding to knowledge of technology.

Conversely, critical thinkers like Freire (1970/2014) focused on pedagogy as goal-driven, motivated by controlling or liberating students, a stark contrast of conceiving pedagogy as static knowledge. Knowledge-centric frameworks like TPACK do not elucidate the challenges teachers face in implementing technology in student-centered ways for diverse learners (Lohnes Watulak \& Kinzer, 2013; Rust, 2017). Furthermore, as a politically neutral framework, TPACK does little to promote critical pedagogy (Koehler, Mishra, Kereluik, Shin, \& Graham, 2014). Critical pedagogies, such as the pedagogy of multiliteracies (New London Group, 1996), empower teachers to supplant traditional approaches to teaching and learning that have upheld long standing educational and social disparities.

Checkland (1981) noted that researchers operationalize problems and situations based on their unique viewpoints. The concept of Weltanschauung emerges in operationalizing key research terms and concepts, allowing for current knowledge and understandings to be 
challenged by alternative forms of thinking about topics (Sylvester et al., 2013). Dilthey (1887/1985) related the notion of Weltanschauung in social sciences to the interpretation of meaning from poetry tied to common human experiences "which are personally limited, composite, and yet incapable of [completely objective] analysis" (p. 34). While this study is primarily concerned with pedagogy with digital technologies by elementary teachers, it must be acknowledged pedagogy is not neutral or enacted in isolation (Britzman, 2003). Likewise, technologies are not free of political or socioeconomic influences (Jesson et al., 2015; Luke et al., 2018; van Deurson and Helsper, 2015; Van Dijk, 2012, 2017).

Prescriptive interventions and approaches ultimately reduce students as actionable objects and cannot fully liberate them from hegemonic, dominant norms (Greene, 2009). Critical pedagogies empower teachers to replace traditional approaches to teaching and learning that have historically upheld educational disparities. By supporting students' authentic construction of knowledge, dispositions, skills, literacies, etc., they will be better equipped to enact social change for themselves and others (McLaren, 2009). Bruner's (1979) conception of creativity as "effectiveness in surprise" (p. 19) relates well to the approach of teaching with technology. Teachers must resist the urge towards obvious or deterministic pedagogical solutions; rather, they should design creative technologically-mediated approaches that transform authentic educational pursuits with respect to learning science and best practices (Yelland, Cope, \& Kalantzis, 2008).

Therefore, for the purposes of this study, pedagogy was operationalized using the definition established by the New London Group (1996), founders of the seminal 'pedagogy of multiliteracies' framework (which will be discussed further in Chapter II of this dissertation). The New London Group defined pedagogy as "a teaching and learning relationship that creates 
the potential for building learning conditions leading to full and equitable social participation" (p. 60).

The New London Group's definition of pedagogy remains student-centered, contrary to historically teacher-centric and transmission-based uses of technology in schools (Armstrong, 1929; Knupfer, 1993; Riley, 1940). Through operationalizing pedagogy within the "dynamics of teaching and learning” (Yelland et al., 2008, p. 197) that take place in elementary classrooms each day, I was able to frame technology integration beyond discussions of teacher-centered (Donovan, Green, \& Hansen, 2012; Tondeur, van Braak, Ertmer, \& Ottenbreit-Leftwich, 2017) or transmission-based approaches (Knupfer, 1993; Meredith, 1971). Additionally, this definition would be classified by Scheffler (1960/1964) as "general... [which] is to be understood in a special way for the space of some discourse" (p. 13) to address problems of practice. In the case

of this study, the discourse revolved around pedagogical approaches with digital technologies in elementary learning settings.

\section{Design and Pedagogical Components}

Since the focal research question and the first sub-question of this study refer to design principles and were derived from the multiliteracies framework, I utilized the New London Group's definitions of the terms design and pedagogical components.

Design was defined within the scope of classroom pedagogy as "the organizational structure...or the process of designing" (New London Group, 1996, pp. 73-74) instruction. Utilizing the New London Group's view of pedagogical design allowed for participants to narrate and share their teaching as a product or artifact of their teaching practices as well as an ongoing, iterative, evolving process rather than constricting their stories within an overlyspecific theoretical construct (Clandinin \& Connelly, 2000; Josselson, 2007; Kim, 2015). 
Pedagogical components were defined as the four components teachers can emphasize at optimal junctures to support the meaning-making and literacy development of culturally-and linguistically-diverse learners: situated practice, overt instruction, critical framing, and transformed practice. Pedagogical components will be discussed further in Chapter II.

\section{Dialogic}

Britzman's (2003) dialogic theory of teacher practice (which will be described further in Chapter II as part of the theoretical framework of this study) positions teacher education and pedagogical development in the "unstable contexts" (p. 30) that teachers face within and between their professional and personal lives. This notion of pedagogy runs counter to knowledge-centric frameworks of teaching with technology (Mishra \& Koehler, 2006) as something to be learned and mastered with a sense of objective, positivistic finality (Bruner, 1986; Eagleton, 2003; Rust, 2017). Dialogic, for the purposes of this study, adhered to Britzman's conception of pedagogy as being in constant dialogue with a variety of personal, sociocultural, and professional factors including “one's biography, present circumstances, deep commitments, affective investments, social context, and conflicting discourses" (p. 31) of teaching.

\section{Significance of the Research}

The results of this study contribute to our understanding of how elementary teachers develop and implement pedagogical approaches with technology, not just within their years of teaching but across a lifetime of experiences (Clandinin \& Connelly, 2000). Depicting how teachers perceive their lived experiences in stories allowed me to better understand elementary teachers' biographies from their perspectives to inform future discussions and conceptualizations of digital pedagogical development (Alsup, 2006). 
By co-constructing stories of digital pedagogical design in action at the elementary level, pedagogy can be better understood outside of static, positivistic, knowledge-based terms (Mishra, Koehler, \& Henriksen, 2011; Rust, 2017; Yelland et al., 2008). Rather, this study contributes to dynamic, narrative ways of knowing, which is how humans make sense of life experiences each day (Bruner, 1986; Kim \& Macintyre Latta, 2010; Lyotard, 1979/1984; Robinson \& Hawpe, 1986; Spector-Mersel, 2010) as they engage in dialogue with the discourses and social elements of the teaching profession (Britzman, 2003).

Developing narrative understanding of digitally-mediated pedagogies at the elementary level provides case-based knowledge (Wertz et al., 2011) of the types of experiences that impacted teachers' pedagogical design in the past and presently in a dialogic sense. Case knowledge, according to Shulman (1986), makes the abstract (such as pedagogy and the processes of effectively teaching and learning content with digital technologies) more tangible and practical for future application in teacher education, professional development, and policy implementation.

In addition, research of pedagogy with digital technologies has been heavily concentrated on the middle school (Seglem \& Garcia, 2018; Woodard, 2015), high school (Holmberg et al., 2017; Roozen et al., 2015), and postsecondary (Donovan et al., 2012; Gill et al., 2015; Kimmons et al., 2015) levels. It is also important to represent elementary teachers in the research base regarding the dialogic development of pedagogical approaches with digital technologies in working with young learners.

\section{Overview of the Study}

Chapter I establishes the institutional and social expectations for teaching and learning with technology in today's schools. The research problem, purpose of the study, and research 
question and sub-questions are stated and key terms are operationalized. The significance of this research is also discussed.

Chapter II includes a review of pertinent literature related to pedagogy with digital technologies by elementary teachers, including a historical overview of educational reforms that have targeted technology in educational settings. The theoretical and conceptual frameworks are described and situated within the scope of this study.

Chapter III grounds this research within the interpretivist paradigm and narrative method. The methods for participant selection, data collection and analysis, and construction of the narratives are detailed. Issues of rigor, authenticity, ethics, and limitations of the study are also discussed.

Chapter $I V$ depicts the co-constructed narratives of the five participants of this study. Each narrative begins with a presentation of the participant's observed teaching practices in which they integrated digital technologies. Next, the broad strokes of the participant's life journey are presented. Finally, the participant's pedagogical design with digital technologies will be shared through narration.

Chapter $V$ ties the five narratives together in a discussion of the analyses through the lenses of the theoretical frameworks. Dialogic factors that emerged within and across the narratives of the participants include core beliefs, district curricula, institutional factors, perceived pedagogical affordances of digital technologies, professional development and collaboration, self-efficacy, student needs, and technology access. Examples of how the participants emphasized the pedagogical components of situated practice, overt instruction, critical framing, and transformed practice are also discussed. 
Chapter VI concludes the dissertation with answers to the research question and subquestions. It was found that elementary teachers develop their digital pedagogical design across their careers as well as throughout their lives. Of the four pedagogical components, critical framing and transformed practice were the least emphasized by the participants. The narratives suggest that elementary teachers have to actively respond to pedagogical dialogue in ways that facilitate their design of truly transformative learning experiences for students with digital technologies. Finally, implications for policymakers, teacher educators, designers of professional development, and elementary teachers are discussed and questions for future research are detailed. 


\section{CHAPTER II: REVIEW OF LITERATURE}

Kim (2015) likened the literature review process to "a farmer plowing the soil before sowing seeds" (p. 91). In reviewing the literature, the researcher seeks to understand the past and current knowledge base and identify problems or gaps in understanding (Wertz et al., 2011). Ravitch and Riggan (2011) cautioned researchers from framing the literature review as a onesided argument for one's research interests; rather, it should ground the planned research within the historical and current discussion of the problem or topic and the intended contributions of the researcher through his or her present study.

To better understand how the pedagogies of elementary teachers develop, evolve, and are enacted with students dialogically, their stories across a lifetime must be told. In this study, I will tell the life stories of elementary teachers who consistently integrate digital technologies in their instruction. In constructing these stories, the dialogic voices and discourses with which these teachers interacted and engaged have to be identified and disseminated. In my endeavors to tell these stories, I sought to truly co-construct them, maintaining the integrity of the participants' narration while theorizing and addressing the research problem of this study: the pedagogical design of elementary teachers with digital technologies. Therefore, I will begin this review of literature by discussing the dialogic nature of pedagogy and teaching through one of the theoretical frameworks of this study: Britzman's (2003) dialogic theory of teacher practice.

To effectively co-construct the life stories of elementary teachers and their pedagogies with digital technologies, it was important to understand the authoritative and internal discourses with which they have been in dialogue. Therefore, analyzing the history of educational reforms, including those that have targeted technologies, was pertinent. In the second portion of this 
literature review, I will provide a historical overview of teacher-centric and student-focused educational reforms, followed by a discussion of technology-focused reforms.

Then, I will discuss the current teaching approaches with digital technologies, including those that fit within knowledge-centered and critical traditions of teaching and learning. Current research has focused heavily on knowledge- (Lohnes Watulak \& Kinzer, 2013; Rust, 2017) and technology-centric (Chandler, 2012; Iannone, 1998; Leu et al., 2015) explorations of digital pedagogy and teaching and learning with technology. Therefore, it was important to select a theoretical framework that allowed me to describe the teaching approaches that emerged in the narratives of the participations that encapsulated critical digital approaches: the New London Group's (1996) pedagogy of multiliteracies framework. I will detail each of the four pedagogical components of the multiliteracies framework I used to describe the digitally-mediated instructional approaches of the participants of this study.

Finally, to construct narratives that reflect the dialogic nature of stories of pedagogy that authentically and equitably present the voices of the participants and the contextual- and temporal-situatedness of the narratives, I selected Bakhtin's (1963/1999a, 1981b) Theory of Novelness as the conceptual framework of this study. I will detail how Bakhtin's novel concepts of polyphony, chronotope, and carnival guided my methodological design and subsequent construction of each narrative to depict the dialogic nature of pedagogical design with digital technologies.

\section{Theoretical Framework: Dialogic Theory of Teacher Practice}

Britzman (2003) presented her dialogic theory of teacher practice through the narratives of two student teachers as part of a larger critical ethnography study. This theory, a counter to scientific views of teaching and pedagogy, stresses the learning and development of teachers 
dialogically (Bakhtin, 1981a), considering the power dynamics of language and discourse in education. Through this lens, teaching and pedagogy is developed and shaped socially rather than in isolation (Holquist, 2002) with respect to the biography, or "life story" (Wertz et al., 2011, p. 226), of the teacher (Greene, 1995). Next, I will discuss the major components of this theory - pedagogical discourses, the social nature of pedagogy, and biography - and how they applied to answering the research questions of this study.

\section{Pedagogical Discourses}

Britzman (2003) theorized language in education in terms of power dynamics, drawing upon Bakhtin’s (1981a) view that all humans “assimilate" (p. 381) language as part of "authoritative discourse and...internally persuasive discourse" (p. 342). In the education sector, authoritative discourse is comprised of social reform efforts funneled through schools in attempts to influence the work of teachers (Eisner, 1979). Additionally, it is fueled by dominant, hegemonic discourse about what is expected from schools, including the hidden and null curricula (Ahwee et al., 2004; Clandinin \& Connelly, 1988).

The work of teachers is embedded in the authoritative discourses of professional traditions and accepted practices laden with histories and dominant values (Dall'Alba, 2009; Mahiri, 2004). Scollon, Scollon, \& Jones (2012) identified the "corporate discourse system" (p. 203) as one of the major strands of discourse in professional environments that serves to accomplish specific goals and maintain the status quo against more individual-oriented discourses. Ever since the scientific curriculum making of the early 20th century, teachers have had to straddle a line between their own experiences, beliefs, and preferences regarding teaching and learning and those promoted via textbooks. Textbook reforms began with the McGuffey Reader in the 19th century (Kliebard, 2004) and continued to the present-day with nationalized 
reforms such as CCSS and ESSA (McGuinn, 2016). Counts (1930) saw the textbook-driven curriculum movement as a way to steer teachers' practices toward promoting social conformity. Internally persuasive discourse, on the other hand, "is always in dialogue with authoritative discourse" (Britzman, 2003, p. 43). It represents the tentative, narrative forms of realizing and knowing (Bruner, 1986) in which authoritative discourses are questioned and challenged. Teachers, in moments where pedagogy can remain aligned to current trajectories or diverge in new directions, engage in dialogue with authoritative discourses (Elbaz-Luwisch, 2007; Rogers, 2007). They must navigate personal beliefs and interpretations of current problems of practice (Alsup, 2006), potentially redefining “excellence in a plural sense” (Greene, 1984, p. 288) through pedagogical shifts and reshapings (Brader \& Luke, 2013; Luke, 2004). Luke (2018) noted that this process of pedagogical dialogue not only changes (or transforms) practices but the teacher as well.

By co-constructing the stories of the participants in this study within the sociocultural discourses of the education system, I was able to understand their experiences dialogically, just as they were perceived by the participants (Chase, 2005). Each participant shared stories of their dialoguing with authoritative and internally persuasive discourses (Britzman, 2003) and how they developed their digital pedagogical designs within the discourses inherent in public school institutions. By co-constructing and analyzing these dialogue-laden narratives, I was able to build deeper, more holistic understanding of their development of pedagogy with digital technologies.

As an example from the literature, Holmberg, Fransson, \& Fors (2017) conducted a participatory case study of eight English as a foreign language (EFL) teachers in secondary school settings where students were equipped with one-to-one technology. Along with providing instructional and technical guidance to the participants, the researchers conducted open-ended 
interviews and observations in addition to analyzing instructional artifacts and the teachers' written reflections on teaching with technology. Holmberg et al. (2017) theoretically framed their analysis within the TPACK framework; however, the teachers' experiences were not so neatly organized within Mishra and Koehler's (2006) knowledge domains of technological knowledge (TK), pedagogical knowledge (PK), and content knowledge (CK), which will be discussed in greater detail later in this literature review. Several participants possessed strong knowledge of operating different apps and websites for instruction, assessment, and student designing; yet,

they still had to work through the challenges of integrating these resources within the constraints of their schools' learning management systems. Additionally, the teachers confronted challenges to their teaching beliefs as they evaluated different digital tools, engaging in a "reframing of practice" (p. 386).

Had these researchers utilized a dialogic theoretical lens instead of a knowledge-based one, this study could have better illuminated the socially-mediated, discourse-laden nature of developing pedagogical approaches with digital technologies (Mishra et al., 2011; Scollon, 2001). Teachers' pedagogies with digital technologies dialogically evolve and change as a result of a variety of social factors, including institutional hurdles (Seglem, 2015) and work with individual students (Garcia \& O’Donnell-Allen, 2015).

\section{Social Nature of Pedagogy}

Pedagogy is socially dialogic in that while the work of a teacher "is individually experienced...in actuality, it is socially negotiated" (Britzman, 2003, p. 31). Through a dialogic lens, pedagogy is developed through teachers' daily interactions with students, administrators, colleagues, etc. (Huber, Caine, Huber, \& Steeves, 2016; Shing et al., 2015). It was imperative that I co-construct the narrative arcs of elementary teachers' lives and careers in this study in 
order to capture the perceived social components that they felt impacted their pedagogical development.

A dialogic lens demythologizes teaching as a simple career path comprised of acquiring knowledge and skills to better portray a socially-derived professional identity - those who profess from curriculum manuals, assign detentions, and create whimsical bulletin board displays. On the contrary, identities of practice are constructed socially in shifting, evolving contexts within which pedagogy is continually forged and recast in response to "social forces...[that] interact with each other" (Eisner, 1979, p. 26) dialogically (Mishler, 1999; Rust, 2017; Whitney, 2008).

Knowledge, to Heidegger (1962/2001) is constituted in the realities of individuals immersed within and between their personal and professional existences. Dewey (1994) believed life experiences (and the knowledge individuals gain from them) should not be viewed in an isolated manner, but rather, in relation to each other. Likewise, Bakhtin (1981a) viewed the meaning of discourse and language as socially-derived (Mahiri, 2004). In a time where teaching is viewed "as discrete, isolated skills that can be taught, mastered, and measured" (Woodard, 2015, p. 53), dialogically understanding the socially-mediated development of pedagogical reasoning and development concerning digital technologies is vital (Voogt, Fisser, Pareja Roblin, \& van Braak, 2012)

For example, Woodard (2015) examined the writing practices of two English language arts teachers in New York City: a male high school teacher and female who taught in a middle school. She was interested in how the teachers' writing practices in their personal lives meshed with their pedagogical approaches in teaching. Woodard found that both teachers reappropriated language from writing activities they participated in outside of school, such as workshops, 
conferences, and blogging. Scollon (2005) would refer to these uses of language across contexts as "mediated discourse" (p. 6), which suggests a dialogic perspective of teaching practices and pedagogy.

Technology can mediate teaching (and learning) practices in educational contexts (Jones \& Hafner, 2012). The objects and symbolic representations of digital content and communication are also significant components of how technology is utilized for teaching (Alcalá, Austin, Granroth, \& Hewitt, 2016; Blumer, 1969). However, technology can be utilized for other noninstructional literacy practices as well (Gee, 2015c; Jones \& Hafner, 2012; Leu et al., 2009, 2013; Scollon, 2001). The authentic digitally-mediated "vernacular practices" (Barton \& Hamilton, 1998, p. 253) of teachers can and do intertwine with professional, pedagogical approaches.

As part of an exploratory case study, Roozen, Woodard, Kline, and Prior (2015), depicted the authentic literacy practices of three teachers. One of the participants, a male high school biology teacher, engaged in regular digital photography and blogging. A member of the National Writing Project, this teacher's blogging efforts blurred between his classroom work and interestdriven efforts. His students brought in insects that laid eggs and provided authentic learning opportunities in which he engaged in additional photography and blogging. Rather than classify this teacher's "laminated" (p. 209) identities and literacy engagement individually within different social contexts, the researchers emphasized the dialogic, discursive nature that existed between them.

Missing from the study by Roozen et al. (2015) was an explanation or description of how the teacher's literacy identities and practices, digital or otherwise, impacted the literacy practices of students (Whitney, 2008). However, the study highlights a connection between authentic 
social practices that can transfer to professional teaching; examples include teachers' compositional efforts as part of the National Writing Project (Lieberman \& Wood, 2003) and engaging in discipline-specific literacy practices, such as publishing fan fiction compositions (Roozen, 2009). Tour (2015) conducted an exploratory case study of three language arts teachers in Australia regarding their personal and professional digital literacy practices whose teaching assignments spanned grades the elementary grade levels (while one participant taught high school seniors). Each teacher's personal technology beliefs and practices shared similar patterns to their pedagogical approaches with digital technologies in their classrooms. The two participants who viewed technology as an addition to their lives tended to only identify technological affordances related to transmission-style pedagogies (which will be discussed at greater length later in this literature review); conversely, the teacher of Chinese language classes in grades 3-4 utilized technology in both her personal and professional practices that reflected "creative assumptions... [about technology that] facilitated digital literacy practices" (p. 135) with students.

Lankshear and Knobel (2006) framed the philosophical beliefs and assumptions individuals have about technology as "mindsets" (p. 33). On one end of the spectrum resides a mindset that views technology in terms of paradigmatic knowledge (Bruner, 1986) in line with historical transmission-based, teacher-centric applications to teaching and learning (Cristia et al., 2017; Knupfer, 1993). At the opposite end is a mindset composed of social, plural views of literacy that may or may not involve mediation by technology (Lankshear \& Knobel, 2003). Scollon (2001) conceptualized human uses of physical and assumed objects, such as digital technology devices and social networks, as "mediated actions" (p. 4) within a web of social practices. These two mindsets do not need to be viewed exclusively in binary terms (Bennett et 
al., 2008; Tour, 2015) as in Prensky's (2001) classification of "Digital Natives" and "Digital Immigrants" (p. 2).

In fact, different digital mindsets may be impacted by institutional factors that, through authoritative discourses, reinforce traditional teaching practices filtered through technologies (Lankshear \& Knobel, 2007). Ultimately, the challenge in integrating digital technologies from personal life into professional teaching is that the spatial-temporal context of the classroom is "conditional" (Mahiri, 2004, p. 219) in relation to real world contexts. Connelly and Clandinin (1999) viewed classroom teaching as "an imagined border-crossing" (p. 103) between different places, times (Bakhtin, 1981b), and the practices teachers associate between them. Traveling between these borders can be fraught with challenges of socially-situated morality and interpersonal complications in the teaching workplace (Clandinin \& Connelly, 1995). Constructing and analyzing narratives of pedagogy, therefore, makes methodological sense considering the dialogic, socially-mediated nature of these daily decisions of teaching with digital technologies.

\section{Biography and Pedagogy}

Through a dialogic lens, internal and external life experiences "are shaped as they shape each other in the process of coming to know" (Britzman, 2003, p. 2). Teachers' pedagogical practices do not develop in a vacuum of distinct knowledge bases (Heitink et al., 2016; Rust, 2017), but rather, through dialogic interactions between "principles, maxims, and norms" (Shulman, 1986, p. 11) developed during their careers and across their entire life journeys (Alsup, 2006; Kim, 2015). History echoes and dialogues with the present as humans construct meaning moving forward (Mahiri, 2004). Several factors within the biographies of teachers can 
contribute to the developmental trajectory of pedagogy concerning digital technologies, including pre-service teacher education and professional development experiences.

Dominant pre-service coursework approaches within teacher education programs such as single technology-focused course offerings (Angeli \& Valanides, 2013; Beschorner \& Kruse, 2016) or knowledge-centric frameworks (Kimmons et al., 2015) have been found to be relatively ineffective at supporting the development of consistent, student-centered pedagogies with digital technologies. Future elementary teachers, like practicing teachers, require sustained, long-term professional development experiences (Darling-Hammond, Hammerness, Grossman, Rust, \& Shulman, 2007; Darling-Hammond, Hyler, \& Gardner, 2017; Tondeur, Roblin, van Braak, Fisser, \& Voogt, 2012). Effective pre-service program approaches include designing coursework experiences that integrate digital pedagogy development through the entire program experiences coupled with field observations of technology and reflection activities (Bower, Highfield, Furney, \& Mowbray, 2013; Donovan et al., 2012; Gill, Dalgarno, \& Carlson, 2015; Opfer \& Pedder, 2011).

Likewise, professional development experiences throughout a teacher's career can impact development of digital pedagogy. For example, Frank et al. (2011) conducted a longitudinal study of the professional computer use of elementary school teachers in ten school districts, resulting in the formation of a three-part knowledge diffusion model for technology use by schoolteachers. In this model, beginners benefit from receiving training to gain knowledge related to professional goals. Next, teachers optimally apply their acquired technology knowledge "to their unique contexts by exploring and experimenting with the innovation" ( $\mathrm{p}$. 150). Finally, teachers refine their new technology practices through ongoing dialogue and collaboration with others. Developing pedagogy for teaching with technologies involves 
increasing one's self-efficacy (Bandura 1977, 1997) to support students' academic achievement and development of skills. The use of technologies in discourses and literacy practices has increased the rate of Redesigned (New London Group, 1996) "discursive practices" (Fairclough, 2010, p. 140), pressing the need for the dialogic study of technology-mediated teaching practices (Britzman, 2003).

Much of the educational reform efforts throughout American history, according to Arendt (1954/2006), attempted to shape teachers' pedagogies through scientific training and instilling skill sets. Such views of pedagogy run counter to the Schutz's (1945) ontological "provinces of meaning” (p. 551) composed of the experiences of a life lived and being lived. Britzman (2003) lamented the "supposed autonomy and very real isolation" (p. 236) that student teachers experience as they transition into professional teaching. The challenge teachers (as well as students) face in schools is that the authoritative discourses of the education system suppress the identities with which they most closely associate (Gee, 2017a, 2017b). Teachers can and will draw upon their life experiences in making meaning and working through challenges of pedagogy (Greene, 1995).

Pre-service teacher education and professional development experiences were certainly explored in the construction of participants' narratives in this study; however, their life histories prior to and during their preparation and professional practice as teachers were of great interest as well. By dialogically co-constructing and reframing the meanings teachers assign to experiences they have lived as narratives (Alsup, 2006), the biographies of teachers authoritative discourses attempt to reproduce (Bakhtin, 1981a) may be more authentically portrayed and understood to inform future practice, professional development, etc. Considering the ongoing biographical dialogue in which teachers engage as they develop and enact their digital 
pedagogies (Britzman, 2003), it was critical to frame the research question of this study towards narrating life stories, not just during years of professional practice.

\section{Discourses of Technology in Education}

In considering the pedagogical approaches of elementary teachers that integrate digital technologies, I recognize that professional teaching practices are continually developed in what Dall'Alba (2009) referred to as "a process of becoming” (p. 41). Teachers do not develop pedagogical repertoires in isolation; rather, teaching practices are formed and evolve socially (Britzman, 2003; Dressman, 2004). Clandinin and Connelly (1988) viewed teachers' experiences as constantly drawing upon past life experiences while simultaneously projecting towards future instruction, mediated and impacted by pedagogical development and teaching objects (such as technologies).

The authoritative discourses with which teachers maintain dialogue as they develop and enact their pedagogical design (Britzman, 2003) are historically embedded in educational traditions and reforms efforts (Dall'Alba, 2009; Eisner, 1979; Mahiri, 2004). Clouse and Nelson (2000) recommended that teaching and learning reforms avoid political bias and emerge from a place of common ground. From an organizational standpoint, Elmore (1993) noted that attempts to centralize and decentralize schools' power to dictate educational directions and reforms have been focused on milieu far removed from effectively impacting or improving daily classroom activities or pedagogy (e.g., accountability to the public, standardization, etc.). Bruner (1979) called for a new model of educational reform, the "institute for curriculum studies" (p. 125), in which the curriculum matches the needs of students with respect to the societal changes and challenges they will confront. 
Therefore, since this study is focused on elementary teachers' stories of pedagogy, which are enacted within classroom contexts that can serve as micro arenas of political and cultural change (Mahiri, 2004), it is pertinent to ground educational technology within the history of American educational reforms.

\section{Historical Authoritative Discourses}

Historically, American education reforms have neither occurred as linear back-and-forth political movements nor cyclical, predictable patterns (Cuban, 1990). Rather, they result from social crises and the imposition of mainstream values, via pressure on schools, as political solutions (Penuel \& O'Connor, 2018; Thomas, 1980). As society has continued to change and evolve, the intrinsic human quest for satisfaction has spurred numerous reform efforts (Schlesinger, 1986). Schools serve as a collective site for continually reinvesting in the future of society, preparing future adults and leaders to carry forth into the unknown future (Arendt, 1954/2006). Of the three forms of education conceptualized by Rousseau (1889) - nature, circumstance, and "that of man" (p. 13) - humans can only fully control the latter, which involves showing students how they might fully thrive as they make their way towards adulthood. Roberts (2007) equated the work of educational reform to conservation in terms of the ever-changing environment in which effective innovations can be complicated and elusive.

School reform philosophies have historically emerged within the classroom context as teacher-centric or student-focused approaches (Katz, 1968/2001; Mills, 1956/2000); however, some movements have included aspects of both and cannot be completely classified in such binary terms (Ornstein, 1990). Elmore (1993) was critical of both types of reform, which he viewed as attempts to centralize or decentralize schools' authority that ultimately result in impasses for educational improvements. His views aligned with Foucault's (1978/1991), who 
decried the evolution of government sovereignty between the 16th and 18th centuries as populations became objectified and ruled on an individual level. Understanding the discourses surrounding technology in education must be foregrounded in the historical discourses of nontechnological educational reforms in U.S. schools in which they are rooted (Greene, 1984; Koetting, 1996). Next, I will present an overview of some of the past and recent authoritative discourses of U.S. educational reforms: teacher-centric reforms, student-focused reforms, and those primarily concerning technologies.

Teacher-centric reforms. Teacher-centric pedagogies have historically been promoted by reform movements in which more control is sought over teaching and learning in schools (Apple, 2013; Katz, 1968/2001; Mills, 1956/2000). In the late 19th century, the National Education Association (1894) formed the Committee of Ten to recommend requirements for college entry, guiding the preparatory efforts of secondary education institutions. The Committee's work was steered by chairman Charles W. Eliot, a scientific thinker who believed schools should serve to foster students' reasoning abilities (Kliebard, 2004). Four specific coursework tracks were recommended by the Committee, which colleges and universities were encouraged to accept for admission purposes, subsequently directing the curricula of secondary schools (Eliot \& Robinson, 1894).

Much like the Committee of Ten's recommendations, contemporary learning standards specify grade level objectives and standardize common educational experiences for students. As an example, the Common Core State Standards (CCSS) for English Language Arts contain K-12 objectives within the domains of reading, writing, speaking and listening, and language (National Governors Association, 2010). Articulating content by grade level strands and promoting standardized learning both have philosophical origins in the Cardinal Principles Report from the 
early 20th century (Kliebard, 2004). The authors of this report recommended seven key objectives laden with references to common experiences, knowledge, and skills for all students, mainly focusing on secondary schools in addition to career and vocational preparation goals (National Education Association, 1918).

Likewise, social efficiency education reformers of the early 20th century pushed for the application of scientific knowledge to foster societal order and predictable vocational training (Ross, 1896), a concept that can be traced as far back as the writings of Plato (360 B.C./1941). Bobbitt (2013) recommended that schools optimize the learning of students through the application of scientific principles, correcting their deficiencies and mistakes along an 'assembly line' toward career tracks differentiated by ability and gender. Snedden $(1933,1934)$ considered specific vocational career preparation to be essential, believing that education only contained value if a student's learning could be transferred to the demands of work and societal living.

Popkewitz and Shutkin (1993) classified scientific-minded educational reforms as a defining feature of the policies of the contemporary U.S. federal government, though such nationalistic thinking has persisted since the mid 20th century. No Child Left Behind (NCLB), in many ways, was "the culmination of changes that began with [the competitive politics and economics of the Cold War] and were further amplified through the Nation at Risk Report" (Roberts, 2007, p. 212). A Nation at Risk, prepared by the National Commission on Excellence in Education (1983) during the Reagan administration, served to compare the effectiveness of the American education system to other countries. Through education, national interest (and international superiority) could be maintained and upheld (Schlesinger, 1986). To be sure, beginning with Russia's aeronautical head start with Sputnik in 1957 and into international competition in world trade markets in the 1970s and 80 s, America began to feel threatened as the 
supreme economic superpower (Guthrie, 1985). Accountability efforts that had previously been focused on equality reforms, such as racial desegregation (Brown v. Board, 1955) and educational access for handicapped students (Public Law 94-142, 1975), were now diverted towards increased standardization and greater expectations on quantifiable student achievement (Tyack, 1993).

Educational reforms serve as a form of political action, integrating new or revised values (Ornstein, 1990) to address the dilemmas of society at large (Meyer, 1979). Two such approaches by the federal government in the current century, NCLB and the Every Student Succeeds Act (ESSA), both tied grant funding to targeted reforms by states and school districts (Public Law 107-110, 2002; Public Law 114-95, 2015). With ESSA, states were positioned to compete for Race to the Top grants by adopting reforms such as common learning standards (i.e., CCSS) (McGuinn, 2016).

Student-focused approaches. Student-focused approaches have been driven by reforms targeting the students themselves (Katz, 1968/2001; Mills, 1956/2000). While obvious legislation toward equitable access to public education fits within this category, such as Title I (Public Law 89-10, 1965), others aimed to enact change through more scientific approaches (Kliebard, 2004). For example, in the late 19th and early 20th centuries, developmentalists, such as G. Stanley Hall (1904), focused on the biological and cognitive development of young learners and sought to optimally structure curriculum and instruction within a developmental trajectory.

In an address to the National Education Association, Dewey (1897) was critical of developmentalist curricular thinking, noting that the needs of individual learners cannot be fully generalized into scientific research. Education, from Dewey’s (1895/1972) perspective, must 
unite psychological learning processes and authentic social living. Dewey (1896) organized his Chicago lab school to liberate the "genuine principle of interest" (p. 9) in students rather than control them through contrived, politically-driven curricula.

Dewey (1966) believed that young students do not naturally distinguish between academic subject divisions, because life experiences are not delineated in such a tidy manner. While adults have had the life and academic experiences to view academic content separately, elementary learners, by and large, have not. Particularly in the elementary setting, Dewey (1895/1972) felt that teachers should facilitate unity in the curriculum and by proxy, the learning experiences of students as a way for these young learners to engage in social living. Bridging divisions between the academic content areas can provide students with a more integrated, authentic learning experience (Shulsky, Baker, Chvala, \& Willis, 2017).

Historical educational technology discourses. Authoritative discourses surrounding technologies, as with other non-technological reforms, have been historically implemented as teacher- and student-centered approaches (Kalmbach, 1996). Unlike the typewriter, which was leveraged to facilitate young students' early writing experiences (Burke, 1939; Haefner, 1932, 1936; Kasson, 1895), most technologies that preceded modern digital innovations (e.g., radio, television, computer-assisted instruction) were primarily utilized to transmit academic content (Armstrong, 1929; Bundy, 1968; Riley, 1940; Thomas, 1980). Contemporary digital technologies have been subject to deterministic, means-end assumptions about their impacts on teaching and learning effectiveness (Chandler, 2012) and applied as teacher-centric approaches (Cristia et al., 2017; Negroponte, 2006; Seglem, 2015).

The use of radio broadcasting gained prominence in the early 20th century (Cassidy, 1998). Students were encouraged to listen to radio broadcast lectures in the classroom without 
question or equivocation. For example, in his book Radio in Education: The Ohio School of Air and Other Experiments, Armstrong (1929) told students, "Learn to concentrate-your success in school depends on it—and in fact, your success all through life" (p. 24). Such approaches with radio broadcasting were widely accepted as the most effective use of this technology, as indicated by Riley's (1940) synopses of the Institutes for Education by Radio at Ohio State University in the late 1930s.

Television replaced radio as the popular technological innovation in education in the mid20th century, due in part to the designation of television ownership by American households as a sign of socioeconomic status in the Coleman Report (Cain, 2018; Coleman et al., 1966). Educational television received federal funding in the early 1970 s as a means of producing free programming with the intent of impacting diverse learners nationwide (Public Law 92-318, 1972). Likewise, through television, the federal government attempted to broadcast instructional programming to American Samoa in the 1960s as a way of improving the education system in this U.S. territory. Thomas (1980) noted that this approach was spurred by the "social-welfareoriented administration [of President Kennedy, which] convinced Washington officials that strong measures would be needed" (p. 157) to improve outcomes for minorities in Samoa. Subsequently, classroom teachers in American Samoa primarily served to supplement and reteach televised lessons (Baldauf, 1981).

The radio and television fell out of favor as prevalent educational technologies due to waning popularity (Slavin, 1989). Thomas (1980) attributed the decline of previous technological innovations in education to their failure to improve teaching and learning, an affordance that had been advertised upon their arrivals. Computer-assisted instruction (CAI) attempted to optimize students' learning minutes at school (Bundy, 1968) through the behaviorist 
principles of Thorndike (1912) and Skinner (1954), but fell out of favor over time as well. Meredith (1971) recommended that teachers take on an authorial role in creating CAI courses, as computer programmers lacked teaching expertise (Futrell and Geisert, 1985), or "pedagogical content knowledge" (Shulman, 1986, p. 9).

As audio-visual technology became more widely used in education and other professions in the mid-20th century, Finn (1953) recognized that these media alone could not transform social practices without shifts in professional approaches. Thorndike (1912) hypothesized about a futuristic technological device that could optimally deliver content at the precise moment a student was prepared to receive it, much like the radio, television, and CAI were used throughout the course of the 20th century. Even in the early 1990s, Knupfer (1993) noted that like previous technologies primarily geared toward transmission, modern digital technologies were initially intended to optimize the delivery of content to learners; however, on a societal level, they became a significant resource used "to foster literacy, transmit culture, inculcate basic civic values, and train students for a competitive economy" (p. 164).

\section{Internally Persuasive Discourses}

Contemporary pedagogical approaches with digital technologies have not been immune to the dialogue of authoritative discourses. In considering their design of instruction and integration of digital technologies, teachers engage in dialogue with and between authoritative and internally persuasive discourses (Britzman, 2003). Some teachers respond to these discourses by utilizing approaches in the banking tradition of education (Freire, 2009). Banking approaches include deterministic perspectives of the affordances of technology as well as knowledge-centric conceptions of digital pedagogy. Other teachers take critical approaches with digital technologies, embedded in concepts such as critical digital literacies and discourse theory. 
Banking approaches. 'Banking' (Freire, 2009) approaches of technology fit within Ely’s (1963) then-popular definition of audiovisual communications focused on controlling the processes of teaching and learning. Contemporary discussions of specific technologies often center around devices and digital tools (Abshire, Cummings, Mason, \& Abernathy, 2014; Milman et al., 2014) and deterministic outlooks on their impacts (Chandler, 2012) as well as knowledge-based conceptions (Mishra \& Koehler, 2006) of teaching with digital technologies.

Technological determinism. Teaching with technology (compared to non-digital pedagogical approaches) requires teachers to develop technical competencies and, if putting devices in students' hands, shift the locus of participation and control of learning activities away from themselves and toward students (Knupfer, 1993). Technology cannot improve teaching and learning processes in and of itself (Harris, Al-Bataineh, \& Al-Bataineh, 2016; Kalantzis \& Cope, 2004). Chandler (2012) defined such means-end beliefs about the educational benefits of technological innovations over non-digital approaches as "technological determinism" (p. 256). Technological determinism involves adhering to dominant social expectations of technology use, where abstention would be viewed as abnormal or odd. Scollon (2001) liked these social pressures to a form of "standardization or credentialization" (p. 136) in that the mediation of individual actions by technologies becomes expected or assumed. Iannone (1998) cautioned educators from privileging technological literacy skills over non-digital ones that students will also need to master (Leu, Forzani, \& Kennedy, 2015).

Deterministic mindsets in the political arena have resulted in the leveraging of educational technologies toward reform goals. The cataclysmic outlook presented in A Nation at Risk fueled reforms meant to increase U.S. competitiveness in the global economy (Elmore, 1993; Guthrie, 1985; Tyack, 1993). Likewise, President Clinton's Educational Technology 
Initiative in the mid-1990s positioned American students' technological competencies as a primary vehicle for vocational preparation and global economic competitiveness (Cassidy, 1998); however, Clinton's administration primarily depicted student use of the Internet as a means of accessing vast amounts of information (Hecht, 1997), much like the promises purported by broadcast radio (Armstrong, 1929; Riley, 1940) and television (Morehead, 1955).

Deterministic mindsets have prevailed in many educational deployments of modern digital technologies, including one-to-one implementations, which involve equipping every student in a defined educational setting (e.g., classroom, school, district, etc.) with a digital device (Harris et al., 2016). Nicholas Negroponte (2006), founder of the One Laptop Per Child (OLPC) organization, served as one of the first public one-to-one proponents. He worked with financial backers and technology producers to distribute inexpensive laptop computers to students throughout the world, targeting remote domestic and international communities he termed "rural" (p. 9). Negroponte believed that by putting technology in each student's hands, they could better direct their own learning and overcome social and educational inequities.

Some one-to-one implementations funded by governments and districts have primarily centered around specific, unilateral software or applications on school-issued devices rather than allowing students or teachers to make those choices (Cristia et al., 2017). When districts unnecessarily mandate some web resources, block others, or restrict teachers from having the flexibility to install apps on mobile devices as needed, effective teaching and learning opportunities are stifled (Seglem, 2015). Initially, the novelty of new digital technologies can be engaging for students; however, these impressions can eventually wane, increasing the importance of collaboration between teachers and students to create authentic learning opportunities with digital tools (Varier et al., 2017). 
Elementary teachers can benefit from greater flexibility to work with students in choosing optimal websites, apps, and digital media to best accomplish learning goals, while engaging the learners' individual interests and needs (Gierhart \& Brown, 2018). For example, in a case study of a racially-diverse group of U.S. fifth graders, Dietrich and Balli (2014) found student choice in engaging with technology for learning purposes to be of great importance; the students indicated, in individual interviews, that they preferred using technology in self-directed ways, such as conducting online research and creating multimodal products of learning.

Regarding teaching with digital technologies, the U.S. Department of Education's Office of Educational Technology (2017) has promoted a student-centered pedagogy in which teachers are both leaders and participants. State governments have responded to calls for increasing student technology use by passing legislation that requires school districts to offer technologybased learning experiences; however, a variety of competing pedagogical approaches for implementation exist, despite many states' support and funding for technology integration in schools (Zheng, Arada, Niiya, \& Warschauer, 2014). Some states require districts to offer online alternatives to traditional face-to-face classroom courses for secondary students; however, accountability measures for alternative online course programs offered in states such as Texas, Michigan, Minnesota, and Missouri have focused mainly on administrative, non-pedagogical matters (e.g., funding, student performance on traditional exams, defining teacher and mentor roles, etc.) (Archambault et al., 2016).

Pedagogy as knowledge. Mishra and Koehler's (2006) technological pedagogical content knowledge (TPACK) framework served as a digital age extension of the pedagogical content knowledge (PCK) framework developed by Shulman (1986). They defined TPACK as the pedagogical knowledge (PK) of how to teach, content knowledge (CK) of what to teach, and the 
ability to effectively harness both while integrating technology (technological knowledge, or TK), which impacts the dynamics of teaching and learning in unique ways. As a three-way intersection of knowledge bases, the framework also explicates the interaction of knowledge pairings: PCK, technological content knowledge, and technological pedagogical knowledge (Koehler, Mishra, \& Cain, 2013).

The TPACK framework has influenced educational research, especially concerning teacher education. It has been applied in pre-service teacher coursework studies to evaluate new interventions for improving students" acquisition of TPACK “competencies” (Angeli \& Valanides, 2013, p. 210), TK (Kafyulilo, Fisser, Pieters, \& Voogt, 2015), and knowledge prediction and assessment (Deng, Chai, So, Qian, \& Chen, 2017). Additionally, TPACK was applied as a conceptual framework by Heitink, Voogt, Verplanken, van Braak, and Fisser (2016) to analyze elementary and secondary teachers' purported rationale for teaching with technology and their actual video-recorded uses of it.

TPACK has also been extended into the Learning by Design (LBD) movement. LBD was initially conceptualized as a process of social engagement and collaboration to improve pedagogy and lesson design amongst teachers (Kalantzis \& Cope, 2010; Yelland et al., 2008). LBD has also been used with college and university instructors to improve online course design and delivery through the TPACK lens (Koehler, Mishra, Hershey, \& Peruski, 2004). Those who participate in design-based professional development initiatives and teacher education programs purportedly access intersections of the TPACK framework by socially engaging in solving current problems of instructional practice (Harris, Mishra, \& Koehler, 2009; Koehler \& Mishra, 2003; Mishra \& Koehler, 2003). 
However, TPACK is an ineffective lens for advancing democratic teaching and learning, because it fails to elucidate the challenges teachers face in implementing technology in studentcentered ways for diverse learners (Lohnes Watulak \& Kinzer, 2013; Rust, 2017). Mishra et al. (2011) conceded as much, admitting that TPACK does not move beyond a knowledge model and lacks full practical applicability.

As an example, Rust (2017) attempted to use TPACK to analyze field notes, interview and email transcripts, and teaching artifacts (e.g., lesson plans, students' digital work samples, etc.) in a descriptive case study. As part of this research, she co-taught and collaborated with a high school English teacher in using social media and digital design software with students. Framing the findings using the TPACK framework proved incredibly challenging. TPACK only considers the knowledge of individual teachers; attempting to collaborate with colleagues and students introduced dialogic perspectives that the TPACK framework could not fully encapsulate in this study (Shing, Saat, \& Loke, 2015).

As an individual-focused construct, TPACK does not incorporate factors related to students and context (Seglem, 2015) nor processes of working through challenges in classroom practice (Garcia and O’Donnell-Allen, 2015). Future research must acknowledge the importance of knowledge while also driving forward educational policies and practices that best serve disadvantaged students in real, non-theoretical settings (Rust, 2017). Teachers do not simply arrive at improved understandings of and approaches with technology by happenstance. In this study, I wanted to co-construct narratives of how elementary teachers developed the strategies that they transferred to classroom action, including all of the personal, social, and professional milieu that played a role in those journeys (Alsup, 2006; Britzman, 2003; Clandinin \& Connelly, 2000). 
Ultimately, Mishra and Koehler did little to advance Shulman's (1986) initial PCK framework, in which he discussed the potential of case knowledge in teacher education and professional development. Case knowledge, according to Shulman, could make the abstract (such as pedagogy and the processes of effectively teaching and learning with digital technologies) more tangible and practical. Case-based reasoning and reflection has been used successfully in the medical industry (Tawfik \& Kolodner, 2016) and should be considered for wider use in developing effective, student-centered pedagogies in the education sector as well (Henry, Castek, Roberts, Coiro, \& Leu, 2004; Rico \& Ertmer, 2015). In a recent article (TPACK cocreator) Koehler authored with Harris, Phillips, and Rosenberg (2017), he called for future research to investigate the knowledge bases of TPACK being enacted by teachers; while I disagree with using TPACK as a research framework, I $d o$ feel I responded to this challenge, in a way, through conducting narrative research about elementary teachers' pedagogical stories of experience in teaching with technology (Clandinin \& Connelly, 2000; Plano Clark \& Creswell, 2010).

Critical approaches. Other scholars position pedagogical approaches with digital technologies within the scope of critical literacies and pedagogies. Through a critical lens, technology can (but does not have to) play a significant role in students' learning, depending on the context and learning at hand (Bruce, 2015). However, digital technologies remain central to participation in modern symbol-driven sociocultural literacy practices (Kalantzis et al., 2003). Cope, Kalantzis, and Smith (2018) noted that traditional views of language and the the 'banking' model of education (Freire, 2009) foster pedagogies that perpetuate inequities for diverse learners. Implementing prescriptive teaching approaches that simply replace (Puentedura, 2014) traditional print-based methods with technological versions (Kimmons, Miller, Amador, 
Desjardins, \& Hall, 2015) only reduces students to actionable objects and cannot fully liberate them from hegemonic, dominant norms (Greene, 2009). Providing technology access to students cannot adequately combat the hegemonic forces and subsequent inequities diverse learners face in today's schools (Forzani \& Leu, 2012; Luke et al., 2018; Tabb, 2008).

Critical pedagogies can empower teachers to supplant traditional approaches to teaching and learning that have upheld long standing educational disparities. By supporting students' authentic construction of knowledge and literacy skills and dispositions, they will be better equipped to enact social change for themselves and others (McLaren, 2009). Students should create their own purposes and approaches for using digital technologies authentically in classroom learning, rather than passively receiving content through learning platforms (Janks, 2013).

The New London Group’s (1996) seminal ‘pedagogy of multiliteracies’ framework influenced thinking about digital literacies and discourses; likewise, it continues to serve as an influential framework for incorporating digital tools with diverse communities of learners. According to the pedagogy of multiliteracies, digital technologies should be used to optimize teacher and student inquiry and extend authentic literacy practices beyond the brick-and-mortar classroom walls (Seglem \& Garcia, 2018). Components of instruction within this framework, which I used as the second theoretical framework of this study, will be discussed in greater detail later in this chapter.

In addition, the NLS movement shifted thinking about literacies as social practices beyond the psychological and cognitive elements of reading and writing (Lankshear \& Knobel, 2003; Street, 1993, 2003). Pluralistic literacies include specific discourses based around multimodal communication (Cope, Kalantzis, \& Smith, 2018). A consideration of NLS is the 
constantly evolving nature of what it means to be literate now (and moving forward) compared to the past, given the impact of technology on authentic social literacy practices (Leu, Kinzer, Coiro, Castek, \& Henry, 2013).

The Four Resources Model of Reading, developed by Freebody and Luke (1990), served as an early example of pluralistic literacies. This model recommended four literacy roles that teachers should support students in enacting as members of a text-laden society: code-breaker (who decodes sounds from letters and symbols), text participant (who constructs and communicates meaning with text), text user (who understands purposes and audiences of texts), and text analyst (who engages in critical literacy practices). These roles transfer to digital literacy practices as well, redefining what has been traditionally understood as 'text' to include other forms of digital media (Lankshear \& Knobel, 2003, 2007).

Students must be able to work with symbols and information for authentic purposes through the development of digital literacies (Lankshear and Knobel, 2003, 2007) rather than traditional forms of learning in which students acquire static knowledge. Leu, O’Byrne, Zawilinski, McVerry, and Everett-Cacopardo (2009) argued for treating technology in educational settings "as a literacy issue, instead of a technology issue" (p. 265). There is a growing recognition of online literacy gaps in addition to the traditional, offline reading achievement gaps schools seek to reduce (Leu et al., 2014; Leu \& Maykel, 2016). Supporting young elementary students' development of "new literacies of the Internet" (Forzani \& Leu, 2012, p. 422) can be included in early classroom literacy experiences as teachers foster “emergent literacy foundations" (Henry et al., 2004, p. 27).

To Luke (2012b), promoting literacy skills and critical dispositions can empower learners to engage in individual and collaborative action, ideally sparking social change. Luke (2018) 
reiterated that the concept of design emphasized by the New London Group was meant to represent multimodal, non-linguistic forms of constructing and communicating meaning as well as making social impacts. Critical literacy, at its core, "entails a process of naming and renaming the world, seeing its patterns, designs, and complexities, and developing the capacity to redesign and reshape it" (Luke, 2012b, p. 9). Digital design-based pedagogical approaches promote student-centered, impact-oriented learning (Yelland et al., 2008). Enforcing policies and curricular restrictions on how students utilize digital technologies (Seglem, 2015) and focusing solely on teaching technology skills (Lohnes Watulak \& Kinzer, 2013) fails to support students' ethical digital participation (Luke et al., 2018). Even with equal access to technologies in the classroom, more privileged students may be better positioned to develop digital literacy skills and pursue networked engagement in sociocultural discourses on a consistent basis outside of school (Jenkins, 2006; Ito et al., 2013; Robinson, 2009; Van Dijk, 2012, 2017).

Gee (2015b) proposed the concept of these discourses being socially-situated. While learners can develop literal understandings of the meanings of words and language, they may struggle to apply them to specific contexts to solve problems, meet goals, etc. Through this lens, language carries both literal and "situated meaning" (Gee, 2015d, p. 65). Situated language is also associated with an individual assuming a situational or contextual identity, allowing him or her to engage in a "big D Discourse" (Gee, 2015a, p. 2). The concept of big D Discourse (hereby referred to as "Discourse") combines language with action, experience, and being. Individuals can shift between different identities and roles in specific contexts, using the situated language called for in that particular time and place (Gee, 2013, 2014, 2015a).

While Discourses can involve objects or tools (Gee, 2005a; Pinch \& Bijker, 1984), Gee (2015c) recognized that NLS and the argument for digital literacies transcended the novelty of 
using digital technologies; rather, modern digital tools serve to mediate authentic and situated social practices centered around language (Jones \& Hafner, 2012; Leu et al., 2009; Scollon, 2001). These social practices can take place in physical and/or digital locales, or "affinity spaces" (Gee, 2009b, p. 223), which are built around shared content, symbols, and situated language. Gee $(2005 b, 2008,2015 b, 2016)$ has used videogames to exemplify how modern digital technologies can support students' situated learning and motivation (Leu et al., 2015).

Videogames have gained traction, or "resonance" (Stornaiuolo et al., 2018, p. 80), as a technology with which students can learn academic content and skills. Trial-and-error is a critical component of game-based learning, as mistakes yield feedback that informs learning and helps players improve future gameplay in real time. Gee (2008) noted that when users learn through gaming, they "store these experiences in memory... and use them to run simulations in their minds to prepare for problem solving in new situations" (p. 21). Additionally, they can apply their learning to new contexts and scenarios, while continually receiving feedback and opportunities to retry. This in-the-moment feedback allows learners to employ formal, situated meaning and language within actual experiences right when they are prepared to do so (Gee, 2015b).

By integrating gameplay in classroom learning, students may become more motivated and engaged by actively experiencing and doing rather than passively receiving information through more traditional approaches (e.g., lecture, textbooks, etc.). They assume a "projective stance" (Gee, 2005b, p. 219) in which the virtual character (or perspective) in the game projects goals onto the player, but the player can do the same to the game and character as well. In addition, gamers often exhibit engagement outside of the game itself in affinity spaces where they learn how to achieve greater levels of competence and/or fandom (Black \& Steinkuehler, 
2014); they might meet up to play with friends in person, chat online, or explore walkthrough screencasts on YouTube (Marsh, 2014; Niemeyer \& Gerber, 2015; Overby \& Jones, 2015).

In engaging with each other in affinity spaces, learners "understand the nature and purpose of the goals, interpretations, practices, explanations, debriefing, and feedback that are integral to learning" (Gee, 2008, p. 23) within a given Discourse. This socioculturally authentic, “constellation of literacy activities" (Black \& Steinkuehler, 2014, p. 277; see also Scollon, 2001) are indicative of truly engaging, social learning experiences (Gee, 2018; Hobbs, 2013, Merchant, 2013).

\section{Theoretical Framework: Pedagogy of Multiliteracies Framework}

The New London Group's (1996) pedagogy of multiliteracies employs the concept of design as a way for teachers to create instruction and learning activities as well as the social discourse and literacy practices in which learners construct and communicate meaning. Using “Available Designs" (p. 74), individuals engage in different discourses with currently-available design elements. In this process of "Designing" (p. 75) within social contexts, "Available Designs" (p. 74) are transformed as "The Redesigned" (p. 76). The Redesigned are not facsimiles of Available Designs; rather, as newly-constructed meaning, become new Available Designs for future utilization. The process of Designing involves shifts in one's identity, which are portrayed and revealed narratively (Chase, 2005; Mishler, 1999; Webster \& Mertova, 2007).

The New London Group (1996) proposed four pedagogical components that may be emphasized at optimal times, per the discretion of teachers, to support the meaning-making and literacy development of culturally- and linguistically-diverse learners: situated practice, overt instruction, critical framing, and transformed practice. These components can serve as effective launching points for theorizing about teaching and learning with (or without) digital 
technologies. I will use the pedagogical components of the multiliteracies framework as a theoretical lens for discussing and answering the second sub-question of this study, which concerns the digitally-mediated teaching practices of elementary teachers.

I also utilized other scholarship, as needed, to discuss and transfer the findings from these narratives to broader audiences (Josselson, 2007) in Chapters $V$ and $V I$, as the multiliteracies framework has limitations. For example, Leander and Boldt (2018) cautioned against the overemphasis of design principles and predestining of students toward transformative goals the students themselves do not authentically discover or choose (Freire, 2009; Gee, 2017a, 2017b). Additionally, the separateness of the contexts of the classroom and the evolving real world, or chronotope (Bakhtin, 1981b), can interfere with authentic Designing (Penuel \& O'Connor, 2018). Finally, Mirra, Morrell, and Filipak (2018) utilized multiliteracies as a springboard for introducing a "pedagogy of digital invention" (p. 15); in this framework, critical literacy in digital contexts is harnessed to develop students' skills and dispositions to achieve new, sociallyrelevant, and self-realized literacy goals. Ultimately though, I found the pedagogical components in the New London Group's framework to be applicable in a practical sense for the purposes of disseminating the narratives constructed in this study.

Next, I will describe each pedagogical component and discuss how they are being taken up in current research and teaching practices.

\section{Situated Practice}

Situated practice involves teachers and students working together to establish connections with experts and bridge authentic sociocultural contexts into learning experiences, increasing motivation and the relevance of academic content for all learners (New London Group, 1996). Mentors can help students select and use digital technologies (or non-digital approaches) to 
accomplish specific goals, depending on the discipline, content, and audience (Gee, 2009a; Limberg, Sundin, \& Talja, 2011). For example, Seglem and Garcia (2018) discussed how a Central Illinois middle school language arts teacher paired students with mentors to communicate digitally (and in person) for interest-driven 'genius hour' projects. When incorporating new technological innovations into classroom learning activities, teachers can also enlist the help of a few students who are knowledgeable to serve as peer 'experts' for the rest of the class (Dooley, Ellison, Welch, Allen, \& Bauer, 2016). From a sociocultural perspective, situated practice is critical for students to understand how and with what tools they might engage in authentic literacy practices and meaning-making (Gee, 2009a).

Elementary learners may especially benefit from making connections between familiar topics and life experiences prior to branching out into the unfamiliar and abstract (Mills \& Levido, 2011). Such practice experiences are especially vital for students who previously lacked technology access or experience (Hargittai, 2002; Jenkins, 2006; Jesson et al., 2015; Robinson, 2009). Likewise, in an inclusive classroom setting, teachers must recognize that students will ascribe a variety of socially-derived purposes to different digital tools. As Pinch and Bijker (1984) pointed out, the meanings people associate with artifacts and tools are sociallyconstructed. Teachers should use research strategies to learn more about their students' backgrounds, interests, and experiences to inform relevant instructional choices (Kincheloe, 2009).

\section{Overt Instruction}

Overt instruction involves classroom teachers intervening and scaffolding learning activities for students; they support students' understanding of new information and development of new skills needed to drive their design and inquiry efforts forward (New London Group, 
1996). Leu et al. (2015) stressed the need for teachers to explicitly teach digital literacy skills, especially with students who display literacy struggles in general, prior to using new digital technologies. For example, Lenters (2016) conducted a case study of four teachers and their classes of second and fourth grade students, comprised of sizeable groups of ELLs and individuals with individualized education plans (IEPs). She reported that one teacher taught the students compositional photography techniques, connecting with these learners emotionally through the feelings he could elicit through taking pictures. This inspired the students to apply these techniques to a history project in which photography was a central component. The students became more collectively engaged in their research efforts through the teacher's intervention and instruction.

In overt instruction, teachers support students in their learning and design efforts rather than directly imparting information to students through 'banking' approaches (Freire, 2009). Teachers must monitor students' progress and interject support or guidance as needed. Digital technologies can offer unique approaches for providing feedback during student-centered learning processes. For example, Varier et al. (2017) described examples of elementary and middle school teachers monitoring students' work on apps such as Google Docs and Edmodo. The teachers provided digital and/or verbal feedback as needed when students exhibited needs for overt instruction.

Additionally, students may benefit from overt instruction and guided critical reflection in their online research efforts. Mills and Levido (2011) reported on the experiences of four Australian teachers and a digital media specialist who used digital critical literacy approaches with students aged 8 and 9 . These instructors scaffolded students in critically evaluating online sources based on power relations and benefits, intended audiences, and implications toward 
diverse others. They also guided students through similar self-evaluations before these learners published their own multimedia content online.

\section{Critical Framing}

In the critical framing component of the New London Group's (1996) multiliteracies framework, students consider the sociocultural contexts of their previous learning experiences and apply them to new ones. Teachers and mentors can facilitate opportunities for learning in the external community (Seglem \& Garcia, 2018); alternatively, students can identify external sources for critical framing. For example, Hobbs (2013) shared the experience of a summer learning program instructor whose group of nine-year-old students noticed a homeless man being robbed while asleep in a Philadelphia park. The teacher chose to develop a multimedia inquiry and advocacy project in which the students explored homelessness issues in their community. Had the teacher not engaged in meaningful dialogue with the students about what they had witnessed, this authentic learning opportunity would have been missed. Also, facilitating students' engagement in advocacy and social action fits within the transformative levels of multicultural and diversity frameworks, such as Banks's (1996) Levels of Integration of Ethnic Content framework.

Through critical framing, students can develop new perspectives or relationships with academic content and skills. Zheng et al. (2014) shared the feedback of elementary students who expressed newfound appreciation and motivation for writing, which they attributed to composing with digital tools. These learners enjoyed publishing their compositions online for authentic audiences, utilizing the spell check features of word processing apps and editing in real-time with a few simple keystrokes and clicks. Through positive and productive uses of digital media for constructing and communicating meaning, students can begin to see how technology can be 
used for academic purposes as well as personal enjoyment (Husbye, Buchholz, Coggin, Powell, \& Wohlwend, 2012; Li, Snow, \& White, 2015; Moreno de Diezmas \& Manzano, 2016).

Lenters (2016) reported that teachers used literature discussions to support elementary students' critical framing, making emotional connections to their research efforts. Students were motivated to own their design work in telling historical stories through digital scrapbook reports, increasing the relevance of their projects. Such engagement with literature encapsulates the spirit of the pedagogy of multiliteracies (Kalantzis et al., 2003; Lemke, 2013), as the students used the text as an affective springboard for constructing meaning in new, purposeful ways. Through designing digital 'texts,' students may connect to academic learning experiences more emotionally (Pangrazio, 2016). Affect scholars like Ahmed (2010) might propose that students would be more likely to ascribe feelings of happiness and enjoyment to future 'reading' and 'writing' if they had previously engaged in positive digital literacy activities.

Finally, individuals with varying positions on world issues produce and publish digital media on a daily basis. Therefore, young learners must develop and exercise critical digital literacies in order to consider how their design choices may be interpreted by and potentially impact intended and unintended audiences online (Hull and Stornaiuolo, 2010). Smith and Hull (2013) reported that secondary level teachers have supported students' development of ethical approaches to online interactions, or cosmopolitanism, by having them produce and discuss social media content about relevant issues with international peers. Ideally, elementary teachers could also incorporate similar activities to develop cosmopolitan dispositions with their young students, focusing on the local before expanding towards more global perspectives (Gierhart, Bonner, Smith, \& Seglem, 2020; Hansen, 2010). 


\section{Transformed Practice}

Stemming from critical framing, students engage in transformed practice by applying their increased understanding and skills to new contexts tied to personal goals (New London Group, 1996). In transformed practice, students may assume what Mills and Levido (2011) call “situated identities" (p. 87; see also Gee, 2013, 2014, 2015a). Some of these authentic sociocultural roles, in which students purposefully utilize digital technologies, may include blogging, podcasting, interviewing, etc. Transformed practice fits within a sociocultural perspective of information literacy, as students engage in authentic social practices with specific tools in both digital and non-digital realms (Limberg et al., 2011).

With elementary learners, Klapwijk and Van Doorn (2015) reported that pedagogical approaches that facilitate students' intimate experiences with authentic others can transform learning and provide new powerful insights. In this study, Dutch students aged 9-12 interviewed peers and grandparents using digital voice-recorders. Their goal was to design a playground that both the young and elderly could use together. In the students' final playground designs, "almost all groups [drew] persons and they explained more about the roles and wishes of these different persons" (p. 162), showing empathy through incorporating a variety of their interviewees' needs.

Collaboration between peers can also authenticate academic and digital practices, transforming literacy engagement for elementary learners. Husbye et al. (2012) observed the writing instruction of two co-teachers in a class of $44 \mathrm{~K}-1$ students in the Midwestern U.S. The teachers organized students into small groups to compose narrative storytelling films with student-designed scenery and puppets. As a pedagogical shift from traditional, print-based writing instruction, these co-teachers valued alternative digital design and composition practices. 
Students felt limited by the written storyboarding activities that the teachers had initially planned; through play and collaborative discussions, the student groups realized they could design multimodal narratives that transcended print-based storytelling. Students considered how set designs, dialogue wording, movements, and camerawork choices would impact the way audiences experienced their stories.

When students engage in digital activities, they can and will shift between critique and technical design foci, depending on the demands of the task and context (Pangrazio, 2016). As they apply language and content knowledge in situated ways, based on specific sociocultural norms and contextual demands, their learning experiences can become deeper and more transformative (Gee, 2009a). Such flexibility is especially important in the modern digital sphere, when text norms shift toward increased interactivity (Forzani \& Leu, 2012; Smith \& Hull, 2013).

\section{Conceptual Framework: Bakhtinian Novelness}

Polkinghorne $(1988,1995)$ conceptualized the construction of meaning from reality within a three-level structure. Human self-consciousness is the primary level of organizing cognition of the other two levels, which are matters of the physical and the living. Subsequently, Polkinghorne advocated for the use of narrative research to generate understanding of human actions and existence, within which multiple discernible realities exist (Schweder, 1991). The narrative researcher resides within these strata as well, in what Clandinin and Connelly (2000) called a "three-dimensional narrative inquiry space" (p. 50) composed of temporality, place, and social matters. All three dimensions are critical to authentically co-constructing a narrative with participants that is sensitive to the dialogue of personal and professional life (Anyon, 1994; Geertz, 2005; Wertz et al., 2011). 
To tell the life stories and pedagogical narratives of elementary teachers, I had to acknowledge the narrative ways that humans view life experiences (Bruner, 1986) in terms of story and plot (Gubrium 2003; Robinson \& Hawpe, 1986; Spector-Mersel, 2010; Wertz et al., 2011). Bruner (1979) saw opportunities for understanding the human experience and identities (Mishler, 1999) through the use novellian elements.

In academic research, the conceptual framework should serve to guide the researcher in rationalizing the significance of studying the problem (or topic) and the appropriateness of the methodological choices (Ravitch \& Riggan, 2011). To conceptualize research of elementary teachers' pedagogies with digital technologies dialogically, I chose a framework that encompasses the discourses and social nature of pedagogy (Flick, 2007) as well as the impacts of teachers' biographies: Bakhtin's (1963/1999a, 1981b) Theory of Novelness. Of the novel concepts identified by Bakhtin from the literature of Dostoevsky, I will utilize polyphony, chronotope, and carnival.

\section{Polyphony}

Bakhtin (1923/1990) was critical of novelists who attempted to provide post-publication commentaries of their work in which they gave insight about a character's experiences and feelings; authors, during the act of writing, are more focused on the creative process and do not vicariously share the experiences of their protagonists; likewise, researchers must be mindful of their situatedness in the research context. Through exercising polyphony, the researcher presents a collective narrative around the focal topic while maintaining each participant's unique voice(s), much like the multiple, dialogic, and sometimes clashing voices Bakhtin (1963/1999a) recognized in the novels of Dostoevsky. Polyphony promotes dialogic progress and understanding, making it an effective conceptual tenet for guiding this study, and more 
specifically, understanding the competing aspects of stories between participants (Frank, 2005; Mishler, 1999; Sauer, 2012) and individual participants' plural identities and voices as well as discourses in which they engage (Britzman, 2003).

In theorizing about the practices of teachers dialogically, Britzman (2003) emphasized that researchers should attend to the plural voices each individual teacher utilizes within different social contexts, mediated by language (Gee, 2015a) and influenced by the discourses of the education system (Mitchell, 2008). Heteroglossia must also be recognized in order to facilitate "mutual understanding...crystalizing into a real, although still relative, unity" (Bakhtin, 1981a, p. 270) of how voices of the past echo in the present, highlighting teachers' biographical dialoguing (Mahiri, 2004; Quantz \& O'Connor, 1988). Essentially, the concept of polyphony highlights the fact that teachers "do not have one voice but many...[which are] contingent upon shifting relationships" (p. 34) between language and discourses, pedagogical approaches, and sociocultural contexts (D’Andrade, 1995; Geertz, 1995).

A polyphonic conceptualization of teaching with digital technologies is incredibly pertinent (Bostad, Brandist, Evensen, \& Faber, 2004; Frank, 2005), considering the continuallyevolving nature of digital pedagogies (Gee, 2016; Luke, 2018; Smith, Stornaiuolo, \& Phillips, 2018). Internal discourse, to Bakhtin (1981a) is in continuous dialogue with the external world, of which technologies are socially ingrained (Kalantzis et al., 2003). As the researcher, I used language and literary elements to portray this dialogic reality, as perceived by the participants (Brettschneider, 2004). I asked questions and soliciting stories from a biographical frame in the initial interviews and narrowing the focus towards dialogic matters in the final interviews with each participant (Atkinson, 2007). 
The concept of polyphony has been applied within the realm of music education to emphasize a plurality of sounds or styles, given the term's origins in music as the integration of simultaneous melodies or rhythms (Fulara, 2013). Hess (2018) deployed polyphony as a part of a conceptual framework for a theoretical discussion about integrating world music into the classroom. She noted that music educators must present multicultural music in ways that do not emphasize the differences and foreignness of these compositions in relation to familiar genres. Kannellopoulos (2011) applied polyphony to the concept of student empowerment through fostering improvisational instrumentation, as opposed to primarily playing pre-written music. Kac (2004) expressed similar sentiments about the dialogic potential of digitally-mediated art. Naot-Ofarim and Solomonic (2016) connected the musical origins of the term 'polyphony' to the representation of different voices in educational contexts. Polyphony highlights different perspectives and through those differences, unique identities can be relationally portrayed (Sidorkin, 2002) and "partial views" (Schweder, 1991, p. 68) can be shed. Likewise, Chase (2005) viewed narration and storytelling as a form of sharing and formulating one's identity. Gubrium and Holstein (2009) drew upon the literature and semiotics concept of "intertextuality" (Kristeva, 1980, p. 36) in that narratives can only be understood in relation to other narratives. True polyphonic dialogue (and narration) must be presented distinctly with respect to how they also interact with each other, which informed how I constructed the narratives in the participant's words as much as possible (Chase, 2005; Lemley \& Mitchell, 2012), focusing on events they each deemed critical to their digital pedagogical development (Webster \& Mertova, 2007).

The narrative interview analysis Chase (1995) conducted in a study of female superintendents exemplifies how one might recognize the polyphonic dialogue that exists within 
individual participants. Chase initially worked to thematize the stories of the participants in her study, but found that in doing so, she fractured the Heteroglossia of their experiences with work, sexism, and overcoming. Therefore, she applied a polyphonic conceptual lens, which she referred to as "narrative strategy" (p. 24; see also Chase, 2005), turning her analytic focus towards "patterns in [each participant's] manner of speaking and in her use of various settled and unsettled discourses" (p. 24). Likewise, I sought to maintain polyphony in each narrative to authentically capture the experiences of the participants as they developed and shaped their digital pedagogical designs.

In fact, as a conceptual lens in past educational research, such as the self-study conducted by Depalma (2010), polyphony has been previously leveraged to highlight matters of dialogism in educational settings. As a professor of a multicultural education course for pre-service teachers, she analyzed online discussion board exchanges between her students to find examples of counter-hegemonic viewpoints that sparked dialogic coursework. Depalma found that her notion of successful dialogue in the course had to be shifted to support polyphonic discussions, including those where the students challenged others' views and opinions, including her own. She also found that when she and her students embodied minority voices in discussions, the students developed greater empathy for polyphonic voices rather than just dominant ones. In my discussion of the findings in Chapter $V$, I strived to not mute narrative findings from the discussion that deviated from more common stories and experiences across other narratives in this study.

\section{Chronotope}

Chronotope represents the temporal and contextual situatedness of experiences that have been lived and then retold narratively (Bakhtin, 1981b) by specific individuals (Bakhtin, 1999b; 
Holquist, 2002; Pinnegar \& Daynes, 2007). Bakhtin applied chronotope in analyzing how novelists depicted the time and space within which their characters resided. The concept of chronotope is also useful in understanding narratives of classrooms and teachers (Kim, 2015; Matusov, 2015). Human actions are embedded within specific times and places in an individual's life (Alsup, 2006; Britzman, 2003; Polkinghorne, 1995; Schutz, 1945). Therefore, teachers' pedagogical stories are "both enabled and constrained" (Chase, 2005, p. 657) by chronotopic factors and authoritative discourses (Mahiri, 1994).

The concept of chronotope resides within the interpretivist paradigm due to how it influences a person's perception of reality and guides subsequent actions and decision-making (Butin, 2009; Foucault, 1976/1978), including the sociocultural norms of a particular time and place (Mahiri, 1994; Quantz \& O'Connor, 1988) and dominant cultural influences (Geertz, 1995). It is through time, real and perceived, across the entirety of their life's contexts that humans experience their journeys (Schutz, 1932/1967). Holquist (2002) stressed the importance of considering the historical situatedness of individuals' life stories in order to better understand how adaptative choices in past events can shape current professional practices (Gubrium, 2003). In the worldview of Bruner (2004), the classroom context anchors how teachers see and narrate their stories in relation to the larger world or "grand narrative" (Clandinin \& Connelly, 2000, p. $32)$.

Rather than solely adopting the simplified literary plot device of the past dictating present circumstances, chronotope stresses the notion of the present shaping narrators' interpretations of the past, as well as the projecting towards the future (Keunen, 2010). The "eventness" (Morson, 2010, p. 94) of chronotope places the context and temporality of the present as more than something proceeding out of the past, lending richness and deeper significance to narratives told 
and reconstructed (Kim, 2015; Wertz et al., 2011). Chronotope is especially useful in framing asynchronous online communication, such as online college course discussion boards, which Kabat (2014) referred to as an "electronic chronotope" (p. 171). Through examining the chronotopes of elementary teachers' lived experiences (Lemley \& Mitchell, 2012) and pedagogical development (Plano Clark \& Creswell, 2010), they can potentially develop “a different relationship with the past and the future...[leveraging] the creative potential of the present" (Wang, 2009, p. 3).

As a teacher's interpretations of meanings from their experiences continue to shift, evolve, and speak to each other dialogically, chronotopic conceptualizations of their pedagogies and practices can be utilized (Britzman, 2003). Narration involves "living, telling, retelling, and reliving stories" (Connelly \& Clandinin, 1990, p. 4) across spatial-temporal contexts. I will inform the participants in this study that my interest is learning about their pedagogical approaches with digital technologies in current (and past) educational settings; therefore, they will share their stories with a focus toward a specific spatial-temporal context and audience (Chase, 2005).

As an example, in a narrative self-reflection, Whelan (1999) described the first year of her elementary teaching career (i.e., time) within a school context (i.e., place) of grades-focused administrators and parents. Rather than focusing her parent-teacher conferences on sharing rich accounts of each child's daily social life and work at school, she conformed to norms and reported entirely on grades and assessments. Many of my participants' stories of practice were grounded in classroom contexts at specific times throughout their careers and lives, colored by ongoing dialogue between their own internally persuasive discourses and authoritative discourses of public school institutions (Britzman, 2003). 
In addition to considering the impact of chronotope in current time and place, researchers must also consider the impact of past chronotopes on how participants construct narratives and understand experiences. Aydarova's (2017) critical ethnographic study of second language teacher education programs in Russia revealed how instructors interpreted the Western pedagogy reforms over time within the grounded context of their country and educational institutions. Throughout this study, I remained keenly aware of how participants dialogued with historicallysituated chronotopes and how school contexts during different times impacted their development of digital pedagogies (Dall'Alba, 2009; Mahiri, 2004).

As a conceptual guide for narrative research, participants' stories within chronotope must be constructed dialogically, understanding that perception and interpretation of experiences is never truly finished, or what Bakhtin (1981a) termed "nezaveriennost"' (p. 426). Familiar chronotopes within the annals of history can be called upon to evoke specific principles or feelings regarding larger issues (Blommaert, 2015), such as matters of digital pedagogy in today's elementary classrooms. Additionally, Bakhtin's (1999b) concept of architectonics can significantly guide the co-construction of narrative research texts, as each narrative's chronotope is preserved and made more intelligible when arranged within the whole of other narratives. Bakhtin's framing of architectonics serves as a conceptual departure from Kant's (1781/1998) systems-focused architectonics founded within scientific knowledge (Derrida, Porter, \& Morris, 1983; Holquist, 2002) rather than knowing narratively (Bruner, 1986). I sought to assemble this melded narrative in discussing the findings of this study in Chapter $V$ while not overgeneralizing the impacts of the specific chronotopic origins of each individual narrative. This is evidenced by my identification and discussion of dialogic factors in Chapter $V$ across the narratives that were 
specific to certain times and places (e.g., district curricula, institutional factors, self-efficacy, etc.).

\section{Carnival}

Aligning to the concept of Bakhtinian carnival guides the researcher to give each participant equitable representation in the narrative of the research text (Clandinin \& Connelly, 2000; Plano Clark \& Creswell, 2010). Bakhtin (1963/1999a; 1965/1984) recognized the social commentary in the comical literary works of Dostoevsky and Rabeleis that embodied the spirit of the carnivalesque, challenging "social boundaries and conventions in order to stand in opposition to authorial positioning" (White, 2014, p. 899).

Bakhtin (1981a) saw carnival as an ethos for challenging the status quo and recognized the line individuals walk between mainstream, hegemonic discourse and their true internal beliefs (Geertz, 1995; Holdway \& Hitchcock, 2018). In Bakhtin's (1963/1999a) analysis of Crime and Punishment, he noted how Dostoevsky framed carnival principles of transformative change through death and rebirth. Carnival, in the traditional sense, served as a celebratory period in which social strata were all equalized with no individual positioned above anybody else. These carnivalesque sentiments are also applicable in educational research, as schools are subject to socially-constructed power relations (Sidorkin, 1997). Likewise, carnival is a fitting frame for interpretive research with social objectives, such as narrative inquiry and its prime goal of co-constructing the stories of others (Lather, 1986), maintaining the authenticity and integrity of how each individual's narrative is positioned in the final research text.

By demythologizing (Britzman, 2003) notions of Bakhtinian 'epic' through carnivalesque thinking (Naughton, 2016), means-end assumptions about how technology in education (Cristia et al., 2017; Pereira \& Pereira, 2015) and authoritative discourses that have upheld long standing 
educational disparities (Cope, Kalantzis, \& Smith, 2018; New London Group, 1996, Luke, 2018) can be challenged. By arranging narratives of teachers' digital pedagogies in an "architectonic whole" (Bakhtin, 1999b, p. 57), I was able to illuminate the distinct nature and reality of this concept as experienced by elementary teachers in practice (Derrida et al., 1983).

While narrative researchers seek stories that serve to address the research problem within the theoretical framework, the mark of importance and relevance of stories should primarily be evaluated by the participants themselves (Gubrium \& Holstein, 2009). Researchers, guided by carnival, do not filter out narratives that diverge from the majority (Andrews et al., 2004; Bamberg, 2012; Chase, 2005; Lemley \& Mitchell, 2012) or position their own narratives, interpretations, or theorization above those of the participants (Gasson, 2004; Kim, 2015; Wertz et al., 2011). I applied Bakhtin's literary carnivalesque views to my research with elementary teachers as a conceptual guide for representing the shared narratives of stories with integrity in the construction of the research text (Charon, 2007; Connelly \& Clandinin, 1990). I did not constrict the narratives to fit my initial theories and perspectives on teaching with digital technologies; rather, I reviewed and utilized additional literature, as needed, in discussing the narratives in relation to the theoretical frameworks and research questions in Chapters $V$ and $V I$ (Josselson, 2007) .

The dialogic theoretical lens I chosen for this study positions teachers' internal discourses in constant dialogue with authoritative discourses (Britzman, 2003). I positioned the concept of carnival to work symbiotically with polyphony to situate the internal discourses of elementary teachers regarding digital pedagogy against institutional and/or dominant discourses (Matusov \& Marjanovic-Shane, 2017; Miyazaki, 2017; Quantz \& O'Connor, 1988). Dressman (2004) saw the literary dialogism of Bakhtin (1963/1999a) as a natural unifier of how to understand texts in 
terms of a social "aesthetic" (p. 48). Through carnival, I considered my own stories of pedagogy as a co-constructor of the participants' narratives while remaining open to stories different from mine (Greene, 1995).

As an example of practical classroom application, Lensmire (1994) used carnival as an instructional guide for reframing a writing workshop instructional approach with third grade students. He intended to supplant the social divides of the community that transferred to classroom interactions between the students as well as increase student voice and control of their authorship. In analyzing interviews, student writing, and fieldnotes among other data sources, it was found that active, student-driven writing participation was facilitated by the intervention. However, student social relations and divides were still reinforced. For example, low-income students had less influence in peer conferences and in some cases, were bullied through how they were depicted in classmates' stories.

Sullivan, Smith, and Matusov (2009) criticized this practical application of carnival with students, because social divides were bolstered rather than challenged (White, 2014). Carnival should not be misconstrued with one 'unified,' monolingual voice (Groys, 2017) or misappropriated to raise certain voices while silencing or condemning others (James, 2015). Matusov and Marjanovic-Shane (2017) recognized that Bakhtin's focus on the carnivalesque centered around challenging authoritative oppression, noting that researchers must also attend to the importance of culture (Kang, 2014). Sociocultural identities and practices significantly impact the way individuals understand and interpret experiences (D'Andrade, 1995; Geertz, 1995, 2005; Mishler, 1999) within specific contexts (Gee, 2013, 2014, 2015a). The participants in my study shared elements of different perceived identities through their stories which they felt 
impacted their dialogue with pedagogy and technologies throughout their lives, including, among others, parenthood and age, to which I was mindful in co-constructing their narratives.

\section{Conclusion}

Pedagogy is dynamic, supersedes knowledge-centric frameworks (Lohnes Watulak \& Kinzer, 2013; Rust, 2017), and cannot be fully understood through scientific, positivist approaches (Bruner, 1986; Eagleton, 2003). Any attempt to understand a teacher's pedagogical journey must take into account their entire biography (Greene, 2005; Wertz et al., 2011) within the social contexts fraught with power relations that they must confront and negotiate (Sidorkin, 1997). The work of teaching occurs amidst the dialogue of historically-rooted authoritative and internally persuasive discourses (Britzman, 2003). Effective theoretical frameworks in qualitative research can connect what is learned within immediate contexts to issues and problems in society (Anyon, 1994; Ravitch \& Riggan, 2011).

Britzman's (2003) dialogic theory of teacher practice was an effective lens for understanding how elementary teachers dialogically develop and enact of digital pedagogies in order to transfer these stories to wider audiences. The pedagogical components from the New London Group's (1996) pedagogy of multiliteracies framework helped me describe in what ways these teachers designed instruction in which they integrated digital technologies with consideration for the transformative potential of critical digital pedagogies. Finally, the novel concepts of Bakhtin (1963/1999a, 1981b) framed my methodological design with respect to the voices of the participants, contextual- and temporal-situatedness of the narratives, and authentic, carnivalesque representation of each narrative in the final research text. 


\section{CHAPTER III: METHODOLOGY}

\section{Restatement of the Research Question}

This study was guided by the following question: What can be learned from the life stories of elementary teachers who consistently integrate digital technologies in their instruction?

I also posed the following two sub-questions: a) What pedagogical components do elementary teachers emphasize when teaching with digital technologies?, and b) What can be learned about the dialogic nature of pedagogy from the life stories of elementary teachers who consistently integrate digital technologies?

A gap in the current research base exists regarding elementary teachers' development of pedagogy with digital technologies. In this study, I co-constructed the life stories of elementary teachers who consistently integrate digital technologies in their instruction, emphasizing the dialogic nature of their pedagogy as it was enacted and evolved (Britzman, 2003). Selecting a methodology that would capture the development of elementary teachers' digital pedagogical designs dialogically, guided by the theoretical and conceptual frameworks I selected, was essential (Ravitch \& Riggan, 2011).

In this chapter, I will situate this study within the interpretivist paradigm and narrative method. Next, I will detail the strategies I used for participant selection and describe the contexts in which the research was conducted. Then, I will describe the data collection procedures, which included life story interviews, artifact-centered focus groups, classroom observations, and follow-up interviews. I will proceed by detailing the approaches I utilized for analyzing the data and co-constructing the narratives for the final research text. Finally, I will discuss matters of 
rigor, authenticity, and ethics with regards to this study as well as limitations of the methodology.

\section{Interpretivist Paradigm}

A research paradigm originates from the researcher's personal beliefs (Glesne, 2010; Spector-Mersel, 2010) and assumptions about knowledge and reality (Lapan, Quartaroli, \& Riemer, 2012). My positions on epistemology and ontology naturally influenced the research question I pursued in this study and the methodology I chose to answer it (Guba \& Lincoln, 1994). Therefore, I grounded this study in the interpretivist paradigm, because I believe that multiple realities exist that are tied specific sociocultural contexts and must be interpreted dialogically (Butin, 2009; Foucault, 1976/1978) through rigorous methods and authentic data (Daniel \& Onwuegbuzie, 2002). The interpretivist paradigm is widely associated with qualitative research methods (Yin, 2010). While often mischaracterized solely by a refrain from numerical data (Pinnegar \& Daynes, 2007), qualitative, as opposed to quantitative, research "relies primarily on human perception and understanding" (Stake, 2010, p. 11) instead of the manipulation of variables and precise measurement.

Positivist and post-positivist thinkers believe that research should be free of bias and values; yet, the mere selection of a topic indicates elements of the researcher's priorities and interests (Ponterotto, 2005). Research questions should integrate the natural passions of the researcher while contributing to the knowledge base in new ways (Stake, 2010). I did not believe I could uncover scientific truth with complete objectivity (Groenewald, 2004), but that did not mean that my research could not be rigorous and generate authentic understanding of others' lived experiences (Eisner, 1990; Morrow, 2005). The educational research base is comprised of several different paradigms (Skrtic, 1990); however, given that my research question focused on 
learning from the stories of other teachers as well as my personal beliefs about the dialogic nature of pedagogy, interpretivism was an effective, fitting paradigm for this study.

\section{Narrative Methodology}

Narrative research can be rationalized using Bruner's (1986) two-fold conceptualization of knowledge as both "paradigmatic" (in the positivist, scientific tradition) and "narrative" (p. 14), in which humans view life in terms of story and plot (Gubrium, 2003; Robinson \& Hawpe, 1986; Spector-Mersel, 2010; Wertz et al., 2011). This methodology heeds Dewey's (1938/1997) call to emphasize internal, cognitive understanding of experiences rather than just the positivist focus on external variables of life (Dilthey, 1887/1985; Kim \& Macintyre Latta, 2010). In the narrative perspective, external experience cannot be cognitively constructed or communicated without narrative knowledge (Lyotard, 1979/1984) and "linguistic forms" (Polkinghorne, 1988, p. 158).

On the debate between scientific and alternative forms of knowledge, Eisner (1990) believed that different research problems require distinct approaches. Narrative methods should be used if the research problem(s) or question(s) concerns the lives and experiences of others who are close to the topic of interest (Mishler, 1999). Through a dialogic lens, I theorized pedagogy as something a teacher develops across a lifetime of experiences, not just during the four years of pre-service education (Britzman, 2003). Pedagogy, in the most realistic and practical sense, is never fully mastered, but continually developed through self-driven learning and reflection (Schein, 1972) and best conveyed narratively (Clandinin \& Connelly, 2000). Therefore, depicting and analyzing the narrative meaning participants shared through stories of living and practice provided greater understanding of pedagogy with digital technologies at the

elementary level (Clandinin \& Connelly, 2000; Hays \& Singh, 2012; Lemley \& Mitchell, 2012). 
Ultimately, my goal was to present the narratives as shared by the participants and, subsequently, how it applied to my research questions, in addition to the implications it had for policymakers, teacher education, professional development, and practicing elementary teachers (Geertz, 1973).

The narrative methodology resides in the interpretivist paradigm. Utilizing narrative methods, I interpreted meaning from the stories of elementary teachers that fit the topical focus of this study. Petty, Jarvis, and Thomas (2018) also associated this methodology within constructivism in that the researcher has to create the final research text from the narration of participants (Clandinin \& Connelly, 2000; Kim, 2015); however, others view interpretivism and constructivism synonymously (Schwandt, 1998). Regardless, stories are the heart of narrative research "as both the method and phenomena of study" (Pinnegar \& Daynes, 2007, p. 5).

Chase (2005) characterized narrative inquiry by its "interdisciplinary analytic lenses, diverse disciplinary approaches, and both traditional and innovative methods" (p. 651), based on the life stories and narratives told by others. I focused this study on co-constructing the narratives of a small group of people (Plano Clark \& Creswell, 2010) with the goal of advancing understanding about specific theoretical foci (Lather, 1986; Lemley \& Mitchell, 2012; Mishler, 1999). However, I was primarily concerned with "the microanalytic picture" (Creswell, 2012, p. 502) of telling participants stories and did not solely focus on broader or more theoretical milieu (Anyon, 1994; Clandinin \& Connelly, 2000; Kim, 2008) at the risk of compromising the authenticity of the co-constructed narratives. I will discuss matters of rigor and authenticity in my design and implementation of this study later in this chapter.

However, applying theory to co-constructed narratives can facilitate the interpretation of narrative meaning for wider audiences without losing the essence of participants' stories (Gasson, 2004; Kim, 2008; Wertz et al., 2011) within the local contexts in which the study was 
conducted (Pinnegar \& Daynes, 2007). For example, in discussing the benefits of analyzing patient narratives in the medical field, Charon (2007) noted that "narrative writing...makes audible and visible that which otherwise would pass without notice" (p. 1266) through purely clinical approaches. Narrative researchers, within the interpretivist paradigm, tentatively interpret the stories of others while also providing the space for readers to do the same (Kim, 2008; Lemley \& Mitchell, 2012).

Mishler (1999) conceptualized narrating as an "identity performance," noting that "we express, display, make claims for who we are - and who we would like to be- in the stories we tell and how we tell them" (p. 19; see also Chase, 2005). Narrative meaning is co-constructed between the researcher and narrator (Guba \& Lincoln, 1994), rather than being collected or measured (Kim \& Macintyre Latta, 2010). Connelly and Clandinin (1990) noted that the relationship between researcher and participant carries "the necessity of time, relationship, space, and voice" (p. 4). Considering the dialogic nature of teaching practices and pedagogy (Britzman, 2003), participants must be allowed to share their stories unfettered (Elbaz-Luwisch, 2007).

However, the researcher is not passive or silent in this process of co-constructing the narrative (Connelly \& Clandinin, 1990). Rather, a carnivalesque balance of voices exists in a well-constructed narrative research text (Charon, 2007). A core component of the "turn" (Spector-Mersel, 2010, p. 204) to the narrative method is the recognition that the researcher and participant(s) will both influence the study (Pinnegar \& Daynes, 2007). The narrative researcher resides within what Clandinin and Connelly (2000) called a "three-dimensional narrative inquiry space” (p. 50) comprised of temporality, context and place, and finally, personal and social matters. All three dimensions are critical to co-creating a narrative with participants that is 
sensitive to chronotope (Bakhtin, 1981b) and social influences (Britzman, 2003) on lived experiences (Anyon, 1994; Elbaz-Luwisch, 2007; Geertz, 2005; Wertz et al., 2011).

In educational contexts, Clandinin and Connelly (2000) felt that narrative research facilitated the understanding of teachers' "personal practical knowledge," or "the nature of their images of teaching" (p. 3). This study was especially focused on practical knowledge elementary teachers had developed across a lifetime concerning technologies and how they integrated them into their instructional design. The notion of personal practical knowledge is not based on positivistic facts and information, but rather, knowing expressed narratively (Bruner, 1986) and comprised of experience and affect (Alsup, 2006; Clandinin \& Connelly, 1988). Reflecting on professional actions and experience leads to narrative understanding (Creswell, 2012; Schön; 1983).

Clandinin and Connelly (2000) cautioned against using narrative inquiry to solve overly specific problems or answer distinct questions, which would impose constricting demands on the narrative. Rather, the narrative should be experienced and portrayed for a specific audience (Lemley \& Mitchell, 2012), supporting readers' interpretations and setting the stage for future actions and experiences (Kim, 2008; Lather, 1986; Lyotard, 1979/1984; Polkinghorne, 1995). I entered my study with a broad research question that allowed for flexibility in authentically coconstructing the narratives of elementary teachers (reserving the integration of theory with the three sub-questions of the study).

\section{Participant Selection}

Since the purpose of this study was to co-construct the stories of elementary teachers and their pedagogical designs with digital technologies, it was essential to purposively secure participants who integrated technology on a consistent basis (Creswell, 2008; Tonbuloğlu \& 
Kiyici, 2018; Tracy, 2013). This frequency-based criterion is rather broad and does not fully specify pedagogical design; therefore, I also asked potential participants to frame their regular technology integration within the spectrum between banking and critical approaches, much like the scope between Enhancement (i.e., Substitution and Augmentation) and Transformation (i.e., Modification and Redefinition) represented in Puentedura's (2014) SAMR model of technology integration.

Pedagogical design, the focal concern of this study, is part of "an active and dynamic process" (New London Group, 1996) of constructing meaning from Available Designs and continually Redesigning one's instruction. I confirmed that each participant regularly integrated technology in ways that transcended 'banking' approaches (e.g., drill-based student activities, reliance on digital textbook resources, etc.). Therefore, I anticipated co-constructing stories involving pedagogical design that, to a certain extent, fostered democratic student participation (Cope, Kalantzis, \& Smith, 2018; Kalantzis et al., 2003) and even transformative, liberating learning experiences (Gee, 2017a, 2017b; McLaren, 2009; Mirra et al., 2018).

Connelly and Clandinin (1990) noted that forming and developing the collaborative relationship between researcher and participant is incredibly important considering the power dynamics involved in the study of teachers. In establishing contact with potential participants, I fully explained the purpose of the study (Plano Clark \& Creswell, 2010) as well as my intent to co-construct share their stories and voices as constituted dialogically (Britzman, 2003).

I had a few approaches at my disposal for soliciting potential participants in this study, given my position as a doctoral student at a large state university and a currently-practicing third grade teacher. I asked my university contacts to recommend participants (Flick, 2007). I also sought participants within my network of elementary teaching contacts. I initiated contact with 
each potential participant via email upon securing their contact information to introduce myself and the scope of the study. In this initial introduction, I informed them that their overall potential time commitment to this study would be approximately five months from start to finish.

Ultimately, I secured a group of five participants who fit the aforementioned criteria and represented the span of K-5 elementary grade levels (Flick, 2007) with the exception of second grade. Co-constructing the stories of elementary teachers from different grade levels gave polyphonic voice and carnivalesque representation (Bakhtin, 1963/1999a; 1965/1984) to divergent perspectives and stories (Foucault, 1976/1978; Gasson, 2003; Mishler, 1999; Mitchell, 2008). Table 1 provides demographic information about each participant, all of whom were female.

Table 1

Participant Demographics

\begin{tabular}{lllll}
\hline Name & Age & Race & Grade Level & Experience (yrs) \\
\hline Felicity & 49 & White & 1 st & 20 \\
Iris & 33 & White & 5 th & 11 \\
Laurel & 46 & White & 4 th & 9 \\
Nora & 24 & White & 3 rd & 3 \\
Thea & 28 & Black & Kindergarten & 5 \\
\hline
\end{tabular}

\section{Research Contexts}

I observed each participant teach in their elementary classroom context, all of which were part of public elementary schools in Central or Western Illinois. All but Thea's kindergarten 
classroom were equipped with one-to-one technology in which the teacher and every student were assigned a device connected to the Internet (Harris et al., 2016). Each classroom was also equipped with at least one interactive digital board (e.g., SMART Board, Promethean Board).

It is important to note that since I solicited stories across the participants' life histories, the narratives were contextualized across other times and places. For example, Thea's narrative takes place between her home and current work location in Central Illinois as well as her two years of teaching second grade in Memphis.

\section{Data Collection}

I selected and implemented data collection methods to compose field texts from which the research text (or narrative) could be derived and understood (Mishler, 1999). Conducting dialogic interviews with participants is one of the primary data collection methods of narrative inquiry (Wertz et al., 2011). It is critical to the integrity of the narrative and representation of the participants' core identities that the researcher and interviewees construct it together (Mishler, 1999). Clandinin and Connelly (2000) liken the narrative interview process to the forming of a relationship between interviewer and interviewee, which helps to balance all perspectives in the co-constructed narrative as a "multiplicity of discourses" (Foucault, 1976/1978, p. 100), including the researcher's interpretations (Clandinin \& Connelly, 2000; Geertz, 1995; Lemley \& Mitchell, 2012; Wertz et al., 2011).

I collected several forms of data in order to co-construct this narrative with the participants. The methods I utilized were interviewing, observing, and collecting artifacts (e.g., photographs, lesson plans, etc.) provided by the participants. Collecting multiple forms of data outside of the interviews more completely supported the temporal, contextual, and social 
dimensions of narrative inquiry (Clandinin \& Connelly, 2000) in my discussion of enacted digital pedagogical design (Kim \& Macintyre Latta, 2010; Schön, 1983; Wertz et al., 2011). Initial Life Story Interviews

Kim (2015) identified two phases of the interview process that serve distinct purposes, though they do not need to necessarily be conducted in a specific order. In the narration phase, conducted in an open-ended, unstructured format, the interviewer primarily listens to a longer narrative told by the interviewee; this may include elements of a life story interview, which the researcher can use to situate the narrative within theory and/or wider social action (Andrews et al., 2004). Holquist (2002) framed the concept of chronotope in the life stories of professionals as significant in revealing "preadaptive" (p. 128) responses to past events that shape current practices (Pinnegar \& Daynes, 2007), fitting with my theorization of teachers remaining in dialogue with their biography (Britzman, 2003). The conversation phase takes on a format similar to a semi-structured interview, in which the researcher questions and probes to learn more about what was shared and how it was shared (Bamberg, 2012).

I interviewed the participants in the two phases outlined by Kim (2015). First, I conducted an unstructured life story interview (Creswell, 2008; Kim, 2008) to situate each participant's development of digital pedagogies within the trajectory of narratives across time and space, or chronotope (Bakhtin, 1963/1999a, 1981). I will describe the conversational, semistructured interview phase that took place after this initial phase in a later subsection, as there were other data collection steps that preceded it.

The life story interviews helped me explore how these educators "have found their own center...[in] the quest for meaning and the importance of caring for persons" (Atkinson, 2007, p. 228). Prior to conducting the initial interviews, I reminded the participants that I was interested 
in learning about their pedagogical approaches with digital technologies in current (and past) educational settings (Appendix A). My intention was to encourage them to share their stories with a focus toward a specific spatial-temporal context and audience (Chase, 2005), reducing the potential length of each interview (Atkinson, 2007). Bruner (2004) viewed narratives in a practical sense for research and learning from the life stories of others, noting that they must be constructed "in a manner that gives form to the content and the continuity of the life" (p. 701). Providing extensive details in the final research text about biographical elements (Lemley \& Mitchell, 2012) to which participants did not perceive critical impact (Webster \& Mertova, 2007) to their teaching with digital technologies was unnecessary, considering the topical and theoretical foci of this study.

I used audio-recording technology to capture the interviews in both phases and saved backup copies in two password-protected cloud accounts in the event of a file corruption (Morgan, 2011). I transcribed the biographical interviews, noting when the participants paused or reflected (Lemley \& Mitchell, 2012), which could potentially signify a critical event in their stories (Canuel \& White, 2014). I will discuss how the transcription approach aligned to my analysis of the data later in this chapter.

\section{Artifacts and Focus Group}

I asked each participant to assemble a collection of at least three photographs, lesson plans, and/or other artifacts they felt were pertinent to their stories of teaching with technology, which Clandinin and Connelly (2000) called "memory boxes" (p. 114). As records and timestamps of pedagogical narratives (Clandinin \& Connelly, 1988), these artifacts facilitated the co-construction of richer narratives and contributed to a fuller collection of field texts (Lemley \& Mitchell, 2012). 
While artifacts could be used as a data source to be analyzed, visual data can also spark memories of stories or show components of daily teaching that may have otherwise gone unnoticed (Bach, 2007). I primarily used the artifacts to elicit stories from the participants (Torre \& Murphy, 2015) as part of one video conference focus group chat, conducted on Zoom, in which the participants dialogically shared and discussed an artifact of their choice with each other and me. I shared a private link to the focus group with the participants via email.

I began the focus group discussion with a brief scripted introduction (Appendix B) in which I stressed that all questions and comments in the discussion should remain non-evaluative. The participants were given the option to opt out of the focus group and discuss all of their artifacts with me; only Nora chose this option due to scheduling conflicts. The other four participants that did participate in the focus group discussed their remaining artifacts in an additional one-on-one interview; Iris discussed her remaining artifacts in two additional interviews due to unforeseen scheduling conflicts. I captured the audio of the focus group session using QuickTime Player and transcribed the discussion afterwards. I used insights about each participant from the focus group to design targeted questions in the individual follow-up interviews I conducted later in the study (Bamberg, 2012).

Since my participants resided in different regions of the state, online video conferencing was an appropriate method to use in conducting the focus group discussion (Janghorban, Roudsari, \& Taghipour, 2014). In using a digital focus group format, I assumed that the participants would be comfortable communicating with video conferencing technology (Hughes $\&$ Lang, 2004), given their regular use of digital technologies in their instructional practices (Tour, 2015). In fact, each individual was given the option to be interviewed in person for the other interviews in this study, and all of them opted to conduct them via video chat on Zoom. 
Since I did not secure student assent and parental consent for this study (Glesne, 2010), I omitted student work samples or photos of students that the participants shared from any potential artifact analyses (Creswell, 2008).

Regarding the photographs, I asked the participants to take pictures of components of their classroom learning environments that they viewed as relevant to their digital pedagogies and teaching practices (Torre \& Murphy, 2015). Narrative inquiry must remain sensitive to the contextual influence of narrative 'knowing' (Bakhtin, 1981; Bruner, 1984; Kim, 2015; Mishler, 1999; Wertz et al., 1999). In the worldview of Bruner (2004), the classroom context anchors how teachers see and narrate their stories in relation to the larger world or "grand narrative" (Clandinin \& Connelly, 2000, p. 32). Allowing the participants to select artifacts and take photos themselves showed respect for their subjectivity and valuation of matters of practice and context they perceived as important (Martin \& Merrotsy, 2006).

\section{Observations}

Upon securing the appropriate district permissions (Posthuma, 2010), I conducted an extended observation within each participant's classroom (for at least two hours) to gain additional understanding of the context and teacher-student social relations (Kim, 2015). I worked with the participants to schedule observations on days they intended to integrate digital technologies in their instruction. Given the shared subjective perspectives (between researcher and participants) inherent in narrative research (Wertz et al., 2011), I composed "dual field texts" (Clandinin \& Connelly, 2000, p. 88), in which I wrote objective field notes about what I observed as well as reflective notes about my experiences in these classrooms (Lindorff \& Sammons, 2018). 
I composed the observational portion of these texts as field notes with thick, rich description of the actions (and interactions) of the teacher and students as well as the classroom context itself (Geertz, 1973) guided by a broad observation protocol (Appendix C), to better capture the chronotopic situatedness (Bakhtin, 1981b) of each participant's pedagogical design. Writing down specific quotations of what the teachers said during moments of instruction also supported later narration of enacted pedagogies with digital technologies (Lindorff \& Sammons, 2018).

Given that I was not able to fully compose the field notes in extensive detail during the time of the observation, I created "jottings" (Emerson, Fretz, \& Shaw, 2011, p. 31), which are short phrases meant that helped further compose field notes with richer description within 24 hours of each classroom visit. Along with observations, written reflections are a crucial part of the researcher's interpretive process of making sense of what is seen and heard (Connelly \& Clandinin, 1990) while acknowledging and, in a sense, compartmentalizing one's subjectivity (Peshkin, 1988). I wrote such a reflection within 24 hours of concluding each observation, informally applying and extending theory based on what I observed (Delamont, 2004).

\section{Follow-Up Interviews}

The purpose of the second, more dialogic interview was to understand what each participant previously shared and how they shared (Bamberg, 2012). I asked targeted, but openended, questions to learn more from each participant regarding matters of pedagogy with digital technologies, framing their teaching narrative dialogically (Britzman, 2003) within the larger life story (Chase, 2005). Engaging in the life story interview first may have primed the participants to narrativize specific stories of practice and ruminate on how their biographies related to their future practices (Atkinson, 2007). 
This interview took on a more conversational format compared to the initial biographyfocused phase, as I focused more on the topical and theoretical foci of this study (Schensul, 2012). Rogers (2007) recommended that narrative interviewers not just attend to what participants explicitly say, but implicit elements that carry impactful insight into the shared stories as well (Lemley \& Mitchell, 2012; Mitchell, 2008). These elements of narrativizing include threads of stories that recur or reappear as well as with whom (or what) the interviewee may be in dialogue (Britzman, 2003) beyond the actual interviewer.

Therefore, I reviewed all of the previously-collected data prior to conducting the followup interviews to inform my design of specific questions to elicit stories of practice and pedagogy with digital technologies, or what Lyle (2003) called "stimulated recall" (p. 861) and "images" (Clandinin \& Connelly, 1988, p. 60) of how the participants viewed their teaching practices. I refrained from judgment or evaluation in my design of these semi-structured interview questions (Josselson, 2007).

Interview questions in both phases of narrative interviewing remained somewhat openended to encourage introspection and personal narration by the participant. Per Kim's (2015) recommendation, I repurposed Morrissey's (1987) two-sentence questioning technique, originally intended for oral history interviews, to design the follow-up interview protocols. In this format, the researcher makes a restatement of previously-discussed information or narration in the first sentence and then asks a question to probe more deeply (typically a "how" question) in the second.

While I could not anticipate all of the specific questions I would ask in these semistructured interviews until collecting the initial data, I designed a semi-structured interview protocol containing general questions I anticipated asking each participant (Appendix D). This 
protocol contained questions focused on the theoretical and topical foci of the study: the dialogic nature of developing pedagogical design with digital technologies at the elementary level (Bamberg, 2012). I supplemented the protocol with additional questions using Morrissey's (1987) format based on what I learned from the initial interviews, artifacts and artifact interviews, focus group, and classroom observations.

\section{Data Analysis}

Data analysis was conducted in two phases. First, I analyzed the field texts (i.e., interview and focus group transcripts, observation field notes, etc.) to construct the narrative of each participant. After they were constructed and member checked, I analyzed the narratives themselves using the theoretical frameworks of this study. Next, I will describe each phase in greater detail.

\section{Construction of the Narratives}

After completing the collection of field texts, I began by analyzing them as a whole before attempting to establish themes or apply theory (Atkinson, 2007). This approach was grounded in hermeneutics in order "to illuminate human experience as it is presented in textual form...to reveal layered meanings that people assign to their lives" (Wertz et al., 2011, p. 240) and involved several readings of the field texts both together and individually. Linde (1987) recommended evaluating the quality of a constructed narrative hermeneutically, focusing on how individual parts work together to tell a story in a way that is not too general or focused on causation, avoiding the use of 'epic' novelization against which Bakhtin (1963/1999a) cautioned. Bakhtin's (1999b) conceptualization of architectonics, or “intertextuality” (Kristeva, 1980, p. 36), stresses the importance of the wholeness of the voice and chronotopic situatedness of each narrative. 
I began constructing the narratives for the final research text as I established a sense of each participant's story, beginning by mapping out an outline of plot points (Kim, 2015). However, it should be noted that the data collection process continued during the analysis process; I followed up via email with participants to ask specific clarifying questions about their narratives (Connelly \& Clandinin, 1990). For example, I emailed Thea a few months after our final interview to clarify the grade level at which she taught during her two years in Memphis, as this was a detail that I could not specifically locate in the transcripts of our interviews.

I utilized a "critical events approach" (Webster \& Mertova, 2007, p. ix) as part of my analysis of the field texts, looking for important "turning points" (Mishler, 1999, p. 60) in the participants' narratives that they felt impacted their development of pedagogy and beliefs about digital technologies. Critical events can be experienced by participants internally, as private realizations and reflections (Mertova \& Webster, 2012), or externally. I noted the participants' words along with their quiet pauses and "silences" (Lemley \& Mitchell, 2012, p. 221) during the transcription process, which supported my identification of potential critical events in their stories (Canuel \& White, 2014). I framed these critical events across participants' biographies during the narrative construction process, focusing on the particular while retaining a sense of the whole (Atkinson, 2007; Linde, 1987; Wertz et al., 2011; Whitney, 2008). I was able to learn about the transfer of their learning from major events and realizations towards "The Redesigned" (New London Group, 1996, p. 76) across their narratives.

The art of narrative inquiry is reducing the distance between the shared stories and research text as much as possible, maintaining a sense of the "autograph" (Gracia, 2012, p. 188) of each participant. To do this, I began by creating several versions of tentative research texts, or "interim texts" (Clandinin \& Connelly, 2000, p. 133), in which I constructed increased meaning 
and understanding. I constructed each narrative using the first person narrative, becoming a narrator much like my participants, as I interpreted and shared their stories. Using the firstperson narrative distinguished my voice from those of the participants, which were shared by directly citing their words in short- and long-block quotations (Chase, 2005; Lemley \& Mitchell, 2012). As needed, I also included quotations of interview dialogue between the participants and me (Mishler, 1999).

In my own narrating, I assumed an "authoritative voice" (Chase, 2005, p. 664), which is distinguished from an empathetic voice, characterized by some oral history, life history, or testimonio research (Lizárraga \& Gutiérrez, 2018; Nance, 2004; Raby, 2012) or “interactive voice" (Chase, 2005, p. 666), which has been employed in narrative ethnography (Frank, 2005; Tedlock, 1991). Conceptually framed by carnival (Bakhtin, 1963/1999a, 1965/1984; Lather, 1986), an authoritative voice does not assume supremacy over the voices of the participants; rather, I presented the voices of the participants through their stories, using their own quoted words (Lemley \& Mitchell, 2012; Lindorff \& Sammons, 2018) separately from my own interpretations and application of theory (Andrews et al., 2004; Charon, 2007; Connelly \& Clandinin, 1990).

Part of retaining the essence of the stories of each participant included integrating Bakhtinian (1999b) architectonics in which each narrative was situated within its chronotopic context (Holquist, 2002), rather than a Kantian (1781/1998) system of timeline, order, and chronicle (Polkinghorne, 1988). Ultimately, my goal was to represent a sense of each participant's "narrative unity... [which is] a meaning-giving account, an interpretation, of [one's] history" (Clandinin \& Connelly, 1988, p. 75) to better comprehend experiences (Emerson et al., 2011; Plano Clark \& Creswell, 2010). Therefore, each participant's narrative begins with a 
depiction of my observation in their classroom, followed by a broad narrative overview of their life history up to the present day. Finally, I narrated their current pedagogical design with digital technologies.

I shared the interim texts and events I identified as critical (Webster \& Mertova, 2007) with the participants to confirm and/or reform my analyses; this form of member checking supported carnivalesque narration (Bakhtin, 1963/1999a, 1981a; Charon, 2007) by securing the participant's approval of how they were narratively represented. It also extended the coconstruction of the narrative that began in the data collection phase (Gubrium \& Holstein, 2009; Lather, 1986; Yin, 2010). I will discuss this process of member checking in greater detail later in this chapter.

\section{Analyzing the Narratives}

In the second phase of data analysis, after constructing the narratives, I transferred the stories for wider consideration towards broader understanding and action (Anyon, 1994; Hays \& Singh, 2012; Kim, 2015), applying the theoretical frameworks chosen for this study that aligned to the two sub-questions: Britzman's (2003) dialogic theory of teacher practice and the New London Group's (1996) pedagogy of multiliteracies framework. Using these theoretical frameworks, I conducted a constant comparative analysis within and across the narratives of the five participants.

First, I conducted several thorough readings of each narrative and inductively coded examples of pedagogy in dialogue with personal, sociocultural, and professional factors (Lapan et al, 2012), reformulating codes as themes collapsed and evolved (Tracy, 2013). Then, I deductively coded the narratives for examples of how the participants emphasized any of the four pedagogical components (i.e., situated practice, overt instruction, critical framing, and 
transformed practice) when teaching with digital technologies. It should be acknowledged that in coding narratives, "contingencies" (McAllum, Fox, Simpson, \& Unson, 2019, p. 369) are established from the outset of the study to utilize elements of storytelling and maintain a sense of each participant's narrative.

Clandinin and Connelly (2000) cautioned against losing the true experiences that were shared for the sake of explicating theory. Theory, or sometimes a combination of multiple theories (Kim, 2015), remains central to the data analysis process in narrative research to make sense of findings and apply them to wider audiences (Lemley \& Mitchell, 2012; Wertz et al., 2011). While I ultimately selected and utilized Britzman's (2003) dialogic theory of teacher practice and the New London Group's (1996) pedagogy of multiliteracies prior to conducting this study, I remained open to utilizing other theories as needed during my analyses to transfer the meaning of these narratives beyond local contexts (Josselson 2007). Ultimately, though, I did not utilize any additional ones.

\section{Rigor and Authenticity}

Aristotle (350 B.C.E./1999) presented one of the earliest standards of research and academic rigor, acknowledging that "precision is not to be sought for alike in all discussions" (p. 4). In conducting narrative research, I could not produce mathematically-derived analyses of interview transcripts, observations, and artifacts within the scope of my specific research problem (Popkewitz, 1990). Smith (1987) argued that the social situatedness of reality should dictate methodological choices over dominant standards. Rigorous research practices within one paradigm and/or method may indeed be rigorous while not matching the practices of another (Connelly \& Clandinin, 1990; Eisner, 1990; Skrtic, 1990). 
By collecting multiple forms of data in addition to the interviews (e.g., observations, artifacts), I was able to triangulate the findings in this study (Creswell, 2008; Glesne, 2010; Lather, 1986; Rocco \& Plakhotnik, 2011). As I conducted observations and composed observational field notes, I also wrote reflective memos and musings as a means of attending to my own subjectivity (Clandinin \& Connelly, 2000; Peshkin, 1988; Wertz et al., 2011). Utilizing multiple sources of data, I presented these stories in a manner where the architectonic whole (Bakhtin, 1999b) and intertextuality (Kristeva, 1980; New London Group, 1996; Polkinghorne, 1988) could be made apparent to readers (Connelly \& Clandinin, 1990). I maintained a password-protected codebook (Rocco \& Plakhotnik, 2011) of the specific people and places to which participants referred in their stories to keep track of pseudonyms and maintain the clarity and integrity of the narratives (Josselson, 2007).

Collecting artifacts and photographs helped "add authenticity" (Ronksley-Pavia \& Grootenboer, 2017, p. 187) to the follow-up interviews, making the dialogic, polyphonic nature of pedagogy in development and practice more explicit (Bakhtin, 1963/1999a; Britzman, 2003).

I framed the narratives of these elementary teachers within the dialogic sphere of authoritative and internal discourses (Britzman, 2003; Rogers, 2007) and across the chronotopic contexts of a lifetime of experiences (Bakhtin, 1981b). Sharing these narratives in the participants' words as much as possible also contributed to the authenticity of this research (Creswell, 2008; Guba \& Lincoln, 1994).

While not generalizable to the larger population (Gasson, 2004), narrative knowing contains great value as an alternative, "tentative" (Pinnegar \& Daynes, 2007, p. 25) way of understanding the particular (Clandinin \& Connelly, 2000). The authenticity of these narratives deepens understanding of the "substance" (Geertz, 2005, p. 86) of pedagogy with digital 
technologies. This substance is not a portrayal of objective reality, but rather, reality as it was portrayed by the participants (Ely, Vinz, Downing, \& Anzul, 1997).

According to Gubrium (2003), stories worthy for constructing narrative meaning and knowledge are those that resonate with others, contain rich detail, and are not laden with superfluous information; ultimately, a story cannot be judged by its veracity, but rather, the way the narrator performs it as a means of sharing his or her identity and active becoming (Mishler, 1999; Webster \& Mertova, 2007). Per Bakhtin's (1963/1999a) carnival, I deferred to the participants to share the stories they felt were of a high quality and relevance to the research topic and interview questions (Gubrium \& Holstein, 2009; Kim, 2015). Ultimately, I had to evaluate the stories to depict in the final research text within the "experience of interest" (Clandinin \& Connelly, 2000, p. 133; see also Linde, 1987) and critical analysis (Webster \& Mertova, 2007); however, as a form of member checking (Glesne, 2010; Yin, 2010), I shared the interim texts with the participants to confirm and/or reform my analyses (Lather, 1986).

Additionally, I wrote in a reflexivity journal and maintained an audit trail from the beginning of the study. As I conducted this research, it was vital to manage my own subjectivities, feelings, and experiences from my own ongoing narrative as an elementary teacher and teacher educator in relation to those of the participants (Wertz et al., 2011). Acknowledging and delineating how my subjectivity interacted with the findings of this study increased the authenticity of this research (Lather, 1986). This is an especially important practice in narrative inquiry, in which the researcher establishes strong relationships with each participant during the process of co-constructing narratives of practice. Journaling about my subjectivities helped me separate my stories and biases from those of the participants (Lemley \& Mitchell, 2012; Newman, Newman, \& Newman, 2011) and more clearly view "the larger landscape on which 
they all live" (Clandinin \& Connelly, 2000, p. 81). As part of this journaling process, I noted how the stories connected or deviated from my understandings about teaching with technology at the elementary level, based on theory (Kim, 2015) and my personal teaching experiences (Clandinin \& Connelly, 2000). The purpose of the audit trail, according to Morrow (2005), is to record "a detailed chronology of research activities and processes, influences on the data collection and analysis; emerging themes, categories, or models; and analytic memos" (p. 252). Maintaining these records allowed me to share my ongoing research efforts with my dissertation committee for feedback and review and clearly disseminate the methods of this study in the final written dissertation (Lather, 1986).

\section{Ethics}

This study was conducted in accordance with the ethical standards expected in research involving human subjects (Public Law 93-438, 1974). Approval for this study was granted by the institutional review board (IRB) at my university, including the informed consent form (Appendix E) and other protocols, in advance of commencing the research (Creswell, 2008, Yin, 2010). Preparing the IRB protocol required communicating the rigorous practices I planned to implement throughout the study, especially considering the interpretive process and broad design principles inherent in narrative research (Josselson, 2007). In addition to IRB approval, I also contacted each participant's school district administration by sending a letter (Appendix F) via email to request written permission to conduct an observation in their classroom (Posthuma, 2010).

I explained the purpose of the study to each potential participant and discussed how they could benefit from participating by co-constructing their narratives to increase social, dialogic insight regarding digital pedagogy (Plano Clark \& Creswell, 2010) as well as greater self- 
understanding (Clandinin \& Connelly, 2000). An additional benefit of participation in the study was the opportunity to engage in dialogue around artifacts of teaching with technology through the focus group discussion. All participants' identities were protected through the use of pseudonyms and omission of other identifying information.

In addition, ethical consideration was given to the relationships I established and maintained with each participant (Clandinin \& Huber, 2010). This was contingent on my development and maintenance of "trust and rapport" (Josselson, 2007, p. 539) with each individual participant to support their comfort in sharing their stories without fear of judgment or evaluation. I presented the narratives of the participants in their own words using short- and long-form quotations (Chase, 2005; Lemley \& Mitchell, 2012), including conversational interview dialogue as needed (Mishler, 1999). Through these practices, I exercised empathy and respect in portraying the narrative meaning and importance of stories the participants chose to share (Creswell, 2008; Guba \& Lincoln, 1994; Mishler, 1999; Webster \& Mertova, 2007).

Finally, I utilized member checking of the interim texts as I constructed the final research text (Lather, 1986; Yin, 2010). In this process, participants were allowed to request, with no penalty, removal or modification of specific passages of narration that could impact how the research text was constructed (Glesne, 2010). The lives and lived experiences of others are the essence of narrative research, which can be challenging to "obscure" (Bell, 2011, p. 578). Ultimately though, protecting the anonymity of participants was critical, especially considering how the participants shared the names of specific people and places from their lives (Plano Clark \& Creswell, 2010). The guiding ethical principle of this study was that I would not include any details in the final research text deemed harmful by the participants (Josselson, 2007). 


\section{Limitations of the Methodology}

In conducting this study using the narrative method, I had to balance numerous considerations in my inquiry, telling each participant's story while connecting them all in the final research text (Linde, 1987) and integrating theories about pedagogy and technology (Anyon, 1994). Restorying a narrative that included components of each participant's life story and pedagogical journey required extensive data collection and time-consuming analysis of field texts (Clandinin \& Connelly, 2000; Kim 2015; Lemley \& Mitchell, 2012; Wertz et al., 2011).

The stories that I present in this dissertation are subject to the scrutiny all narrative research studies face in that they are inherently context-bound and subject to interpretive biases (DaMatta, 1994; Gracia, 2012) and the constrictions of narrative genre elements (Andrews et al., 2004; Derrida, 1981). While the participants offered explanations of their practices in the stories they shared, these cannot be misconstrued as establishments of causation or relationships between variables (Connelly \& Clandinin, 1990). Also, this study was limited by the small group size of the participants (Gasson, 2004)

In addition, my positionality as a currently-practicing elementary teacher could have limited the ways I theorized teaching and learning with digital technologies (Höckert \& Ljung, 2009).Yet, Spector-Mersel (2010) pointed out that to truly engage in narrative inquiry, the researcher must marry their beliefs regarding ontology and epistemology (Glesne, 2010; Guba \& Lincoln, 1994; Lapan, Quartaroli, \& Riemer, 2012). Allen (2008) distinguished Weltanschauung, or worldview, from Lebenswelt, or lifeworld, noting that elements of one's lifeworld is primarily composed by external factors (Merleu-Ponty, 1945/2002; Sohn, Thomas, Greenberg, \& Pollio, 2017; van Manen, 2016); on the other hand, one's worldview is formed through conscious, reflective reasoning and experiences. My theorization and Weltanschauung about teaching and 
learning with technological innovations supported my co-construction of narrative understanding of past behavior and experiences (Koltko-Rivera, 2004) in this research that is useful and applicable for elementary educators and stakeholders (Eisner, 1990; Höckert \& Ljung, 2013; Sylvester et al., 2013). 


\section{CHAPTER IV: NARRATIVE FINDINGS}

In this chapter, I will present the co-constructed narrative of each participant. Each narrative is organized in three parts. To begin, I presented a first-person narration of my observation of their teaching with digital technologies in their classroom. Next, I narrated an overview of their life story. Finally, I presented the co-constructed narrative of their pedagogical design with digital technologies.

\section{Felicity}

\section{Felicity's Classroom: January 2019}

I arrive at the high school side of Felicity's school in late January 2019. The one story building, which houses all grades K-12 for Felicity's small rural Illinois district, stretches widely across the property with a main hallway that runs east-west. The superintendent, who also serves as the high school principal, greets and escorts me to the elementary end of the building where Felicity's first grade classroom is located.

The first graders have just returned for afternoon activities and are listening to a cassette tape read aloud of the book Somebody and the Three Blairs by Marilyn Tolhurst. A female student is turning the pages of the print version of the book at an easel while the rest of the class follows along from a brown shag carpet in the middle of the classroom floor. I count a total of 15 students present today. Felicity is passing out math worksheets and preparing work for an absent student. She is wearing tan slacks and a blue blouse, her brunette hair tied back in a ponytail with bangs cascading laterally across her forehead near the sides of her thick frame glasses. She stops and mentions in a self-deprecating way that she is still in the "dinosaur days," because she continues to use older technologies, pointing out her blue cassette boombox that is plugged in near the right side of her SMART Board. 
Part way through this rendition of the classic Goldilocks fairy tale, Felicity pauses the tape and asks the class, "So are you noticing some things?...Why are they not calling them bears, but calling them Blairs?"

A student responds that "Blair" rhymes with "bear," a similarity between both versions. "It does sound like bear," Felicity responded. "They are rhyming it."

Finally, one student realizes that "Blair" was the character's last name. After eliciting some student predictions about how the story would conclude based on their prior knowledge of the classic version of this tale, Felicity says, "Let's see if our prediction is right," and continues playing the tape.

All of the students sit cross-legged and listen intently after this check-in conversation. Instead of Goldilocks being the intruder in this story, a bear referred to as "Somebody" enters the home of Mr., Mrs. and Baby Blair. Felicity notes, "So, it wasn't exactly the same, but when we talk about story structure... were they kind of the same?...It wasn't Goldilocks. Did they tell us who it was?"

After concluding the literature discussion, Felicity leads the class in transitioning to today's math lesson. The students return to their desks and preview the worksheets that Felicity had distributed. "You know, it does kind of look like a test," Felicity tells the class. "But what do we always have before a test? A practice, and that's what this is - a practice."

She projects the test "Reteaching" page on the board, which is a facsimile of the students' first work page from the math curricular program purchased by the school district. Several months after this observation, Felicity discussed the positives and negatives of the math curricular program her district purchased about five years ago, which includes digital resources, and how it impacts her design of math instruction in which she integrates digital technologies: 
Well I'll tell you, time-wise, yay! Because I don't have to go search for stuff. It's there. It's ready to go...They always have, like, a little videoclip, and it's interactive, and the kids answer. You know, the only bad thing is...is that it's probably a little behind times. It's not as updated. You know, it's five years old, and five years old in technology world is old... [Also] you saw that day that everybody wants a turn, and the SMART Boards we have don't allow for that. So, um, you know, yes, I like it for the fact that it's...it's easy. It's at my fingertips. And I can use it as I need. Um, boo sometimes that it's not better quality. But it does go right along with what I'm teaching. (personal communication, April 30, 2019)

Felicity turns to the SMART Board and sees that the resolution is a little askew. "We should probably recalibrate," she announces, "because it likes to get tricky sometimes...Doesn't always go the way we want to, right?"

Felicity speaks audibly but not in a boisterous manner; everybody can clearly hear her and her voice has a calm tenor. She initiates a recalibration and taps the four corners of the SMART Board with the pen tool. The resolution looks a little larger and clearer. "When your name's on your paper, wave your hands in the air."

Felicity begins the lesson by leading the students in reading aloud the directions chorally from the first page about adding tens using a 100 chart (which is included on the page for the students to use). Then, Felicity calls on a volunteer to model how to solve the problem ' $35+20$ ' by beginning at 35, circling it in black with the SMART Board pen tool, and then counting down two rows on the chart to add two groups of ten. "You can circle the 55," Felicity explains. "And how did we know the answer was 55 ? Where did we start?" 
As Felicity and her students work through the next few problems together, she notices several members of the class become visibly frustrated that they were not being picked to model a solution on the 100 chart displayed on SMART Board. "If you don't get a turn with the SMART Board today," assured Felicity, "there's always another turn tomorrow."

After completing a few more guided practice problems and informally assessing students' work by visiting them at their desks, Felicity disperses the students into their routine centers activities. "Teacher's helper - if you are the teacher's helper," Felicity called out, "turn off the board... Lights, turn on the lights."

A group of five male students bring their math packets to a wooden rectangular table at the back left corner of the room. Felicity engages them in additional differentiated practice for today's math objective. "Did they regroup?" she asks the group. "Yes. So would you circle the 'yes.' And when they regrouped, how many did they end up with?'

Felicity stops by the table where I am seated encourages me to walk around the room and check out what the students were doing for their centers work. I see several students using iPads that they retrieved from a white wire storage unit on the wooden counter to the right of the boombox, which also has a CD player component on the top. They are logged into MobyMax through the iPad Safari browser and are typing in usernames and passwords independently, wearing audio headphones they have plugged into these tablets. An instructional aide enters the room and appears to be monitoring the students who are working independently. One female student had a question about a problem on MobyMax and after having her hand up for a few seconds, the aide approaches her and works through the problem with the students. 
There is a black leather couch on metallic legs on the left wall near the door. Two male students have also retrieved book boxes. One is reading a Mercer Mayer Critter book silently. The other boy has an iPad with headphones and appears to be playing on MobyMax. A third student is sitting in a chair hidden by a white mini-fridge and is reading aloud a short picture book with nice expression when there is dialogue. She is video recording herself using the iPad Camera app. I see that she had the iPad propped in her lap on the right side and the camera can mainly see the book pages but not her face. She finishes and begins playing her video back. It is audible to the point that the entire classroom could hear it. Eventually, she stops the video, plugs in black headphones and continues viewing her recording. Several students stop me as I walk about the room and proudly share parts of their recordings. One student notes that they had made a few fluency mistakes in their initial recording, so they went back and re-recorded it.

"Oh! Joe is thinking," I hear Felicity say to her current math group. "Tell them what you're thinking Joe?... So are we going to have to regroup?” (FO)

Felicity is working with a new math group at her back table. She stops for a moment and asks the aide to help a male student put on his headphones before he starts recording a fluency video. They discuss if he will read the book standing up or sitting down. He chooses to stand near the couch, and the aide helps the student situate his headphones, book, and iPad. He eventually kneels in front of the couch and begins his recording. Felicity turns to me and explains that the aide is a high school student that volunteers her time. "The advantages of having the high school here!" (FO) she notes.

I notice the iPads either have black rubber cases with a "kickstand" on the back that folds out and props up the device for ease of viewing or blue rubber cases with no stands attached. The 
students' headphones are stored in some small plastic bins under their coat hooks area on the right wall of the classroom or on a wooden shelf above them. These are also numbered with smaller white stickers. The blue plastic book boxes, numbered with stickers on the front, contain approximately 5-10 texts each and are stored on a mobile metal shelving unit near the iPads.

Eventually, Felicity dismisses her final group. "First grade, if you have reading boxes, you need to put them away," she announces. "MobyMax-ers, be sure to double click...and close it out."

\section{Felicity's Journey}

“Am I the right candidate for you?" Felicity asked me at the beginning of our initial interview. "I don't know how much technology that you need. And I read on [the consent form], it said, like, 'Three times a week...' I am not a technology guru at all” (personal communication, February 14, 2019).

A contact of mine, Lyla, recommended Felicity for this research study based on what she knew of Felicity's technology use in the classroom as well as her engagement in local professional development opportunities. Felicity explained why she thought Lyla suggested I contact her for this study:

I think Lyla probably threw my name out to you, because when I didn't have a lot of [devices]...one thing I did - and I still do - not every day, but a lot, at least once a week, [my first graders] have to record reading to me, and I do running records off of that, depending on what their independence level is. (personal communication, February 14, 2019) 
After chatting with Felicity for a few minutes, it was very clear that she integrated digital technologies in her instructional design frequently enough to qualify for participation in this study, so I asked her to share the broad details of her life's journey.

Felicity, the youngest of five children, was born in Texas; her mother gave birth to all of them within a six-and-a-half year time span. "For most of my life, I had a single mom," Felicity told me. "I was a little bit of a latchkey kid" (personal communication, February 14, 2019).

Felicity's family relocated to rural Kansas when she was in third grade to be closer to her grandparents following her mother's divorce from her stepfather, who had been physically abusive toward her brother. Her mother had been teaching courses in business, accounting, and typing at a school in Texas; however, she also held an accounting degree and transitioned to that line of work in Kansas. Felicity recalled being exposed to technology at an early age based on what her mother brought home for her teaching and accounting work:

I got to mess around on...the typewriter before a lot of my friends had one, because my mom actually taught keyboarding. So like, I knew keyboarding...before a lot of my other...classmates did, because my mom, that was what she did...And, you know, this goes way back. I mean, you had to put the paper in. You had to crank the machine. But, I remember the keys, like, stroke up to the paper. That's how old this one was...So we fiddled a lot. My sister and I were only 11 months apart. So, we just, like, played school, you know...and typed words and numbers. And then, [my mother] even brought home an adding machine with adding machine tape. So we just did a lot of...playing, if you will. (personal communication, February 14, 2019)

Felicity attributed these early experiences with technology at home to her adeptness with word processing and using technology in high school and college. She took keyboarding classes 
in high school, which helped her improve her typing speed even more and become one of the fastest typers in her school:

When I was in high school, I remember the typing teacher had us type to music. So she actually played music that had a beat, and then we had to do the keys, you know, with the beat. And she would have it up on the overhead projector...Like, I was really good at that. And then I got to become the editor of our school yearbook and newspaper, because I just had so much, like, I could actually type. [laughs] So, I got...good typing skills. (personal communication, April 30, 2019)

After high school, Felicity attended a junior college. She and her now-husband were "high school sweethearts" (personal communication, February 14, 2019), and after she became pregnant with their first child, Dinah, they got married and both went off to attend college at a large state institution:

We just went to school together, the two of us with the baby... That baby who is now 30 and a...physician assistant in the E.R. So...Dinah has done very well for herself...We tease her. She got to go to college twice. 'Cause she started out in college. Why wouldn't she go? (personal communication, February 14, 2019)

Felicity shared that she and her husband had their own personal computer (PC) on their campus, which was rare at the time. In the following interview exchange, Felicity explained how having a PC for her college work was helpful for completing course papers and assignments:

Felicity: Like, yeah! Everybody else had to go to the library and that's where - isn't that terrible? That's where you had to do all of your papers!

Aaron: Yeah. 
Felicity: In the library! But, we were fortunate that we had one. It was a gift somebody had given us, and we had one in our apartment with a printer. That was like, "Ooh! Ahh!" Aaron: Yep.

Felicity: I know! Isn't that crazy?

Aaron: Yeah.

Felicity: That -

Aaron: Was it the printer that had, like, the little perforated holes on the edges?

Felicity: Yes! And you had to feed 'em in. It was a monochromatic screen. It, it typed only in orange. You had a black screen with orange...letters. (personal communication, February 14, 2019)

Felicity noted that throughout her career, she has never been afraid to incorporate new or incoming technologies in her instructional design. Since childhood, she used technologies fairly consistently and developed skills and comfort with them. As she moved forward from college into her professional teaching career, technological and digital approaches were approaches she could draw upon in her instruction. Her past was in dialogue with her developing pedagogy. "I feel like I was always one of the first...like, when teachers are still using... VHS tapes," she remarked, "I wasn't afraid to use YouTube videos to show kids things...I was always willing to dabble in it a little bit" (personal communication, February 14, 2019).

Felicity graduated a year before her husband, so she took a job as part of a pilot program that worked with elementary schools near her university that promoted collaboration between teachers:

There were about, uh, 15 of us that worked for the regional office. And we would come together and we would meet and we would take these whole language lessons into a 
classroom. And we would teach the entire day...I had a co-teacher, and we would go to the first grade rooms. We brought in all our materials...And, it was whole language. So like, I remember one of the lessons we did was, like, on flight, on airplane. And so we, we, all we got was their schedule of when their kids needed to go to P.E., when they had a break, when we needed to get to lunch, and then we put our own reading, writing, and math into that day. And we always had a video - that was our technology side of it...They did that for about a year. (personal communication, February 14, 2019)

After Felicity's husband completed his engineering degree, he accepted a position with a major agriculture machinery producer in Illinois. Upon relocating to rural Western Illinois, Felicity took on a variety of substitute teaching assignments for about 18 months and filled a special education aide vacancy for two semesters. Then, she was brought on as a kindergarten teacher for a semester, followed by two years of teaching second grade. After this, she looped with a class, teaching them in their first and second grade years. Finally, she taught second grade for one more year and then moved back to teaching first grade, which has been her full time teaching assignment for the past 15 years. It was during this period of consistently teaching first grade that Felicity began to develop her pedagogical design with digital technologies in earnest.

\section{Felicity's Pedagogical Design}

Teaching in a smaller district in which the elementary, middle, and high schools are all located in the same one-story building, Felicity has experienced fluctuating class sizes throughout her career. She explained that "a lot of it has to do with the rural population," but also some administrators that "deem...numbers as a...hindrance and some that are like, 'Eh. You, You're a good teacher. You can do it"” (personal communication, March 14, 2019). 
Felicity shared how low student enrollment numbers one year particularly impacted her teaching assignment:

We didn't have as many students enroll...[as] they thought were going to enroll, so we had a situation where we didn't have enough students for the two classrooms in first grade. So I volunteered to be... an interventionist. And so, I set up my own...[they] had never had one. I was like, "Hey guys! I'll pilot this for ya." And they were like, "Sure!" I did that until December, and then we got, like, four kids in first grade and it was too much. So then we broke back off into two sections. So I taught first grade in the morning, and then I did interventions in the afternoon. But I ended my day in first grade, so that my kids could start with me and finish with me. We had all of our specials in the afternoon. So really, I didn't miss any instruction time with them. (personal communication, February 14, 2019)

Felicity went on to discuss how growing class size numbers "about seven or eight years ago" (personal communication, February 14, 2019) prompted her to integrate her own personal iPad in her instructional design in order to continue hearing each first grader read aloud on a consistent basis:

One year I had 28 first graders. And I just felt like...I couldn't...I couldn't do it all, you know? And so that's when I kind of doubled myself and started video recording. I, I remember a teacher would use a cassette player, and she would record students reading and then go home and listen to them and do running records off of that. And I had done that sometimes, just to make sure, you know, double check myself that I was doing things correctly. But I had an iPad, and it was an old iPad. I started having kids...I set up a recording studio and they thought that was like, oh so cool. But I only did it with the 
students I felt could handle it. And, I mean, everybody got a turn, but I did more with students I knew could handle it. And then I didn't feel like I had to meet with them as often, but then I started feeling guilty that they are six and seven. They still need me. I can't just depend on the technology. So that's kind of how that started as far as the recording. (personal communication, February 14, 2019)

Felicity's introduction of recording in her reading fluency assessment repertoire was sparked by a few factors with which she was in dialogue. As a matter of practicality, by recording the students, Felicity was able to more feasibly listen to each student in her large class read aloud and collect data to inform and differentiate her instructional design. Felicity went ahead with this digital approach, even to the point of having to utilize her own personal iPad. Despite the lack of access to mobile technologies at her school, Felicity saw audio/video recording as the most effective way to monitor each students' reading progress.

The design of the recording studio in Felicity's classroom has evolved each year based on the needs and input of the students. At the time of this study, Felicity had modified the space to be comfortable, equipping it with features to support students' independent reading and recording:

But what it is, it's just a curtain rod - you know, shower rod...Basically, there's a chart hanging in there, and it talks to them about how to video record. And then, there's usually, whatever material I want them to read, I leave in there. There's a little, it's really like a footrest thing, but it's padded, so they can sit on that. And they have a book in there. And they go in there, and they have to, of course, push the video. Um, actually, it's just an iPad. I have hooks that it hangs on, and they introduce the story, and they read to me. And if they get stuck on a word, I want to see...what are they doing to help 
themselves read. And, it has really, it almost doubles me, because if I can't get to everybody in the week, I know that I can still go in...and listen. (personal communication, March 6, 2019)

The recording studio (Figure 1) also functioned as a space for a recent student to use as a calm-down area, which prompted Felicity to further modify its design by adding a world map shower curtain:

It's a dual...purpose. Um, so I have one student that has a behavior...plan in progress right now, and we had to make use of that space. He's outgrowing it, but I didn't want to get rid of it. So, if the map is closed, then it's closed off to other students. He's in there doing one of the breathing techniques. And when he comes out, we're able to use it. (personal communication, March 6, 2019)

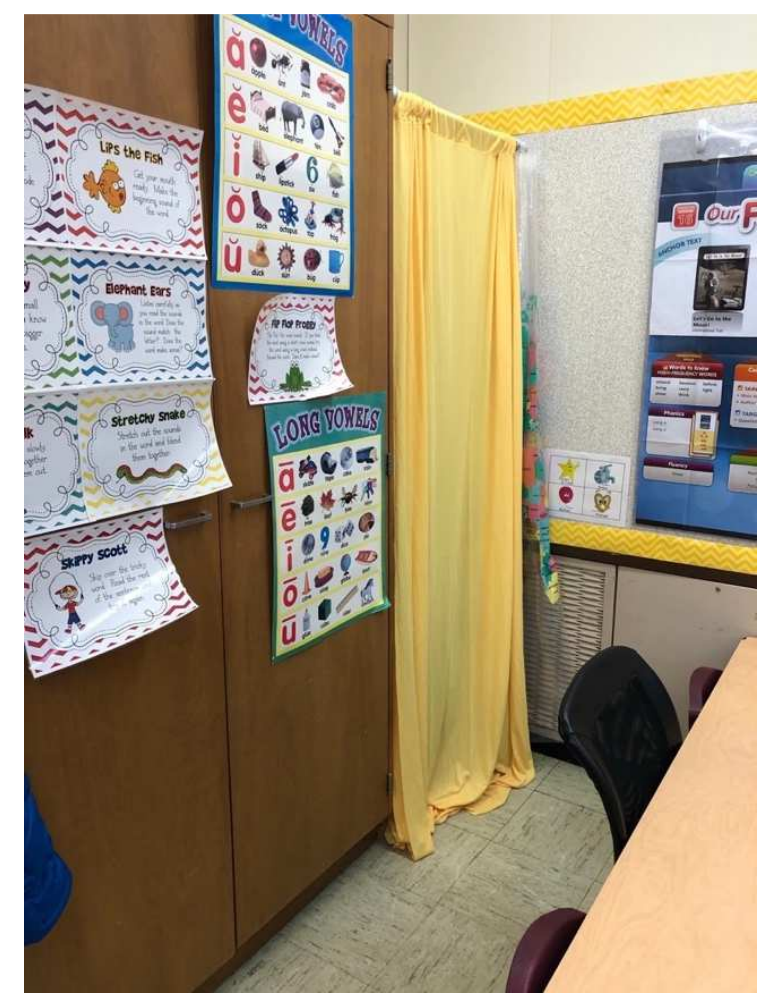

Figure 1. Felicity's class recording booth/studio 
About two years ago, Felicity felt compelled to request additional mobile devices for her students to use. Up to that point, she had only been provided with a few stationary desktop computers and four iPads for her classroom (in addition to two iPads she had brought from home):

Felicity: I went to our technology person. I said, "You know, I think we're doing this backwards." I said, "My kids sit down and they want to reach out and touch the screen, and they're still having to use a mouse." You know, the little kids, we always get all the old stuff. And I said, "They come -" Your daughter is two.

Aaron: Mm-hmm.

Felicity: She already knows how to touch the screen.

Aaron: She knows how to swipe through pictures on my iPhone, yeah.

Felicity: Exactly! So that's what I'm getting. So I went and argued a little bit that...I feel like first graders...need more up-to-date stuff. All the high school had ChromeBook. All the junior high has ChromeBook. And yet, I'm sitting down here with six iPads, two from my house. And $I$ didn't have any more stand-alones. They had all died. All the dinosaurs died. So I said, "You know, what can we do?" And this grant came about, and so...our technology person has three daughters himself, and he said, "Yeah...you're right. It's, you know, we need a little more." So they're actually, the iPads, are supposed to be shared with kindergarten-first grade. And, um, kindergarten said, "I have 12. I don't want to go one-to-one yet.” I said, "Oh! Okay! I'll take 16.” Aaron: Mm-hmm.

Felicity: So I took what I needed. (personal communication, February 14, 2019) 
Now that Felicity has one-to-one mobile technology in her classroom, she has continued to make changes to her students' fluency recording experiences, modifying the routines and physical space to meet the needs of her students. In recent years, Felicity has designed formal and informal recording opportunities for her first graders. During learning centers time, her students have the opportunity to engage in repeated readings of leveled texts and record (and rerecord) them, watching them back afterwards.

I observed Felicity's students go through this process when I visited her classroom. On more than one occasion, students approached me to share the books they read and how they had re-recorded themselves to correct accuracy miscues they had identified when reviewing their videos; many smiles of accomplishment and pride accompanied these sharing opportunities. The students engaged in situated practice of reading texts they self-selected. In self-assessing and finalizing recordings, they critically framed their reading in relation to the fluency benchmarks (e.g., accuracy, rate, expression, etc.).

In addition to informing her design of individualized instruction, Felicity uses her students' recordings as exemplars of reading fluency, subsequently helping them view their own reading fluency through a critical frame to promote targeted skills:

In a minute, you can pick up on some struggles. [However], you can pick up on some successes. And the most amazing thing is when I $d o$, at the end of the day, they love if I pick one of their videos. And I'm like, “Oh, you guys have to hear this expression when so-and-so reads." And so, I show a short clip and...what do you think I get the next day? When they're reading, I get expression from everybody! [laughs] So, it's really...neat, and I do try to, you know, pick out everyone at some time so they, all students feel like they are successful. (personal communication, March 14, 2019) 
Felicity reads aloud most of the texts she puts in the book boxes prior to making them available for students to select for independent and partner reading. In addition, she tries to be purposeful about the texts she has the students read and record in the studio space to assess their application of targeted reading and phonics strategies. She shared an example of this in our focus group conversation:

Like this week, our skill is long /o./ So then I can see if they're applying it. So, they're not cold reads. This one is actually, we have read the story. It was our whole group story that we were doing. But I feel like I...time is getting more limited. We have more and more kids. By the time you try to do whole group and guided reading and intervention, um, I feel like our main story is gettin' the squeeze. So, I feel like this is just another way that these kids can go back and see that story. So, we've read it whole group. They've read it with a partner. And then this gives them a chance to go back and...you know, depending on where they fall in the list, some people might have seen it a couple more times. But then again, I can still see whether they're getting the skills or not. A lot of them kept missing "spacesuits" this week. [laughs] So I just, I went back in front of the room and we all got our books out and our magnifying glasses and I would say some vocabulary words and have them go back and find them. And I'm like, "You know, this is a tricky one. There's two $S$-words together. How are we going to know the difference?" So it really guides where they're struggling. And I've also found that I don't waste as much time on things...that they already know. Just because the teacher's manual says we need to do that, well if they know it and they can prove it, then let me go...and teach them something they don't know. (personal communication, March 6, 2019) 
The video format of the recordings has been particularly helpful for Felicity to assess individual students' reading fluency strengths and areas of improvement, which has informed her subsequent reading instructional design:

Just having that video recording, you know, being able to, to actually see them when they're reading, because...watching readings tells you so much, like when...they're struggling or, you know, they'd look at the video and when they'd skip a word, or... I don't know. I think seeing them is just as important as hearing them...when they're reading. (personal communication, February 14, 2019)

Felicity has also found that by allowing the first graders to view each other's recordings, students promote new literature amongst themselves, motivating each other to read new texts: And then I also let them, with the recordings, not the running record ones but when they do the reading box ones, when you are reading to self, they also can listen to the other stories. And they really like to do that. They like to hear their other classmates, and they'll be like, "Oh, you read that magnets book. I'm going to read it tomorrow." (personal communication, March 6, 2019)

Felicity has integrated daily reading fluency practice in her design of learning activities since she became a first grade teacher 15 years ago. She explained when she started teaching first grade, two colleagues really helped her incorporate the facilitation of daily independent reading as a core approach:

I had an amazing...two co-teachers. They were just...the godfathers of first grade. And they...really did a lot of...'daily sustained silent reading' is what they used to call it. I don't know if you remember that or not. But they wanted kids to read to self. And then, um, you know, the listening center was important. So some of those things I've just never 
let go of, but you just tweak them to fit the needs of kids today. Like recording - they're still reading. They're still reading to themselves. (personal communication, March 14, 2019)

While Felicity progress monitors her students' reading face-to-face on a weekly basis, she shared how collecting recordings of students has provided her with other valuable data. By collecting recordings of her first graders' reading throughout the school year, she has been able to digitally amass a fluency 'portfolio' of sorts for each student. Felicity has shared recordings at learning celebration events and expressed a desire to integrate students' reading samples at parent-teacher conferences. She also explained how helpful the recordings have been as a form of evidence for gaining additional supports and services for her students:

I had a student who was really struggling with speech. But, the people around him were like, “Oh, no! He's fine!” And I took [a reading recording of this student to] an RtI meeting, and I said, “Here's the story he's reading." And...they couldn't see the book, and...they're like, “Oh, wow! We didn’t realize he didn't know that many sounds!” Because they're so used to being around him, they've learned his language. So it's helped me out in RtI meetings. (personal communication, March 6, 2019) In addition to using modern mobile technologies, Felicity also integrates older technologies, such as the cassette tape player I observed her use to play an audio read aloud. We discussed her decision to use a combination of digital and 'analog' technologies in our final interview. Felicity has accumulated resources, such as cassette tape read alouds recorded by actual authors, over the course of her career that she feels she can use in her design of effective learning experiences. She shared one example in the following interview exchange: 
Felicity: I could pull it up on YouTube and have YouTube read it, but...some of the people that are reading some of those books, like, I don't know if you know Chicka Chicka Boom Boom?

Aaron: Mm-hmm.

Felicity: That's Bill Martin, $J r$.

Aaron: Yeah.

Felicity: And I have them on [tape] recording. I don't wanna,' I don't wanna' give that up. [laughs]

Aaron: Absolutely. I don't blame you at all...

F: So I've just continued to use...what I have. (personal communication, April 30, 2019)

Felicity also leverages aspects of non-digital technologies for her students to use in engaging in literacy practices in new ways. She shared an example of how she had her most recent class of first graders create audio read alouds on an older cassette tape recorder she still had in her classroom:

Felicity: You're gonna' laugh, but honestly, sitting on my counter right now, we just started long 'a,' and in one of our books, it talked about...they taped their band. And the kids -

Aaron: No idea.

Felicity: - didn’t know what that meant.

Aaron: Yeah.

Felicity: So, I pulled out my cassette tape with the microphone, and they got to record themselves. And we had a bell [to chime that signaled] to turn the pages, and they got to make their own recording. 
Aaron: [gasps]

Felicity: And then we shared it with the other class. And then the other teacher recorded them, and they got to share [an audio read aloud] with us. And, oh my gosh! Here they have all this technology that's new, and the iPads, and they've seen themselves recorded. But to have to just listen...it's great...

Aaron: [laughs] There's almost some, like a sense of, like, intimacy or creativity when you work with older technology where there's like a physical action of pushing the button, or, $I$, 'cause -

Felicity: Yes!

Aaron: - I, 'cause I have a vinyl player at my house. And like, I still like to maintain a sense of that as well. My daughter, when we put that on, she's like super-duper into it. She wants to watch the record spin.

Felicity: Yeah.

Aaron: Yeah.

Felicity: So, I, uh, em, I, I guess it's a good thing that I'm 50, 'cause they're gonna' get to see cassettes, see CDs, and iPad. (personal communication, February 14, 2019)

While Felicity had retained select 'analog' technologies and approaches in her pedagogical repertoire, she also articulated the affordances of the modern digital technologies that her students regularly use, such as iPads:

The...use of the machinery is so much easier. So when they [recorded with] the tape player, you know, I had to have a little sticker on there that said 'Stop.' This one was 'Record.' Really, I just pushed the record button down with play, and then all they had to do was pause and unpause. But, um...[pauses] the thing was, kids, not everybody has a 
tape player at their house. So...it's actually easier for them to use a tablet, because everybody has a tablet. Cassette players and recording, kids just didn't do that...They just didn't record [effectively]. So it's almost easier on the iPad. The other thing is, with the iPads...they're portable. You can go anywhere in the classroom. You saw that [when you were here]. And when I want a specific reading, that goes behind the curtain. That's in the recording studio. (personal communication, April 30, 2019)

Having her students use iPads for recording has also fostered more student independence, particularly with Felicity's most recent group of first graders. With cassette tape recorders in the past, Felicity had to troubleshoot and manage the device much more frequently. With the iPads, her students often troubleshoot for each other:

I'm not tied to the iPads. They, they run the iPads. What I love right now about this class in particular is, um, they are very good at...if somebody doesn't know how to do something, many times, I will say, "I just helped Maya with that. You should go ask her to show you." And...as soon as Maya hears her name, man, she's, "Mm-hmm!” She'll help. They, they love being student-led. I mean, it's, they love it. And I love giving up some of that [laughs] responsibility. Is that fair to say? (personal communication, April 30, 2019)

Given the young age of her students, Felicity feels that establishing core routines for her students' use of digital technologies is critical for designing learning opportunities that are both practical and effective. Traditionally, she has used a gradual release approach with students recording themselves reading on the iPads:

I don't have them start recording until January. Um, the first half of the school year, you know, they're first graders. They're still pretty young and the independence isn't quite 
there. So [in the] second quarter we start...using the iPads as a recording device. They might partner record when they're reading...so they get used to it. And then, I go from partner reading [to independent], self-selected reading. They can take an iPad after they've practiced a book. Then they can record themselves reading a book, and they really like that. And then now, they can go into the booth and they can record...the material [stays] in there for the week...It's kind of a progression throughout the school year. (personal communication, March 6, 2019)

Due to the popularity of the recording studio process with her first graders, Felicity has also established routines for how students take turns to go in and read the assigned text each week:

We have a chart at the front of the room that has their names on it...So, they're already used to going top-to-bottom or bottom-up. So I will just tell them, like, "Okay, we're going to go top-to-bottom!" So Maya, you're gonna' go first, and when you're done, you can go tap the next person and tell 'em, "I'm out of the booth!" And so they just, they just use the $\mathrm{ABC}$ order of the classroom. I have considered making a chart with a clothespin, so they know where they're at and $I$ know where they're at, 'cause right now, I'm like, “Hey Maya! Did you tap the next person?” (personal communication, March 6, 2019) Felicity's students are very motivated to informally record their reading outside of the required work in the studio; therefore, she has set routines when the students read and record with a partner in order to promote the development of decoding strategies and phonemic awareness:

And let me tell you, every day, "Can we record?" Which means, "Can we read?" So I, you know what I'm gonna say. "Well, yeah!" But what I've really, really worked on right 
now is I don't allow kids to tell other kids words. They can tell them a strategy. They can tell them - okay, so we're working on long vowels right now. And today, a kid was stuck on a word. And I said, "Can you tell them something about the vowel?" And they go, “Oh, there's a 'e-a' together. Do you remember what 'e-a' says?” So instead of saying, "That's says /ee/," they have to ask them. Or they give them, "I see the 'e-a' together. I see the 'a-consonant-e.' Magic 'e' can help you with this." And I'm gonna' tell you what - I told them when they record... So, one person has to be the coach. One person has to be the reader. And I tell them I am listening to both of them. And we do this little scoring thing, these little tally marks. And I try to see, "How much do you help your [partner]? How much do your help yourself?" And they are loving that now. So, yeah. But it's just a different way of... It's also tells me do they understand how to word attack. You know? Do, do they understand the rules? They come to a word they don't know, what, and they're just sittin' there stuck. (personal communication, April 30, 2019)

The one-to-one implementation of iPads requires Felicity to establish device management routines with the students. For example, Felicity and her students must keep the class set of iPads consistently charged; however, the classroom is not equipped with an adequate amount of electrical outlets. She explained how she had formulated a charging routine, and subsequently, her classroom space (Figure 2):

In the little iPad area...I only have two plug-ins. You can see one is behind the blue stool. That's kind of how I protect it from being unplugged. And they had to run a cord all the way over, 'cause my SMART Board had to be plugged in too...I felt like that was a good home base to plug into the six iPads. They have to share...three... I only have three chargers. So...I can charge those right on the counter. You can see two are charging 
currently as we speak. And then the...stack, those are the ones that we run back-and-forth from the [charging cart in the] media center. And my students, I don't even have to ask them. I told them anytime they're at 30-percent or lower at the end of the day, they can put 'em on the table and we'll plug 'em in...You know. They're babies when they come in, but you always have those really good little mother hens and little... I have one little guy and one little girl that they've been doing it for, plugging them in since October. And it's funny, 'cause then somebody else wants to try, so I'll say, "Well today, why don't you take so-and-so.

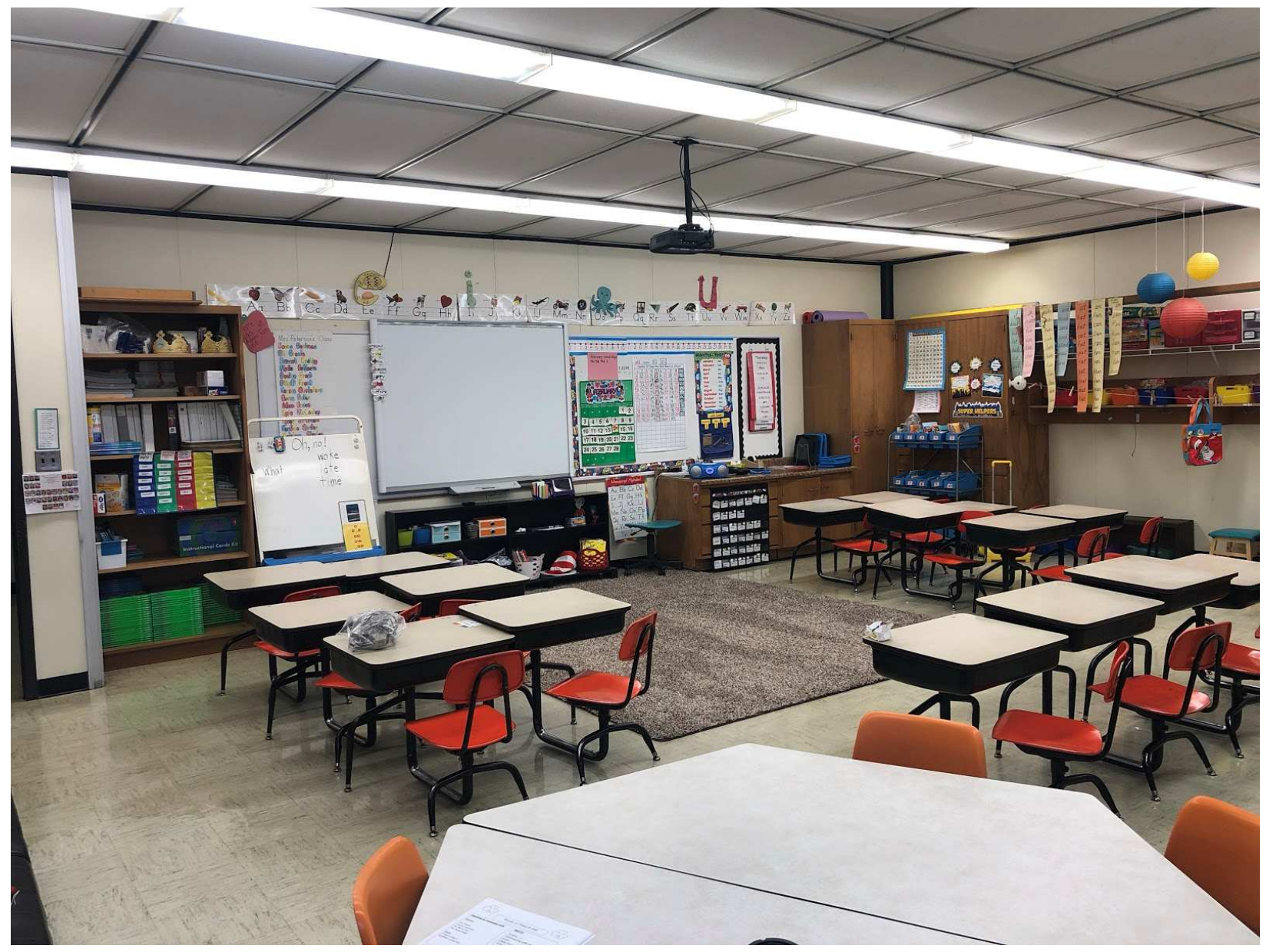

Figure 2. Felicity's first grade classroom 
But remember, we have to hear the ding when we plug 'em in." So, it's funny, 'cause they make sure, 'cause sometimes, that cart in the media center gets unplugged for whatever reason, so I don't know. So if they don't hear the ding, they have to come tell me and then I get the cart. (personal communication, March 14, 2019)

Felicity has had to continually modify other classroom technology management routines based on the young age of her students through trial-and-error. She discussed the process of finding an optimal way for her students to store their audio headphones:

So, um...headphones...make me crazy...So, the first time we did it, we don't have a lot of things in our desk. I thought, "Well maybe in our desks...No. Maybe not." So then I went to a full basket storage. Ugh! Girl basket. Boy basket. Well I have 11 boys, five girls. It doesn't work. Then I bought a pocket chart that was for headphones. And it was on the back of the easel. Well then it took away the back of the easel. So I couldn't use both sides of the easel. The pocket chart - the shorter kids...couldn't reach, and they ripped the chart. And so...last year, I was over headphones. And I'm like, "I need to do something." So, I dipped in my own pockets, and...at the far, far edge of the room where they hang their coats...[I arranged]...little rubber bins. And they were expensive, but I just took a permanent marker and they already have a mailbox number, so I put numbers on the bins. They fit beautifully above, and then the ag shop made me benches...So they made me benches, so that kids would have storage above their name and below their name. I've always had the benches. Like, I put 'em out in the hall; we put snowboots on 'em, or whatever. Well, when I got the bins, we needed more places for these...bins, so that's where they put those but they can still put hats and gloves and stuff on top. And everybody has their own bin, and everybody gets a baggie. And the reason I do the 
baggie is we've had cords dragging down the hall to go to the computer labs. Somebody steps on it; you snap the cord...So anyhow, um... I'm going to tell you if I had to give the headphone baggies, bins a grade, they'd get a 92-percent...First graders are small...that some of them can't reach up high. So we would just trade bins up and down and now they're established. And they still don't always, um, want to put them in the baggie. My one issue, the, why it only gets a 92 , is...I don't know why, but, and I don't know if it's the baggie or just the kid, but I have a couple of kids that want to wind the cord. And then when, you know what happens when they go to get it out - it gets a big knot. So we, we practiced how to put 'em in. And you open the baggie and you drop it in like a snake. [laughs] (personal communication, March 14, 2019) I asked Felicity how she manages the routine of getting students turns at the SMART Board, as some students were upset about not getting to show their solutions at the board during the math lesson I observed. She explained that students do not always get equal turns, but rather, use this technology as frequently as needed to maintain their engagement in math lessons:

You know, they really don't get equal turns. And...we talk a lot about that, that some things, you, "Sometimes you do. Sometimes you don't." And...I try. Like, in my own mind, this is gonna' sound crazy, I pull popsicle sticks or pull cards. But, like, I might start with corners. I might try to get all the corners. And then if I know every, all the corners had a turn today, then I might go for the [students who sit on the] inside next time. It's just little, you know...And then sometimes, I have to pull up kids more than once just to keep them engaged, where some kids are a little more independent. And it's not that they don't deserve equal time, but, you know, to be honest with you, fair is not always equal. (personal communication, April 30, 2019) 
Felicity has been able to utilize five different aides in her classroom to facilitate routines, including supporting students' use of digital technologies. The consistency of the aides during the most recent school year has helped her design learning opportunities in which her young students use iPads. "They know the routine," Felicity explained. "The kids know them. So they've been really good." (personal communication, March 14, 2019).

The role of the aides regarding how they support student use of the classroom iPads evolves throughout the year, as Felicity explained:

It really changes a lot in the school year for first graders. At the beginning, I needed an aide in there just to get them logged in until they learned their login. And that took quite a bit of time. And then once they learned their login, then their seat buddy, I would have them help their buddy login and then they login. You know. And now...they don't need anybody to log them in. They don't need anybody to oversee their technology side of it. So now I'm able to use that aide as, like, she can help do a running record. She can help $d o$ word work with kids that need word work. (personal communication, April 30, 2019) In addition to utilizing aides, Felicity has coordinated a digital writing project in which high school students work one-on-one with her first graders to produce and print a piece of writing. In recent years, she has only been able to collaborate with the high schoolers once a year but expressed a desire to do this more frequently:

Yeah, right now we only get to do that once a year. And it's not that we only get to do it once a year. We just happen to tie it in with, um... I coach with the high school English teacher...About five years ago...I told her that one of my Common Core goals was that I had to have this written piece that was produced. And what a nightmare it had been for me, because I was producing them. Like, one kid would get to come to me. I was making 
a class book. And $I$ was typing what they said. $I$ was inserting the pictures. So I thought it was kind of, like, by the time we got done, it took 16 weeks to make a book. So, this is cool because we have two class periods. We go down, we read books. The next one, we produce...the work. And that's a little more on pace with our 24/7 world and the kids' turnaround time. They're excited about that, to see it...back at them so quickly. Um, $I$ probably need to do a better job of maybe utilizing that a little more. We need to do something every quarter...[However] the high school schedule changes at semester...So, this, that quarter happens to work out. (personal communication, April 30, 2019) Unlike the aides, Felicity has been unable to consistently design learning activities in which her district's high school students provide individual support for her young learners' digital composing. In an ideal world, she would pair her first graders up with high school students to digitally write, print, and publish regularly; however, current schedules do not allow her class to connect with their neighbors across the long hallway of the K-12 school building. An integral part of Felicity's routines for technology use in her classroom, specifically with the reading fluency recordings her students create each week, was establishing a classroom culture in which students could all feel safe to make mistakes:

Really early in the school year, I start that. I show that it's safe. It's safe to share, and if you mess up while you're sharing, no big deal. Take a deep breath. Keep going. And what I've noticed is some of my weaker readers, um, they are still picking DEAR books to record. But...they're reading, and they are reading more fluent than they were. So I think that it allows kids...you know, that exploring, if, if you will...It's okay to make mistakes. And it's okay to take risks. But the biggest thing too is...I think sometimes...kids don't hear themselves. 'Cause I've even taken an iPad when someone was reading a 
story, and I said, “Hey guys, let's listen to this story today, and let's talk about what's working and what's not working." (personal communication, April 30, 2019)

As part of this safe environment, Felicity provides encouraging feedback on her students' reading. Likewise, she feels the first graders can self-assess their progress by physically seeing and hearing themselves read on their recordings each week:

Because before, they're trying to be independent and they're 6- and 7-years-old. And you know what they wanna' say about every 30 seconds: "Look it! Look it!” They want that reassurance. Well when they're on the video recorder, um...they're getting that feedback, because they're seeing themselves. And I try, I have sticky notes, and I try to drop 'em a little note. I don't do it all the time, but I'll say, um, "You had great expression when you were reading," you know, "Piggy and Elephant." Or, and I'll just leave 'em a little sticky note on their desk. They, oh my gosh. You wouldn't think a little piece of paper... But if I validate that I've watched that video, the next day, I mean, I'm gettin' some more professional videos than what I have on YouTube for kids to watch in the classroom sometimes...because they're hitting that expression. They're wanting to do it more. So I just think the video is taking it to a new level. (personal communication, April 30, 2019)

Felicity also expressed an openness to trying new recording apps. Following my visit to Felicity's classroom, her principal inquired more about my research and Felicity's pedagogical design with digital technologies that I had observed. The following focus group exchange highlights her continued efforts at improving her pedagogical design with digital technologies: 
Felicity: Our high school principal came in, and she had seen that Aaron was there, and I was telling her, and she said, "I think there is an app out there, where they can all go to that app, and then it send it to you." You put -

Laurel: Yeah. Yeah.

Felicity: I just have a smiley face -

Aaron: She's talking about -

Felicity: - on the back of that one that they can use.

Aaron: She's talking about FlipGrid I, I wanna' say.

Felicity: She probably, she said she used it for math or something -

Aaron: Yep.

Felicity: - or recording, like, a response. So $I$ -

Laurel: Yeah.

Felicity: - don't know. If there's something out there, I'd be happy.

Laurel: I'll look and see. There was one that you can record, and then you can, um, send it to your yourself and then you can file it under that student's name.

Felicity: Because -

Laurel: Or -

Felicity: - right now, I have them use one iPad, and then this way, they could use whatever iPad.

Laurel: Right! And then it automatically sends it...to your, it, it categorizes them and then it automatically sends it to, um, that file folder, that student. And you can take Felicity: And you can like -

Laurel: like, pictures of their work. I'll have to look and see. 
Felicity: Okay. FlipGrid? (personal communication, March 6, 2019)

Felicity and I discussed the possibility of her adopting a video platform, such as FlipGrid, with future classes. She expanded on the ongoing reflection process she had been engaging in for some time regarding the fluency recording process:

Well, one thing that would make it easier for me is I wouldn't have to go through every iPad. [laughs]...So as of right now, I have not found that app. But, um, I have decided that all my kids have a mail number. So I thought about designating an iPad number. But still, I'm going through every iPad. So I'd like to get away from that, because I think it would help me be able to, um, it would cut down on time. And...it would be convenient. I mean, I could bring it home and sit down and listen to kids read. I, I'd double myself when I do that. And I love it. I'm not gonna' bring home 16 iPads. So it's something I have to do at school. So out of convenience, I think that's gonna help me. Um, the other thing I'd like to do is start...archiving some of those, so that $I$ have a monthly reading to show kids how their building. And I told you, I already am taking those recordings to RtI meetings. (personal communication, April 30, 2019)

Learning about new technologies and ways to use them as part of her instructional design continues to be an important part of Felicity's self-driven professional development efforts. I was able to observe Felicity engage in informal professional learning through shared dialogue in the focus group discussion as well as our final interview conversation. She also shared how she has learned about new digital technologies and ways she might use them in her teaching from her husband and five children:

Felicity: I have kids that range from, I have a high schooler, I have a college student, and then I have a daughter that is in an E.R. as a doctor. And if I want to know what that 
seventeen-year-old is doing, when it's the buy-one/get-one Apple phone, I have the Apple phone. So I, I know, she keeps me up-to-date.

Aaron: Sure.

Felicity: Does that make sense?

Aaron: Oh, no. For sure. It does.

Felicity: Yeah. So $I$ think that just...being a parent has helped me stay up on technology. My husband also works for [a large agricultural equipment manufacturer].

Aaron: Yep.

Felicity: And so they're on the cutting edge of so many things. Um, you know, like Google Docs and how to put presentations together without being...everybody in the same room and connecting those things. He's been a really big help. Before grades were online, he helped me design a...we did a, we did an Excel spreadsheet.

Aaron: Yep.

Felicity: So he's like, "Why are you doing grades in a gradebook? Let me show you somethin.",

Aaron: [laughs]

Felicity: And, he put the formulas in. I could put the kids' names in, and all my grades were being calculated -

Aaron: Yeah.

Felicity: - before we ever had our school [online assessment] program. So Aaron: How long ago was that, that he showed you that?

Felicity: Oh my gosh. Um, again, we've only had [the online grading program] at our school for maybe, I'm trying to think back. Actually, I had a high school kid, um...help 
me with my [it]. I had a senior helper. Um, it, it, it's probably less than you think. I think about, probably ten years ago I started using Excel or whatever.

Aaron: Yeah.

Felicity: You know? It was available. I'm trying to think. I remember Excel 2010 for sure...But I was using a digital gradebook...before it was mandatory -

Aaron: Yeah.

Felicity: - at our school...Yeah, it calculated the grades for me! [laughs]... It saved me a lot of time!...I got lucky having a husband that's an engineer...because he has, I mean, he uses formulas all the time. (personal communication, April 30, 2019)

Likewise, Felicity is also willing to share her approaches for designing instruction in which she integrates technologies with others. Moira, Felicity’s current grade level colleague, had noticed I was observing in Felicity's classroom and asked her about why I had been there. Their conversation led to some student-led professional development of sorts, as shown in the following interview exchange:

Felicity: But I will tell you, um, my co-teacher Moira, who you met Aaron: Mm-hmm.

Felicity: - who's a little bit older than me, so we're both from kind of the dinosaur age here. Um, she did allow my first graders to teach her first graders how to read and record. Aaron: When did that happen?

Felicity: That happened last week.

Aaron: How'd it -

Felicity: She -

Aaron: go? 
Felicity: - goes, "So, what is, what is all this that you're doing with Aaron?" And... Aaron: [laughs]

F: "Well you know," I said, "that's, that's great you ask." And I have told her about it before, but she just, she's a little bit more nervous about the technology side of things. So, I, uh, I said, “You know what?” I said, "We don't need to teach them. Let's have students student teach." So the first day, um, they all came in my room. It was loud, but that's okay, and they all practiced reading. And then my class did the managing of the iPad and talking. So I told 'em they could touch, but they had to tell them what they were touching. And then the second day, we split into two groups -

Aaron: Mm-hmm.

Felicity: - and half went in her room, and my class only talked and her class got to do all the touching on the iPad.

Aaron: Okay.

Felicity: And now she's recording too.

Aaron: Wow!

Felicity: I know.

Aaron: Well that's exciting. Our worlds are colliding a lot more than I intended but in a good way. That's good.

Felicity: Yes. (personal communication, March 14, 2019)

In our final interview, Felicity and I discussed how she developed her willingness to try new teaching approaches with different digital technologies. She explained that while her experiences with technology from a young age were a contributing factor, she ultimately considers the needs of her students and extended classroom community when designing 
instruction. In a way, she views her teaching with technology fluidly, knowing that there are new digital technologies she can use; however, she wants to intentionally and effectively utilize the ones she ultimately chooses to implement:

When I went to first grade with my co-teacher Cecille, she's ten years older than me. And it scared her to death. She still did a handwritten newsletter. And $I$ already did 'em in Excel. It was a big thing. It was like, “Ooh! Ahh!” So, I had these different squares, and I could put in any information and she was like, "Do the newsletters. I don't wanna' touch 'em." And, so I still do a weekly newsletter. But, um, that's my next adventure, is to go to...having it so that parents don't have that little piece of paper coming home. So many of them still like that. So if we try to get them to go more green, and it would be so much easier for me...to have [an online] page. And I don't know yet how I'm gonna' do that. I don't know if I'm gonna' have, like, a blog. I don't know if I wanna' have a web page. I don't know...They say on the school website, we could access that way as well. I just haven't taken that next step...So, I haven't made the leap, but I'm not scared to make the leap. It's more about...understanding it and making sure that it fits...my needs and the parents' needs. So, we'll see where I go in the future. (personal communication, April 30, 2019)

\section{Iris}

\section{Iris's Classroom: March 2019}

When I arrived to Iris's classroom (Figure 3) in March 2019, the first of her two sections of fifth graders were entering her sports-themed classroom and getting situated at their clustered rows of desks that perpendicularly faced Iris's Promethean board. Iris had her long curly brunette hair, which featured subtle highlights, tied in a partial ponytail. She wore a purple and black long 
sleeve shirt, black pants, and black flats. A few months along in her pregnancy at the time with her second child, Mia, Iris was comfortably dressed for the unseasonably cold weather and ice rain that was falling outside of her classroom windows that morning. Her put-together, yet relaxed, style mirrored the atmosphere and tenor of the classroom.

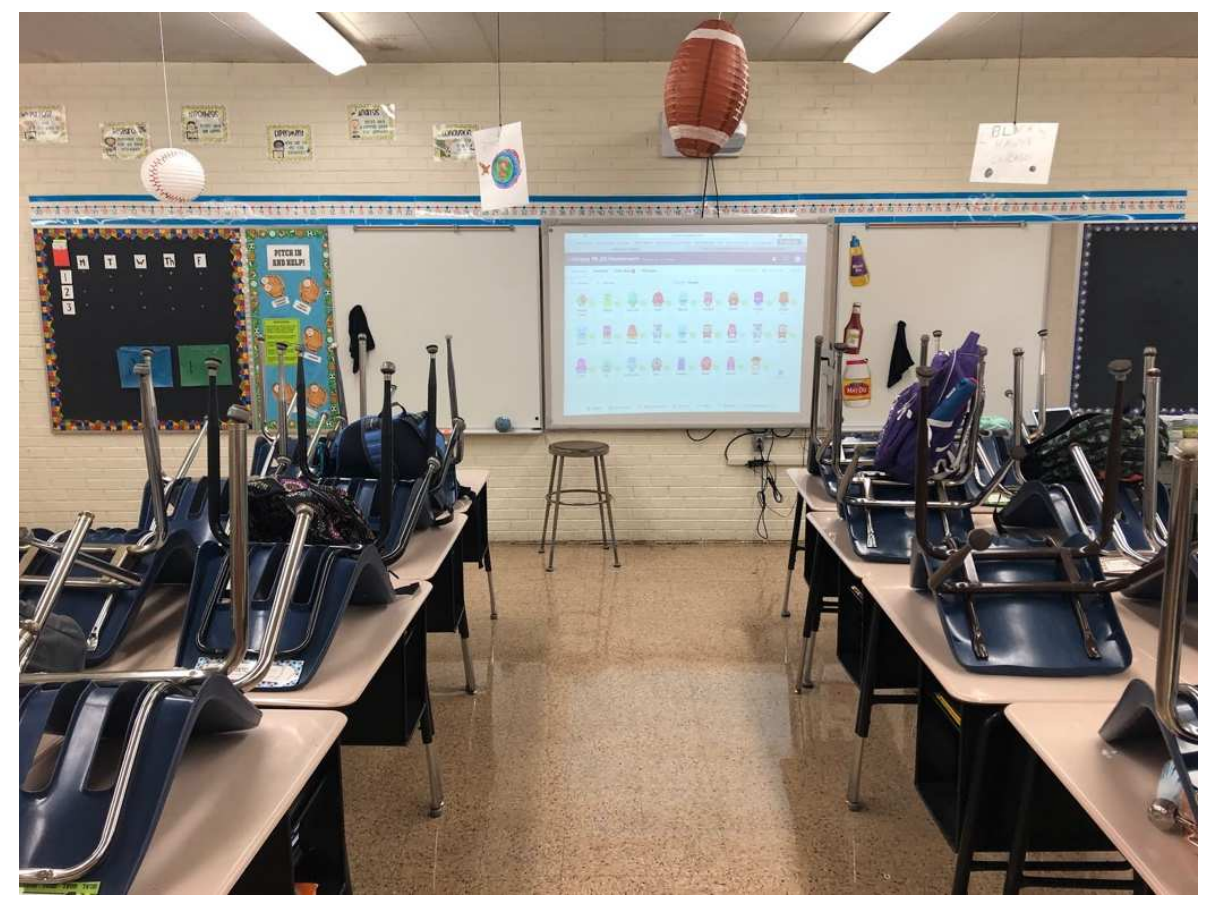

Figure 3. Iris's fifth grade classroom

Iris began the lesson with a brief review conversation with the class to situate the events of the Boston Massacre in the context of the looming Revolutionary War. "After the French-andIndian War...the colonists win...Let's start from the beginning here," said Iris. "Who's fighting the French and Indian War...The Indians are on the French side...Initially, the French and the Indians are winning."

It became clear based on some responses to Iris's guiding questions that several students needed additional clarification on the historical background of this time period from their recent 
social studies learning. Iris attempted to illustrate the building tension at this time between the colonies and England with an analogy:

So hooray, now the Ohio River Valley and all this territory belong to the colonists...The Native Americans get upset and they have a rebellion...Remember, I said it's like blowing up a balloon...It's getting bigger and bigger and eventually it's going to pop. King George upsets the colonists even further, because what act does he pass?

Iris called on a student who explained that King George passed the Stamp Act and discussed its implications. After some more introductory discussion and vocabulary review, Iris began to introduce the primary (e.g., testimonies) and secondary (e.g., photographs, news articles) sources that the students would access and analyze digitally from her blog. The work packet in which students recorded their analyses and responses included questions that required the students to a) explain if the source they were using was primary or secondary, and b) analyze the presented perspectives as it relates to what actually happened at the Boston Massacre.

Iris led the students in a whole class analysis of the testimony of Captain Thomas Preston as guided practice for the work they would complete within their table group clusters. She began reading aloud the testimony from her Promethean board. She stopped intermittently to clarify and explain parts of the testimony, such as asking the students what a bayonet was, for example. Then, Iris asked, "Is this a primary source or secondary source?"

When a student responded that this was a primary source, Iris confirmed this thinking. "He was there," Iris responded. "He was a part of it. He witnessed it. He was in charge of the loyalist sources that were there." 
Iris led the students in completing their remaining responses in their work packets utilizing this primary source as evidence, but also reminded the students that the catalyst of the Boston Massacre appears quite inconclusive. "So this is from his perspective," Iris noted, "but we're going to be reading other people's perspectives too."

Next, Iris displayed her blog on the board and previewed the links she posted in the social studies section for this activity. Then she said, "Okay, I'll call up groups once I'm ready. Go ahead and get started."

This page featured a title banner at the top of several of her students posing and smiling wildly. Several links in red font for the day's activity were typed on separate lines and aligned on the left side of the page. Links from previous activities were included below, denoted by text headings in black font.

I walked around the room and observed students accessing sources from the four links on Iris's blog. Some were talking with their neighbors at their tables and others chose to work more quietly and independently. I heard students using focal vocabulary from this unit of study that Iris previewed before the lesson, such as "loyalist."

While the students began working, Iris was setting up a mock crime scene by her board. She displayed printed papers, rocks, crumpled papers, and a baseball bat on the floor in front of the board with a picture of downtown Boston projected on the Promethean. I asked her to share the origins of this activity. She thought the work packet was something she purchased from Teachers Pay Teachers, while the crime scene ideas came from Pinterest. I later asked Iris why she designed a component of this activity in which students had to work collaboratively and disconnect from their ChromeBooks. She explained that she liked doing these types of primarily 
non-digital activities to "get them out of their seats so they aren't on the ChromeBooks the entire time."

After checking in with students as they continued analyzing and writing responses about the sources linked on her blog, Iris taped a final printed page on red construction paper backing on the board and then announced that the crime scene was ready. "Anything in red, make sure you read those exhibits," Iris said. "It will help you form your opinion...These are snowballs," she noted as they held up one of the crumpled papers.

She called up the "Steelers," one of the defined desk groups - denoted by signs hanging from the ceiling - in her classroom. A group of four students approached the crime scene and began viewing and discussing the items in the 'crime scene' with Iris and each other. The other students continued their investigation work at their seats. I approached the crime scene as Iris discussed the context with the students and elicited their interpretations. Some of the papers in the crime scene had a chalk outline of a dead body surrounded by yellow crime scene tape in the printed picture. The signs said "DEAD" in large letters and provided the name of someone who died in the Boston Massacre, such as 'James Caldwell' and 'Crispus Attucks.' Iris called new groups up to participate in this brief activity every three minutes or so.

As the social studies block concluded for this first section of fifth graders, they put away their in-progress packets to finish on another day and filtered out as the second section arrived. Iris then introduced and facilitated the same activity again, this time with additional previewing and scaffolding. She explained to me later that the two sections were leveled by ability at the beginning of the year: 
Teaching it twice is, I actually enjoy it, [although]...the second class always gets the better lesson, just 'cause I've worked out the kinks...with the first group. But my first group is the higher group, so, you know, it's kind of okay, 'cause they can always kind of pick up, um, more easily the next day...Essentially, it's the same lesson; it's just delivered sometimes in a different manner. (personal communication, April 23, 2019)

With the second section of students, Iris took much more time to preview events leading up to the Revolutionary War than she did with the previous group. She also provided much more whole class guidance and elicited more discussion from the students in the practice analysis of Captain Preston's testimony. "We're going to do some of these testimonies together," Iris announced to the class, "so open up to Evidence 2 [which] should be at the top......You guys are gonna' decide if he was telling the truth - if he did not give the order [to fire]."

In a conversation about a month after she taught this lesson, Iris reflected on her differentiation of the Boston Massacre learning activities:

I kind of saw what the first group were struggling with, and I thought, "Okay. If [the higher group is] struggling with this, then my lower group are really going to struggle with it." So, it's a point that I need to make, you know, as a whole group....and visit that topic before they get started independently. So I think it's helpful in that manner, and like I said, it, it's the same objectives just kind of taught differently. (personal communication, April 23, 2019)

Iris pointed out more details in the testimony with this group, such as how the photo was dark, indicating that the events of this testimony occurred during the night time. "So what he thought was for fire...the guard that came said, 'No, they're going to get together and plan an attack on us,", Iris noted. 
Iris continued this much more deliberate approach with this group, comprised of some struggling readers and writers, as she introduced the rest of the investigation activity. "You are going to be the jury...When you read their testimony, you're going to be like, 'Are they telling the truth?...Were the patriots using self-defense, or are the loyalists cold-blooded murderers?'” After completing the first analysis with the students as a whole class, Iris previewed each of the other linked sources from her blog at the Promethean board. She explained some of the abbreviations used on the links and described the photographs the students would view, something she did not do with the first group:

This is an engraving that Paul Revere made, although as you will read, his friend Henry actually drew up a picture first...Kinda' scroll down. Do you think that these people here lined up are loyalists or patriots?...How did you know?...Their red coats! Loyalists wore red coats. According to this, it kind of looks like they lined these loyalists up and fired on a crowd of people...We have some patriots bleeding. Some of them look like they are oozing blood...Notice how this one makes the loyalists in bright colors and the colonists in black and white...That's why we study history so we don't repeat our mistakes. Before allowing the students to officially begin analyzing the primary and secondary sources at their desk clusters, Iris gave this group a few final instructions that she did not provide to the first section of fifth graders:

Don't worry about Evidence 3. We'll do it tomorrow...I encourage you to talk to your neighbors...anything you don’t understand, your opinions, anything to help you fill out your investigative notebook...If you are stuck, raise your hand...If you are waiting, you may want to ask a neighbor and see if they can help. 
The students began to start their work and Iris immediately began checking in with each table before initiating the crime scene activity again.

\section{Iris's Journey}

Iris, a lifelong Steelers fan, was born in Pittsburgh, Pennsylvania, and lived there until her family moved to Delaware when she was two years old for her father's job. After living there for about seven years, Iris's family relocated to the suburbs of Chicago where she spent the rest of her childhood and adolescence until departing for college in Central Illinois.

After completing her degree, Iris accepted a fourth grade teaching position in a large metropolitan city on the east coast. The position was attractive to her because she had "always wanted to live there," and her father had also just been transferred to a position in this area "[so] everything just kind of fell into place” (personal communication, January 24, 2019).

After one year in on the east coast, Iris returned back to the Chicago suburbs to be closer to her then-boyfriend, Roy, whom she would eventually marry. Iris explained that when she returned to Illinois, she had a really difficult time finding a full-time teaching position. She took on a one-one-one aide position with a third grade special education student in a somewhat affluent Chicago suburb in for her first year back. Then, Iris served as a long-term substitute teacher for two different maternity leaves that lasted most of the following school year.

Iris relocated to Iowa in 2011, because Roy accepted a position with a large agricultural engineering company. She took a job as a third grade teacher on the other side of the Mississippi River in a small, rural Illinois district. After four years, she transferred to a fifth grade opening in another elementary building in this district.

When Iris was hired in this Illinois district, she had not previously taught in a classroom setting in which each child was equipped with their own device, not even as a student herself. As 
a second grader in Delaware, Iris recalled her school's PTA funding their first computer lab where her class "[went] in and [used] the big, old school box computers...typing up stories" (personal communication, January 24, 2019).

She also shared memories of when her family purchased their first computer:

I remember it was $1995 \ldots$.. [and] for Christmas, we got...a desktop computer and that was, like, huge back then. A big ol' giant box in the family room! And at that point, it was just like, you know, computer games were popular then. So, like Animaniacs, playing on the computer. (personal communication, January 24, 2019)

In middle school, Iris began to use technology in her social life, including the AOL Instant Messenger (AIM) application:

So middle school was when AIM was becoming a thing, because I remember using that to talk with friends, or to people - this sounds super unsafe - but, like [laughs] going on, like, the group chats of like random strangers. I remember going on, like, a Tara Lipinski fan webchat.

In her experiences as a middle school student, Iris engaged in word processing practice "with Microsoft Word and how to copy, paste, edit - simple things that our kids are doing now" (personal communication, January 24, 2019).

Even through high school, Iris did not remember any of her peers owning their own personal device. Finding resources for school projects mainly involved utilizing print media at the library through her middle school years. By high school, "that's when a lot of the research was done...on our own," Iris said. "Sometimes time was allotted for us to use [the computer lab] then during class...but I feel like it was mostly on our own" (personal communication, January 24, 2019). 
As an education major in college in Central Illinois, Iris observed and student taught in schools with similar computer lab setups to those from her previous experiences as a student. She had even less access to technology during her year teaching on the east coast. "They had some computers set up in the library, but... [this district]...just didn't have the money to... to spend on technology" (personal communication, January 24, 2019).

Upon being hired in her current district in rural Illinois, Iris understood right away that the availability of technology would be unlike her previous teaching contexts:

I never used an iPad before, and in my interview [they] asked, "You know, we have iPads. How would you use them?" And I know that I really struggled with that question, because...I had really no...experience with them...[I] had a basic understanding of them and tried to pull stuff that way, you know, using educational apps, but really...the one-on-

one device was not until I came [here]. (personal communication, January 24, 2019)

By the very nature of the one-to-one technology infrastructure of her new district, Iris had ample devices available to integrate technologies consistently in her instructional design; however, she also needed individualized support to learn about digital resources and pedagogical approaches, as these were not approaches she had previously utilized for designing instruction.

\section{Iris's Pedagogical Design}

When Iris began teaching third grade in rural Illinois, the district had just transitioned two classroom teachers to serve as full time technology coaches at the elementary level. Iris was required to meet weekly with her assigned coach, Oliver. She described Oliver as "a huge resource" and helped her understand "how I could...use [one-to-one iPad Minis] for an educational purpose, not just, 'Hey, if you get your work done early...you could play an app on the iPad"' (personal communication, January 24, 2019). 
Iris shared a story with me from one of her first years of teaching third grade about a simple machines science report project she designed with Oliver:

So they had to pick a simple machine, and then it was, like, a trading card that they created. So, uh, like, a picture, how it was used, you know, how it was made...the different parts of the simple machine. Um, so really I would say through those meetings...I would tell him what we were doing in the curriculum. Kind of throw out ideas, and then he had the knowledge of all the apps that, you know, that would work well with what my ideas were. (personal communication, January 24, 2019) Iris felt a certain level of expectation from administration to integrate technology in her instructional design efforts, because the district had invested funds for the one-to-one technology implementation in addition to the coaching role and weekly meetings. "The fact that they were asking about it in [my initial job] interview," Iris mentioned, "I knew it was important to them" (personal communication, April 23, 2019).

However, Iris viewed this expectation somewhat positively, as she felt it extrinsically pushed her to plan ahead and find with which instructional objectives from the curriculum she could leverage digital technologies. However, Iris felt there were also drawbacks to the weekly technology coaching meetings, as it forced technology into her instructional design at times she would have otherwise chosen non-digital approaches:

I was [just] coming into the district. I wasn't comfortable with the curriculum yet...One of the downfalls of it was there wasn't always something to meet about on a weekly basis. So sometimes I felt like I was always kind of scrounging for things...But Oliver was really great about just kind of introducing me to apps or ideas that he had...But I did feel...pressure, because we were required to have these meetings to come up with 
something. At the time, I just...didn't have a place for it in my instruction. (personal communication, April 23, 2019)

Iris collaborated with Oliver for "at least three [years], if not four," until the school district "got rid of the [coaching] position" (personal communication, January 24, 2019).

After the district stopped providing formal technology coaching, due to deficit spending as a result of state underfunding, Iris still utilized templates and project ideas in her instructional design efforts from her work with Oliver; however, she felt less accountable to seek out new technologies and approaches with the students' iPads:

You felt like you had to come to the table with something, or else it's a pointless meeting. So when you don't have that scheduled meeting, you tend to kind of use that time for something else that's going on in your classroom - grading, or planning - instead of taking time and saying, "You know, I'm going to spend these 30 minutes trying to figure out how I can integrate more technology.” Especially when I have, you know, three years of ideas to fall back on. (personal communication, January 24, 2019)

Iris wanted to push herself more independently to integrate new digital technology approaches in her instructional design, but the lack of formal expectations and support along with time constraints made this challenging. With regards to her teaching practices and pedagogical design efforts, she was engaged in dialogue with a variety of factors and pushing new technologies into the mix became less of an immediate priority. She drew upon her thencurrent digital pedagogy, attending to other demands on her time rather than incorporating new approaches with technologies into her instruction.

When Iris transitioned to teach in a new building in her district in 2015 , there were two sections of fifth grade classes. Iris's new fifth grade colleague, Caitlin, primarily taught 
mathematics, so Iris was mainly responsible for teaching social studies and science. Both of them taught English language arts for their respective 'homeroom' groups. This new role appealed to and motivated Iris, because her father had instilled a passion for U.S. and world in her when she lived in Delaware:

He used to take us everywhere. Like, Washington D.C., Gettysburg. I've seen [the] Liberty Bell. I've seen Plymouth Rock...And so, I've just kind of carried on with that. So I've loved learning about our history, and not even necessarily United States alone. Like I love, it sounds morbid, but I loved learning about the Holocaust...He really kind of instilled that passion...so it's just kind of stuck with me, so I...try and instill that passion with my students. (personal communication, March 12, 2019)

In the school years that followed, she began to integrate technology much more consistently for a myriad of purposes, particularly in the area of social studies. First, Iris developed her classroom blog site over the past few years, when she "became a little more comfortable with the fifth grade curriculum" (personal communication, March 8, 2019). Iris's evolving design and integration of her blog highlights her shifting perspectives on integrating digital technologies in her instructional design efforts towards tasks led by the students themselves:

We were required to have the blogs, really, when I started teaching here eight years ago. But it's definitely evolved over time, you know. But, actually, with third grade, I didn't have them...[use] my blog to get assignments. I would post [audiobooks] that we would read... And now it's definitely more student-centered with fifth grade and I really kind of just took that all when I moved to fifth grade four years ago. (personal communication, March 8, 2019) 
In many social studies activities, such as the one I observed about the Boston Massacre, Iris posts digital content her students access on her blog for their classwork. "I think it prepares them...to get into middle school," Iris said, "[and] it's just more...student-centered finding the information than...just, you know, lecturing it to them" (personal communication, March 8, 2019).

As another example in which her students conducted online research, Iris had her students complete a Native American tribe research project that she developed in recent years. Her district-issued social studies textbook "goes over, maybe like, three different tribes, briefly" (personal communication, March 12, 2019).

Therefore, Iris expanded the scope of this unit of study, so the fifth graders could choose from a list of 20 tribes to research online, creating a multimedia presentation using the opensource Adobe Spark web resource. Iris provided the students with a note-taking template sheet (Figure 4) on which they would each handwrite notes from their online research about their tribe of choice.

Iris also provided students with a rubric (Figure 5) for this project. "I always show them the rubric, so they're not surprised when they're graded... [They also use the rubric] when we're editing the work...so they can keep referencing in case they need to make some changes" (personal communication, March 12, 2019).

Such projects stemmed, in part, from grade level curricular revision efforts about three years ago between Iris and her fifth grade colleagues to compensate for a social studies textbook she described as "completely outdated" (personal communication, March 8, 2019): 


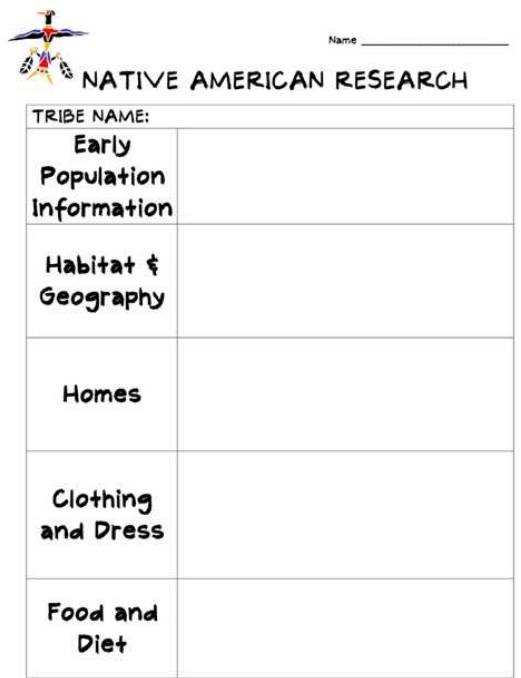

\begin{tabular}{|c|}
\hline TRIBE NAME: \\
Customs \\
Tools/ \\
Weapons \\
\hline $\begin{array}{c}\text { Art and } \\
\text { Artwork }\end{array}$ \\
\hline $\begin{array}{c}\text { Famous } \\
\text { Native } \\
\text { Americans }\end{array}$ \\
\hline $\begin{array}{c}\text { Interesting } \\
\text { Facts (at } \\
\text { least 3!!) }\end{array}$ \\
\hline
\end{tabular}

Figure 4. Iris's Native American research guide template

There will be very important parts of our history, and they'll just be given, you know, a couple sentences about it. And, after getting approval from administration, as the whole fifth grade across the district, we had decided to eliminate some of the things...that we were originally expected to teach...We really just focus on U.S. history... [and] have narrowed it down to what we think they need to take away as fifth graders so that they can go more in depth with important parts of our history. (personal communication, March 8, 2019)

Iris acknowledged that her passion for history remains in constant dialogue with her design of social studies and use of technology to make her students' learning more relevant and impactful: 
Native American Project Rubric

\begin{tabular}{|c|c|c|c|c|}
\hline & $\begin{array}{l}1 \text { - Need to } \\
\text { Improve }\end{array}$ & 2 - Getting There & 3 - Nicely Done & 4 - WOW! \\
\hline \multicolumn{5}{|l|}{ Slideshow } \\
\hline \multicolumn{5}{|l|}{$\begin{array}{l}\text { All required } \\
\text { information is } \\
\text { present }\end{array}$} \\
\hline \multicolumn{5}{|l|}{$\begin{array}{l}\text { Information is } \\
\text { accurate and } \\
\text { thorough (x2) }\end{array}$} \\
\hline \multicolumn{5}{|l|}{$\begin{array}{l}\text { Pictures are } \\
\text { present on } \\
\text { required slides }\end{array}$} \\
\hline \multicolumn{5}{|l|}{$\begin{array}{l}\text { Pages are free } \\
\text { from grammatical/ } \\
\text { spelling errors }\end{array}$} \\
\hline $\begin{array}{l}\text { Completed on } \\
\text { time }\end{array}$ & No & Yes & $x$ & $x$ \\
\hline \multicolumn{5}{|l|}{$\begin{array}{l}\text { Information is } \\
\text { presented in an } \\
\text { appealing manner }\end{array}$} \\
\hline \multicolumn{5}{|l|}{$\begin{array}{l}\text { Slides are in } \\
\text { sequential order } \\
\text { according to } \\
\text { packet. }\end{array}$} \\
\hline \multicolumn{5}{|l|}{$\begin{array}{l}\text { Presentation Skill: } \\
\text { loud, clear voice }\end{array}$} \\
\hline \multicolumn{5}{|l|}{ Model } \\
\hline $\begin{array}{l}\text { Commitment form } \\
\text { turned in on time }\end{array}$ & No & Yes & $x$ & $x$ \\
\hline $\begin{array}{l}\text { Model turned in on } \\
\text { time }\end{array}$ & No & Yes & $x$ & $x$ \\
\hline \multicolumn{5}{|l|}{$\begin{array}{l}\text { Model is neat, it } \\
\text { was clear that time } \\
\text { was spend on the } \\
\text { project }(x 2)\end{array}$} \\
\hline $\begin{array}{l}\text { Paragraph is } \\
\text { written with } \\
\text { complete/accurate } \\
\text { infrormation }\end{array}$ & & & & \\
\hline
\end{tabular}

Total Points:

Figure 5. Iris's Native American tribe Adobe Spark rubric

I like to incorporate activities that are meaningful, that they're going to take away something from this, and it's important that they do, because it's our country's history.

So the technology, I feel like, is more engaging...Rather than just reading from the 
textbook...they're able to also do things, kind of, at their own pace, their own comfort level...I'd say it's easier for me to get the information out to them without just...lecturing ...so they're just, you know, more invested in their own learning. (personal communication, April 23, 2019)

Iris designs social studies activities so her students can utilize digital technologies to regularly engage in self-paced learning. In the activity I observed Iris implement about the Boston Massacre, she provided the primary and secondary source material digitally so the students could access them independently, as-needed. A few weeks after observing the Boston Massacre learning activity, I asked Iris why she shared the testimonies and photographs with the students on her blog instead of providing them with printed copies. She had several reasons for taking a digital approach to facilitate for situated practice and meaning-making opportunities with historical artifacts.

First, as a matter of simple practicality, she explained that digitally, the students could view all of the sources in color, since the school only has a black-and-white printer:

I think it's really important that they look at the color that was on that war propaganda...They specifically choose certain colors, and there's a...purpose behind everything that an artist [creates]. So I wanted them to see everything in color, and I also want them to have the ability to zoom [in] and then look at things more closely. (personal communication, April 23, 2019)

A story Iris shared about a recent lesson on 9/11 highlighted the affordances she has found in designing learning experiences involving digital image analysis:

[I brought] up pictures of, "This is what the skyline used to look like. This is what it looks like now. This is how we...remember the survivors. And this is how we remember 
the people that lost their lives - heroes." So I like to show them photographs...of those types of things. Like I said, $[\mathrm{I}]$ just extended my lessons beyond the textbook, and a lot of times, that...involves, um...you know, using technology...because I want them, I don't want to just lecture to them. I want them to actually see it so that they remember it. And then hopefully, that's something that would spark an interest, and they would talk about it at home. Especially 9/11, because their parents lived through it. (personal communication, April 25, 2019)

Next, sharing the sources digitally helped Iris's students toggle between their paper-based work packets and multiple sources, some of which were several pages in length:

I wanted them to have the ability to really see that closely and analyze it, which would be better done on a computer screen. And then it allows them to kind of, I mean, I guess you could do it with paper. I just feel like the paper, there was so many testimonies that they needed to look at. I feel like it was more organized on the computer of just opening the tabs and then clicking back to the tabs that they [needed]. (personal communication, April 23, 2019)

Iris recognized that her students could analyze the primary source images more effectively in color to meet their learning goals. Likewise, sharing the images digitally was much more pragmatic, organized, and efficient than printing numerous copies of limited, non-color resources. She also based her decision to share the sources digitally based on her experiences as a teacher as well as a student:

You know, in the past, the first year I did something similar to this. I had stations. So there would be paper copies at each station. Then you'd have some kids that would read faster than others. So then they'd be ready to move to the next station, but then there's 
not a seat for them. And then they'd get to chatting with the people that are right next to them, because they have to pull up a chair...This definitely seems like a more organized manner. Then they can just move more at their own pace and not feel that pressure that I know that $I$ used to feel as a student when I would see people, you know, even in college, like turning in their papers or, um, their tests before me, because I'm a slow test-taker. And feeling that pressure, like, “Oh my gosh! I'm not done yet! I'm not done yet! They must be better at this." Where [in the Boston Massacre activity] they don't have to physically transition, so they can kind of just be comfortable at their own pace, 'cause they don't have to do what everyone else is doing. (personal communication, April 23, 2019)

Iris's enacted pedagogy was in dialogue with voices of the past - her case knowledge from years of teaching experience and feelings of being overwhelmed and rushed as a student herself.

Iris shared several factors and experiences she found influential in her journey towards designing more activities involving digital technologies. For example, when she transitioned to teaching fifth grade, Iris pushed herself to create more student-centered learning opportunities as part of her professional growth plan with the school district:

At the beginning of the year, we [had] to come up with a goal for administration, and obviously for ourselves, of how we would like to grow and improve during the school year...My goal was to create a unit...that was more student-centered...By fifth grade, I'm trying to prepare them for middle school, and I don't want it to be me that's always the person relaying information to them. So I wanted them to work more independently and have them motivated. (personal communication, March 12, 2019) 
In her work towards this meeting goal, Iris created a choice board with "nine to 12 different activities to choose from" (personal communication, March 12, 2019) in a unit of study about the original American colonies.

One of the choices on the board that involved the use of digital technologies by the fifth graders was to create a brochure from the perspective of an American colonist. Students picked a region or specific colony and utilized a set of linked sources Iris curated on her blog, as well as two print-based biographical texts, to research colonial life. If students located digital images they wanted to print and glue on their brochure, they could email them to Iris to send to the school's printer. Using the information, students "had to pretend that they were living in the colonies, and they were...sending a brochure to their families in England" (personal communication, March 12, 2019).

With this particular group of fifth graders, however, many students struggled in satisfactorily completing tasks they chose from the board, and ultimately, Iris phased out the use of choice boards with that class:

I felt like they...had a lot of questions about the directions...You had some kids aiming for a lower grade. [Many would] get confused because they'd think like, “Oh, I'm doing these...three or four projects. That's, you know, fifty-some points. That's a $B$ !' I'm like, "No. You're not guaranteed that grade. You have to...earn it. You have to turn in B work. It doesn't mean because you did those activities, that's the grade that you get." While the choice board format to designing and grading learning activities did not always work out in implementation, Iris continued to develop effective assessment approaches in her design of digitally-mediated instruction. She successfully completed the National Board Certified Teacher (NBCT) program, submitting her final paperwork in late 2017 while she "was 
actually having contractions" (personal communication, March 12, 2019) preceding the birth of her son, Malcolm.

As part of her work for NBCT in a component centered on differentiation and student growth, Iris and Caitlin developed a rubric (Figure 6) that she regularly uses to assess fictional writing compositions from her students.

So we'd actually both, since we were both doing National Board at the same time...wanted to make our own rubric. We definitely pulled from other resources, kind of looking online at rubrics that people used, and then we came up with what we thought would be most appropriate for our students...And these are all categories that we focus on...[what] we do [by the] third quarter...By then, they've had lessons on how to use dialogue and write with voice...and [proofread] their work for spelling and grammar mistakes. (personal communication, March 12, 2019)

Iris used this rubric in a recent digital writing activity with her fifth graders. "I posted...three pictures [on my blog]" Iris told me, "and they got to choose which picture was kind of like their prompt to write a story around" (personal communication, March 12, 2019).

The students composed their narrative piece using Google Docs. "After they typed it, they emailed it to me," said Iris. "And then, I...print it out for them and attach it to the rubric and send it home" (personal communication, March 12, 2019).

Iris finds that providing rubrics to students helps establish clear expectations in advance, given the expanded options her students can and do utilize when composing digital media on apps such as Google Docs, Adobe Spark, and iMovie. The rubric supports Iris's overt instruction as she guides students in using technologies to create media and develop core literacy and digital 
literacy skills; also, the rubrics guide Iris's students to use digital technologies in purposeful ways rather than customizing or editing their multimedia content just for the sake of doing so.

For example, in sharing about her students' fictional narratives, Iris explained some of the fifth graders changed the color of the font in their writing without reasons for how this effectively or purposefully enhanced or transformed their writing in ways unique to digital multimedia.

\begin{tabular}{|c|c|c|c|c|c|}
\hline Ideas & Organization & Voice & Word Choice & $\begin{array}{l}\text { Sentence } \\
\text { Fluency }\end{array}$ & Conventions \\
\hline $\begin{array}{l}5 \text { - Includes } \\
\text { interesting details } \\
\text { throughout the } \\
\text { entire story. Always } \\
\text { on topic. }\end{array}$ & $\begin{array}{l}5 \text { - All ideas are in } \\
\text { sequential order. }\end{array}$ & $\begin{array}{l}5 \text { - Writer's voice } \\
\text { creates an } \\
\text { unforgettable } \\
\text { experience and } \\
\text { dialogue is used } \\
\text { throughout. }\end{array}$ & $\begin{array}{l}5 \text { - Specific nouns, } \\
\text { adjectives and } \\
\text { verbs are used } \\
\text { throughout the } \\
\text { entire story. }\end{array}$ & $\begin{array}{l}5 \text { - Sentences are } \\
\text { skillfully written and } \\
\text { original. They keep } \\
\text { the reader's } \\
\text { attention. }\end{array}$ & $\begin{array}{l}5 \text { - Grammar and } \\
\text { punctuation are } \\
\text { correct and the } \\
\text { writing is free of } 5 \text { th } \\
\text { grade spelling } \\
\text { errors. }\end{array}$ \\
\hline $\begin{array}{l}4 \text { - Includes } \\
\text { interesting details } \\
\text { throughout most of } \\
\text { the story. Always } \\
\text { on topic. }\end{array}$ & $\begin{array}{l}4 \text { - Most ideas are } \\
\text { in order and the } \\
\text { story can be easily } \\
\text { understood. }\end{array}$ & $\begin{array}{l}4 \text { - Interest is } \\
\text { created and } \\
\text { dialogue is used. }\end{array}$ & $\begin{array}{l}4 \text { - Specific nouns, } \\
\text { adjectives and } \\
\text { verbs are used } \\
\text { throughout most of } \\
\text { the story. }\end{array}$ & $\begin{array}{l}4 \text { - Sentences show } \\
\text { variety and are } \\
\text { easy to read and } \\
\text { understand. }\end{array}$ & $\begin{array}{l}4 \text { - There are } 1-2 \\
\text { minor errors in } \\
\text { grammar, } \\
\text { punctuation and } \\
\text { spelling. }\end{array}$ \\
\hline $\begin{array}{l}\text { 3-Includes some } \\
\text { details throughout } \\
\text { the story. }\end{array}$ & $\begin{array}{l}3 \text { - Some ideas are } \\
\text { out of order } \\
\text { interrupting the flow } \\
\text { of the story. }\end{array}$ & $\begin{array}{l}3 \text { - The voice } \\
\text { creates interest, but } \\
\text { more dialogue is } \\
\text { needed. }\end{array}$ & $\begin{array}{l}3 \text { - Specific nouns, } \\
\text { adjectives and } \\
\text { verbs are used } \\
\text { throughout some of } \\
\text { the story. }\end{array}$ & $\begin{array}{l}3 \text { - Sentences are } \\
\text { varied, but should } \\
\text { flow more } \\
\text { smoothly. }\end{array}$ & $\begin{array}{l}3 \text { - There are } 3-4 \\
\text { errors in grammar, } \\
\text { punctuation and } \\
\text { spelling. }\end{array}$ \\
\hline $\begin{array}{l}2 \text { - Includes few } \\
\text { details throughout } \\
\text { the story and } \\
\text { moves away from } \\
\text { the topic. }\end{array}$ & $\begin{array}{l}2 \text { - Many ideas are } \\
\text { out of order } \\
\text { interrupting the flow } \\
\text { of the story. }\end{array}$ & $\begin{array}{l}2 \text { - The voice is } \\
\text { weak and more } \\
\text { dialogue is needed. }\end{array}$ & $\begin{array}{l}2 \text { - Very few nouns, } \\
\text { adjectives, and } \\
\text { verbs are in the } \\
\text { story. }\end{array}$ & $\begin{array}{l}2 \text { - Very little variety } \\
\text { in sentence } \\
\text { beginnings. }\end{array}$ & $\begin{array}{l}2 \text { - There are 5-6 } \\
\text { errors in grammar, } \\
\text { punctuation and } \\
\text { spelling. }\end{array}$ \\
\hline $\begin{array}{l}1 \text { - Doesn't include } \\
\text { details and goes off } \\
\text { topic. }\end{array}$ & $\begin{array}{l}1 \text { - Order does not } \\
\text { make sense } \\
\text { interrupting the flow } \\
\text { of the story. }\end{array}$ & $\begin{array}{l}1 \text { - No dialogue is } \\
\text { used throughout } \\
\text { the story. }\end{array}$ & $\begin{array}{l}\text { 1- General and } \\
\text { over-used words } \\
\text { are used, which do } \\
\text { not paint a clear } \\
\text { picture. }\end{array}$ & $\begin{array}{l}1 \text { - Sentence } \\
\text { beginnings are } \\
\text { repetitive and } \\
\text { writing is choppy. }\end{array}$ & $\begin{array}{l}1-7 \text { or more } \\
\text { mistakes that make } \\
\text { the story confusing } \\
\text { and hard to read. }\end{array}$ \\
\hline
\end{tabular}

Figure 6. Iris's fictional writing rubric developed as part of NBCT work

In several of our conversations, Iris likened this technocentric mindset of students to the amount of screen time in which today's youth regularly engage. "All the kids have screen time...out of the womb," (personal communication, March 6, 2019) Iris remarked in our focus group conversation. 
Iris, several months pregnant at the time of our final interview in April 2019, lamented the amount of screen time her own son had been given in recent months and related it to her perception of her students' technology use:

"I do think that there's too much screen time, and I'll have to say, like, being pregnant right now, Malcolm's had more screen time the past couple months than he has his whole life. 'Cause...survival mode for me!...As a parent, I'm just kind of more aware now, and especially when [students] just talk about video games and all this...I'm in my eleventh year teaching and I see a change in their behavior and their ability to focus on a task for an extended period of time. Which goes back to screen time. I would say I'm probably a little more sensitive to it now, being a mom...[With my students], I do try to balance. I don't want everything on a screen, just because I know that they go home and they have a lot of screen time too. But...it is a 21 st century skill that we have to teach and get them ready for in their professional careers, in their future. (personal communication, April 25, 2019)

The dialogic balancing act Iris faces in her instructional design with digital technologies totters like a metaphorical seesaw. On one side are the perceived, extrinsic demands and expectations of preparing her students to use district-purchased technologies regularly and effectively. On the other side, informed in part by her identity as a mother, is an intrinsic pull to limit students' overuse of technology, making sure their digital engagement is purposeful.

However, Iris also acknowledged she does appreciate that groups of fifth graders she has worked with in the last few years have generally come in with strong knowledge and experience (both academically and personally) with digital technologies. Four years ago when she began teaching fifth grade and her students were equipped one-to-one with ChromeBook laptop 
computers, Iris still had them primarily submit handwritten compositions. In more recent years, Iris has only had to do "a quick review in the beginning of the year when we...do our first Google Doc, just as a refresher...of how to name the document, how to share it with me" (personal communication, March 12, 2019).

Iris went on to share that it is because her incoming students in recent years have possessed a strong background in using digital technologies for composing multimedia that she is more comfortable integrating these tools in her instructional design:

If they...weren't using the ChromeBooks or these tools [prior to fifth grade]...I would have to keep giving reminders and refreshers...And that would probably be very frustrating for me, which would probably...make it more of, "If you get done writing your final draft, then you can type it," as opposed to now, they are expected to type their final draft. It would be more of a thing of, "This is kind of an enrichment activity once your handwritten one is done," because I think I would just be so frustrated putting out fires. (personal communication, March 12, 2019)

Other "fires" Iris has had to work through in the past have included students' inappropriate use of technology in the classroom. She had a lot of trust in her most recent class to conduct web searches appropriately and communicate respectfully online. For example, if questionable content came up even when students were using kid-safe search engines in class, Iris noted, "They notify me instead of showing...the other students, 'Look what came up. Look what I found."”

In the following interview exchange, Iris shared memories of past classes who used technology inappropriately and how those teaching experiences impacted her subsequent instructional design efforts: 
Iris: I've had extremely inappropriate students, um, that have gone out of their way...to look up things that... For example, Urban Dictionary, looking up what beerboarding is, which $I$ didn't know what it was, until Aaron: I don't know what that is.

Iris: It's like waterboarding, I think -

Aaron: Oh, Jesus!

Iris: - but with beer.

Aaron: Um, oh, gosh. Wow.

I: So many things. Those classes...um...just kind of like a few would ruin it. So sometimes, technology would be taken away from students, but specifically [if they] were repeat offenders. But it also just kind of made me sway away from allowing them to use technology as a whole group. Or I would find three very specific sites, and it was, "You are not allowed to go on a search engine. You have to use this site. This is where this information is coming from." And [they] had to be just, um, closely supervised, constantly walking and making sure they, you know... Because they're, they're smart. They'll put up two tabs and then try to switch to the other tab that shows that they're on task. So, it, in the past, I've had to kind of stray away from some of those things because of the maturity level. (personal communication, April 25, 2019)

Iris also shared worries about technology functionality and students' ease of use with her district's purchase of a new NGSS-aligned science curricular program. Around the end of Iris's first year teaching fifth grade, she and her other grade level colleagues across the district were invited to a meeting with representatives from two different curricular program companies. One rep promoted that their program had an online-only textbook that could be continually updated 
rather than becoming outdated over time. "That part was a positive," Iris told me, "because I look at..our social studies curriculum [and] it's so outdated" (personal communication, March 12, 2019).

However, Iris and her colleagues ultimately recommended that the district purchase the other program that was presented instead, which still had online components as well as printbased resources:

If you had everybody online, not only if there was, you know, wi-fi issues or connection issues...you would spend so much time during your lesson putting out fires for kids that can't problem-solve or just haven't been exposed...to looking at textbooks online, that it would just take away from so much instructional time. So that was a big reason why, nobody, most everybody didn’t want it. (personal communication, March 12, 2019) Regarding technology, functionality and time spent troubleshooting are considerations that are very important to Iris. These are factors with which she remains in dialogue as she designs instruction that weigh heavily in her evaluation of new technologies she chooses to integrate.

Without Oliver formally supporting her as a technology coach for several years now, Iris finds new digital approaches and technologies for her instructional design at district in-service presentations she attends as well as informal conversations with fellow colleagues and educators. I asked Iris to share a recent example of this and what came to her mind was when she learned of SMART Exchange - a resource hub with downloadable SMART files and lesson plans - from Thea as part of our focus group conversation for this dissertation study. Iris mentioned that it is difficult to learn about new, applicable technology resources from Caitlin. "It's kind of hard," 
Iris said, "cause like, with Caitlin, she teaches math [and] a lot of hers are math-oriented" (personal communication, April 23, 2019).

Iris also shared that having the available time to explore new ways to integrate digital technologies in her instruction is a challenge now more than in the early years of her career: I feel like every year when I become more comfortable with the curriculum, I add in something. Some new pieces each year. I wish that [the technology coaching] was more of...a sign up, volunteer basis. Like, "Hey, I've got this, this idea. I'm just not really sure...how to carry it out, um, and what resources are out there.” [exhales] So I...just kind of a combination of things, where I'm at in my life. I'm using less than I probably could...I mean, I still use technology...but I think that there's definitely, um, opportunity to use it more than what I do. (personal communication, April 23, 2019)

Being a mother to a toddler and a newborn is a primary identity 'hat' Iris has begun to wear in recent years. It impacts the time she has available to explore new digital approaches and resources and has shaped her views on how much time children should spend on technology. However, Iris still maintains a desire to continue pushing herself to refine and increase her integration of digital technologies in her instructional design.

\section{Laurel}

\section{Laurel's Classroom: February 2019}

I arrive in Laurel's classroom (Figure 7) on a cold late-February morning and sit at a vacant table in the back of the room. Laurel is wearing dark yellow pants and a blue long sleeve top, fitting for the snow and freezing rain that has been coming down outside since the late evening yesterday. She wears her hair down in a layered style. 


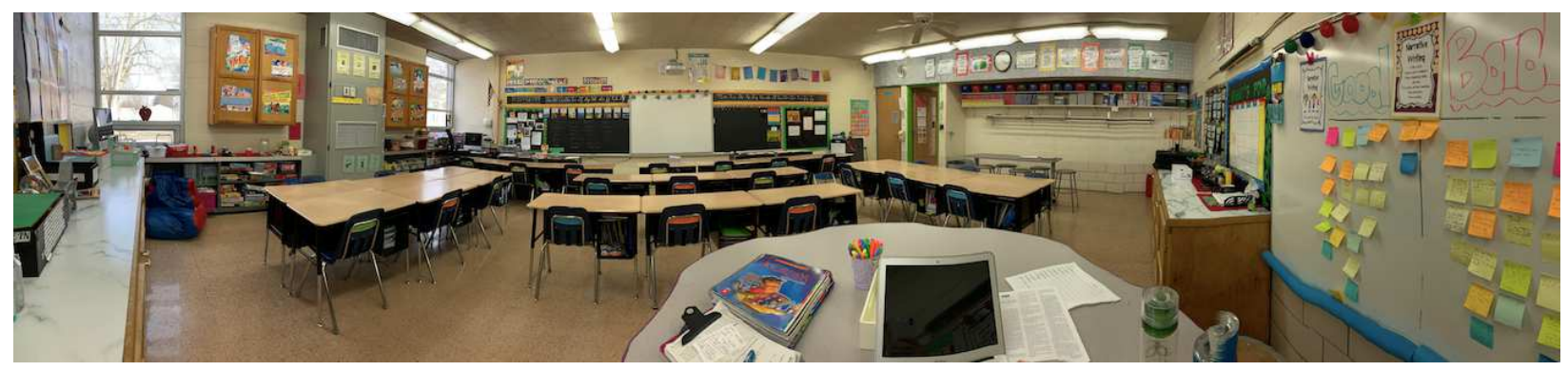

Figure 7. Laurel's fourth grade classroom

The first of Laurel's two sections of fourth grade students arrived before me and are getting situated for today's math lesson. Once the children get seated in their desks, which are organized in small clusters, they begin solving a 'problem of the day' that is posted on Laurel's Promethean Board via the ActiveInspire application. Her stationary Apple computer is plugged into the board with a hard line.

Laurel discusses the problem of the day that the students have been solving independently. She proposes eliminating some of the multiple choice answers that could not possibly be the solution. "We know we don't want it to be greater than 81 ," she notes.

After discussing the solution of the problem, Laurel instructs the students to take out their homework from yesterday's lesson. She posts the answer key to last night's math homework on the board as students trade papers with a member of their table group. She asks the whole class questions as they review the assignment together and does not seem to expect them to raise their hand during this time. Rather, there is an open dialogue between Laurel and the students about the solutions. For example, a student asks a question about an alternative form of a fraction, seemingly as an inside joke with Laurel. "Last time I checked, they are not the same," Laurel replies and she exchanges a sly smile with the student. 
Laurel directs the class to check and correct the problems on the back side of the homework page and then pass it back to the owner after calculating the total points earned on the assignment. "Anyone have any questions on why they missed one?" she asks as they wrap up.

Laurel conferences with a student about how he could have expressed a fraction response on his homework in simplest form. "Twelve is divisible by...?" she asks the student.

The student seems satisfied with her clarification on this question, and Laurel moves on to collecting each group's homework pages while the class talks loudly amongst themselves. "We're very chatty today," Laurel states to the class. "Why is that?"

Laurel shrugs her shoulders and raises her eyebrows, nonverbally indicating to the students that it is time to start today's work. This will be the final lesson in the current unit of study about fractions. Laurel explains that the class will take the chapter test in two days:

You should already have in your planner that tomorrow is the study guide, and Friday is our test. So tomorrow, we'll do our study guide and Friday we'll take the test, 'cause we can't split it up because of all of our snow days...If you need more time, we can always find extra time.

Laurel displays a new ActiveInspire flipchart on the board and introduces today's goal: students will create fraction diagrams to solve story problems in which they must add repeated fractional values. She leads the class in annotating the problem in red on their corresponding workbook pages using the Promethean pen tool, underlining and circling fractional values and the question the students are being asked to solve. "I'm so glad you have an idea. You predicted an idea," Laurel says as she praises a student for offering a suggestion for how to diagram the problem. 
Then, Laurel taps on provided arrow links in the flipchart to reveal new guiding steps on subsequent slides for how the class can proceed in solving the problem. "We are going to act it out using fraction circles," she explains.

A student asks if the class might use fraction strips instead of fraction circles to solve this problem. Laurel integrates this idea into the whole class discussion. "So what we're going to do is we're gonna' start with three-fourths, and another three-fourths, and another three-fourths," she explains. "And eventually you're going to see how many we need, and we might not need fraction circles."

Laurel shades three-fourths portions the fraction circle images on the board, so the class can see how they can combine and simplify these values with any leftovers that didn't make an additional whole circle. She writes possible combined whole number values at the top of the board and when students concur that these would yield leftovers, she crosses them out as possible solutions to the problem.

Many students are proffering their predictions for whole number values that the class should model next, and Laurel continues to guide them by referring to the digital annotations they have been discussing from the board. "I see what you're saying. Three plus three plus three plus three is...? This makes three one-pound bags with zero leftover," Laurel says, singing the “zero" part of this statement in a falsetto pitch.

After solving the initial, multi-step problem, Laurel clicks through to the next one. She points out the word 'quiche' in the problem and stops to make sure the students all understand what this term means. "Does anybody know this word?" she asks. 
A student correctly pronounces the word and Laurel clarifies, "It's kind of like an egg casserole."

Laurel continues to model by adding digital annotations and notes on the board as they break down what information is provided in the problem, and specifically, what the focal question is asking. A student suggests that Laurel should also circle the word 'each' in the problem. "Okay. Thank you," Laurel responses as she circles this word in the problem.

Laurel switches to a shading tool on ActiveInspire and traces a two-sixths portion in the first fraction circle model. After shading this first wedge in red, she repeats the process on another two-sixths portion using blue and then the third one in pink. A student raises his hand and describes an alternative way to multiply and combine the two-sixths portions to find the corresponding whole number solution. "Whatever way your brain works," Laurel acknowledges.

After finishing the second problem, Laurel asks the class to vote on whether they want to complete their next practice problems independently or in small groups. The vote is relatively even, so she gives them the choice for either format. Several students remain at their desks and others congregate at a large wooden table in the back of the classroom. One female student asks Laurel to help her find a group to join. "Zoe? Amanda? Can Donna join your group?"

Laurel sits down with a few students near the Promethean Board who requested to work with her. "Are you looking for a group?” Laurel asks another student who seems to be looking for a group to join. "You can join us. We're cool!"

Two more female students also join Laurel's group at the front of the room as Barry, a male student from the group is adding ' $11 / 4+11 / 4$ ' on the Promethean Board using different colors for each addend. "Barry, tell us what you're doing," Laurel encourages. 
Another student in the group asks Laurel if they are required to draw a model, since their worksheets specify this strategy. Laurel responses, "You don't have to. Technically, you're supposed to, but you don't have to.”

Laurel sits down in her desk chair in front of her group and rolls to the board to add annotations to Barry's written work, assisting him in combining the fractional parts of the mixed numbers. Then, Barry repeats the process, writing another addition fact to add up the whole number portion of each value, including four of the fourths he combined into an additional whole with Laurel.

Laurel moves directly behind Barry and reaches around him to point out what he still needs to add. He uses the eraser tool and makes a correction to his written sum. Another male student in the group joins Barry at the board to talk through the remaining quantities left to add. After correctly finding the sum of $6 \frac{1}{4}$, Barry high fives his group mate.

“Alright, why don't you go ahead and wrap up whatever you're working on and we'll go over this," Laurel announces to the class.

Laurel has a few different students explain different approaches they used to solve the first practice problem while she annotates them at the Promethean Board. Laurel calls on Barry to share some of his reasoning and additional work verbally as well. She uses magenta with her writing, the third color she has used in modeling at the board so far students can distinguish between each solution strategy.

One student describes a modeling strategy and Laurel switches to the shape tool on ActiveInspire, creating several circles to partition by dragging the pen in short bursts diagonally. Then, she switches back to the magenta pen color and divides some circles in fourths while 
shading the wholes. While this is not the simplest model based on the lesson's focal strategy from today, Laurel allows the student to share his thinking. Then, she circles four of the partitioned models to show how they could have been more easily combined. A female student offers a multiplication approach to the problem, and Laurel writes the suggested equation on the right side of the board. "Do you know what property you used to solve this?," Laurel asks the student. "Not Commutative. Not Associative..."

Another student raises their hand and correctly identifies the Distributive Property of Multiplication. "Distributive? "Right!...You used the Distributive Property and didn't even know it," Laurel confirms. "It's amazing how our brain works sometimes."

After the discussion concludes, Laurel asks the students to take out their homework for today's lesson and goes over the assigned problems. Then, she tells the students that they can begin working on their homework for the remainder of class. "If you need help," Laurel announces, "I'll be at the back table."

Laurel sits down at her table. A student tries to get her attention for help on a homework problem, and Laurel says, "You can come sit back here."

The student joins Laurel and they begin reading a story problem aloud. After a few minutes, a handful of students finish the homework and begin working on their ChromeBook laptops. One student at the front of the room is accessing a math fact practice app on an iPad and is joined by a peer who is using the same app.

After finishing with the student at her table, Laurel sorts through the rest of last night's homework pages, intermittently stopping to assist students who approach her for help. A plastic 
McDonald's iced coffee cup with about three-fourths still unconsumed rests next to her grading pile.

"Hey boys and girls of 402," Laurel announces to the class after grading all of their homework assignments from last night. "Nobody missed more than two on the back! So we will be treating ourselves."

A girl is retrieving something from her backpack near me, so I quietly ask her about the jar. She said there are Starburst candies in it that they can take when they are rewarded by Laurel. I thank her for clarifying this for me and she moves along back to her seat. "Middle group," Laurel announces, "you may use the restroom and then treat yourself when you come back."

Laurel approaches me and asks if I have any questions. I ask about the apps and sites the students are using and she tells me they can choose from Freckle, Khan Academy, or an app from the Math folder on the class set of iPads. Before math class begins, the only ones they are allowed to use are the flashcards on the iPads. She also shares that the two sections of fourth graders are leveled academically, and this group is the more advanced of the two that engages in more higher-order thinking and problem solving.

After we finish chatting, Laurel dismisses the current section and prepares for the second section to enter for today's learning activities.

\section{Laurel's Journey}

Laurel, the youngest of five children, was born in Northeastern Iowa. When she was around ten years old, her parents divorced and she primarily lived with her mother, who moved across the Mississippi River to rural Northwestern Illinois. 
In reminiscing about her use of technology as a young student, Laurel mainly recalled transmission-style approaches:

Laurel: So I would say early elementary, the only technology I could probably even come up with is, like, the film strips. I don't know. Is that considered technology? Aaron: Absolutely! Yeah. Yeah.

Laurel: Umm...I remember...going into the library and watching, um, a television show, um...The Electric Company I think it was? So, we watched that on a television. Uh, and then I remember film strips, but I think that the one thing I remember the most, um, before moving to Illinois - so that would've been fourth grade - was the speed reading...Basically, it, they projected it on a screen and it would just be one sentence at a time and it would be at a certain pace. So they were trying to get you to be able to read faster, and I always remember being lost. Like, I could never keep up with that. (personal communication, January 25, 2019)

In high school, Laurel felt her use of technology for learning purposes did not expand much:

Laurel: We didn't get much past the VCR.

Aaron: Okay.

Laurel: Film strips and stuff. Yeah.

Aaron: Did, um, did your personal use evolve at all...over those high school years?

Laurel: Not really. I mean, just the same, you know, VCR and Aaron: Mm-hmm.

Laurel: - that's about it. (personal communication, January 25, 2019) 
After graduating high school, Laurel attended college at a large state school in Central Illinois, majoring in education. Outside of the use of overhead projectors by professors, "there wasn't much...discussion or even teaching on...technology at all” (personal communication, January 25, 2019).

Laurel went on to share details about the limited technology use she saw in her clinical experiences, including her student teaching semester in a fourth grade classroom:

I mean, I did some clinicals in, um, younger [grade levels], like a kindergarten class. I would not say there was any technology there. When I did student teach in fourth grade, the only thing she had was a projector where you used the, um, wipe off markers on the, um... And she didn't use it very often. I used [the overhead projector] probably the most when I student taught...I just found it an easy way to project and feel like everyone could see what I was doing...So, you could model it and project it. Or if we were doing a worksheet on there or something, I could just project it and they could see it. (personal communication, January 25, 2019)

Laurel graduated from college and moved back to her hometown in rural Illinois. "Two weeks after I graduated,” said Laurel, “I married my high school sweetheart. And [we] started our family right away. Had five kids, home for sixteen years..." (personal communication, January 25, 2019)

During the sixteen years following college that Laurel stayed home to raise her children, she maintained a connection to the teaching profession through her children's experiences in school. "[I] definitely knew what was going on," Laurel explained, "and the changes in the 
curriculum...Once your kids are in school, you definitely follow it" (personal communication, January 25, 2019).

Throughout the years of raising their five children, Laurel and her husband established ground rules for technology use in their home, which Laurel detailed during our initial interview:

We had the basics again. The, um, TVs, VCRs, DVD player actually came into play. I kind of was a stickler parent on, um, gaming systems...My sister bought my kids, um, PlayStation One. And, uh, the kids played it a little bit, but it was definitely monitored. They couldn't play it a lot. Um, and then eventually, when the Wii came out, it was so popular. After it had been out a couple years, we purchased the Wii [as a] Christmas gift for the kids. Um, however, it was, uh, not, I wouldn't say a fight, but I think my... I have one son, and the big thing when he was in high school was the PlayStations or the, you know, the gaming they can play with each other. And I remember him being like, "I'm the only one without one. It's crazy." So finally, when he was...sixteen, I think - so he's eighteen now, so that was probably two-and-a-half years ago, I gave in and just bought him $a$, um, I think he has a PlayStation. But, it proved...to be right that it, it consumed him. I mean, it physically consumed him. He, you know, it was constantly on it. So, um, I'm, I would also say that we were parents who, um... So, my oldest daughter who is 24 , so when she, you know, cell phones started to become popular when she was like in...early middle school? Seventh grade? And again, we held out until she went to high school, and she swears she was the only one without a phone. Um, but just something we kind of just felt that as soon as we gave it to them, it becomes, um, consuming. And so, because I just don't think they knew how to handle it or monitor it, or, so... The rule in our house was that you had to be 14 to get a cell phone... which was rough, especially the 
younger ones, 'cause...my youngest is 16 , and I think we did give in...a year early. She did get it when she was 13 ...So, really at home, you know, it's kind of surprising how I don't, I don't push the technology, or...I, moni...I should say I monitor it more, um, than...what you would think, someone who pushes, or uses a lot of technology in their classroom kind of does. So...yeah. (personal communication, January 25, 2019) Laurel did some substitute teaching prior to returning to teaching full time. She reflected on her experiences of getting back into teaching as well as interviewing for a fulltime classroom teaching position:

[I] felt like I could...um, fall [back] into it. Um, my college was the time of whole language...So you'd pick one subject or one thing and you taught math and science and social studies all about it. It was all included in that. Um, but I will say, uh, as much as I thought I was connected when I went into an interview to go back to teaching, I was extremely far removed...So when they would ask about certain things, I'm like, "I' $m$ not sure." Like, RtI or, you know, anything...like that. Just not something I had ever taught in college... I had applied for a full-time teaching position and was not, um, hired. So then they offered me the part-time parent coordinator position. (personal communication, January 25, 2019)

In this coordinator role for the district's preschool program, Laurel "did all the screenings,...just organized, did the audits when the state would come in... That kind of stuff" (personal communication, January 25, 2019). 
After Laurel's year as the preschool coordinator, a vacancy opened up in a fourth grade classroom in this district due to a retirement. Laurel was offered this position and accepted. She has been teaching fourth grade in that same classroom for the past nine years.

\section{Laurel's Pedagogical Design}

Entering her first 'official' classroom sixteen years after completing college, when she primarily used overhead projectors, the technology with which Laurel was provided by her district was limited to a digital projector paired with a large stationary whiteboard. She described her initial technology integration approaches in the following interview exchange:

Laurel: So I did a lot of, just, downloading, um, [from] Promethean Planet. But I do remember going to an in-service with, uh, the technology...department at our school, and I did create, I remember creating one of my own flipcharts that they taught you how to...create those. I did a lot of those. Um, -

Aaron: Would that -

Laurel: - but mostly, I just kind of downloaded from Promethean Planet.

Aaron: Would that have been ActiveInspire? Was that was you were using to create Laurel: Yes.

Aaron: - your own then? Okay.

Laurel: Yup.

Aaron: Yup.

Laurel: And I still use that...Once you know it, you hate to get rid of it. (personal communication, January 25, 2019) 
In discussing the lesson I observed in her classroom, I asked Laurel about her use of a variety of multimedia (e.g., colors, shapes, etc.) as she modeled and annotated the fraction concepts with the ActiveInspire app on the Promethean. Laurel explained that as she explored available technologies, such as ActiveInspire, she found new tools and facets she could integrate into her instructional design:

That is something that, um, I think evolved more when I did the academic leveling of my students. Um, I noticed even when I took it slow, they still weren't just getting, they'd kind of just stare at me. But I feel like the more I can, like... When they're adding twosixths at a time, I think I found that if I shade the two-sixths and I highlight it in one color and then highlight where that two-sixths, they just can make those connections more...I feel like switching colors also just kind of changes it up a little for 'em too. Um, I get tired of the same color over and over. Um, but, $I$ would say probably not right away, but I definitely - I'm trying to think - I found, when I figured out... 'Cause at first, I just has the basic colors, and then I found the way to add a bunch of different colors to it. And then I was like, "Wow! Look at all these colors!" And I kind of just had fun using them, and I realized that it made more sense to use different colors to show different parts. (personal communication, March 4, 2019)

In short order, Laurel began designing her own digital content to use in providing overt instruction on the board. Her instructional design was informed by professional development work in her district; however, she also drew upon previous work experiences. Laurel identified approaches with digital technologies she wanted to use in her future instructional design when she was working as a substitute teacher: 
So I subbed a lot [for a few elementary teachers] who, at the time, had Promethean boards in their rooms. So when I would $s u b$ for them, I was...very intrigued by it, because I love the interaction, and, um...just, to, you know, almost like a big screen TV kind of thing, you know? Um, so when $I$ started teaching, I...asked for one and got one. And...they hooked me up. That's kind of when I hooked up, uh...with Oliver. (personal communication, January 25, 2019)

Laurel began collaborating with Oliver, a technology teacher in her district. "He came into our school, and the kids had a computer class, like as a special," said Laurel. "And...I really was intrigued by what he did. And so, I referred to him a lot with the Promethean board and everything" (personal communication, January 25, 2019).

During Laurel's first year of teaching, Oliver received funding from the district to attend an educational technology conference. He was asked to choose "a couple teachers he felt used technology in the district that would also benefit" (personal communication, January 25, 2019).

Laurel was among those Oliver chose due to her eagerness to learn about and integrate digital technologies in her instructional design. "I just was kind of always [asking] him questions, like, 'How do I do this? How do I do that?' And...I hadn't been there very long - a couple years, maybe" (personal communication, April 24, 2019).

Laurel felt her experiences at this conference were highly impactful towards how she integrated digital technologies in her instructional design efforts, particularly with iPads, which were relatively new at the time:

That is when I really learned all the different ways to use technology - that it's not just to project things and, you know, do flipcharts. So, I spent, I think it was like three days at that conference and just came back with so much. Because I did that, I was one of the 
first teachers, I think, that was given, like, iPads one-to-one [by the district]...So $I$ would say it was really just a year or two that I was into teaching that I was kind of given a lot of technology, because I'd gone to the conference and I'd just shown so much interest in it...So mainly, the conference was a lot of iPad and the apps...and just the different apps and the different ways you can use them. So, just to see that there's so many apps out there for me to use as an educator, but also with my students as learners to have them...available at their, um, hands...to, just, do it a different way. Um, I was never the pen-and-pencil kind of teacher, but I felt like there was only so much you can do without pen and pencil to, um, analyze or assess or anything like that. But, going to the conference, you just learn there's so much. (personal communication, January 25, 2019) Within the first two years of Laurel's career as a fourth grade teacher, Laurel opened up dialogue with new experiences and colleagues. The technology conference she attended introduced new knowledge and approaches she could draw upon with newly released devices and apps. Laurel developed increased confidence and agency in her profession, requesting new technologies from her district in order to expand her ongoing instructional design efforts. Most importantly, she remained in consistent dialogue with Oliver, who she could turn to for support, and guidance.

Like Iris, Laurel met with Oliver weekly in district-mandated technology coaching sessions. She took advantage of these weekly meetings to further hone her digital knowledge and approaches:

Those were the times where I either had, "Hey, I wanna' try this!” And he's like, "Hey! I saw this! I think it'd be really good with your math." Or whatever. So, that was kind of the opening of technology as just...everywhere. And there's so much... And, you know, 
you might want to do some kind of recording with you students and you realize there's like 20 apps out there that... And so, Oliver was really good about, you know, investigating them and seeing which ones were the best and which ones weren't. And so, he did a lot of the, you know, the behind-the-scenes work for that, but it made a big difference. (personal communication, January 25, 2019)

After the district reassigned Oliver out of the technology coaching role due to budget cuts, Laurel still collaborated with him on an as-needed basis. Ultimately, she found the less formal format she and Oliver had established before he worked in the coaching role to better fit her needs:

So the nice thing, I think I'd built quite a relationship with Oliver...So, I still feel like I reached out to him, um...for ideas of if I said, "Hey, I want to try to do this," there was... My kids had done a narrative story, and they made slideshows to go with it, but I really wanted them to read their story to go with their slideshow. So I said something to him about that, even though we weren't meeting still...one-to-one. Um, and he researched and he's like, “Hey, I found this ScreenCastify. I think it'll be great! It's perfect!” And he's like, "If you want me to, I can still come into the classroom." And he actually still came into my classroom and we taught it together. Um, so I don't know that I ever...released Oliver from his...responsibilities to me, 'cause...[he] made me feel like I could always go to him...I think I was past the weekly things [anyways], because..I had, had so many tools now in my toolbox that...I felt that I wasn't quite ready... I felt that sometimes we would meet, and I, I'd feel like I should try something new, so he'd give me something new. But I could never find the time to, like, try it. Or I'd introduce it to the kids, and they're like, "When are we going to do that again?" And I'm like, "We don't have time to do that 
again.” So then, I felt like I was just forcing technology in, because that's what I was supposed to be doing with these weekly meetings. So it was almost kind of a relief when we didn't have to meet week-to-week, um, and it was just an as-needed basis, because I felt like, "Okay, I want to try this. What's out there?" And then it felt, then we used it, and we used it over and over, and I didn't feel like I had to try something new all the time, 'cause I felt like our district's so generous with technology that you constantly kind of felt like, "I gotta' keep using it. I gotta' keep getting better and trying new things." When I think I finally realized that's not really what they want from us. They want us to use the technology to, to the best of our teaching, then I kind of realized that, um, what I'm using is good. And I'm always kind of out there looking for something else. (personal communication, January 25, 2019) In addition to her ongoing collaboration with Oliver, Laurel finds new digital tools and approaches to integrate through social media:

I would say Twitter is probably where I get a lot of it. Um, I've been doing...a lot of, just, self-PD. And, um, like, I did a... So, I used Google Classroom and I thought I knew Google Classroom...okay. So, I did this Google Classroom PD, and I learned so much that I'm missing out in...And then, like, Alice Keeler. I follow her on Twitter. I can't keep up with everything she introduces, but I definitely, like, put things to the side that, when I have time, I'm going to go do that. I did a, um - and I didn't quite finish it - I'm half way through [an online module about] all the different things you can do with Google spreadsheets. [All you can you] blows my mind. (personal communication, January 25, 2019) 
Laurel shared that her original pathway to social media was not to engage in informal professional development, but rather, to monitor her children's use of platforms like Twitter or Facebook:

Laurel: You know...it's kind of funny, 'cause up until a while ago, I wasn't even on Twitter. Probably, I've probably been on Twitter maybe four or five years. But, when I first went on Twitter, all social media I went on first was because a rule in our house was "if you're on social media, I'm your friend on it." So, someone got Twitter. I don't know which one of my kids got Twitter. And I'm like, “Oh, okay! Well, I'll set up a Twitter, and I'll follow you," and, um... But now, like, Twitter is a huge resource for [me]. (personal communication, April 24, 2019)

Having had a Promethean Board installed in her room during her first few years of teaching, Laurel also continued to search for new ways to integrate this tool to facilitate opportunities for situated practice of core skills. As an example, Laurel shared a digital tool called DocHub that she experimented with during the most recent school year:

Laurel: I can't believe I never knew this - I just learned about DocHub?

Aaron: [shrugs to indicate lack of knowledge about this tool]

Laurel: Which, I, well if you don't know about it, you're going to love it. So basically, what you can do is you can pull any document and make it to where you can turn it and use your...board and write on it.

Aaron: What -

Laurel: It's an extension through Google.

Aaron: Kind of like annotating it, in a way? 
Laurel: Abs-, yeah, absolutely...But, I was talking to [my grade level colleague] Grace about some of these worksheets...that I think are really good. We do most of those of those in class, as the group, together.

Aaron: Mm-hmm.

Laurel: But sometimes I feel like the kids who are a little...maybe slower or can't quite keep up, when I just speak it, they are the ones who...can't quite always get the answers down. And they're the ones who need it. So, um, I was telling Grace, and she's like, "Well $I$ use this thing called DocHub." And you just take a PDF and you open it, you put that extension, and whenever you open a PDF in your Google, it'll ask you [if you want to use it]...So I definitely feel like I'll use it more [than my document camera], only because the kids can come up and do it now. I mean, not that the kids couldn't come up and write on the paper [under the document camera], but it wasn't as...easy for them. Um, so this is more of a way where the kids can come up and, like the, and we just, and I was talking about, 'cause we were doing, um... [pauses] Oh, what were we doing? Oh, uh, relative ad-, uh, adverbs and pronouns? So you had to underline and circle and I'm like, I felt horrible, because I'm like, "Okay. Circle this word. Like, find that," when the kids could come up and do it. You know, the kids would tell me what to circle, and I think, like, the kids needs out of their seats and -

Aaron: Yep.

Laurel: - up and down, and, um, and a visual. They need, some kids need a visual. So, um, so yeah. We used it and it was great. Kids get to be part of it and all of that, so... (personal communication, March 4, 2019) 
This revised mindset moved her away from facilitating passive engagement with technology, such as what she had experienced as a student up through her years in college. Presenting content through this tool allowed Laurel to leverage the interactive capabilities of the Promethean Board, making her grammar lessons more engaging and participatory. Students could more actively engage in situated practice with Laurel's guidance and support.

Laurel continues to explore new digital approaches within her personal learning network (comprised of social media and fellow colleagues). She applied for and was awarded a grant from a local education foundation to purchase a new Promethean Board, replacing her dated one. Laurel expressed her excitement about this upgrade in her classroom for the upcoming school year, including how it will help her facilitate purposeful, student-centered learning experiences: Laurel: I' $m$ hoping [the new Promethean] will, um, have the students more involved than they are now. Um, the Promethean board with the pen, when they get up they and they try and write, they struggle with it. Um, it drags or it does this and then they have to erase and then did that. You know what I mean?

Aaron: Yeah.

Laurel: Like, instead of going up and writing " 40 ," it takes, which would take 'em, like, you know, three seconds, it takes 'em almost 30 seconds to a minute to write something, because it, it's just older. Now, Grace also said that the new touch is very sensitive. Um, but, I think...we'll learn to deal with that more. So I'm hoping it'll be more, it'll involve the kids more. It's more user-friendly.

Aaron: You probably almost want it more sensitive than not enough, like what you have L: Right! (personal communication, April 24, 2019) 
Laurel currently frames her perspective on integrating digital technologies in her instructional design in terms of a "quality versus quantity kind of thing" (personal communication, January 25,2019 ) in which she wants to implement a core set of digital approaches with high integrity:

And I felt like the more I did, the, you know, the better it was, [however]...I found that to be super false, because I never perfected anything and the kids just felt overwhelmed. And...there, uh, if we had a glitch, I'd like, “I don't know! Just...turn it off!" Where eventually, when you keep doing something, you figure out how to work through the glitches or how to, and, so then it became frustration or, you know, things like that. So, I definitely learned that, uh, quality is way better [than quantity]. (personal communication, January 25, 2019)

With this mindset, Laurel transforms her practices through implementation, reflection, and ongoing learning and professional development. In the focus group, Laurel shared how she recently reformulated an expository writing activity sequence in which her students wrote and edited in a Google Docs template (Figure 8).

Her students used ChromeBook laptops for this lesson, as the district had equipped all fourth graders with these devices in a one-to-one implementation about three years ago. Laurel detailed how she leveraged technology to provide effective overt instruction and facilitate the students' situated practice based on their developing skills (e.g., researching, organizing, revising, etc.) as young authors: 


\section{Body Paragraph 1}

First Main Idea

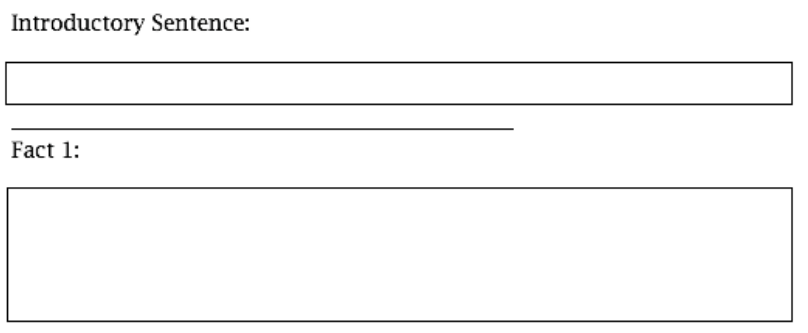

Fact 2:

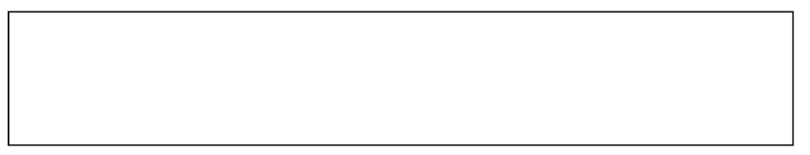

Fact 3:

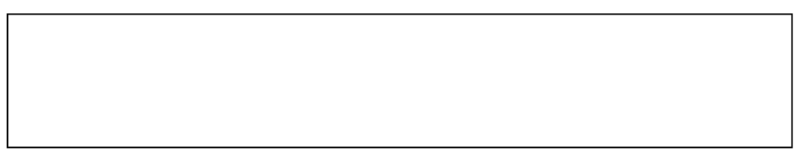

Wrap Up Sentence:

Figure 8. Excerpt of Laurel's Google Doc expository writing template

This is, this was an expository essay...We work on those throughout the year. We actually write two expository essays throughout the year. One, kind of, at the beginning of the year and another one at the end of the year...Our main goal is five paragraphs: an introductory paragraph, three main idea paragraphs, and then, a conclusion paragraph. Um...I turned this into a Google Doc, uh, just this year. They've always done it just on paper...And then, we just kind of go through this step-by-step. You'll see it goes in order. So it's kind of, um, odd to start with the three main ideas...We pick habitat, diet, and characteristics...And then they actually research...I use KidRex, and they go in there and they can look up videos. They can read articles. They can do whatever. And they have to come up with three facts to go with those three main ideas, so if the first one's 
diet, they have to come up with three facts about that. And these are not sentences; these are just simple notes that they do...So, we take...from the first main idea. So this is diet. We...we do a lot of the first fact together. We write an introductory...sentence together. We kind of come up with three sentences for the three facts. The wrap-up sentence can either be a wrap-up sentence or lead into the next paragraph. Um, and then we do Body Paragraph Two, which is habitat, and Body Paragraph Three: characteristics...And then we actually do introduction and conclusion last after we have already come up with our three ideas. We, um...brain-, we talk about, you know, "In your introduction, you need to about, listing the three things and..." And it's not, you don't tell 'em; you just kinda'...do it and then...lead-in, and then the conclusion. So...um, this is the first year we did it, and...when they would...type in these text boxes. It messed 'em up and they got, some kids got very, um, concerned about that. So yeah... So, um...they, that was kind of a struggle. Text boxes, they can delete the words, the words can delete, so we ran into some problems with that. Um, I think there's a way where you can...do some- - I haven't found it yet - but where you can put writing on there and it's not able to be deleted. I need to mess with that a little bit. I think you can lock it...And then, we had them do the final, um, essay on a Google Doc themselves, and we learned how to do the copy-and-paste. We learned Control-Z right away, really quick. Because they were like, "It's all gone!" And I'm like, "Control-Z." And they're like, "It's all back." So, um, but we learned to copy-and-paste and we learned how to, like, do a lot of the technology, uh, shortcuts, like, um, Select All, and we picked all the same font. We picked all the same spacing...and just things like that. So it was a lot of technology involved with this, and they did an awesome job. They turned out really nice. We did it once. We printed it off, 
and then we did editing with a pencil on the typed paper. Um, now I had to print 'em off, which wasn't horrible. It just was a little time consuming. Um, and then they made edits and revisions and then they went back in and did that in their Google Doc and then submitted their final copy. So...that's what they did...I think when I was planning this lesson, when I started to try to plan the introduction, it was too hard, because you needed the information from...the main ideas to write the introduction. So, the one part I $d o$ find in doing it on pen-and-paper or on the ChromeBooks, putting it in order, that they understand that the introduction has to go before the first three paragraphs. And then the conclusion goes at the end. They do struggle a little bit with that. Some of the kids who, they want to go in the order of the pages. But, um, the nice thing is on the ChromeBook, you just copy-and-paste or cut it and paste it where it belongs. But, it just made sense to do the main ideas and then, um, go back to the introduction and the conclusion, and I teach that the introduction and the conclusion should really be about the same thing. They should connect. Like, you introduce it...I always teach it, "Hi! Welcome to my house." You know, "We talk. We do all of this. Thank you for coming to my house." So it's really like reinstating what the intro is. So those really are one lesson and it's just almost, for my beginning writers, the ones that struggle, it's just, "In this essay, you will learn..." and then at the end, "In this essay, you learned..." You just change the tense of the verb. The kids who...are better writers can then put their own spin on it. But, really, sometimes, this is the first time they are introduced to multi-paragraph essays. (personal communication, March 6, 2019)

In reflecting on this lesson in our final interview, Laurel made explicit how her pedagogy shifted from implementing this activity. By facilitating the students writing revisions in a digital 
format, Laurel's young students could critically frame the writing conventions and grammar they learned in class with greater ease:

Laurel: So the nice thing was they didn't get so...like, when you say, "Okay, we're gonna' revise and rewrite it," they're... just deflated. Like, "You're kidding me!" Like, you want... Or when you have 'em do revisions, they can't fit their revisions Aaron: Yeah.

Laurel: - in those teeny, tiny, little spaces.

Aaron: That was big for me [in my own teaching] the past couple years too.

Laurel: So then, do you go, "Okay, skip every other line," or use bigger paper. And then they go to do the final copy and they're skipping lines. I'm like, “Oh my gosh! No! That's not what we want." So it was really nice to do the editing and revising, um, and for me to also monitor their, um...progress along the way. I could easily go in and check on the [student's written work online], you know, at night, without their paper. (personal communication, April 24, 2019)

While she integrates digital technologies in her instructional designing efforts consistently, Laurel remains in dialogue with her identity and experiences as a mother, cautious about how much screen time her students get in the classroom. In our final interview, I asked her to share more about how she developed her current perspectives on technology use by children: I noticed, what bothered me the most, was...parents are putting their kids on electronics almost as pacifiers...We would go to, like, a band concert if one of my kids was in a band concert or a sporting event, or whatever, and the kids, their kids, are quiet, don't get me wrong. They're sitting right next to 'em. But they're so involved in this, um, electronic in front of 'em, they have no idea what's going on around them, so they're not, I mean, not 
that you have to watch a band concert or watch a sporting event, but it was almost like these kids...couldn't pacify themselves without [technology]. (personal communication, April 24, 2019).

Rather than utilizing digital technologies as 'pacifiers' or 'busywork' for her classes, Laurel wants her students' use of these resources to be purposeful. She developed this sentiment as part of the process of becoming a National Boards Certified Teacher (NBCT), which she successfully completed in 2017. Laurel attributes a lot of her current views on designing instruction to her NBCT efforts:

National Board changed everything! Definitely. Um, I don't even know where to begin. I thought I was a pretty good teacher before I did National Board. And then you go through National Board, and it's like, “A distinguished teacher does this. A distinguished teacher does that." And I'm like, "My gosh! I'm a horrible teacher! I don't do any of that!" But it was so... National Board was life changing in my teaching, and the planning. More the planning the outcome...First you know your students...and then you, you're planning what you want your outcome to be. And every time you do something, there's evaluate, you know, analyze. Do they get it? What do you need to work... And then you figure out the next... I mean, yeah. I don't even, I can't even... And [I] even said [during the process], "If I don't certify, it doesn't matter to me, because this has changed me tremendously as a...teacher.” (personal communication, January 25, 2019) In our final interview, Laurel and I discussed how she feels the NBCT process impacted her teaching with digital technologies. Laurel shared a story about leveraging Google Classroom to differentiate how she provided feedback on her students' writing. In this story, Laurel 
ultimately summarized her ethos of teaching with digital technologies, which centers around meeting the needs of individual learners:

So I think when I went through National Boards, and we were talking about...one of the main things is, "What do your students need and how are you going to meet their needs?" And I thought, “Well, dang. How do I meet all of these students' needs?” And I think that's when I started researching, um, different types of technology that would allow me to do that, where students could move at their pace. Um, I can check in on 'em, like using Google Classroom. We did a writing thing. I could go in and check on their writing, ‘cause they had shared it with me. "Where were they at? How's it going?" And I can comment back. I can pull 'em over [to my desk]. I can look at whatever. And the kids who are doing fine, I just let 'em go. Where before, you'd have to collect the papers, you know, and all of that. They can't work on it 'cause I've got it until I can get through all of 'em and...thing like that...The nice thing is they listen to my feedback, they watch me through their paper talk through it, and then they can go back and look...So I kind of...looked into technology to help me differentiate a lot and meet my students' needs with that. (personal communication, April 24, 2019)

\section{Nora}

\section{Nora's Classroom: March 2019}

I enter Nora's nautical-themed classroom (Figure 9) in early March 2019 as she sorts through papers and hurriedly eats a bagel sandwich for lunch. Her blonde hair is pulled back into a tight ponytail that drapes down the back of her short frame. She is wearing a red polo shirt and blue jeans and has forgone the thick-framed glasses I have seen her wear during some of our previous video conference interviews. 


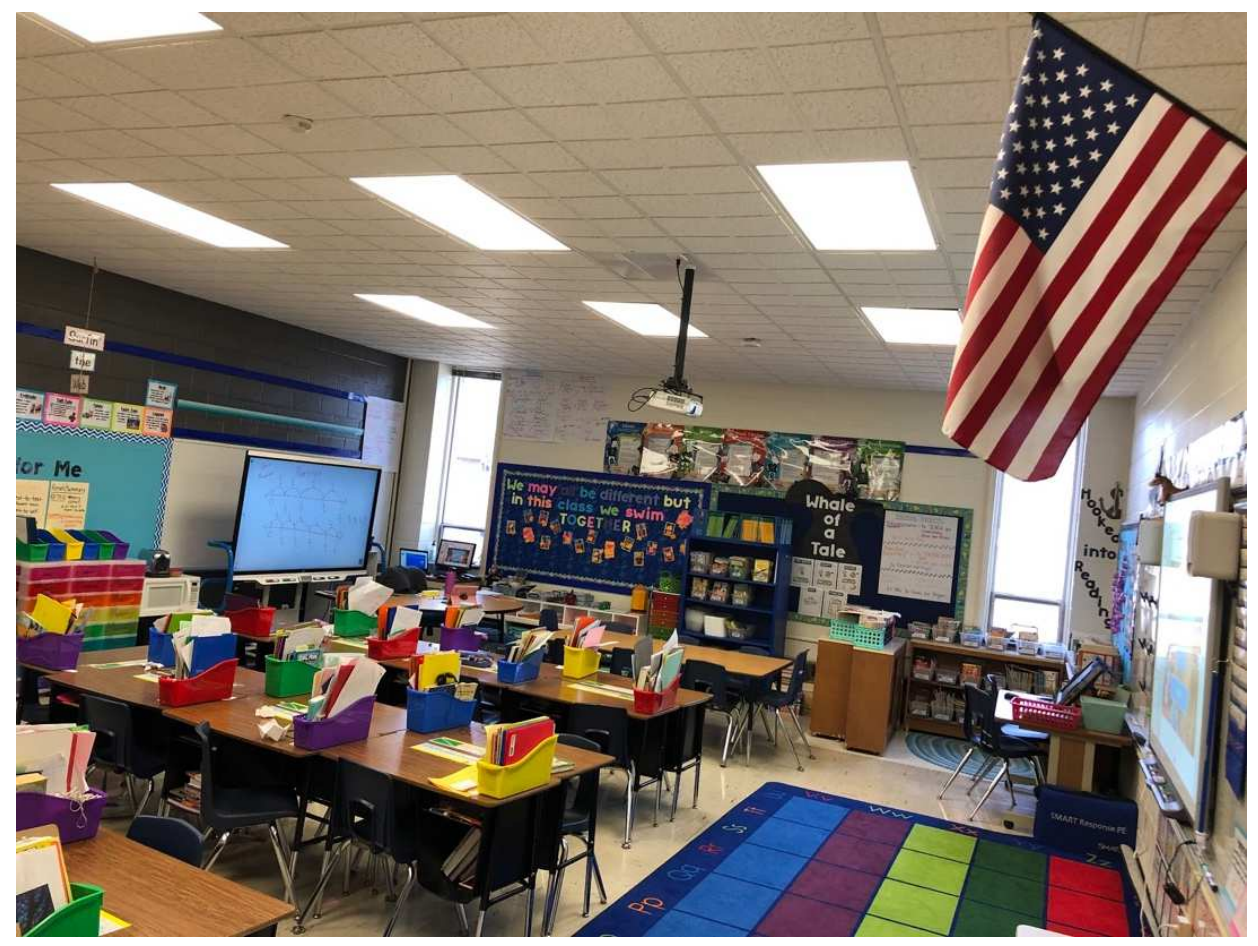

Figure 9. Nora's third grade classroom

I compliment Nora on the fun vibe of her room - which features display boards with titles such as "SEArious about Math" and "Yo Ho A Readers Life for Me" - and she remarks that blue is a calming color, which is suitable for her current group of students. She informs me that one of her students that struggles with behavior management issues was removed from the classroom and sent home before lunch today. She goes on to detail the numerous items on her plate right now, including the initial work of planning her wedding.

Nora's classroom features two SMART Boards: a large stationary one on the front wall of the classroom towards which all the students' desks are oriented and a mobile one behind her wooden group work table, which also functions as part of her desk space. She plays soothing piano music from the speakers of the stationary SMART Board. A curved piano image is displayed on the board amidst stars and space and the classroom lights are turned off. The students return from recess and begin to situate their desk spaces and individual DELL laptop 
computers for their afternoon work. I notice the class is somewhat racially diverse: more than half of the students are African American, a few are Latinx, and the rest are Caucasian. "Show me you can go there and come right back please," Nora says in a cheery but firm voice.

The students log into their laptop computers and take a seat within individual squares on the blue carpet in front of the SMART Board. "I appreciate those who [were]... proactive to get ready for the afternoon," Nora remarks.

After leading the students through some stretching and breathing exercises, Nora directs the students to move to their routine locations to begin their learning centers activities. The piano music is still playing as students go to different locations in the classroom - some at the half circle table at the back of the room, others at their desks, and some at a work table near the students coat hooks. Nora reiterates to a student that she has spoken to him three times to redirect his direction following. She approaches and speaks with him quietly but intently and then sits with a group of six students at her back table who are waiting for her to begin their reading group work. Classroom Dojo is displayed on the large SMART Board. "I will start the timer as soon as I see everyone working," Nora announces.

I take a walk around the room to observe the various activities in which the third graders are engaging. Two students are at a table near the doorway wall working on a sheet about a novel study. Others are working from their laptops on ReadWorks or A-Z Reader and are completing a checklist activity about informational text features. A group of three students are logged into Lexia completing word sorts. An aide enters the room and is supporting the three students on Lexia. A few other students are practicing writing cursive letter ' $Q$ ' on pink handwriting 
worksheets. Nora provides a checklist of activities they work on throughout the whole week in centers, but they only have to finish as much as they are able by Friday.

A student at one of the desks raises her hand for help and Nora encourages her to work through the issue as best as she can and she will visit her shortly. She went over about two minutes later or so. Then Nora points out how a student is working hard on a quiz in one of the centers and she awards him two Dojo points. A chime sound is heard twice, once on her computer and once through the SMART Board speakers. A visual alert showing this student was awarded two points is displayed on the board and his avatar's score increases by two.

A male African American student walks by and gives me an intimidating look. He sits at a rectangular wooden table near me that hadn't been used yet. The aide asks him if he would like her to get him some headphones. He replies to her a slightly aggressive and sarcastic way, appearing visibly annoyed and frustrated. The aide sits with him and talks with him as he completes his assigned work on the laptop in this center. After a few minutes, his mood seems to improve as he is earning more points on the phonics game he is playing. He is distracted by my presence a few times and mistakes me for Nora's fiancé from a photo she had shared with the class, but Nora reassures him that I am just there to observe her teaching. The center rotation ends and the bell alert sounds on the board timer. "Red group!" calls Nora.

The 15-second transition timer goes off. The students finish up moving to the next center. The aide exits the room. "Writing center! Remember, we're starting a new writing journal today. You have to go to our course Moodle," Nora announces. 
"Can you practice that for one minute while I go check in with everyone?" Nora asks her current reading group, comprised of three male students, including the boy who had given me the look earlier.

The students begin reading aloud from a text in a binder. She clarifies directions on the journaling activity with one student. "So if the others need help, you can help them, right?" she asks a female student.

The student nods affirmatively and begins her journaling work by typing in a textbox on the Moodle page. A prompt is displayed at the top of the page, asking them to write about the one food they would want to eat for the rest of their lives if they could only have one.

"Alright my loves. Are you ready for me?" Nora asks the reading group as she begins reading short phrases from the binder aloud with the three members of this group chorally.

She praises the boy who sat near me earlier and he asks her if she is going to give his family a phone call home today. She says, 'You've been rockin' it today. I hope I get to make that call."

The bell alert eventually sounds again and the students transition to their next centers. During the switch, Nora negotiates a direction-following issue with the boy who was working to earn that positive phone call home. He eventually complies and goes to read with the aide at the table near the coat hooks. A new group of five students sit with Nora.

After previewing today's focal text and making a few predictions, Nora turns to the mobile SMART Board behind the table and explains that the group will work on reading with fluency today. She writes a list of the elements of fluency on the board: 1) rate, 2) expressing, 3) breathing, and 4) accuracy. The students are referring to a fluency posting from the 'Yo Ho' 
bulletin board display to suggest elements for her to write. She circles Expression and writes "feelings, talk like the characters" next to it. Next to Rate, she writes "speed." She and the students brainstorm and model different forms of emotional expression, such as happiness and sadness, which Nora logs on the board. She writes "punctuation" next to Breathing and reminds them that they must stop at punctuation. After working with the new aide to help a student with a technical question on his laptop, she turns to a student in her group and encouragingly says, "Alright...show me the best expression ever." She crouches near the student as they read together with emphasized expression.

Nora transitions the class into their daily math block next. The students bring mini whiteboards to the carpet and face the large SMART Board, and she begins leading them through a series of practice and review problems. She scrolls down the page she has loaded from her computer to a problem in which students describe the value of the digit ' 3 ' in the number ' 435 ,' underlining the ' 3 ' with the pen tool.

Another student enters with a laptop and gives Nora a note. She asks him, "Are you having a good day?"

He replies that he is. Then, he sits at a table in front of the reading table where I am seated and begins working on his computer. He appears to be a student from an older grade level. Nora scrolls to a problem in which students calculate an elapsed time using the provided starting and ending times. "Who can come up and be our master teacher?...Who's going to be a good teacher today?"

A female student writes a starting and ending time on either side of a provided number line on the SMART Board using one of the pen tools. Annotating in blue, she shows her 
counting of elapsed time from the starting point - two jumps of 60 minutes. Nora narrates the work to the class as the student models it on the board. Then, they talk through an issue the student had run into during the solution and poses alternative ways of counting, such as using more manageable groups of 30 minutes at a time.

Nora calls up another student to model a solution for a similar problem. The SMART Board pen malfunctions and writes off to the left of where he wants to write. He erases and tries again with a different pen. "I forgot to mention, friends. Don't forget that label," Nora reminds the class.

While this student is writing, she asks the visiting student about an award medal he is wearing. He says it is for basketball and she congratulates him. Then, a handful of students hold up their solutions on their whiteboards when she asks the class to share. 'I'm impressed, friends! Very impressed!" Nora proclaims.

After the students complete these practice problems, she tells the class that they are going to complete a Quizizz. The students move back to their seats and login using the game code she has displayed on the board. A countdown clock ticks down from ten to zero, and the third graders begin solving time problems on their computers. They must individually answer questions in which they choose from four provided digital times to match the analog clock picture that is shown on their screens. Nora projects a display of student progress on the board, showing where students rank in their accuracy of solutions with green and red meter bars. "Friends we want Quizizz, not Quizlet," Nora reminds the class after helping a student navigate to the correct site. 
After the students work for a few minutes, Nora calls out, "Alright! One more minute and we are going to look at that data along with our new learning for today!"

Several students dance in a celebratory way or jump up when they answer questions correctly. Nora clicks "End Game" at the top of the screen, much to the dismay of a few children in the class. She tells the class return to the carpet and reviews the questions the students just answered. The data of their responses are displayed in a color coded chart itemized by question. Green questions indicated a majority or all of the class answered them correctly. Yellow showed that only some were successful, while red would signal overall struggles for the class. "We're only going to go over those yellow ones. We don't have any red," Nora explains to the class.

"Who can do Number 3 for me and describe what Number 3 is?" Nora asks the class.

Nora calls on a female student to share her work on Question 3. Students are passing into the hallway loudly and Nora goes out to reprimand them. The female student continues her explanation of one of the yellow problems to the class undeterred with her peers' undivided attention. The class applauds when she finishes, even while Nora is still reprimanding the students audibly in the hallway. "I'm sure you did fantastical while I was away," Nora says as she returns.

Nora leads the class through the remainder of the math learning block, introducing a new approach for calculating starting times by counting backwards from ending times using provided elapsed times. After this, the students work in pairs as part of a math fluency activity, reading times from analog clocks shown on a page as quickly as possible for one minute. The students provide coaching and tips to each other as needed and log their scores on a daily data sheet found in the individual folders Nora has prepared for them. 
After the math block concludes, the students begin packing some items in their backpacks as they transition to the last activity of the day. "Thank you for those who have come in from Mrs. Allen!" Nora says to the class as they transition to their Response to Intervention (RtI) block. "I'll start releasing friends who are sitting quietly with a clean desk and a clean floor under their desk."

Many of Nora's third graders disperse to different classrooms for RtI time while students from other third, fourth, and fifth grade classrooms enter and sit down. Nora reviews how the students used an online resource space that she created. Students had previously posted "silly or fun things" on here and she explained that this should not happen again. She explains that they will be eventually posting to a "kid blog...to an authentic audience outside of our classroom."

Nora models on the board how they should access today's resources in Edmodo and shares an example of the inappropriate comments that were left on there yesterday. "Now back to what this is being used for..."

Nora shows them some research resources they are adding, and shares a digital form that students must complete in which they share elements of the research project they are proposing. "You are going to give me a detailed plan to tell me what you're going to $d o$ each day," she explains.

She verbally provides an example of the level of detail she is looking for in this project plan. After fielding a few students' questions, she says, "Everyone is submitting a new proposal today!"

As the students begin working on their research proposals independently or in small groups, Nora checks in with individual students, matching up children who have similar research 
interests. A pair of students near me are searching on Google and then open Microsoft Powerpoint instead of submitting their initial proposal. "[This is] excellent [but] the first thing I need is your proposal...The proposal's gotta' be done," Nora explains. "So go to the Edmodo [and complete] what I just showed you."

Nora finds that many students are engaging in research prior to submitting a proposal on Edmodo. She stops the class and reiterates her expectations for their new round of research projects. "Remember, [the] proposal needs to be done first. I may come back on Tuesday and say, 'Your idea is a no-go,"” Nora reminds the class. "I'm seeing friends who are already researching. Submit, then start researching."

I hear a student at the table where I am seated talking about listing Animoto as a possible tool to use in her project. Another student near me asks a peer if she knows how to send Nora a video. Others are looking up various images to help them create their proposals. "I like how I see [you] writing down [what] research questions [you are] going to be using!" Nora states aloud so the whole class can hear. The students continue brainstorming new research ventures as Nora facilitates their design of focused questions to guide their inquiries.

\section{Nora's Journey}

Nora is an only child who grew up in Central Illinois her entire life and attended a parochial institution through middle school. She did not recall using much technology in her formative school years outside of some routine keyboarding practice in the computer lab. "It was just...good ol' textbooks and all of that in the regular classroom," she explained. "We went once a week [to the computer lab] and we just did typing. We were on Mavis-Beacon Typing I think" (personal communication, January 25, 2019). 
In high school, Nora's parents bought her a cell phone and iPad. She had access to her own personal computer for the majority of her life as well. The following interview exchange exemplifies the deftness with digital technologies Nora has possessed since at least her high school years:

Nora: So my computer I mainly used for instant messaging. That was a thing when I was little...And email...At that time, my best friend lived in Texas, so we would email back and forth all the time. And then my iPad...I mostly used - and I had an iPod too - I taught dance, so I used it for all my music, and I put my routines in there that I was gonna' teach my kids, and all that.

Aaron: When you say you put your routines on there, do you mean, like, you would create mixes of music you would use for the routines?

Nora: I did that, and I would also write down, like, what we were doing, so...little kid ballet you had to do a plie and then [an] arabesque, or whatever.

Aaron: Do you remember what apps you would be using for something like that?

Nora: For writing down what I was doing, I used the Notes [app] and for the music, I used...GarageBand. (personal communication, January 25, 2019)

Nora's academic technology use was much different in the university-aligned lab high school she attended. Since high school, Nora has seen and engaged in technology use for educational purposes on a consistent basis:

It was very different. We had our own NetBooks there, so we had our own laptops that the school gave us that we took home...All of our teachers there had projectors that they used. And those NetBooks, like, connected to it, so they could draw on it and it would 
come up on the screen...In math, we had this notebook that we could take our notes on and draw on the screen and everything. And I remember that in math. And in writing, we used it to type and research things and make papers...and all that. But, it was really nothing exciting...I remember lots of Powerpoints. And [for] some teachers, we would turn things in via DropBox. Just DropBox sometimes...We used Blackboard...Basically, and you would go in there and get assignments and download them to your computer and complete them and then send them back to the teacher. (personal communication, January $25,2019)$

In college, which Nora attended in her hometown area, Nora recalled observing elementary teachers during her field experiences use digital technologies regularly in their instructional design. One experience in particular stood out for her:

Nora: I remember being in the one room and there were different kinds of technology in there... like, 3D printers and all that stuff that could do...things $I$ had never seen before. Aaron: Mm-hmm...What did you think about that?...Did it...affect the way that you thought about designing instruction or working with children?

Nora: My main thing was I saw how excited those kids were and how engaged they were. I mean, it all seemed very successful what I was seeing in the use of technology from different teachers. (personal communication, January 25, 2019)

Nora took several educational technology courses during her college years as well as in the master's program she recently completed:

I took lots of ed tech classes, and now I really am and do...using the badging system rather than traditional grading, so that was very different...Using all kinds of different apps and tools to present your information. Lots of multimodal use of technology and 194 
making your presentations more than just written paper...Lots of student choice in what you got to do 'cause there's so many different apps that you could use...Different ways of sharing out information. Discussion boards became huge when I was in college. We were doing that for a lot of classes. And my [master's] classes now, in some of my projects, I can do just a voice recording, a video. I can do a paper. So just lots of opportunities to kind of choose how you wanna' present your information...They're my favorite classes. I love taking them. I like learning all the different apps and tools and new ways to do things, so it's totally different from when $I$ was in school. Like, my classroom could not be more far from the classrooms I was in growing up. (personal communication, January 25, 2019)

Nora student taught for a full year as part of a professional development school (PDS) experience in Southern Illinois. She was originally going to student teach in her hometown, but a speaker visited her campus and presented the PDS alternative:

[They] talked about how [this district]...was...really rough...and some of the schools were really rough, but if you could survive your year there, you would gather so many skills that it would be...worth it to you. So we were like, "Well, guess we'll do it!" And we went there, and it was definitely eye opening for me, because I came from 'Jesus' school to [a lab high school], then to [a state university], so I never really experienced that...It's actually now the lowest achieving school in all of Illinois. (personal communication, January 25, 2019)

Nora student taught first grade for the first half of her year of student teaching and then third grade for the second half. The classrooms in which she taught "had a ton of technology 
because [the district] was so, so, so impoverished [and] there was lots of money coming into it:" (personal communication, January 25, 2019)

Nora: We had a class set of...iPads. And that was really cool to see how [the third grade $\mathrm{CT}]$ used that, and different apps. And then while $I$ was there, they got an Apple TV, which was super awesome, because anything the kids did on their iPad, we could display onto the board, which was really unique. They also had... a rotating class set of laptops that you could use. So it was a much different...view...It was just where I happened to be placed at, but it was cool to see how that school really had a lot of resources.

Aaron: Did you feel that technology, in working with those lower income kids...did you feel technology helped make your instruction more or less effective, or did...how did you view its purpose in that setting?

Nora: For that particular group, it was a very behaviorally challenging group, and it kind of helped engage them and it also gave those that were lower more differentiating options. They could be on a different app while these kids were on this app and it made it a little bit easier, 'cause they could all go into one thing and it was leveled within that program. Also, just the, you know, apps like Kahoot and Quizizz are super engaging and the kids love 'em, and it was one way to get those kids motivated to work for you. (personal communication, January 25, 2019)

Nora's story from high school through her year-long student teaching experience were ripe with the use of digital technologies. As a student, she used technology to engage in academic content and complete and submit assignments. She learned about digital technologies and approaches in her college coursework and observed teachers integrate them in the field. Eventually, Nora worked in classrooms as a student teacher in which she had access to several 
different devices and applications she used to differentiate instruction and meet her students' diverse needs. 'Digital' was an option for Nora's pedagogical design, at least conceptually, long before she began her professional teaching career. Her past experiences with technology in educational settings, among other competing factors and obstacles, remained in dialogue with her present and future as she commenced her professional teaching career.

\section{Nora's Pedagogical Design}

Following college, Nora was hired in her hometown district as a third grade teacher and continued in her college's master's program. Nora happens to be provided with a myriad of current digital technologies in her current role as a third grade teacher. In addition to the one-toone student laptops and two SMART Boards, she moved into a new classroom in her school at the beginning of the most recent school year that was equipped with a zSpace. zSpace is an augmented/virtual reality device with which Nora gained experience two summers ago. She found zSpace to be incredibly engaging and interactive for students in addition to serving as a support for a student who struggled with classroom behavior and emotional management:

I taught a STEM camp, which...over the summer, all of the schools in my district come together at one school. And then, we...teach by grade level and you have a design challenge that you're targeting. So, our theme was all around villains, and they had to defeat different villains and mine was Loki [from The Avengers]. And we utilized the zSpace and then also We-Do-Toos, which was a Lego technology where you...code it to...literally knock him over...And then when I came back to school, I had one in my classroom, which is awesome. Now at STEM camp, we had 14 in our rooms. It was a little bit better, because then everybody could be doing it...The design challenge...at STEM camp...we used with the [zSpace app with] plants and the butterflies and they 
could do the life cycle and they could find the different... They could find, first, the butterfly and then they had to find the egg. And then they had to find the cocoon. And then, they had to put it together in its life cycle and kind of make the life cycle...without me giving it to them first. So, I can't remember exactly what the questions were, but it was very vague, you know. "What do you see in this picture?" - it was how it started. "What could this be teaching you?" And then eventually, it led to, "Create for me...the butterfly life cycle." And they had to create a little poster of it...It had them getting all of the knowledge on their own. I didn't really do anything besides walk around and facilitate. And then, also, they, they were in the environment. They were in the woods. They could find the milkweed leaves and that's where the eggs were [located]. They could explore that and just kind of immerse themselves in it. [One] particular student, he's actually not mine. He...is from the classroom next door and he has some very...extreme behaviors, and this is something we can put him on that he can...be successful at and it doesn't set him off like a lot of other things...He's very physically aggressive, with other students and teachers. So in this...way, I don't know if he's just so, like, in the...moment, but when he does this, he never has issues. So, we kind of use it as a reward or break for him and, also, he missed out on a lot of classroom time, so when I can give him just little...tidbits of things to do to kind of help him out a little bit. And his teacher also was on maternity leave for the first, uh...twelve weeks of the school year. So I think that, kind of, was a struggle as well. (personal communication, February 18, 2019) Nora expressed a desire to use the zSpace more consistently in the context of her classroom; however, unlike at the STEM camp, her classroom is only equipped with one of these devices. There is a connected stylus and "Driver" 3D glasses for the student who can manipulate 
the digital objects and two "Passenger" glasses for a pair of other students to observe what is happening:

Since I only have one in my classroom, I can really only have three people working at a time...So if I had two [other] kids, they could watch what [the Driver is] doing, but they couldn't control it...I use...my zSpace as more of a station, because I can only have a couple of kids there at a time. So they get, like, a learning challenge, just a little sheet that they'll work through, and...different things...It has to be a station or it has to be a special activity. Even when I do, like, a design challenge with them - we did that more at the beginning of the year - but that took so long for all of my kids to have an opportunity to use it. It was just wasn't practical, I guess. It took us like two weeks for everybody to get their turn...And I only have 20 minutes to teach science anyways, so...it just did not work out well. 'Cause I have 23 kids, and...science always gets pushed back if we have an assembly or a picture day, to be honest. (personal communication, February 18, 2019) Nora's zSpace quandary illustrates the crux between the availability of technology and its practical implementation in a classroom of young elementary students. She would like to utilize the zSpace in more integral ways to support her students' learning and engagement with academic content; however, Nora also has to consider the sonorous dialogue between the size of her class as well as time constraints and curricular pacing. She can utilize the SMART Boards with the whole class or small groups and the laptop computers with individual students to more readily maximize students' active engagement and learning. I observed this throughout my visit in her classroom between her centers, differentiated reading groups, math lesson, and RtI research block; even individual students used technology in ways different from the rest of the class. 
Nora also remains in dialogue with her student teaching experiences, which she feels prepared her to integrate digital technologies with diverse learners in her current teaching position:

Nora: [That year of student teaching is] definitely helping me now in my current school. Aaron: In what ways?

Nora: Just...dealing with behaviors...I'm also in a Title I school, and we have a lot of behaviors. And knowing how to engage those students and kind of understanding their...life outside of school and all that. (personal communication, January 25, 2019) In a few of our conversations, Nora remarked that technology helps her meet the needs of all of her students. This tenet of Nora's teaching philosophy was evident during my observation in her classroom, as she interacted one-on-one with students as often as possible and utilized a variety of digital technologies (e.g., SMART Board, Quizizz, Moodle, Lexia, etc.) to differentiate their learning efforts. I later asked her to share an example of how she leverages digital technologies to design individual learning opportunities for students, and a student who struggled to stay in her classroom came to mind immediately:

One of my students is a runner. He's always been a runner since he was at my school. And he no longer runs anymore! So, that's like my biggest thing. I actually teach beforeschool tutoring at my school, and he, he walks to school every morning to make it to before-school tutoring with me on Tuesdays and Thursdays. Not every morning. And, he does not need tutoring. He loves being in my classroom...Like, he's developed that love of learning, which I love. I've seen that kind of develop in all of my students, is they wanna' do math and they wanna' do all of those things. So that kind of shift...I also have that IEP cluster, the BB, and the ED, and the ID, and the ELL cluster. So I have all, I take 
all the clusters. So I have a lot of behavior needs with that, but I also get a lot of support with that. So I have a lot of adults in and out of my room and me and my LBS1 work really well together. And her para and I work really well. She has, her students are the ones who are particularly challenging. But, with the technology, it really helps to be able to differentiate things to their needs. So we use CoWriter to help publish their writing. We use Lexia to help them with their reading. Like, ReadWorks Digital, I can put them on a much easier level or have it to text-to-speech without other kids knowing. So I think once they realize that they can be successful and they...can learn in my classroom, they...feel different. I think that's the biggest difference. And knowing those [digital] tools that can [facilitate] that. (personal communication, February 18, 2019)

Nora's mindset that all students can and should experience success in her classroom was a driving impetus of the success of her struggling learners. She leverages Available Designs with digital technologies to Redesign her students' future learning experiences and mindsets toward what is possible to achieve academically.

Educational technologies have been a part of Nora's education experiences in a significant way since she was a high school student; however, she has continued to explore and learn about approaches with instructional technologies through her master's coursework and independently outside the workday:

I'm that [teacher] that you're not supposed to be. Not supposed to go to professional development. Only supposed to change one thing. I was there for professional development; I wanted to change everything. That's why I'm so tired all the time. [laughs] But...uh...the biggest thing is just finding different things I can do. There's so much out there that I never even knew...existed and tools that you can use and 
[approaches]... Like, my first year when I got the laptops, I just used it to...make them listen to me. But now I use it in much different ways. The more that I've learned, the more tools that I've found on them, and... And I didn't know you could go on virtual field trips. You could, you know...Skype with other classes... I didn't know any of that [existed]. (personal communication, May 3, 2019)

Between her first and second years of teaching third grade, Nora's district equipped her and her colleagues with more digital technologies, including her own laptop computer. For example, she gained the mobile SMART Board during the most recent school year. She pointed out that she has many colleagues that do not utilize the available technology in the district. Nora, on the other hand, actively works at integrating digital technologies in her instruction on a consistent basis. "There are teachers who don't even touch their SMART Board, and that's why I ended up with the two SMART Boards, is I do use them so much," Nora explained. "I actually have SMART files for everything that I teach" (personal communication, May 3, 2019).

Nora shared examples (Figure 10) of how she uses her SMART Board to engage her students in fun, motivating activities in which she can collect real-time assessment data and analyze it collaboratively with the class:

So this is...off of my SMART Board. And we got the new SMART technology this year. And, one of...the activities that you can put on there is Monster Quiz. My kids think it's the best thing ever. And it's a collaborative quiz that they take with their laptops. And...it gives you the data afterwards, which is what I really like about it is I've been working on going over data after I give formative assessments. So this shows the data we were going over after [a geometry lesson]...They get logged in...[and] connect to our class. Then, I can determine how many groups I can have or I can group them myself. And...they start 
answering the questions, and they have to break their little monster out of their box, and whoever breaks their box first wins. However, I was telling the kids, "I would rather you have a higher percentage than be the first one done. And afterwards, we go over that data. And usually, I use this as, like, a 'we do' part of gradual release. And there's also a similar activity. It's independent I usually do after that to get the individual data from. But I use this a lot, not this particular app, but I use Quizizz or Kahoot. After we take 'em, we always go back over the data. So that was really why I showed this, because before I had all the technology, I didn't really go over data with my students because I didn't have the time to create a graph of every single problem on every single assessment that we did and go over it. Where now, I can easily pull it up and "Oh, we didn't get this one!" When we use Quizizz, we always go back over our yellow and red questions, And, "What were you confused about? How can I help you with this?" type of deal. [This image] is actually my first [geometry unit] lesson. So it only has a "point," "line," "line segment," "intersecting lines," and "parallel lines." Now we're up to all of those, all the triangles, all the quadrilaterals, all the polygons. So there's like 24 words now that they're supposed to know and have those...definitions down. And really, if they don't have those down, you can't really move on to doing the classifying and all of that, so I've, right now, I'm using it mainly for vocab just to get that in their brain. And now, we've started using Quizlet, which is more collaborative. I like that one a little better, but I waited until I taught all the different words first. And then once they've got the vocab down, we'll go into classifying them and making generalizations and all of that. Once...I make them all get 90 percent or above. We were 80 , but I decided that was too easy. 


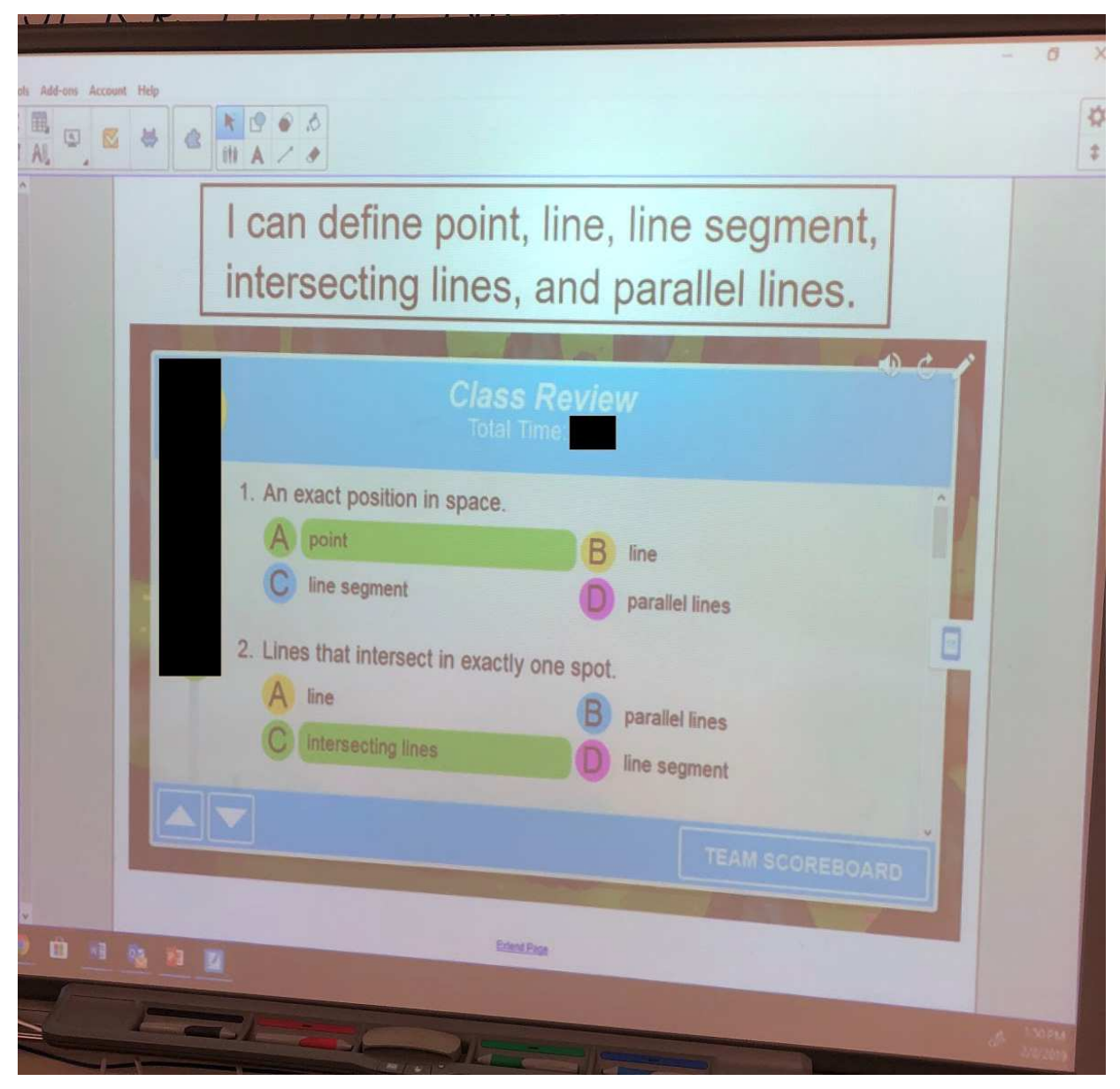

Figure 10. Nora's geometry Monster Quiz SMART Board activity

Now I make 'em go for $90 . .$. We'll go back over the ones that aren't good...We might go back to our anchor chart we made and talk about 'em again. And usually, if they do really poorly on it, I can just reset it and change their groups and they can just do the whole activity again before we go on to having them work independently. And if it's all green, I don't really talk about it if they got a hundred percent correct. We don't really spend much time on it. And I, sometimes, I will realize they're not getting it. I need to spend a whole 'nother day on it and I...adjust...my lesson planning that way as well...I love it for that reason...' cause they are such fakers! I will think they've all got it down and they're giving me their 'thumbs up' - "I'm a four, Ms. Nora!” And then they take the 
quiz and they bomb it! And I'm like, "You guys are fired!" And then we'll go back and we'll talk about it again. Just...I don't know. My first year, we didn't have all of this. We didn't have this form of SMART. I didn't use the data at all. I actually learned about using data in a class I took, uh, through my district last semester. So I just started doing this, but before, I just would've moved on and I wouldn't have known that, "We need to go back and talk about [these topics]!" (personal communication, February 18, 2019) A major reason Nora pushes herself to explore and find ways to integrate new digital technologies in her instructional design is to meet the needs of her diverse learners:

Well, I kind of learned over time all the different things that we have. And we have a new Symbaloo that I can see all the apps we have. And after I did that STEM camp, I learned about different things that we...could check out and use. And I always bring those in mainly...and a lot of times makes it a little more authentic than just paper-and-pencil learning...I [start by looking] at what our district supports. So we have a Symbaloo that has all these links...in it. They never taught us what all these, well at least not me, what all those links were. So, my first, like, two years, I spent most of my time just exploring all the buttons and seeing what they were. Then, if they had different accounts, I could email tech and say, like, "Could you get me an account for...whatever program?" And they would. Usually I try it out. If it bombs, I don't do it again. If it goes well, then I keep integrating it in different ways. And usually, I strategically pick one group of kids I'm gonna' try it with, because throughout my day, I have so much in-and-out, in-and-out, inand-out, um...in my classroom. So I'll strategically pick who I try it with and then just adapt it...from there. (personal communication, May 3, 2019) 
The following interview exchange exemplifies Nora's regular exploration and professional development around digital technologies she can integrate in her instructional design. She also mentioned several of the apps and digital tools she currently draws upon as part of her instructional design efforts:

Aaron: You said you got teacher laptops and you started learning about more apps and things. Take me through that process of how you went about learning about that new technology that you were provided with.

Nora: So, I really did all that on my own. And we have a district Symbaloo and there's a whole bunch of stuff on there and nobody necessarily taught me any of them, but I kind of figured them out...myself. I like to...play with things and I always like new resources I can use and I researched it myself. It was really mostly my own discovery. And I did take a Year 1 mentoring class and in that we learned a couple of different tools that I use. And I always go to all the trainings I can take. I love technology!... There's a new teacher this year, and she is super overwhelmed. "I have no idea what I'm doing!" And she looks there and there's all these apps. And nobody ever teaches use how to use those apps. So I've been trying to help her with that, but...it was really just me figuring them out on my own.

Aaron: So...can you give me a specific app you remember, kind of, diving into during that second year?

Nora: Well...[pauses]

Aaron: Or, one that stands out that you use now even?

Nora: That I use? I use...I use a ton of apps, but probably...I've learned...Kahoot I did see in my student teaching. I learned Quizizz. I learned ReadWorks Digital, 'cause I've been 
using Readworks, the paper version. So when we got the student laptops and I saw that was an option, I figured that one out. I use, uh, Lexia for, as a reading app. I use Education City. I use, um, Classroom Dojo for behavior management. I use Nearpod Nearpod is one I learned my first year. It was introduced in my mentoring class and I signed up to learn that one. And they really just gave me a membership then, and I kind of figured it out on my own and I used that all the time. I use...Quizlet. And we also just got a new version of SMART, so it has all these different activities and games that you can put into it. And they have trainings, but I don't ever go. I, I guess only select people get to go to those trainings. So I haven't gotten to go to any of the ones on the SMARTBoards yet. But, I know that some people have. I just don't know how you...do that.

Aaron: You mentioned that you would, like, sign up to learn about new - I mean, are those like in-district workshops or what does that look like?

Nora: So, Lexia is one that I signed up for a training on, and my principal just sent out an email and said that they're gonna' hold a training on Lexia. "Is anybody interested?" And I said, "Yes." And I went to that one.

Aaron: Okay.

Nora: So we don't really have, like, a formal way. I wish we did, 'cause I feel like I miss out on some trainings just ‘cause I don't hear about them. But...the ones I have been to is just been a, kind of, see the principal sent out an email [to the staff] and then I sign up. (personal communication, February 18, 2019) In addition to engaging in independent exploration, professional development, and coursework to learn about new digital approaches and technologies, she reaches out to 
individuals within her personal learning network. In the following interview exchange, Nora shared how a media specialist in her school has supported her in adding new tools and approaches to her pedagogical repertoire as well as modifying her approaches with digital technologies:

Nora: I found that [with the district-issued app] Net Support, if I want to share something off of one kid's screen out to everybody, then I can do that easily that way. So, say we're making models or something, or whatever it may be. If one kid has something really awesome, I can click on their screen and make it go to everybody's screen. And then we can talk about that, so that is [a] more in-the-moment...use of it. Or, like sometimes, I'll give them something, we'll be talking about something, and I'll say, "Well go research it." I'll have them go look it up, and I can have whoever found the best article or whatever it may be, I can pull that and send it to everybody. Aaron: That's awesome. Did you Nora: Or put it on $m y$ screen. Aaron: Yeah. Yeah, absolutely. Did you....use it that way very much your first year? As you do currently?

Nora: No. My first year, I used it to make sure they were on what they were supposed to. Plus, that was our first time getting the laptops. They came halfway through the school year. So, a lot of the kids, I think, you know it was this "new screen, I can do whatever I want." But I think over time, they learned the expectations a little bit better of what the use of the laptops should be. But yes, my first year, it was mainly for supervision and I would keep it up on my screen, and that way I could see what everybody was on. 
Aaron: And...was it just the different students that second year, um, that made you kind of use it...in that shifted way you described, or what? Did you tinker around with it over the summer? Or where did that shift come from in terms of using it more as [an] instructional in-the-moment type of tool?

Nora: [Pauses] I messed around with it a little bit. I also talked to my...[library/media] person about it... I wanted to do some things in our... We're really encouraged to use Moodle, but there are a couple of things that I wanted to do that my Moodle couldn't do for me. And she showed me Net Support and all the different things it could do, so I've started using it a little bit more now...And that was just an in-the-moment, ten-minute mini lesson she gave me on...the different ways I could send websites and send work, return work, share their screens, block their screens. I just learned that from her, because I couldn't get what I wanted out of our Moodle.

Aaron: What else did you, were you not getting out of it that you wanted, besides that? Nora: [Pauses] I wanted to be able to...send and receive documents, like a template for publishing writing...was a big one. So, I had 'em creating a, a, a...brochure. And I had already made the template, and I wanted to have some way to get it to them so they could use that template and then save it. And I couldn't do that through the Moodle, 'cause it couldn't go into their OneDrive, which is where we save all of our work. So that was kind of where I started my...use of Net Support a little more, because after I asked her about that, she was like, "Yeah! Use Net Support. It's much easier." And I did that, and it worked really well. And that's what kind of got me to messing around with it a little bit more...because that was so easy...I still ask questions quite a bit. I know, for... I just...recently learned about Reading Counts. Do you use Reading Counts? 
Aaron: We do not. What is that?

Nora: It is a...it's through Scholastic. It has pretty much every book that exists with premade quizzes on it. But I've started doing that instead of doing a weekly reading log. They can read any books and they can get points based on how many words were in that book or on the quiz...We're doing a competition between three third grades. It's made it a little more exciting, and that way, I know they're actually reading instead of randomly putting minutes down on their reading logs. So she taught me that this year. Just recently. Well, probably a couple months ago. So really, just any time I have a tech question, I'll go and ask her. (personal communication, February 18, 2019)

Nora shared other ways she has transformed her use of digital tools over time. For example, Nearpod was an app Nora began using with her third graders during her first year of teaching to share content in engaging ways while also allowing students to submit responses digitally. Nearpod comes with a library of pre-created presentations that Nora tended to use. When she utilizes Nearpod now, she designs her own presentations:

Aaron: You mentioned that...over time, you felt it was better to start creating your own, instead of using pre-made ones...Was there, like, a certain jumping off point were you kind of switched...toward that mindset? And, um, why do you feel that way now?

Nora: So I took a district course. We just got a new...assistant superintendent. I guess of 'curriculum and instruction.' I took a course with her on assessment...last semester. And I learned all about assessment blueprints, so I took all of the standards and broke 'em down and made assessment blueprints of exactly what I want to teach and how I want to meet that standard. And...it there really just was an awesome Nearpod like that, so I just made 
it myself, so that I knew I was exactly targeting $m y$ standard and everything that I wanted the kids to know...in my own way. (personal communication, January 25, 2019)

Nora shared an example of an assessment blueprint she created (Figure 11) for a math unit about fractions. This approach to curricular planning and targeted assessment has helped Nora design more intentional instruction that is aligned to learning standards she is required to help her students meet. When we spoke in the spring of 2019, she mentioned that she was learning about technology theories and frameworks, such as TPACK, in her master's coursework. She had intentions of integrating technology goals and competencies for students in her blueprints. "That's kind of my next..step if I can [add]...the tech goals," Nora explained. "I don't do anything with ISTE or any of those right now, 'cause...nobody ever told me about them!" (personal communication, March 1, 2019)

STANDARD: 3.NF.A.3.A

Understand a two fractions as equivalent (equal) if they are the same size, or the same point on a number line.

\begin{tabular}{|c|c|c|c|c|c|c|c|c|}
\hline Objective & Skill & 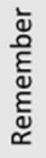 & 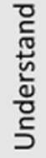 & $\frac{7}{\frac{7}{2}}$ & 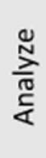 & 总 & 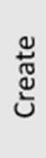 & Lesson \\
\hline \multirow{4}{*}{$\begin{array}{l}\text { Understand two fractions as equivalent } \\
\text { (equal) if they are the same size. }\end{array}$} & Define equivalent. & $x$ & & & & & & 10.5 \\
\hline & $\begin{array}{l}\text { Explain what an } \\
\text { equivalent } \\
\text { fraction is. }\end{array}$ & & $x$ & & & & & 10.5 \\
\hline & $\begin{array}{l}\text { Apply your } \\
\text { knowledge of } \\
\text { equivalence to } \\
\text { identify if two } \\
\text { fractions of a } \\
\text { whole are the } \\
\text { same. }\end{array}$ & & & $x$ & $x$ & & & 10.5 \\
\hline & $\begin{array}{l}\text { Justify your } \\
\text { choice if two } \\
\text { fractions of a } \\
\text { whole are the } \\
\text { same using a } \\
\text { fraction model. }\end{array}$ & & & & $x$ & $x$ & & 10.5 \\
\hline
\end{tabular}

Figure 11. Excerpt from Nora's fraction unit assessment blueprint 
I asked Nora to explain how she designs instruction with technologies intentionally. "I have the ED, ID, ELL, IEP...clusters...in my classroom,” Nora said. “And $I$ love it, [however]...in my classroom, yes, I have insane needs" (personal communication, January 25, 2019).

She later told me that she is drawn towards digital technologies that can differentiate content and learning processes to individual students' needs:

So the biggest thing I can do with tech to engage is to find stuff at every kid's level. And even in the same programs. [For example]...in ReadWorks, they have an article at their level. If they're on Education City, they have games at their level. And just kind of trying to find something at every kid's level, and then I can also tier it to their interests. So I, you know, have a student who...hates reading, but he loves football. So if I can find something about football, then usually he'll read it for me. Or, I have a student that...likes to write. So he'll write on the blog, but he won't write with a pencil and paper for me. So I'm trying to find what works for each kid, and [there are opportunities] to do that with technology. (personal communication, May 3, 2019)

By leveraging digital resources to provide technologically-mediated overt instruction of foundational skills and knowledge for literacy and problem-solving, Nora's students will be better empowered to engage in more transformative learning experiences. She expressed a desire to facilitate these impactful learning opportunities in less-mandated contexts. Nora has worked hard to create assessment blueprints to more intentionally align her instructional design with mandated district curricula and state learning standards; however, by being in less dialogue with those institutional requirements, such as at the summer STEM camp she worked at a few summers ago, she felt less constrained to emphasize a wider variety of pedagogical components: 
The kids loved it. They were all so excited to come....and it was really cool. And I also think, $I$ think the main reason it was so much fun is we didn't have to teach certain standards and there wasn't that pressure. Like right now I'm feeling the pressure in my classroom. You know, I have a lot of stuff to get done, where with [the STEM camp], it was so free. You could do whatever you wanted, but we still got ELA, math... We got everything in. It just wasn't as stressful, so it could be more...fun, I guess...It was very freeing. All we had to do was create one STEM lesson plan for some time throughout the week. Everything else was pretty much whatever we wanted to do. And we had so much technology. I also used the Caterpillars, which are one of the coolest things ever. And that was really just to use the technology. And there was a huge focus on coding. So like, when we had our [media center] time, they learned about coding. And then, I always put aside 30 minutes of the day to do coding, and their We-Do-Toos involved coding. And...then I also brought in math. I brought in science. Really, kind of everything tied together, but it wasn't, "I need you to teach this standard or that." All we had to do was create a very vague STEM plan. So like, "How are you going to involve science? How are you going to involve technology? How are you going to involve engineering? Or how are you going to involve math?" And that was...all that really was required, and the rest was for $u s$ to decide. (personal communication, February 18, 2019) In the STEM camp context, Nora was unencumbered by the curricular pacing demands and standards-based expectations with which she must remain in dialogue during the school year. She felt more liberated to design opportunities to critically frame literacy, math, science, and engineering practices for purposes the students found authentic and motivating, such as dethroning Loki like Thor did on the silver screen. 
Nevertheless, Nora does feel like she has the freedom from her administration to try new digital approaches with her students:

I think my building principal is super supportive...and I think that really helps. And also, we really have complete freedom at our school. There's no, like...expectation of "do this." Like, as long as our kids are learning and we're doing the standards, it's kind of...go for it. So I think that helps. You know, I don't have someone breathing down my neck that I have to be using this curriculum and I have to be doing it this way. And...I think having that freedom helps. Just...do what I want. (personal communication, May 3, 2019) Nora works with academically-advanced third through fifth grade students during her RtI block, during which she facilitates a Genius Hour-style research workshop. Students design focus questions to digitally research independently or in small groups. To share their learning, the students design a myriad of print- and digitally-based projects.

Nora takes time in class to introduce, explore, and explicitly teach aspects of different multimodal digital media tools and applications:

And I'll ask the kids. Like, they love certain programs that we do that I didn't even think were gonna' be that exciting. So, I always ask them their input and whatnot. And now into this year, a lot of what I've been doing I, I find online or that I've learned in my classes or projects that I've had to do, like programs I've had to use, I will use with them. And, like...my RtI group, because they're so high, I can use a lot...of things with them I can't necessarily use with my whole class this year. (personal communication, May 3, 2019)

By providing overt instruction about new technologies, the students can drive their research and design efforts more independently, critically framing their new insights toward 
larger questions they are seeking to answer; subsequently, they can design products of learning using digital tools they choose to best share their newly constructed understanding. It is Nora's student-centered mindset that ultimately drives her instructional design, including her integration of digital technologies:

I am very passionate. I'm very driven. $I$ love my...students and I am a perfectionist, so I have to do my best every single day. And the more that I learn, the better I can be. And I have also seen the payoff in all of the classes I've done. This year, I have the most challenging class, and like, since kindergarten, they've been labelled as the most challenging class. I've known it was coming and coming. And, I've had so much success with them this year despite them being...challenging. And, I don't know, I feel like it's all paying off. This year is when I've really seen it start to pay off, because the more I learn and the better I teach, the better they do and the more engaged they are. You know...I $d o$ take everything personally that they do, 'cause if they're running out of the classroom, that means $I$ had to do something better. And the better I get, the less of those behavior issues I have. I have extreme...like, my first week, the behaviors were so bad! It was so extreme! But I've gotten, like, they have gone down so much. I don't, I can't remember the last time I had the principal in my room or had to have a kid removed. And I look next door, and that is not happening over across the hall. I don't know. I've just seen the payoff of it, and...it is my passion. I'm very driven. I love it. (personal communication, February 18, 2019) 


\section{Thea}

\section{Thea's Classroom: March 2019}

I arrive and check in at the office at Thea's school on a blustery morning in early March. Upon arriving at Thea's kindergarten classroom (Figure 12) just down the hall from the main entrance of the school, I notice her name featured on a brown placard with white lettering above her classroom door.

Thea waves to me as she finishes a phone call. Seated at her desk near the doorway, she is wearing a blue long sleeve top and tan slacks. Her braids are pulled back in a ponytail style. She explains that she is a co-leader for her school's student council this year and was speaking with a sales rep about ordering a new sign for the front of the school. The current sign, from Thea's vantage point, is old and rough-looking.

After chatting with me for a few minutes, Thea retrieves her students from P.E. class. Several greet me upon entering the room and sit in their short black chairs in groups around four large wooden tables situated in front of Thea's SMART Board. The chairs have blue "Seat Sacks" hanging on the back rests and contain the students' folders, mini whiteboards, and other loose materials. I count a total of 17 students in the room; the majority of the class is African American. Thea later informs me that three students are absent today.

Thea opens a bar graph on a desktop computer at the back of the room. She turns on her SMART Board and projects it for the entire class to see and explains that each student will come to the board for a math warm up activity. They must fill in a new data point on the graph to indicate if they are wearing red, blue, both colors, or neither today. "If you know how to read this with me, you can. Did you wear red or blue today?" Thea asks as she leads the class in reading the labels of the bars on the graph. 


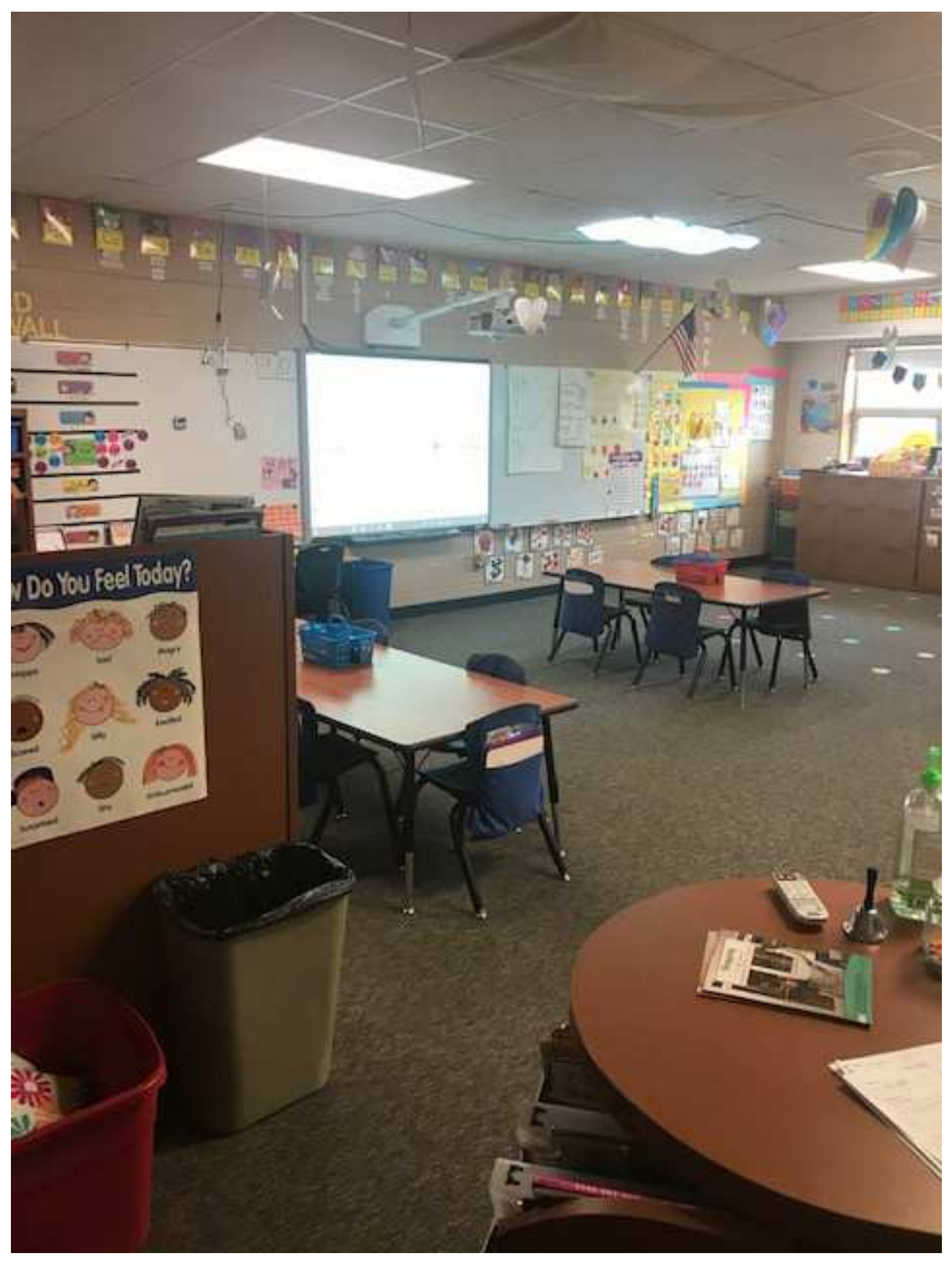

Figure 12. Thea's kindergarten classroom

As an example, Thea points out that one female student is wearing all pink and would fill in one data point on the bar graph in the "neither" column. "Look at what you wore today!" Thea says, smiling at the student in pink attire. 
As another model before asking the students to come to the board to graph independently, Thea asks a male student to model how to use one finger to drag a new rectangle from the bottom left corner of the graph up to the bar corresponding with the colors of his clothing. The student she called to the board moved a rectangle to the seventh space of the "blue" bar. Thea asks the students to evaluate this graphing by showing a "thumbs up or thumbs down." In our final interview, Thea emphasized the importance of modeling skills and strategies with her young students, including how to use the SMART Board itself:

It helps them, you know, know what to...expect and kind of...know how to interact with [the SMART Board] too. So, um, I don't know. Yeah, with kindergarten, I get - and I'm sure you do too - but [I] give, like, a billion examples before we start something and show how to manipulate the board...or whatever activity we're doing. (personal communication, April 29, 2019)

Thea calls on a student who points out that in a bar graph, they must always fill in the lowest space available in the bar. After allowing the modeling student to correct his error, she begins calling up the students one table group at a time to graph their clothing colors. The students wait patiently in a line in front of the SMART Board to take their turns. "Which one is going to have the most?," Thea asks the class as students continue graphing. "Which one will have the least? What are you thinking?"

Thea encourages the students to make predictions for the final graphing results amongst their table groups. Almost every student is engaged in discussion about the graph or watching their remaining peers add the final data in the bar graph. As the final student approaches the board for his turn. "Give him a light drumroll with two fingers," Thea tells the class. 
The students drum on their tabletops while the last student graphs his data. After adding her own rectangle to the blue bar, Thea turns to the class and began asking targeted questions to help the students in analyze the data in the newly-created bar graph. "Curtis, tell me how many [voted] for blue," Thea asks.

Curtis correctly interprets that five students wore blue clothes today. "Raise your hand if you are one of those people that chose blue today," Thea tells the class.

Then, Thea asks the class to identify which color choice was worn by the most students as well as the least. "Ten. Is ten the most or the least?" Thea asks.

The students respond in unison, "Most!"

Then, Thea asks about the least and after some students respond incorrectly, she points out that the least is actually the column for "neither" which had no data graphed in the bar. She previews that tomorrow, the class will graph about their pajamas for students who choose to wear those for Pajama Day.

Thea transitions the class to today's independent practice activity, connecting it to their recent read aloud of Dr. Seuss's One Fish, Two Fish, Red Fish, Blue Fish. Today, the students will receive a cup filled with Goldfish crackers and must graph them by color. She shows the inside of a Dixie cup full of crackers on the SMART Board using a connected document camera and previews the colors. "The Assistants are going to get you a Kleenex," Thea explains. “[You'll] dump your Goldfish on it...I know! All those different colors. Check it out!"

Thea places a worksheet with a bar graph template under the document camera and points out that it has a column for "Purple;" however, there are no Goldfish of that color. She shows the students how they can draw a wiggly line through this column. Then, she models how to color 
the heading title at the bottom of each column of the bar graph template with the corresponding color as a visual aid for their graphing. "Where should I start coloring?" she asks the students.

A student says she should only color where the letters are for the column heading right now. "What does this say?" Thea asks. "The only color that starts with a Y!"

The class chorally identifies that this word is "yellow." Then, Thea jokingly states that she is going to eat the Goldfish crackers, and the students warn her not to because she hasn't graphed them yet. "We have to fill out how many we have for each one," Thea explains. "And then, maybe Ms. [Thea] will let us have some."

She displays on the document camera how to place the Goldfish crackers directly on the worksheet, putting "one in each box" of the corresponding color bar.

"You're going to be a pro at this, aren't you?" Thea encourages. "Do you see how I was careful and didn't throw them all on there at once. I put one at a time."

The students are engaged and giving Thea recommendations on where to place each Goldfish. Thea gives the class some final tips for how to organize the Goldfish by color before using crayons to more permanently graph their individual data.

Do you notice how I'm starting at the bottom?...Bottom to top, okay?...Yep. Bottom to top...If you have a broken Goldfish...still put it on your graph. It will still be fine...Thumbs up if you saw how careful I was with this.

Then, Thea models how to count the Goldfish, one at a time in each column before coloring. "How many reds did I have?" Thea asks the class. 
The students chorally respond that she has five reds. "I'm going to write this number right here," says Thea as she writes " 5 " in red crayon under the column label.

She repeats this process with the class for orange, green, and yellow. After Thea finishes, she leads the class in counting while she shades in the bar graph bars, one at a time from the bottom upwards as the students count chorally with her.

Noticing the time on the clock, Thea apologizes to the student who has the Calendar Helper job this week. "We might have to miss calendar time today, because this took [us] a long time, but that's okay."

Then, Thea gives final instructions before distributing the remaining materials for the activity. "If you [finish] every step...you can chillax and eat your Goldfish....Right now, you need to make sure you have out a red, orange, green, and yellow crayon."

Thea repeats each color again slowly while the students take their crayons out of Ziploc baggies at their tables. She asks a few students to distribute Kleenexes for each member of the class to use as a mat for their Goldfish crackers. Other students are distributing the bar graph worksheet, and the kindergarteners begin coloring the column labels on their graphs.

Thea walks around the room to monitor the students' progress. "Some students already have this done...Okay, my friends that are ready," says Thea, "I'm going to come around and give you your Goldfish. Are you going to start eating them right away?"

One student reminds the class to write their names on their papers as Thea passes out Dixie cups filled with Goldfish crackers from a blue plastic bin she carries like a serving tray. The students at the table near me have dumped their crackers on the provided Kleenex and are placing them carefully on their worksheets, one-at-a-time. Thea crouches down at a table to 
check in with students one-on-one. "[They] are making sure they are writing their numbers," Thea points out aloud, encouraging the rest of the class to do the same. "Don't forget, once you write your numbers, put them in your cup and color how much you had for each color."

Thea checks in at another table and some students share their final color counts. "You have very similar numbers to what I had," Thea remarks to one student.

Then, Thea approaches a student at the table near where I am seated and counts the data he colored with her finger. "Nice!" she says in a congratulatory tone. "Okay. Looks like you are good to eat."

As more students finish up, Thea encourages the kindergarteners to share their results with each other:

If you are done...talk to the people at your table who are also done. Talk about your numbers. I saw some friends at Table 4 who had very similar numbers...Did you have any tie? I saw several people who had ties.

A digital timer goes off at the board, and Thea walks over and turns it off. She adds two more minutes and tells the class she wants everyone to have their data graphed and be ready to discuss it in a whole class conversation in two minutes.

I see several students eating their crackers and chatting. Some are sharing about their graphs. One student near me points out that his neighbor's cracker has both orange and green on it. A few students are still coloring while others walk over and approach Thea to share their work. She encourages them to go back to their tables with a simple arm gesture is not dismissive in tone, but rather, as a simple reminder of classroom expectations during this independent work time. 
The timer goes off again as Thea opens another page on her SMART file. The board says "How many fish do you have?" and it lists each color word written in the corresponding font hue. She calls on students to share how many green crackers they had. "How many students also had four?" Thea asks after one student shares that they had four greens.

A few students raise their hands. She pulls popsicle sticks that feature the students' names out of a small metal canister to determine who she calls on next. She repeats the discussion process for each cracker color. When the class gets to the color yellow, Thea asks if any students had more than ten yellow Goldfish.

To reinforce the concept of most and least, Thea asks the students to turn to a neighbor at their tables and share which colors of which they had the most and least. After the students take a minute or so to discuss at their tables, she directs the students to begin putting away their crayons and other materials. The students deposit their worksheets in a folder they retrieve from their Seat Sacks.

While the students are putting away their materials, Thea says, "Let's vote. Go Noodle or StoryBots?"

The students overwhelmingly vote for StoryBots. "Okay,” says Thea. "Get your tables cleaned up and I'll get StoryBots ready."

Many students finish cleaning up and start dancing by their seats with excitement. "I love StoryBots," I hear one female student say.

"Mmm. Let's do some addition," says Thea as she walks to the PC at the back of the room to $\log$ into StoryBots. 
The StoryBots display appears on the board depicting the photo of the face of a male student from Thea's class with a cartoon body of a frog-like creature. The class shouts his name and he approaches the SMART Board to solve the addition problem " $8+3$ " in which the addends are displayed as illustrations of acorns. After he correctly clicks the sum of "11" with his finger on the board, audible celebratory music plays from speakers that are mounted on the wall at the back of the classroom. A few students congratulate this student and dance in their seats along with the dancing avatar of this boy that appears on the board.

The students shout out the name of the next several students whose avatars appear on the screen. In turn, each member of the class gets an opportunity to solve a computational problem from StoryBots. The third student to get a turn miscounts her addition problem that is accompanied by snowflake picture models. She looks to Thea, who responds, "Try again."

Then she walks over and helps the student count the pictures by pointing at them one at a time with her finger. While the students are engaged with StoryBots, Thea is tidying up areas of the room and dismissing students to prepare for lunchtime. "If you've already gone [on StoryBots]," Thea tells the students, "go to the restroom!"

Thea notices some of the students have migrated near the front of the SMART Board and are dancing around, preventing others from solving their problems. She directs them to back up and leave space by the board area. "Three plus three," Thea reads from the board for the current student's problem. "You could probably do this on your fingers too. Don't tell her what it is [though]. She's solving it...Three plus three on your fingers, people out here!"

After the last student takes a turn, Thea asks the kindergarteners, "Did we ace it?" 
The depicts a dancing blue creature surrounded by confetti that confirms the class responded to all of the questions correctly, so she lines them up at the door and escorts them out for lunch.

\section{Thea's Journey}

Thea (28) was born in Central Illinois in a community with a large university. She and her four siblings were raised by her mother, though her oldest sister is 16 years older than her and lived at home only two years past Thea's birth.

Thea's family experienced hardships during her childhood, though her education experiences were consistent:

So, it was me, and three brothers, and my mom. And...[mom] worked multiple jobs, and, um, we just bounced around...living-wise, um, just because, you know, rent going up and things like that. We were homeless a few times growing up. Um, but yeah. We remained in the same school, which was nice. My mom, um, made sure to do that for us, because she went to eight different schools from the time she was in kindergarten until eighth grade, so...she didn't want that for us, so... Yeah, made sure to go to the same school. (personal communication, January 27, 2019)

By the time she reached middle school, Thea's family's living situation was more steady: [Those years] were stable. We actually...[laughs] were living...somewhere where we should've been going to a different junior high, but, um, we just kind of fudged that and kind of still ended up staying where we were for junior high and high school. Just following our friends from elementary. (personal communication, January 27, 2019) Thea played videogames on a regular basis with her brothers and independently during her childhood: 
So we had the Nintendo 64, of course. And...the Dreamcast...We each personally had, like, GameBoy...We were super into that...We still played outside and were very athletic. But, yeah...Crazy Taxi was probably one of my favorites. And...oh, what else? Just Sonic and all the Mario games. Donkey Kong. Um...The Sims! There were a couple years, like, uh, I remember summer specifically where I actually lost weight, because while my mom was at work...I was going into seventh grade. I'd just kind of sit there and starve myself and just play The Sims for hours creating families and houses, and I remember getting sick several times. And my mom...we were trying to figure out...it's because I wasn't eating during the day...It was kind of ridiculous...It's funny because...Maybe it's not funny, but...in 2017, I noticed, uh, it was on sale. And I don't own an Xbox, but my brother does. So, I purchased it for my brother's Xbox [so] when I [visit him], I have it to play...But my roommate, she thinks it's because I get to control...[laughs] uh, these people...She's like, "I feel like you...can't control your life, so you're controlling these little lives - and you're living through them." [laughs] It's...I don't know... It was fun. Just fun to build and tell them what to $d o$, I guess. (personal communication, January 27, 2019)

Thea recalled her family getting a home computer in her elementary years. In the following interview exchange, she recounted a misunderstanding she experienced while using an instant messaging app:

Thea: It was in third grade when we got [a computer]. I was in third grade, so it was like '99...I remember chatting with my friends when AOL Messenger was a thing. It was huge. It was super cool. That was when...those...you know, the short-hand things... I remember saying "lol," and [a classmate's] mom saw that I put "lol" and blocked me, 
because she didn't know was it meant, and so...I was reported. [laughs] I remember that in third grade, so I was like, “Oh my gosh! I just said 'lol!”” Aaron: Did it...get cleared up? Or...how did that shake out?

Thea: I, I don't remember. But I remember... I do remember going to school and being like, “Tommy, I like, I didn’t... 'Lol’ means ‘laugh out loud!” He's like, “Ohh...well...” I don't remember how it was even...solved, but I remember being very upset, because I was, I was like, nine! I don’t know. I was like, "I didn’t send anything bad!” Aaron: [laughs]

Thea: But yeah, to be using "lol" back then was... [laughs] pretty funny. (personal communication, January 27, 2019)

In her formative schooling years, Thea mainly used computers "for inside recess...just playing games and looking up song lyrics" (personal communication, January 27, 2019).

However, in high school, she began to utilize provided computers for academic purposes that she found engaging and motivating:

Oh gosh! I...remember one time specifically where we were doing some research. We had a topic to research, and, um, yeah, we were just in the computer lab doing that. I just remember being, like, “Is this what it's like to be in college?"...I think I was a freshman or sophomore. But, it was, like, our first time going in, and like, we spent a couple of weeks in that lab, just researching and doing that whole process. (personal communication, January 27, 2019)

After graduating high school in 2009, Thea attended the university in her hometown and lived on campus. She declared as an Early Childhood Education major, because she "wanted to be a preschool teacher and own a preschool" (personal communication, January 27, 2019). 
Thea and her mother purchased an economical computer when she began college. She noted, "It was kind of a big deal to me, because it was expensive... [laughs] and we didn't have that much money. So, I had to get one. It wasn't a really good one" (personal communication, January 27, 2019).

Around her sophomore year of college, Thea applied for and was awarded a scholarship for a new laptop computer and bag:

They gave you a new, a free computer, a free bag, and you [had] to...participate in, like, a presentation...I wish I could remember what it was called. But I entered and I won, so I ended up working with this group and we had to do a presentation. So...that was the computer that took me through the rest of college into my first couple years of teaching. (personal communication, January 27, 2019)

During college, Thea remembered using her computer for engaging in social media networks as well as completing her coursework, sometimes taking it to class. She recalled using it to use it in one class in particular to work around an injury. "We had a paper test," Thea recalled, "but I had to do it on the computer, because I fractured my finger" (personal communication, January 27, 2019).

In her education courses and field experiences, with the exception of a SMART Board training session, Thea recalled observing somewhat limited uses of digital technologies:

So...professors... I remember we did a lot of slideshows. That's the big thing I remember for tech...And then for when I would go out in clinicals...I don't remember [them] using much at all. Like, I honestly, I would be there Mondays and Wednesdays and it was rare that she would even use it. She wrote a lot on the board, and then read... They kind of had a script too...which was interesting. But, it did not really involve much 
technology...There was a student teacher [at my school] last year, and I was kind of showing her some things on SMART Notebook and she never knew them. Even the most, kind of, what I thought were basic and simple things. And I was telling her, "Well, when I was, you know, [in college], they required us to go to this...SMART Board training." And...I remember that being so helpful. Like, I learned a lot from that. (personal communication, January 27, 2019)

While her exposure to digital pedagogical approaches were limited, during her student teaching semester in a second grade classroom, Thea developed an affinity for teaching with a SMART Board, a staple of her kindergarten instruction today:

In student teaching, my [cooperating teacher] used it a lot. She loved using the SMART Notebook app...And so I think that's where I, like, developed my love [for] it, 'cause I use it a lot and kind of rely on it. She used it daily in our, like, math... Like, an introduction to math. She'd put, maybe, a clock on there and then she'd move the hands and they'd have to write what time it was on their board. And then, she's pick a kid, and they'd come move the hands, and then it would just keep going just as a warm-up to start math that day...There were review games, um, using the - I don't even know it's still there. I tried to find it and I think they took it out - but it's called Vortex. There's these two spinning... things, and, um, it says, like, Fiction, and then, Non-Fiction, and then she'll put a title of a book and they'll have to move to, they'll move it to the right one and it sucks it up. If they move it to the wrong one, it, like, spits it out...Um, then we played Jeopardy to review things. And...there's just so many different ways that it was used. (personal communication, January 27, 2019) 
Thea did not begin her classroom teaching career immediately after college. She attributed this decision, in part, to an experience she had at the end of her student teaching semester:

So, right after college I got a little overwhelmed...Right before graduating, I kind of had a...[laughs] a thought. I was like, "I don't know if I'm ready for this." Because it just seemed like a lot, and really, the reason, what made me overwhelmed was during my student teaching placement that we had to do room walks. So we walked into different teachers' rooms...and, I went into this teacher's room who had just so many things and she was just so prepared and organized. And just the thought of all that, like, applying for jobs, and possibly getting one in the next couple months, it overwhelmed me. So I was like, "I'm not ready to go into this yet." So, I, um, worked in a daycare for a year-and-ahalf. And then after working at that daycare for a year-and-a-half, I was definitely ready to get into a classroom. [laughs] (personal communication, January 27, 2019) Thea began interviewing for classroom teaching positions in the districts in and around her hometown:

I just wasn't getting anything and had some really awful interviews. I just was not a good interviewer. And [laughs] I went down to, I just felt kind of called to go to Memphis, Tennessee. So, I taught [second grade] there for two years, and...had an okay experience. I think it was good, a good experience for my first two years, because there were a lot of behaviors there and I feel like I, that's where I grew the most. (personal communication, January 27, 2019)

In January 2016, during Thea's second year in Memphis, her mother suffered a stroke. At the time, her mother owned and operated her own cleaning business. Thea mentioned that 
currently, her mother had "been out of work, just creating things and sewing things [to] sell them" (personal communication, February 14, 2019).

Thea felt compelled to move back to her hometown to be closer to her mother following the stroke. She applied for positions in her hometown district again. Though she had been looking to continue teaching second grade, she ultimately accepted the full time kindergarten classroom teaching position she has held for the past three school years. Thea noted, "It's actually the same school [where] I did that teacher walk...where I was feeling a little overwhelmed" (personal communication, February 14, 2019).

She explained how her journey was further entangled with this teacher with whom she had been both impressed and intimidated:

It's so funny, because that's how I got the job, because...my friend whose room I'm in now, she ended up taking that first grade position. So, my friend Emiko was teaching kindergarten, and then this lady, the first grade teacher who had collected all these things, and her classroom was so amazing, she had been teaching for years and years, she retired. My friend moved up into her classroom, and I moved up into, um, the classroom that my friend moved out of...So, it's kind of funny, because [laughs] she's not the reason [I was initially unconfident.] I mean, I felt wrong by myself...It makes sense now. This lady's been teaching forever. Of course she had it all together. (personal communication, February 14, 2019)

Over the past few years, Thea has been taking graduate courses at her alma mater to earn a master's degree in Teaching and Learning. "I knew I always wanted to get it," said Thea, "just to keep moving up and, you know, keep learning” (personal communication, January 27, 2019). 


\section{Thea's Pedagogical Design}

Thea characterized the Memphis school where she spent two years teaching second grade as "shady" (personal communication, January 27, 2019). In the following interview exchange, she shared that curricular pacing was rigidly standardized and the school environment was not very inspiring:

Thea: [Expectations were] communicated in...um, sometimes not the nicest words and sometimes yelling by other adults. And -

Aaron: Really?

Thea: Um, yeah. Like, we had to be very uniform in everything that we did. So as a second grade team, there were five of us. And...we needed to have everything the same. Like, everything from...the morning to math, science to reading, that all had to be the same and taught the same, the exact same time too. And so there was a time Aaron: [exhales in disbelief]

Thea: - you know, when I was teaching math, and my...coworker next to me, she was teaching science. Science was her thing, you know. She was all about science. Aaron: Mm-hmm.

Thea: And I was on math. I moved on, like I was supposed to. Aaron: Okay.

Thea: And I got yelled at and called out. We were on two different subjects. Aaron: Wow.

Thea: Yes. It was...it was just not the type of, you know, environment. It's just not conducive for teachers and students... That is very stressful to work under. 
Aaron: I know you were kind of, like, called back to [your hometown] because of your mom's health and stuff -

Thea: Mm-hmm.

Aaron: - but do you feel you would've stuck around Memphis much longer anyways, even if you mom hadn't had the health issues?

Thea: No, I really don't think so. Um, I never imagined myself being there for good. Aaron: Okay.

Thea: When I, when I moved there, I was really excited, but after...year two of teaching at that school, I was starting to get nervous, 'cause...I had felt like I was getting brainwashed their way...There had been teachers there that had worked there for 30 or 40 years and who wanted so badly to get out, but they felt that they couldn't. So, I started to see, I started to hear their stories, and I was, like, afraid that that was gonna' be me. So, I knew I didn't want to be there, but I was afraid that I wouldn't, you know, get...anything else.

Aaron: Yeah. Well I'm glad you did, and I appreciate -

Thea: Me too!

Aaron: - you sharing that, 'cause that's... That sucks, that you had to put up with that for as long as you did.

Thea: Yeah...I just feel for the people that stayed in it, because they were, you know, it was almost, like, just verbal abuse from our administration.

Aaron: I would say so. Yeah. 
Thea: Yeah. They would yell during, like, I remember one specifically, um, [the administrator] was yelling during her observation...She was like, "No! That's wrong!" And I'm like, "No, aren't you supposed to be typing during the observation?" Aaron: Oh my god...

Thea: Yeah, and she was, like, screaming in front of her third graders. Aaron: [laughs]

Thea: It was just, it was not a great environment. But I am very grateful to be out. (personal communication, April 29, 2019)

In addition to the stressful school climate, the technology available to Thea was limited compared to her student teaching experience:

We were provided with...errr...a little SMART Board...It really was used as a projecting screen, because it didn't hook up, and it didn't really work as a SMART Board. And it was on wheels. It was like a movable and portable one and it was...really interesting. And I wished it would've...been used as one. But yeah, it was just kind of used as a projection... [Our district-issued laptop computers] were not supposed to leave the building... This one [I'm video chatting with you on] now, it's, this is my school one...I use it all the time. But...yeah...we were not allowed to take it...I remember using [the SMART Board] in a lesson once, and the lady who observed me, she had been teaching for years and years, and I remember her commenting. She was like, "I never thought to use my SMART Board in that way." "Cause I put, for my lesson, they had to write a letter. And so... they...went up, and, like, I had them draw lines. So, my kids had to use... an Expo marker [laughs], which didn't wipe off easily, but that was the only way we could write on it. So they had to go up and, like, put the parts, like, where they go, which 
is pretty cool. So, that stuck out just because...she...I don't know how much they used...that board in that way, those teachers in general, in that building, um, but she was just very shocked at that, and I didn't think that that was that big of a deal. Um, but that stands out. But yeah, I used it pretty much as, um, a projector...unfortunately...I think [I had] four or five desktops, in the classroom to use...I had 32 students, so for six of them, that's where they sat unfortunately...We'd have to move the keyboard up so they could do their work or eat their breakfast. (personal communication, January 27, 2019) With technology access and stifling school culture challenges, Thea felt limited in how she could design instruction that incorporated digital technologies, especially student-centered digital learning experiences. Designing interactive lessons in which students could manipulate content on the board was an approach Thea knew she could draw upon if only she had the instructional and creative freedom along with the needed hardware; however, she was only really able to utilize the SMART Board to design overt instruction (e.g., projecting content) or situated practice (e.g., allowing students to annotate with dry erase markers) opportunities.

Thea changed classrooms between her first and second year in Memphis. She explained how the physical formats of these two spaces impacted her design of instruction with digital technologies in different ways:

With my second year there, I had more room. And so...I think that helped a lot. So, we did a lot of Go Noodle, and I introduced them to that. Just a lot of fun videos and...different things...It was just a big open area. It was called open space, and we were not in our own classrooms, but we were in a big, giant area. So, we had to, like, section off our classroom with something. So, like, I used these black milk crates to kinda' section it off, and that was my space. Um, but all the... There was one area though that 
we used these things that slid. I can't even explain what they were. They were like these big partitions. And we would just slide 'em and it kind of closes off the area. And so, my second year, I was moved into that area, and I was the only one that could, like...close off the area...It was, like, four times the size of where I was before. So, I thought, like, that first year, I couldn't really, like, do too much with, you know, them getting up and, "Let's do Go Noodle!" Or do a calm down video or something, because it would be heard and kind of too loud for the other classes. But with me being in that new area, I did more of that, because I could close my little partition thingies. Oh my gosh. So...[pauses and exhales] There were five of us; five second grade teachers. And one teacher that taught special ed. So, six of us...And you have to keep their attention. I'd have to get up there and do backflips to, like, keep their attention...Y You know, you'd get them looking [over] here, because as soon as another class, like, played a song or just did anything or...even if a kid got upset, it's just all eyes over there...I feel like because of that, and that first year, I just couldn't do as much, because I was trying to be, you know, considerate of those other sections...I feel like I definitely used [the SMART Board] more that second year, because I was over there and I didn't have to, you know, worry about bothering anyone or if it was too loud or if my kids laughed too much at a funny part of something. (personal communication, January 27, 2019)

During her first year in the shared space, Thea had to remain in dialogue with considerations for other classes with regards to her uses of digital technologies. Conversely, Thea's kindergarten classroom in her hometown district, where she currently teaches, has brickand-mortar walls and is equipped with a SMART Board with which her students can interact and 
manipulate digital content regularly. The privacy and technology of Thea's current room had subsequently impacted her instructional design differently than her spaces in Memphis:

I think I'm able to do more, because I don't have to worry about, um...[pauses] you know, like, if it's too loud or...[if] my kids' reactions are too over-the-top. Um, because that's something I had to worry about often in...you know, in Memphis with, uh, everyone else so close. So now, you know, I have four walls and a door, so that's really nice. We're able to, like today, we did StoryBots, and their reactions when we do that are just, like, off-the-wall. And so, that is something I could not have done in Memphis, just because it would've been, I would've had to monitor that and probably skip it or just pick a time where, you know, other classes were out...Yeah, it has a major impact. (personal communication, April 29, 2019)

In several of our discussions, Thea shared how central the SMART Board is to her instructional design, especially for teaching mathematics. "I [use] it daily for math," said Thea. "Like, [the SMART tech] pretty much drives my math lessons...I rely heavily on it" (personal communication, January 27, 2019).

Activities like the clothing color graphing activity I observed in which students can individually manipulate content on the SMART Board are popular among Thea's kindergarteners. During our final interview, I asked her to share routines and strategies she uses (besides the popsicle sticks approach I saw during my classroom visit) to ensure the students get equal turns to work at the board:

One that they really enjoy, where I'll call the whole table up and...we'll put something, like, put like a little game on there. And they'll have, like, a minute to answer as many questions as they can. Like, one, the whole table is standing there in a line, one kid comes 
up and chooses an answer and goes to the end of the line, and they just keep going. Um, and we'll do that for each table...And another way, I'll call a random boy or girl and then once their turn is over, they have to choose someone of the opposite sex so then, [everyone gets a] little bit of [an equal] chance. (personal communication, April 29, 2019)

Thea explained the specific elements of the SMART Board that she leverages for engaging her young kindergarten students. For some activities, the visual references and annotations from the board spark meaningful dialogue and problem-solving between the children. She shared a specific example from a recent subtraction lesson (Figure 13):

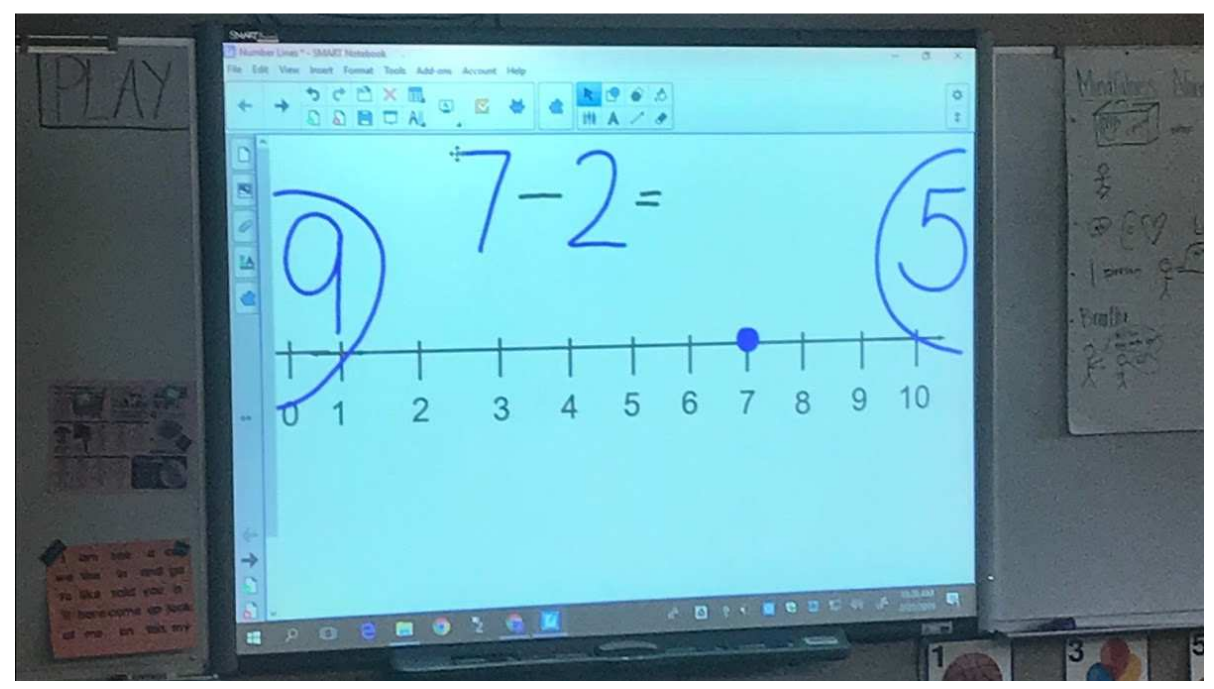

Figure 13. Thea's subtraction SMART Board activity

Okay. This makes me laugh, because they...are like, crazy with this. So, um, this is when we were doing...subtraction and learning how to use a number line to subtract...I'd write a problem on the board and they would have to...go to that side of the room. Like, "If you think it's five, go to that side, and if you think the answer's nine, go to that side of the room." Um, so...yeah, they would take a few minutes to try to figure it out by themselves and then move to wherever they thought. And once they got to that spot, they had to talk 238 
to the people who were also in that group and talk about why they know it's their answer. [laughs] Like, thinking seven minus two is nine. "How do you know?" And then, I choose, like, two representatives from each...side, and they have to...explain their reasoning behind it. So, it's, it's hilarious..because it's so funny to hear them explaining it, because they're, you know, they're so little. Their...little explanations are just so cute and, like, the seven [laughs], the people who chose nine, they just know they're right! They're like, "Well, you know, see, you put it together," and, like, it's funny, because, like, my seven minus two people, like, my five answer people, they'll be like..."I looked where the dot is and I went back five times and landed on two." And then it's so funny to see kids from the nine section be like, "You're right." And then like, move over there. It's a fun activity...So then, after listening to their, you know, their spiels, I take the answer, and I move it. So, I'll, like, take the five and move it up, and then, everyone that's on that side, like, loses their minds, and, um... But we've talked about, 'cause they get so excited when they're right, they're on the right side, so we talked about...say "good try" to the people. So it's so cute. So they walk over to the other side and they're shaking hands like, “Good try! Next time you'll get it!” It's so great! Like, they celebrate with their little "Yes, we were right!" and then they go over and shake hands. (personal communication, March, 19, 2019)

In this particular example, the approaches Thea drew upon were not just limited to the SMART technologies. Rather, she used visual models and annotations from the SMART Board to integrate rich discussion and debate, having students justify their reasoning for how to solve math equations. In this scenario, the students critically framed the subtraction examples, applying reasoning and modeling strategies to solve new equations. 
Thea and I discussed this particular lesson again during our final interview. In that conversation, she explained the affordances of integrating the SMART Board for this activity:

The visual's there, so I think that's really helpful, because they can kind of see it. And in that particular lesson...seeing it there and having someone talk about it helped a couple students see that, "Oh, I shouldn't be on this side. I should be on the other side." Um, so just, like, having the visual there while they were explaining it helps a lot, because I can't imagine not, you know, them not seeing it...You know, they all learn in so many different ways that it would be hard for me not to see it up there while I'm discussing it or while I'm trying to solve it...They're like, 'Oh, well I started at seven, and it says 'minus two,' so I jumped backwards two times." And then they'll even point to it and show us some points. (personal communication, April 29, 2019)

Thea finds and downloads many SMART files from a website called SMART Exchange where educators can post and download freely. During our focus group, Thea shared an example of a math pattern lesson (Figure 14) she taught in which she used a SMART Exchange resource: This is one of quite a few slides talking about, um, pattern blocks with my kindergarteners. Um, this was, like, later on in the unit when we are just doing some patterns with them. Um, and they have to come up and put them in the right order. And...just talk about what comes next and all that stuff...It's a SMART Notebook file...I got it from...SMART Exchange. I don't know if you ladies have heard of it, but it's a pretty cool resource. You can go and just type in, like, any subject and...there's all types of things on there, uh, free, free for you to download and use and tweak for your liking...There were several slides and different patterns. So, they could come up and move a piece and then choose a friend to move the next piece... They did a really great job. 
Today, we went back, 'cause this was months ago, but today, um, we actually went back, uh, to...one of these slides, 'cause they wanted to build. So, on another slide, there's an animal or some sort of object...It uses a bunch of pattern blocks and they have to build, so it was pretty fun. Um, it's a really cool document. It just has so many, just a big variety of things in it...After we practiced the slides a few times, they got the chance to come up with their own patterns, and, um, have their friends guess it, 'cause we were talking a lot about A-B patterns and things like that, so... They got a chance to work with the [digital] manipulatives themselves. (personal communication, March 6, 2019)

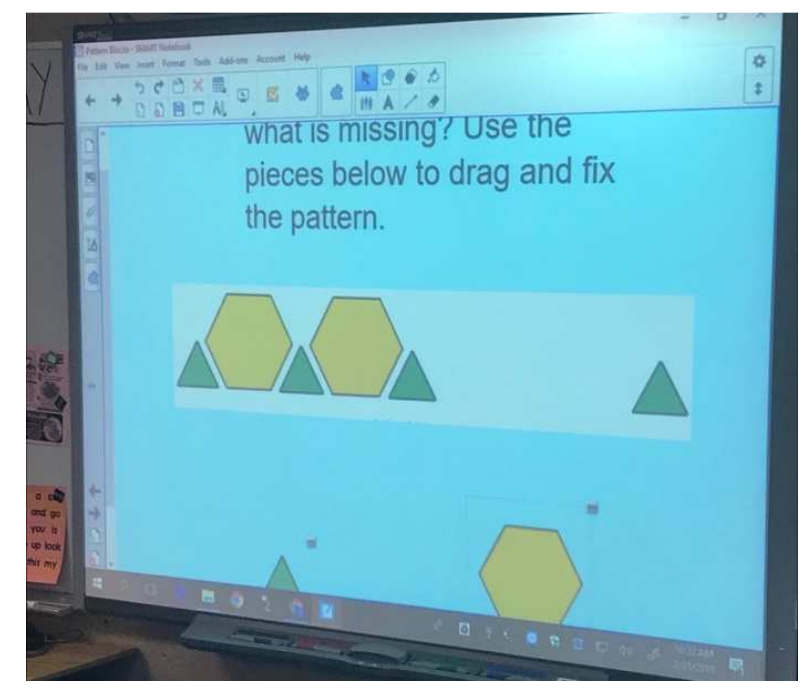

Figure 14. SMART Notebook slide from Thea's mathematics pattern lesson

Thea previews files on SMART Exchange before downloading them. Her primary evaluation criteria are that they are appropriate for the learning needs of her students and will help her facilitate active student participation. In the following interview exchange, Thea shared a story about a time she was searching for a geometry activity:

Thea: About a month ago, I was looking...for, um, some slides or...a document for, uh, shapes.

Aaron: Mm-hmm. 
Thea: So, um...I just logged on and typed in, um, "shapes," and then put "kindergarten," and then clicked through and just found some...different ones for that.

Aaron: Mm-hmm.

Thea: And...I clicked through, and some were just, like, basic, like identifying shapes, and some, um, the ones I actually ended up keeping had, like, really cool slides where it was, like, comparing and, like...differentiating between the different shapes. It just had different activities on every page.

Aaron: Yeah.

Thea: Um, so I kind of pick it based off of that, because if it's like...pretty basic, you know, I could throw that together [myself]. So when I'm looking on there, I'm kind of looking for something that's gonna' be...pretty interactive and...have a lot of good stuff. Aaron: Okay. Can you, like, when you're looking at 'em on SMART Exchange - 'cause I'm not, I'm not familiar with it at all - can you, like, preview the slides in your browser or do -

Thea: Yeah!

Aaron: - you have to download them and go through 'em? How does that work?

Thea: Yeah, you can preview it. You can actually look there, right there. You just click this arrow -

Aaron: Okay.

Thea: - you go through all the slides. It's, for you -

Aaron: Nice. That's definitely more helpful than downloading them.

Thea: - to not have to download it beforehand.

Aaron: Yeah. Absolutely. (personal communication, April 29, 2019) 
It has been helpful for Thea to be able to take home her district-issued laptop computer, as opposed to her district in Memphis that prohibited laptops to leave the school premises:

Oh, it, like, enhances [my instructional design] a whole bunch, because then, even though I don't want to spend too much time outside of school on it, it really does help...I'm more comfortable at home, and I'm able just to, like, open a bunch of tabs and, you know, find a...bunch of different things and...yeah...I'm kind of rushed at school. (personal communication, April 29, 2019)

Thea modifies her downloaded SMART files and creates her own as well. "I can't think of too many times where I have not added something or taken something out from something that I've downloaded," she said.

Thea remains in dialogue with the diverse needs of her young learners as she selects and modifies SMART files:

There's a few things. Like, one is just, kind of, bringing it to $m y$ students' level. Some things on there are really good. I love the idea, but I'm like, "Maybe we're not there yet," or "Maybe we're a little past this, so I'll make this a little harder." Or, like, I'll add their names too, 'cause that's huge. So, like, if I take out a couple names in a problem and add my students' names... (personal communication, January 27, 2019)

Thea shared the story of when she modified a SMART Exchange resource for her positive behavioral interventions and supports (PBIS) group during a recent school year: So, [my co-coach and I] had to create a review game...I'm a PBIS coach at my school, and so we had to create...kind of like a norms and rules and expectations game for, um, when we came back from winter break. Just to...review with students. And, so, in SMART Exchange, you, like, it was just a Jeopardy game. Kind of a blank game. And so what we 
did was we just made...you know...filled in questions and answers. It was just a blank game and it had categories...And, yeah. Just edited it and the questions and answers. (personal communication, April 29, 2019)

Thea also designs SMART Board content to use for conducting interactive assessments with individual students. She shared an example of a SMART file she created to assess phonemic awareness in her reading intervention group (Figure 15):

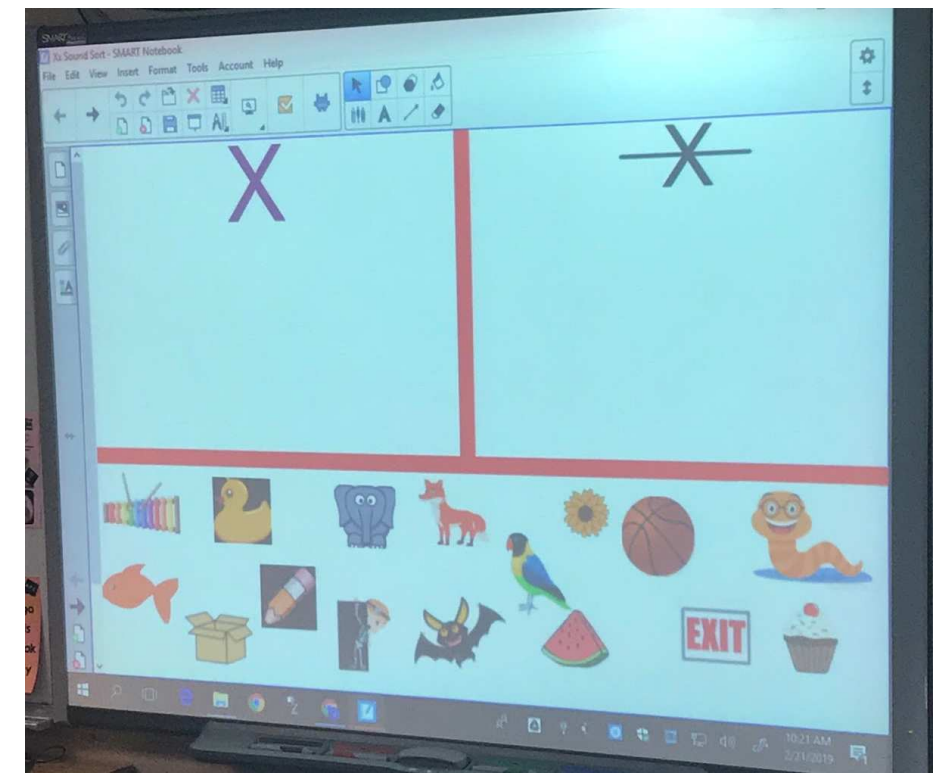

Figure 15. SMART Notebook slide from Thea's intervention lesson

Thea: So this is actually from my intervention group, from, like, the very, very beginning of the year -

Aaron: Okay.

Thea: - when we do a lot of [different] sounds. Um, yeah, so they, we talk about it and watch a couple videos on it and they have to come up and kind of show me what they know. I use this kind of as an assessment Aaron: Mm-hmm. 
Thea: - um, in a way, just to kind of see, like, “Oh!” You know, as they come up, I'll jot their name down, so, you know, "Quentin thinks 'cupcake' has the 'x' sound in it." Aaron: Mm-hmm.

Thea: So, it's a good way to do that. And it's fun for them,' 'cause they love any chance to manipulative the board and -

Aaron: Sure.

Thea: - come up there. Um, it's, uh, yeah.

Aaron: And was this something that you, um, you downloaded that was precreated?

Thea: $I$ created it, actually.

Aaron: Nice. Do you -

Thea: Yeah.

Aaron: - do you create a lot of stuff like this for those intervention phonics lessons?

Thea: Oh yeah. Yeah. For intervention and math, yeah. I create a lot. I should upload it on [SMART Exchange], because they have a ton of things, and I use it a lot. So I, maybe I should give back. [laughs] (personal communication, March, 19, 2019)

Moving forward into her fourth year of teaching kindergarten, Thea looks forward to completing the final courses in her master's program. She also wants to continue finding ways to improve her instruction so the students can more actively participate in learning activities. We discussed her goals for her teaching, including designing instruction in which she does not use the SMART Board:

Aaron: How do you decide when to not use technology in your teaching? 
Thea: Oh! How do I decide when not to use technology in my teaching? [pauses]

Uh...that's, I don't know how to answer that...I guess when I'm...trying to get students to be more...like, hands-on and when it's more student-led-

Aaron: Okay.

Thea: - because, you know, when I teach up there on the SMART Board, it's pretty, I, teacher-led.

Aaron: Can you think of an example of when you didn't use the SMART Board and it was more that...student-led context you're talkin' about?

Thea: Umm...one time, they had to go around the room and find, um, equations. Aaron: Oh, fun!

Thea: And if they found it, they did it, and they solved 'em. Only, I just used the document cam and solved it, solved 'em together -

Aaron: Awesome.

Thea: - to check. (personal communication, April 29, 2019)

\section{Conclusion}

In Chapter IV, I presented the co-constructed narrative of each participant in three parts. First, I presented a first-person narration of my classroom observation of their teaching with digital technologies. Next, I narrated an overview of their life story. Finally, I presented the coconstructed narrative of their pedagogical design with digital technologies. The pedagogical components each participant used in their teaching as well as the myriad of factors with which the participants were in dialogue were depicted in each co-constructed narrative. The results of my analysis are shared thematically next in Chapter $V$. Then, in Chapter VI, I answer the 
research question and secondary questions, discuss implications of the study, and pose questions and direction for future research. 


\section{CHAPTER V: DISCUSSION}

I conducted a constant comparative analysis within and across the narratives of the five participants using the theoretical frameworks that guided this study: Britzman's (2003) dialogic theory of teacher practice and the New London Group's (1996) pedagogy of multiliteracies framework. Specifically, I conducted several thorough readings of each narrative and inductively coded examples of pedagogy in dialogue with personal, sociocultural, and professional factors, reformulating codes as themes emerged and evolved (Tracy, 2013). Additionally, I deductively coded the narratives when the participants emphasized any of the four pedagogical components (i.e., situated practice, overt instruction, critical framing, and transformed practice) when teaching with digital technologies.

In this chapter, I will discuss the results of these analyses and position them within the research base. I will present the factors with which the participants were in dialogue thematically and the pedagogical components they emphasized categorically. Parsing out the findings from the dense, lengthy co-constructed narratives presented in Chapter IV facilitated the tasks directly addressing and answering the research question and sub-questions, discussing the implications of this study, and making recommendations for future research in Chapter VI.

\section{Pedagogy in Dialogue}

The participants' narratives revealed their teaching practices and pedagogical design efforts did not occur in a vacuum. Rather, they were engaged in ongoing dialogue with a myriad of factors that included the following: core beliefs, district curricula, institutional factors, perceived pedagogical affordances of digital technologies, professional development and collaboration, self-efficacy, student needs, and technology access. 


\section{Core Beliefs}

Personal core beliefs and principles were a dialogue partner for many of the participants as they designed digitally-mediated instruction. Nora's pedagogical design is driven by her core belief in providing individualized support for each learner to help them experience success at school. She developed this mindset through her student teaching and graduate school experiences. Nora evaluates and selects new digital tools to use based on if they contain components that will help her accommodate individual learners.

Iris's father instilled a passion for U.S. and world history in her at a young age, bolstered by their trips to historical sites when her family lived on the east coast. This passion carried over into her design of social studies learning activities, such as in lessons in which she supported her fifth graders' development of appreciation and respect for the victims, survivors, and first responders of $9 / 11$.

Likewise, Felicity developed a core pedagogical belief about the importance of students having regular opportunities to read independently. She felt this conviction informed her facilitation of students' fluency recording experiences. Felicity also felt strongly enough about primary-age students using modern digital technologies in the classroom that she brought in her own personal iPads and advocated to her district's technology coordinator about getting new devices her students.

An additional concern for both Iris and Laurel was the idea of limiting students' screen time, informed in part by their identities as mothers. They both expressed a desire to use technology in intentional ways, reducing students' errant time spent on digital devices when other effective non-digital alternatives were available. 
Valcke, Sang, Rots, and Hermans (2010) defined the core beliefs teachers possess and draw upon in their professional practices through a cognitive lens. These beliefs primarily serve as "filters" (Barnes, Brighton, Fives, \& Moon, 2019, p. 527) for how teachers view the students they teach, epistemology, contextual matters, and, among other factors, media and digital multimedia (Abu Al Rub, 2015). Teachers' beliefs impact how they view the daily happenings in their classrooms and subsequently, their design of instruction (Bethke Wendell \& Rogers, 2013; Roose, Vantieghem, Vanderlinde, \& Van Avermaet, 2019). An educator's beliefs and subsequent actions may be shaped by what they perceive as within their control and influence versus factors that they view as permanent and unchangeable (Dweck \& Leggett, 1988); however, experiences and professional development opportunities teachers perceive as impactful can spark shifts in these beliefs (Lanterman \& Applequist, 2018).

Felicity and Nora shared core beliefs about how they intentionally designed the cultures of their classrooms, expressing how classroom culture was integral to how they fostered student uses of digital technologies. Felicity shared a story of how she spoke with her first graders often at the beginning of the school year about how making mistakes was a critical part of learning and growth. In creating their reading fluency recordings on the iPads, students were encouraged to correct oral reading miscues and keep going. The students were allowed to be critical of their recordings and redo them as needed while having the freedom to make mistakes without being judged by Felicity or their peers.

In a likeminded fashion, Nora maintains an ethos that each individual learner can and should be able to experience success and growth in her third grade classroom. This mindset informs how she explores, evaluates, and implements new digital tools. In our interviews, she shared a few stories of specific students she has worked with who struggled with severe 
behaviors and/or emotions and how she leveraged technological innovations (e.g., zSpace, Lexia, etc.) to provide individualized learning experiences and comfort.

A liberating classroom culture does not assign students to a prescribed track based on economic, social, or academic status (Airhihenbuwa, 2007). The core ethos central to the classroom environments established by Felicity and Nora were founded on principles of critical pedagogy, leveraging digital technologies in ways that positioned students not as actionable objects (Greene, 2009), but rather, empowering their learners to achieve success and transcend social barriers (Forzani \& Leu, 2012; Kerkhoff, 2017; Luke et al., 2018; Tabb, 2008).

\section{District Curricula}

Designing instruction that met the learning objectives and standards of mandated district curricula was a concern woven into each participant's stories. Thea faced rigid standardization and pacing in her district in Memphis that restricted her pedagogical creativity. Felicity utilized digital resources from her district's math curriculum; having these interactive resources available to use on her SMART Board saved her time in designing something new, but she felt the content was outdated and could have been better.

Nora designed assessment blueprints to guide her design of instruction, helping her intentionally teach and assess within the scope of district curricula. However, she expressed feeling freer in teaching with technologies at a summer STEM camp in which she was not bound to specific pacing or standards. In the STEM camp setting, she could design learning activities driven by purposes the students found authentic and motivating.

Iris was in constant dialogue with her district's curriculum in different ways throughout her time as a third and fifth grade teacher. As a new teacher to her district, she was still becoming familiar with the curriculum, which made the added task of integrating digital 
technologies into her teaching more challenging. As she became more comfortable with the curriculum in subsequent years, she developed digital approaches, including the greater utilization of her blog as a teaching resource. She also designed digital learning activities to supplement the limitations of her district's outdated fifth grade social studies curricular program.

Digital technologies have reframed literacy in a plural sense (Lankshear \& Knobel, 2003, 2007; Leu et al., 2009) in that students can participate in different socially-situated discourses (Gee, 2015b; Street, 1993, 2003), some of which take place primarily in multimodal, digitallymediated contexts (Cope, Kalantzis, \& Smith, 2018; Jones \& Hafner, 2012; Steffen et al., 2019). What comprises literacy now is different from past conceptions and will undoubtedly evolve in the future (Leu et al., 2013).

However, recent U.S. standardization reforms (e.g., CCSS, Race to the Top, etc.) have promoted common educational experiences that states and districts must adopt to receive federal funding (McGuinn, 2016). Implementing such reforms at the district, school, and even classroom level often funnels standardized curricula through pre-packaged textbooks and kits, a form of maintaining hegemonic, politically-driven norms (Counts, 1930; Kliebard, 2004; Scollon et al., 2012). Classroom teachers maintain unending dialogue with curricula and associated educational reforms as well as their own internal discourses (e.g., beliefs, interpretations, PCK, etc.) in designing instruction (Alsup, 2006; Britzman, 2003; Chase, 2005). To teach mandated curricular content, several of the participants used transmission-based approaches.

Historically, transmission approaches with technologies have been widely used for teaching and learning purposes (Cassidy, 1998; Knupfer, 1993; Meredith, 1971). Teachercentered instructional strategies and control over curriculum and instruction have been promoted since the late 19th century dating back to the work of the Committee of Ten (National Education 
Association, 1894) up through the present day with reforms such as CCSS (National Governors Association, 2010) and Race to the Top (McGuinn, 2016).

Each participant utilized digital technologies to transmit academic content to students. In some cases, the transmission was passive in nature, in that the students did not directly interact with the content outside of watching, listening, and/or discussing. Some participants also designed instruction that included interactive transmission in which the students directly interacted with or manipulated the digital content in some way. For the purposes of this discussion, I distinguish transmission from other forms of student technology use in that the teacher, not the students, curated, designed, or remixed the content being transmitted.

Many of the participants utilized their digital classroom boards to facilitate passive transmission, projecting content as part of whole class teaching. Thea modeled how to conduct the Goldfish cracker graphing activity on her SMART Board using a connected document camera. Similarly, Nora and Laurel used their boards to project math problems, as visual aids, to solve with their classes. Nora also used her mobile SMART Board as a resource for writing notes in a small group discussion about reading aloud with expression. Iris led her fifth graders through a guided reading and analysis of a Boston Massacre testimonial on her Promethean Board before having the students complete similar analyses on their own; she also used passive transmission in digitally sharing these primary sources with the class on her blog.

As an example of passive transmission that did not involve the use of a digital board, Felicity played an audio read aloud of Somebody and the Three Blairs from a cassette tape player while a student turned the pages of the print version at an easel.

Each of the participants utilized their digital boards to facilitate interactive transmission in their teaching. Thea's students plotted data on precreated graphs and solved problems she 
projected from SMART files or websites like StoryBots. Felicity, Nora, and Laurel displayed math problems that their students annotated to discuss and solve with the whole class. Likewise, Laurel used her Promethean Board for students in an impromptu small group to annotate and solve a fraction problem during a collaborative breakout time in the math lesson I observed.

\section{Institutional Factors}

Throughout their narratives, each participant exchanged dialogue with various institutional factors in their elementary school contexts. At times in their careers, both Laurel and Iris perceived implicit pressure from their district administration to regularly utilize technology in their teaching, due in part to mandated coaching meetings and the large investment in modern devices for students. Several of the participants noted unspoken expectations they felt to ensure their students were prepared for digital society in the 21 st century. Deterministic mindsets about technology persist throughout society (Chandler, 2012), including schools, which are treated as microcosms of humanity and are subject to pressures and control efforts (Arendt, 1954/2006; Cuban, 1990; Mahiri, 2004; Penuel \& O’Connor, 2018; Thomas, 1980). Teachers may experience tacit pressures to shift their instructional Designing toward digital formats simply because it is 'expected' (Scollon, 2001).

The participants also shared institutional factors that they felt positively impacted their teaching with technology. Felicity teaches in a small rural district with one large school building in which the elementary students are just a hallway stroll away from the high schoolers. This proximity allowed her to coordinate with a colleague to arrange high schoolers to help her first graders type and print multimodal compositions. The professional growth plan Iris was required to develop in her district pushed her to design opportunities for student-centered uses of technology in her social studies lessons. Nora felt supported and encouraged by her building 
principal - who provided her with a second SMART Board - to teach in innovative ways with digital technologies.

School leaders and administrators have influence over the professional development and support of classroom teachers to varying degrees. In Finland, for example, principals' contracts and evaluations contain specific language about goals they must meet, including fostering teachers' professional development and providing consistent instructional guidance. Finnish principals are also required to maintain teaching credentials and stay abreast of grade level/department curricula (Darling-Hammond \& Rothman, 2015). Principals and school leaders can more readily provide support, including providing access to resources, when institutional barriers and stringent regulations are reduced or removed (Clandinin \& Connelly, 1995; Seglem, 2015).

\section{Perceived Pedagogical Affordances of Digital Technologies}

As part of their Designing, the participants considered the pedagogical affordances of digital technologies they utilized in their instruction. Thea extolled the visual benefits of modeling subtraction equations using an annotated number line on her board, which promoted rich debates and discussions amongst her kindergarteners. Felicity found pedagogical affordances in the 'analog' technologies she continues to use with her first graders, such as the cassette tape recorder that her students used to record an audio read aloud book. The students were actively engaged as they used the external microphone and rang a bell to signify a cue to turn to the next page.

Nora has been drawn to digital tools that allow her to share in-the-moment performance data with her students, which also drives her future instructional design efforts. Laurel leverages the color palette and digital annotation components of the ActiveInspire application on her 
Promethean Board to emphasize and distinguish content and processes in her math instruction. She has also facilitated her students' digital writing on Google Docs, noting that her students were able to digitally edit and make revisions to their rough drafts with greater ease than on lined paper (which would require erasing and physically rewriting a final copy). Laurel was also able to check in on her students' progress on these digital compositions without collecting physical copies, assessing their work and preparing feedback and future instruction at her convenience. Iris also turned to digital means to solve problems of practice, specifically in her social studies lessons. In her Boston Massacre learning activity, she posted all of the sources students were to use as linked digital documents on her blog. Utilizing the digital format kept the primary source material more organized for the students. In addition, since her building only has blackand-white printers, digitally sharing war propaganda posters from the Revolutionary War era allowed the students to view and analyze them in color.

Several participants also shared stories of how they continued to evaluate digital tools they were using, sometimes finding other options that were more effective or useful. Felicity's students enjoyed creating a cassette-based read aloud recording; however, she is glad to have switched to a digital recording format in recent years for her students' daily fluency work due to the portability and ease of use of the more-modern iPads. Laurel utilized a grant she was awarded to purchase a newer Promethean Board for her classroom that will allow students to annotate content with greater ease. She also began exploring new annotation apps, like DocHub, for her students to use at the board.

Being able to assess students' learning and growth was a concern that remained on the minds of the participants as they designed instruction in which they integrated digital technologies. In short, the participants' viewed assessability as a key pedagogical affordance. 
Classroom teachers must be able to measure each learner's performance against defined objectives and standards and report them in a coherent manner to key stakeholders (Muñoz \& Guskey, 2015). Given that the participants taught in public schools at the time of the study, assessing students' performance against curricular goals was a mandated professional responsibility.

Thea implemented interactive phonics sorting activities on her SMART Board as an engaging way to assess students in her reading intervention group. Felicity leveraged the video recordings her first graders created of their reading to assess their fluency; she also selected specific texts for students to read and record in her classroom studio as a means of assessing targeted skills and strategies. Simply put, effectively monitoring and implementing interventions and targeting instruction requires collecting data regularly to inform future decisions (Penuel \& Shepard, 2016).

Nora is drawn to digital tools that allow her to assess each student's performance and review whole class assessment data during lessons in real time. Likewise, Laurel used the digital access she had to her fourth graders' writing drafts through Google Classroom to check on their progress and provide individualized instruction. Iris creates rubrics to share with her students prior to having them complete digital assignments and projects. These rubrics not only guide her assessment of nontraditional, multimodal assignments, but they establish expectations for the students as they complete these tasks as well.

Incorporating multimodal work, such as content students design with digital technologies, in classroom learning activities is inherently disruptive to institutional views of literacy, including how students can be assessed outside of traditional text- and print-based approaches (Bazalgette \& Buckingham, 2013). Subsequently, assessing students' digital products of learning 
can be complicated by institutional mandates and norms for assessment (Cope, Kalantzis, \& Smith, 2018; Elmore, 1993). Much like rubrics (Smith, 2017), digital badging, an assessment approach that can be used in digitally-mediated learning (Devedžic \& Jovanović, 2015), requires ascribing criteria that align to curricular objectives and learning standards (Hensiek et al., 2017). In spite of these challenges, facilitating digital composition work with students can allow teachers opportunities to assess and provide feedback in real time, both synchronously and asynchronously (Gierhart \& Brown, 2018; Neumann \& Kopcha, 2019). Assessment in the digital frontier still contains untapped potential that must be explored, such as data from students' digital writing efforts (e.g., timestamps, edit/version history, etc.) that can be quantified, analyzed, and applied to current teaching and learning practices (Smith, Cope, \& Kalantzis, 2018).

The idea of humans leveraging affordances, cognitively or physically, as a way of interacting with or modifying their environments was initially posed by Gibson (1986). Norman (1999) later distinguished between physical affordances of technological devices and perceived affordances, or those that individuals consciously identify and use, "even if the system does not support the real affordance" (p. 40).

Fitting with the dialogic focus of this study, though, is Blewett and Hugo's (2016) concept of "actant affordances" (p. 66), which emphasizes two-way networked interactions between objects and actors (i.e., teachers/students and digital technologies) (Kabat, 2014). Through a design-based lens, teachers explore technologies, redesigning their practices within the chronotope of their careers and life histories (Bakhtin, 1981b; Holquist, 2002). The affordances leveraged by the participants in this study were not learned in a professional development session or workshop and then implemented in a procedural, recipe-like fashion 
(Rust, 2017; Shing et al., 2015). Rather, they were developed through a dialogic continuum of experiences and enacted pedagogy (Britzman, 2003).

Technologies can be harnessed to enhance or even transform teaching and learning processes, allowing educators and students act, think, relate, and communicate in ways unique to the use of digitally-mediated approaches (Jones \& Hafner, 2012; Steffen et al., 2019). The participants mainly leveraged technologies as a matter of solving problems of practice more practically or efficiently compared to non-digital approaches (Leighton et al., 2018; Nolen \& Koretsky, 2018). Furthermore, affordances are tenuous and negotiable, in that they may not always be the best solutions to problems of practice nor transform teaching and learning meaningfully (Kim \& Xing, 2019). Finding new ways to leverage the affordances of digital technologies is central to constructing new professional meaning (Blewett \& Hugo, 2016; Roswell, Kosnik, \& Beck, 2008).

\section{Professional Development and Collaboration}

Professional development and collaborative efforts were both key themes in the narratives of the participants. In sharing her stories of practice, Nora made it clear that she valued continual professional development. This included her educational technology coursework she completed as part of her master's program as well as the in-service workshops and sessions she voluntary attended in her district. Effective professional development must focus on specific domains of academic content, include models of effective implementation, and involve active learning and collaboration (Darling-Hammond et al., 2007, 2017; Desimone \& Pak, 2017; Tondeur et al., 2012). Desimone (2009) recommended that teachers engage in a minimum of 20 cumulative hours of professional development to truly improve teaching practices toward a defined goal (Wolf \& Peele, 2019). Sustained, ongoing professional development is critical to 
supporting teachers' evolving and shifting perceptions toward new pedagogical approaches (Guskey, 2002; Norman, 1999), including those that are mediated by technologies (Davis, 1989). The participants also attributed some of their current approaches of teaching with digital technologies to past and/or current collaboration. Thea's predilection towards teaching with SMART Boards was sparked by her experiences as a student teacher. Having been equipped with a fully functional SMART Board in her current kindergarten classroom (as opposed to the noninteractive one she had in Memphis), she draws upon this approach daily. Felicity developed a high regard for 'reading-to-self' from her former first grade colleagues and digitized this approach with recent classes.

Laurel and Iris both expressed the benefits of working with Oliver, their former district technology coach, in learning about new digital tools that they could integrate into their pedagogical design. While the meetings were mandated on a weekly basis by their administration, both women attributed much of their initial progress in teaching with digital technologies to this collaborative relationship. In particular, Laurel often sought out Oliver's guidance and expertise before, during, and after the existence of the formal technology coaching program in her district. Also, while it is not a formal coaching relationship, Nora regularly converses with her school's media specialist to ask questions and learn about new digital approaches.

Successful instructional coaches are not authoritative, but rather, establish partnerships by designing and reflecting with teachers, empowering their voice, pedagogy, and expertise (Knight, 2007). Like effective professional development, impactful coaching should focus on specific teaching content, promote collaboration, and take place over an extended number of hours (Desimone \& Pak, 2017). Technology coaching can be guided by models such as Kurz, 
Reddy, and Glover's (2017) multidisciplinary framework of instructional coaching, which centers around defining desired outcomes, coaching actions, and the scope (e.g., skills, processes, developments) of the coaching relationship. Technology coaches must also 'meet' teachers at their current practices and expertise, providing and adapting guidance, supports, and resources for each individual practitioner (Frank et al., 2011; Freeman et al., 2017).

\section{Self-Efficacy}

Bandura $(1977,1997)$ posed the role of efficacy and outcome expectations in explaining human behavior through social cognitive learning theory. Framing the phenomenon of classroom technology use this way, teachers must first believe they can successfully implement it in order to achieve the expected outcome (e.g., smooth implementation with students, student engagement and achievement, student-centered learning, etc.) (Davis, 1989). A teacher's lack of confidence in their ability to implement technology to meet the expected outcomes "determines whether they will even try to cope with difficult situations" (Bandura, 1977, p. 79) that may arise when doing so.

Some participants shared how they felt their self-efficacy was impacted by their students' needs or behaviors. Felicity felt confident that her most recent group of first graders could troubleshoot technical issues for each other and self-direct their digital routines, freeing her up to teach small groups at her back table. Oppositely, Iris recalled fifth grade groups in the past that accessed inappropriate online content, fracturing her trust and deterring her from planning activities that involved independent technology use by students. On the other hand, Iris also spoke of how her recent fifth grade classes have developed knowledge and skills for working with digital technologies in previous grades. The students' prior experiences with Google apps 
helped her feel more self-efficacious that she could successfully implement digitally-mediated activities with little troubleshooting or student training required.

Participants also felt that past experiences and uses of technologies impacted their selfefficacy. Felicity had developed knowledge and skills with technology dating back to her use of her mother's typing keyboard during childhood. She continues to intentionally utilize a combination of 'analog' and digital technologies, depending on the instructional goal at hand, and shared that she was not scared to take up new digital tools and approaches. Nora also grew up using a variety of (primarily digital) technologies in her personal and academic pursuits from a young age up through her time as a student teacher. She maintained her consistent use of digital technologies as Available Designs in her teaching.

The availability of classroom aides seemed to impact a few participants' self-efficacy in positive ways. Felicity's aides were available on a consistent basis, so she felt she could depend on them to help students manage different apps and websites, freeing her up to teach differentiated groups of first graders uninterrupted. I also observed aides in Nora's third grade classroom support students in their use of leveled apps and websites, such as Lexia.

The participants in this study were in constant dialogue with their own self-efficacy, which they attributed to a variety of factors in their personal and professional lives. This may be particularly challenging for teachers of young children, as effectively facilitating studentcentered uses of technology involves conceding some degree of control to the students (Johnson \& Liber, 2008; Knupfer, 1993) and encouraging them to solve problems in unfamiliar ways (Lee \& Brett, 2015).

With their young elementary learners using a wide variety of technologies, Felicity and Nora both shared how helpful consistent classroom aides have been in facilitating students' 
digital efforts. Nora's class contained students with many challenging needs, so having the aides allowed her to deploy individual support for those specific learners. I observed a student in her classroom who struggled with managing his behavior and impulses working with an aide on the Lexia phonics program. Felicity utilizes her aides, depending on the time of year, in different ways. At the beginning of the year, her first graders need more help logging into different sites and managing the iPads. As they master these basic skills, Felicity transitions the aides from monitoring the students' use of technology to other helpful tasks, such as administering running record reading assessments.

Routines and procedures have been utilized to facilitate self-regulated learning experiences, particularly in primary grade classrooms (Xu \& Ko, 2019). Optimizing the classroom environment, including "temporal organization of routines and activities" (Han \& Kemple, 2006, p. 243), sets the stage for student success, particularly in students' formative years of schooling. Teachers form and reform classroom procedures based on case knowledge developed over their careers (Shulman, 1986). They must exercise pedagogical and developmental wisdom of how to best integrate different approaches, including digital ones, effectively and pragmatically with young children (Fiese et al., 2002).

Both Thea and Felicity have set routines for getting students turns to manipulate digital content at the SMART Board. They attributed these turn-taking routines as critical for promoting equitable and safe participation with this large scale classroom device. In addition to whole class use of the SMART Board, Felicity has also established and modified routines and procedures in her classroom over the years to support her students' independent use of iPads. This has included furnishing and altering the physical classroom space (e.g., recording booth, couches, headphones storage, etc.) to support her students' daily mobile work. 
As will be discussed later in this chapter and more so in Chapter VI with regards to the second sub-question of the study, self-efficacy is also tethered to one's attitude towards a given task to be accomplished (Mintzes, Marcum, Messerschmidt-Yates, \& Mark, 2012). Designing transformative teaching and learning opportunities involves a willing mindset by teachers.

Classroom aides, routines, and procedures can be leveraged to help young learners successfully engage in impactful digitally-mediated activities rather than routinizing students' educations just for the sake of facilitating classroom management.

\section{Student Needs}

The art of teaching is comprised of the pedagogical creativity of professionals that respond to and meet the learning needs of students in real time (Eisner, 1979). Through social changes, including the evolution of what is means to be literate (Leu et al., 2013), teachers and schools must adapt their practices and pedagogical design (Bruner, 1979). The narratives each participant co-constructed revealed that the needs of the individual learners in their classrooms were a primary concern in how they designed and implemented instruction with digital technologies.

Thea repeatedly modeled how to add to a shared bar graph on her SMART Board so her young kindergarten students would be able to successfully and accurately input data. Similarly, Laurel and Iris both teach leveled groups of fourth and fifth graders, respectively, and incorporate more modeling and review of content with groups that struggle with literacy and academics, utilizing visual aids on their Promethean Board. Additionally, Felicity differentiates her struggling math students' learning by providing additional opportunities to engage in guided practice at the SMART Board during lessons. 
Knowing how motivated and engaged her students are by manipulating content at the board, Thea searches for and designs (or modifies) SMART files that will facilitate her kindergarteners' active participation in learning activities. Likewise, Nora selects apps and digital tools that can offer individualized learning experiences for each member of her third grade class. In some cases, Nora has leveraged engaging technologies, such as zSpace, to support extreme student needs and find opportunities for those learners to experience success at school. Recognizing that her students needed varying amounts of time to find information and complete assignments, Iris began linking social studies content on her blog so students could access and use it to complete tasks at their own pace. As a young student, she had felt pressure to 'keep up' with the pace of when her work was expected to be completed; her view of students' needs, in a way, was also dialogically informed by her own needs as a past student.

\section{Technology Access}

Access to technology within the context of the classroom or school was a clear dialogic factor in the participants' stories of practice. In Memphis, Thea could not draw upon her previously-developed approaches from student teaching due to her provided SMART Board lacking interactive capabilities. Likewise, Nora expressed a desire to integrate the zSpace into her regular instructional design; however, having only one zSpace device in her classroom makes consistent use for all of her third graders rather impractical. Felicity had to bring in her own personal iPads to supplement the lack of technology provided by her district in past school years. To make up for the lack of color printing access in her school, Iris posted color versions of Revolutionary War propaganda on her blog so students could analyze these primary sources more effectively. 
By providing technology access in classrooms for students and teachers, schools can contribute to access that some learners may lack in their personal lives, "promoting social inclusion and equality" (Warschauer \& Tate, 2018, p. 64). While access may represent an initial step in tackling digital divides, teachers must also facilitate students' equitable and ethical participation in digital landscapes (Gierhart et al., in press; Jenkins, 2006; Luke et al., 2018). Intentionally fostering critical digital literacies is also essential to combat the litany of injustices and hegemonic norms that perpetuate digital spheres (Friesen, 2008; Losh, 2018).

\section{Pedagogical Components}

The New London Group (1996) defined four pedagogical components in the pedagogy of multiliteracies framework that teachers can emphasize at optimal junctures to support the meaning-making and literacy development of culturally- and linguistically-diverse learners: situated practice, overt instruction, critical framing, and transformed practice.

In reality, the participants continually engaged in "weaving" (Luke, Freebody, Cazden, \& Lin, 2004, p. 2) between different pedagogical components as part of their Designing (New London Group, 1996). However, for the purpose of disseminating my analyses of the narratives, I will discuss the ways the participants emphasized each of the four individual pedagogical components in their teaching with digital technologies.

\section{Situated Practice}

In situated practice, learners engage in discourses mentored by experts, developing "conscious awareness and control over the intra-systematic relations of a system" (New London Group, 1996, p. 95). Approaching situated practice from a global perspective informs instructional design in ways that facilitate diverse learners' participation in academic discourses (Kerkhoff, 2017). While multiliteracies are not synonymous with digital or multimodal 
approaches, technologies have impacted the way today's teachers and students engage in situated practice, and really, literacy practices in general (Thibaut \& Curwood, 2018). Situated practice was emphasized in a few stories in this study by the teachers enlisting mentors other than themselves; other times, the teacher served as the expert for the students.

Thea emphasizes situated practice as a central component of how she facilitates regular opportunities for each kindergartener in her class to manipulate content on her SMART Board in math class. For example, Thea's narrative includes stories of her students modeling addition and subtraction computations, extending and creating patterns, and graphing data to gain mastery of core skills under her guidance. I observed Thea ask leading questions to support her students' thinking and efforts at the board.

In my observation in Laurel's classroom, she dispersed the students to complete a few practice math problems independently or with small groups, eventually regrouping the class to discuss and share their work. A few learners opted to work on their problems in a group with Laurel at the Promethean Board. Laurel served as a mentor in the group's work on this fraction problem while facilitating other members of the group in their mentoring and support of Barry as he solved a multistep problem.

Some participants facilitated their students in digitally composing media. Tinnell (2018) likened composing with modern digital media to other forms of constructing and communicating knowledge aesthetically. Therefore, what I call "composing" refers generally to students' creation of original content mediated by digital technologies. Nora's third graders typed journal entries on her class Moodle page. Laurel and Iris facilitated their students in typing essays and stories using ChromeBooks, sometimes integrating digital images and other media. 
Felicity shared a story of how the high school students in her district provided one-on-one mentoring to her first graders in digitally composing and printing a multimodal text. Her first graders lacked extensive digital literacies as well as full mastery of proper writing conventions to compose a cohesive, extended writing response; therefore, the high schoolers served as experts to facilitate Felicity's young learners' digital production of a multimodal composition.

Besides composing via typing, a few of the participants facilitated student composing with digital tools that did not feature text as the primary mode of communicating meaning. Felicity's first graders compose almost daily by performing and recording their read alouds fluently to share with Felicity and each other. Nora's enrichment group was allowed to choose from a variety of text-based and multimodal tools to create projects to share their research results. For example, I overheard one student group discussing plans to create their final research project using a video-based tool called Animoto.

As part of composing digitally, some participants facilitated students' engagement in digital research focused on defined curricular topics and purposes. Laurel's fourth graders researched the habitat, diet, and characteristics of an animal of their choice using a kid-safe search engine called KidRex. They searched for and found text- and video-based sources to use in writing an expository essay. Iris's fifth grade students chose from a list of 20 Native American tribes to investigate online, finding information about several aspects of the tribe's lifestyle (e.g., lodgings, customs, etc.). Laurel and Iris regularly equip their students with graphic organizers to guide their digital research and note-taking, which is helpful to young learners that may lack formal online research experience (Morris, 2018).

Publishing products of digital composing allows students to share their work with authentic audiences as they participate in ongoing, socially-situated Discourses (Zheng et al., 
2014; Gee, 2015a). Nora and Iris were the only participants who shared stories about having students publish their digital compositions online for defined academic purposes and topics. Nora's third graders published digital journaling on her class Moodle during her afternoon learning centers block. Likewise, Iris's students published their Native American research projects using an open source, multimodal media tool called Adobe Spark. Felicity currently allows her first graders to share their reading fluency recordings with each other on the classroom iPads; however, she expressed a desire to curate and publish the students' recordings in the future.

\section{Overt Instruction}

Overt instruction is characterized by the "active interventions...of the teacher and other experts that scaffold learning activities" (New London Group, 1996, p. 86) so the learners can continue to participate in academic discourses (Gee, 2015b). Many of the participants emphasized this pedagogical component in their integration of digital technologies. In practice, this may be more easily observed by looking for ways elementary teachers make new or complex concepts more explicit and tangible for students (Cope \& Kalantzis, 2009; Kalantzis \& Cope, 2010).

Thea frequently uses the SMART Board as a multimodal cue for modeling content and skills, such as the graphing and pattern lessons she shared. Similarly, Nora used her mobile SMART Board to log elements of reading aloud with vocal expression in a small reading group discussion I observed. Laurel leveraged multicolored annotation options on her Promethean Board using the ActiveInspire application to help her fourth graders visually conceptualize how to combine repeated fractional values to form whole number values. Finally, Iris used her 
Promethean Board to model how students could access and critically analyze testimonies and images from the Boston Massacre prior to her fifth graders doing this semi-independently.

\section{Critical Framing}

In critical framing, teachers support students in reflecting on their learning and progress, taking a step back to view these experiences outside of the original context. The elementary teachers that participated in this study did not share stories of practice in which they emphasized critical framing "in relation to...historical, social, cultural, political, ideological, and valuecentered relations” (New London Group, 1996, p. 86; see also Penuel \& O’Connor, 2018); however, their narratives include examples of critical framing centered on fostering metacognitive, critical reflection with students about academic content outside of traditional lesson contexts, worksheets, and activities (Seglem \& Garcia, 2018). In young students' digital work, this could include critically framing design choices and focusing on intentional communication (Angay-Crowder, Choi, \& Yi, 2013; Schroeter, 2019 ); however, the New London Group sought to transform social futures (Brader \& Luke, 2013; Luke, 2018) and were not solely focused on issues of multimodality, which has been misappropriated in previous scholarship (Dallacqua, Kersten, \& Rhoades, 2015).

Thea emphasizes critical framing when her students debate how to model and solve math equations she shares and annotates at the SMART Board. She facilitates opportunities for students to justify their thinking and apply previous learning to new problems, offering spirited critiques of their opposing classmates' perspectives and responses.

In many ways, Felicity's students critically frame their reading as a performance each time they create a digital recording. They read and reread as a form of rehearsal with every new text. After recording, her first graders critique and evaluate the quality of their reading aloud, 
deciding whether to re-record or commit to their original production. Felicity also facilitates partner recordings in which one student coaches the other as they read and decode new texts. This format allows the coaches to apply fluency strategies outside of the independent, text decoding context in which they would typically read for academic or personal purposes.

Nora's enrichment RtI group pursues interest-based research questions. In conducting these investigations, her students must critically frame literacies they have developed, applying them towards self-driven, authentic purposes. During my observation in Nora's classroom, the students were commencing new projects and designing procedural plans for completing these projects. I overheard several students discussing their desired topics, approaches for finding sources and media, and digital applications to use for sharing their new insights.

\section{Transformed Practice}

In transformed practice, "we try to re-create a discourse by engaging in it for our own real purposes" (New London Group, 1996, p. 87). Of the four pedagogical components, critical framing and transformed practice were emphasized the least in the narratives of these five teachers. It should be noted that critical framing and transformed practice do not automatically emerge from emphasizing situated practice and overt instruction; rather, these components must be intentionally emphasized as part of an educator's Designing (Kim \& Xing, 2019).

While I will discuss it much more in Chapter VI, it should be noted that transformative, critical pedagogical design involves deep commitment and responsiveness by a teacher. The narratives of the participants suggest that teachers need to actively and willingly (Mintzes et al., 2012) respond to the dialogue of this profession to design truly transformative learning opportunities for students (Roberts, 2007). 
Felicity's grade level colleague, Moira, inquired about the fluency recording process that Felicity's students had been doing over the past few school years. Instead of teaching Moira's students how to record their independent reading on the iPads herself, Felicity empowered her first graders to gradually impart this process.

Felicity's students taught Moira's class the technical steps of using the iPads; however, they also modeled the preparatory routine of 'reading-to-self' and rehearsing for the 'performance' that would be committed to digitally-compressed audio and video. Her students took the fluency recording process and culture they developed in their classroom and authentically passed it on to another class. The first graders shared a real authentic purpose in their collaboration with Moira's students: imparting the elements of their fluency recording process in addition to helping them establish the arduous, yet rewarding culture of pushing oneself and your one's peers to continually improve at reading fluently.

In this example, Felicity's students took on a new 'situated identity' as teachers or mentors to Moira's students (Gee, 2013, 2014, 2015a; Mills \& Levido, 2011). Such experiences can be seen as particularly valuable for primary students in that they empathize with the needs of novices (Borke, 1971) as they train them and meet them at their level of basic expertise (Klapwijk \& Van Doorn, 2015).

A key feature of transformed practice is that "students can demonstrate how they can design and carry out, in a reflective manner, new practices embedded in their own goals and values" (New London Group, 1996, p. 87). The genius hour-inspired research projects Nora facilitated with her enrichment group exemplify the pedagogical component of transformed practice. The members of her group, students in grades 3-5, created focal research questions and planned for how they would answer them. The students conducted research digitally and selected 
digital tools to use in designing and sharing authentic products of learning. Nora fostered and assessed the students' developing literacies in projects that were student-driven within Discourses (Gee, 2015d) that were truly meaningful to them (Seglem \& Garcia, 2018). Researchbased learning can become transformative when it is centered around meaningful problems and/or student-selected topics and interests (Morris, 2018).

Focus questions are a central component of the Understanding by Design curricular framework popularized by Wiggins and McTighe (2005) and guide students to probe topics of interest deeply, questioning their own interpretations and those established socially and/or hegemonically (Geertz, 1995). Teachers should not only foster students' development of technical online research skills but also strategies for critically analyzing and integrating online content in constructing new meaning (Leu, Castek, Hartman, Coiro, \& Henry, 2005; Kingsley, Cassady, \& Tancock, 2015). Also relevant here is Cope and Kalantzis's (2010) Learning by Design movement, which stresses social constructivist principles as a focal part of actively designing and developing one's pedagogy (Yelland et al., 2008).

\section{Conclusion}

In Chapter $V$, I discussed the results of my analyses of the co-constructed narratives and position them within the research base. The factors with which the participants were in dialogue as they developed and enacted their pedagogical design with digital technologies included the following: assessability of students' digital efforts, core beliefs, district curricula, institutional factors, pedagogical affordances of digital technologies, professional development and collaboration, self-efficacy, student needs, and technology access. Across the five narratives, all four pedagogical components of the New London Group's (1996) pedagogy of multiliteracies framework (i.e., situated practice, overt instruction, critical framing, and transformed practice) 
were emphasized by at least some of the participants. Critical framing and transformed practice were less emphasized than situated practice and overt instruction.

Having parsed out the findings from the co-constructed narratives thematically in Chapter V, I will answer the research question and sub-questions in Chapter VI. I will also discuss the implications of this study and make recommendations for future research regarding elementary teachers' pedagogical design with digital technologies. 


\section{CHAPTER VI: CONCLUSIONS}

Over the course of five months, I learned about the life stories and digital pedagogical design of five elementary teachers who consistently integrate digital technologies in their instruction. Using data collected through interviews, focus groups, teaching artifacts, and classroom observations, I co-constructed the narrative of each participant.

In Chapter $V$, I discussed the results of my narrative analyses through the lenses of the New London Group's (1996) pedagogy of multiliteracies framework and Britzman’s (2003) dialogic theory of teacher practice. In this chapter, I will answer the research question and secondary questions. Then, I will discuss the implications of the study as they relate to federal and state policymakers, teacher education programs, and elementary classroom teachers. Finally, I will make recommendations for future research.

\section{Answering the Research Questions}

Primary Research Question: How do elementary teachers who consistently integrate digital technologies develop their pedagogical design across their careers?

Three central factors about digital pedagogical design emerged from the narratives of the participants. First, elementary teachers not only develop their pedagogical design with digital technologies across their careers, but more specifically, throughout their biography of experiences. Secondly, these experiences are laden with personal and professional dialogue that elementary teachers must negotiate and make ongoing meaning of as they continue to develop and enact their digital pedagogical design. Finally, the narratives of the participants suggest that teachers must actively respond to this pedagogical dialogue in ways that facilitate their design of transformative learning experiences for students. I will next disseminate each of these three ideas. 


\section{Biography}

Elementary teachers develop their pedagogical design with digital technologies across their careers and further, across the narratives of their entire life journeys. Starting with the macro view of biography, a teacher's career is situated along the chronotope (Bakhtin, 1981b) of an ongoing biographical narrative (Alsup, 2006; Britzman, 2003; Kim, 2015; Mahiri, 2004). Elementary teachers are people with lived experiences that shaped how they are today. Their past experiences resound in an ongoing internal forum of dialogue with present professional experiences. The narratives of the participants included stories of how they dialogued with experiences from their narratives that preceded the years of their pre-service training and professional teaching careers.

Iris attributed her design of digitally-mediated social studies activities (e.g., 9/11 lesson, research projects) to the passion for U.S. and world history she developed by her family's trips to historical sites when she lived on the east coast as a young girl. Evaluating her district's fifth grade social studies program, she felt she had to supplement it to better provide learning opportunities closer to the level of her insightful experiences as a young child. Iris does not simply leave her experiences of visiting Gettysburg, Plymouth Rock, and the historical landmarks in Washington, D.C. at the door when she designs social studies lessons for her fifth graders. On the contrary, her regard for the importance of history and learning from our country's past dialogues with her present design of digitally-mediated instruction. Iris wants to share and impart her passion for history and informed citizenship and subsequently, leverages digital technologies as an Available Design for accomplishing that.

Felicity and Nora both used a variety of technologies from a young age, developing selfefficacy for integrating them in their instructional design efforts during their professional careers. 
Having taught for two decades, Felicity shared the variety of technologies she has encountered and evaluated in developing and enacting her digital pedagogical design. From her mother's typewriter during her childhood up to modern digital technologies (e.g., iPads, laptop computers, etc.), she has assessed each new tool as a potential opportunity to more effectively design impactful learning opportunities for her young students. When she joked about being a teacher stuck in the "dinosaur age" (personal communication, March 14, 2019), what Felicity meant was that she has developed her digital pedagogical design across a lifetime of experiences. She is confident enough to draw upon approaches and resources that predate the advent of digital innovations in teaching (e.g., cassette tape audio books) if they still remain effective. However, she has also developed self-efficacy for trying new digital approaches and tools, especially if she can use them to improve her professional practices. In exploring the affordances of iPads, she found that she could continue her fluency recording approach but implement it more efficiently, and make the experience more student-led. While she establishing the recording process as a routine, her students did not create their 'performances' in rote, mechanical fashion; rather, they critically framed and evaluated their fluency against fluency criteria. Eventually, they imparted this recording 'culture' to their first grade peers in another classroom.

Like Felicity, Nora had used technologies throughout her entire life; however, being 25 years younger that Felicity, most of Nora's experiences had been on the digital side. She has used the Internet for most of her life, leveraging the affordances of digital technologies for completing and submitting school assignments and pursuing personal interests (e.g., editing dance performance music tracks, communicating with friends, etc.). Like Felicity, Nora carried her technological self-efficacy over to her professional teaching, evaluating new technologies and applying them with openness and confidence in her classroom. Informed by a lifetime of 
experiences using technologies, 'digital' has been an Available Design for Redesigning her students educational experiences and outcomes (New London Group, 1996) from the outset of her career. Nora is constantly looking for new approaches to meet the needs of her diverse learners. She is comfortable trying new digital tools or approaches if they can help her design opportunities to provide engaging and individualized learning opportunities for her third graders or help her solve problems of practice.

Laurel's professional journey was different than the other participants in that she did not being teaching in classrooms in the first few years following her pre-service teacher education in college. Rather, she stayed at home and primarily raised her five children. Upon formally returning to the profession as a fourth grade teacher, her experiences as a mother in an increasingly digital society informed her instructional approaches with technologies. Laurel felt her cautious restrictions on her children's technology use at home (e.g., limiting unnecessary screen time, setting rules for using cell phones and videogames, etc.) carried over to how she evaluated new technologies and facilitated her students' use of digital tools. She ensures her students use it in the classroom only in ways that are intentional. For example, by having her students type essays in Google Doc templates, they can more effectively organize and edit their writing.

\section{Career Experiences}

The participants' narratives are also laden with experiences during their pre-service and professional years of teaching with which they remain in dialogue as they develop and enact their digital pedagogical design. Next, I will share some examples of this, and later in this chapter, in my response to the second sub-question of this study, I will disseminate these dialogic factors more categorically. 
Iris engaged in critical coaching experiences with Oliver that shifted her teaching within a one-to-one technology structure. Years later, after a grade level change and becoming familiar with new curricula, she turned to digital approaches (e.g., online student research and composition, linking digital resources on her blog, etc.) to supplement a social studies program she found outdated and lacking. Her past collaboration with Oliver to develop digital pedagogical design along with the motivation of providing her students a better social studies education motivated Iris to Redesign her instructional approaches.

During her time teaching second grade in Memphis, Thea was prohibited from bringing home her district-issued computer. Additionally, the district enforced strict curricular mandates on what she could teach and when she could teach it. In her current district, Thea readily takes her district-issued laptop computer home and searches for SMART files to modify and use with her kindergarteners; she had developed this digital approach during her time as a student teacher but was not allowed to utilize it in within the restrictive culture of her Memphis district. Now, Thea appreciates and takes advantage of the freedom she has to leverage digital technologies in designing engaging learning activities for her students.

Years ago, Felicity wanted to integrate mobile technologies in her first grade classroom to facilitate literacy experiences with relevant, interactive devices; however, her school district was not providing one-to-one technology in the primary grade levels. In response to this dialogue with institutional factors and access hurdles, Felicity brought in a few of her personal iPads from home for students to use. Eventually, she appealed to her district's technology coordinator and was able to secure additional technology. Felicity was able to lean into digital approaches with this increased student access to mobile technology, developing the procedure and culture around 
the reading recording process that has become a central part of her first graders' fluency development.

\section{Transformative Pedagogical Design}

I will disseminate the pedagogical components emphasized by the participants of this study more specifically in the next section of this chapter; however, it bears acknowledging that the types of approaches elementary teachers use when integrating digital technologies proceeded from constant dialoguing and varying degrees of critical digital pedagogy. The pedagogical components of critical framing and transformed practice were less emphasized than the components of situated practice and overt instruction (New London Group, 1996).

In spite of the pressures and weight of authoritative discourses (Britzman, 2003) with which teachers are confronted, critical approaches with digital technologies are paramount to Designing equitable social futures (New London Group, 1996). Ultimately, what I learned about how elementary teachers who consistently integrate digital technologies develop their pedagogical design across their careers comes down to responsiveness. Developing and maintaining critical pedagogical design is watermarked by how the teacher responds to past and current dialogue in this “process of becoming” (Dall'Alba, 2009, p. 41).

For example, Nora recognizes that several of her students had needs that required individualized support; in some cases, just helping a student be able to stay in her classroom without being removed or sent home due to behavioral and/or emotional challenges was a significant initial 'win.' She leverages digital technologies to provide individualized learning opportunities for each student, allowing them to transcend personal and academic struggles and experience success. 
Felicity's colleague Moira inquired about her instructional design with digital technologies that had piqued the interest of a doctoral student working on a dissertation study. While Felicity could have taught Moira's students how to carry out the procedures of recording their independent reading using iPads, she recognized an opportunity for her first graders to assume the situated identity of mentors and experts. With her support, her students gradually imparted the technical and procedural skills of their reading fluency recording process with Moira's class; however, her first graders also shared and helped extend their culture of effort and literacy growth as part of this sharing experience.

Ultimately, elementary teachers develop their pedagogical design from tangible experiences throughout their personal and professional lives as well as internal beliefs and perceptions with which they also interact as they make daily decisions of teaching with digital technologies. Recognizing critical digital approaches to teaching and actually developing and enacting such a pedagogy are two completely different things. Teachers dialogue with many factors (several of which I will expound upon later in this chapter). They must respond to this dialogue by actively designing learning opportunities that are authentic, equitable, and transformative.

\section{Answering the Sub-Questions}

Secondary Research Question 1: What pedagogical components do elementary teachers emphasize when teaching with digital technologies? The pedagogical components of situated practice, overt instruction, critical framing, and transformed practice from the New London Group's (1996) pedagogy of multiliteracies framework were emphasized and used by at least some of the participants. 
With situated practice, the participants leveraged digital technologies in ways that facilitated their students' participation in academic discourses (Kerkhoff, 2017; New London Group, 1996). Thea's kindergarteners manipulated and annotated at the board to model and solve basic addition and subtraction facts, graphing data, and extending patterns; the students discussed, debated, and shared their understanding with Thea and each other. Laurel and Iris's students digitally composed multimodal reports and essays, editing and sharing their work in engaging, multimodal formats with their peers and families. These opportunities for situated practice involved students' using digital technologies to socially construct meaning and participate in academic Discourses (Gee, 2009a). In the case of Thea's class, digital technologies helped make abstract mathematics concepts more tangible and relatable (Mills \& Levido, 2011).

Through overt instruction, the participants provided students with appropriate guidance and support at opportune junctures (New London Group, 1996) in their learners' ongoing participation in academic discourses (Gee, 2015b; Lenters, 2016). Thea modeled and manipulated digital math content in unique, engaging ways with her SMART Board to introduce or review new math concepts and procedures. Using the digital color palette on her Promethean Board, Laurel annotated fraction problems with different colors to provide her fourth graders with a model they could use to distinguish each equal value they combined into whole number values.

Of the four pedagogical components, critical framing and transformed practice were the least emphasized by the participants. Designing transformative educational experiences with digital technologies requires critical pedagogical approaches (Tabb, 2008). Equally important in developing and enacting critical pedagogies is how educators and stakeholders define what makes teaching and learning transformative. Authoritative discourses (Britzman, 2003) call for 
teaching to be transformed by technologies to increase efficiency with a focus on tools and digital infrastructures (Office of Educational Technology, 2017; Yelland et al., 2008).

Internally persuasive discourses (Brtizman, 2003), on the other hand, may be calling educators to design instruction that liberates (Freire, 1970/2014), empowers (Eng, 2016), and promotes equitable digital participation (Ito et al., 2013; Jenkins, 2006). Sometimes, teachers must even become a "participant" (Mills \& Jennings, 2011, p. 594) along with the students, engaging in literacy practices as an experienced partner and collaborator rather than an authoritative instructor. The New London Group (1996) emphasized social transformation (Brader \& Luke, 2013; Luke, 2018) that may or may not involve multimodal and/or digitallymediated designing (Dallacqua et al., 2015).

In critical framing, a few participants supported students in viewing their learning outside of the original context (New London Group, 1996). Specifically, they fostered students' engagement in metacognitive reflection about academic content outside of traditional lesson contexts, worksheets, etc. (Seglem \& Garcia, 2018). Thea facilitated opportunities for students to utilize digital models of math problems to engage in debate in which her kindergarteners had to defend their solutions. Felicity's first graders critically frame each reading recording they create against the criteria of reading fluency she has taught them in whole class and small group settings. Nora's enrichment group of students in grades 3-5 critically frame literacy skills they have developed, applying them toward the design of self-driven, authentic digital research projects.

In transformed practice, students apply their new understanding and skills to personal goals and new contexts (New London Group, 1996). Transformed practice may involve students' use of digital tools to engage in situated, authentic discourses and roles (Gee, 2013, 2014, 2015a; 
Limberg et al., 2011; Mills \& Levido, 2011). Felicity's students became mentor-experts when they shared their fluency recording procedure with Moira's class. Through this collaborative opportunity, her students moved beyond learning and utilizing fluency and decoding strategies and shared their culture of continual practice, effort, and growth with their friends. Nora's intervention group applied their literacies towards digital research projects centered around interest-based questions and self-selected project designs. Nora allowed the students to design their plan of inquiry and choose the tools they would use to share their new understandings with peers and extended audiences.

Despite the liberating impacts of critical framing and transformed practice, these components elude the enacted pedagogical design of many elementary teachers' as they integrate digital technologies. The easy explanation would be to cast blame on teachers for not doing more for students in need; however, in reality, they are caught in an ongoing, often-conflicting dialogue between internally persuasive and authoritative discourses (Britzman, 2003). Teachers must actively choose to emphasize critical, socially-just approaches (Kim \& Xing, 2019) with students to promote the equitable participation the New London Group (1996) called for in the multiliteracies framework; however, elementary teachers must negotiate countless "social forces" (Eisner, 1979, p. 26) in digitally-mediated instruction (Huber et al., 2016; Shing et al., 2015), which will be discussed next with regards to the second sub-question of this study.

The second sub-question was What can be learned about the dialogic nature of pedagogy from the life stories of elementary teachers who consistently integrate digital technologies?

In short, the participants' narratives revealed that pedagogy is incredibly dialogic and is not developed in isolation. The specific factors with which the participants were in dialogue, discussed in greater detail in Chapter $V$, included the following: core beliefs, district curricula, 
institutional factors, perceived pedagogical affordances of digital technologies, professional development and collaboration, self-efficacy, student needs, and technology access.

Using Britzman's (2003) dialogic lens, core beliefs, professional development and collaboration, self-efficacy, and perceived pedagogical affordances of digital technologies are those that reside internally and over which teachers have some semblance of control and power. Authoritative discourses encapsulate the dialogue with district curricula, institutional factors, student needs, technology access that are more or less static and nonnegotiable.

However, these dialogic factors cannot always be so neatly categorized in the binary hierarchy of internally persuasive and authoritative discourse of Britzman's (2003) dialogic theory of teacher practice. The notion of dialogue indicates just that - dialogue. In dialogue, there are two or more parties, human or metaphorical, that are listening and responding to varying degrees. On paper, factors such as mandated curricula, institutional forces, and access to technology may be more readily influenced by stakeholders with greater influence than classroom teachers (e.g., administrators, policymakers, etc.).

However, several stories shared by the participants in this study exemplify the importance of teacher response in the ongoing dialogue inherent in pedagogy. Iris and her colleagues advocated for better learning experiences than those prescribed in her district's outdated social studies curriculum. They successfully advocated for the instructional freedom to supplement the curriculum with more engaging learning activities, including those mediated by digital technologies (e.g., digital research, multimodal reports, etc.). Felicity integrated her own personal iPads and successfully convinced district higher-ups to purchase iPads class sets of iPads for first graders at her school. As I discussed earlier in this chapter, she has leveraged these new devices to facilitate transformative reading fluency experiences and a classroom culture 
inclusive of all students. Nora applied her core belief that all learners deserve to experience academic success to the challenging needs of her third graders. She leverages digital tools and approaches to transform her students' academic experiences, empowering them to find success rather than viewing their needs as deficits that are insurmountable.

It is critical that elementary teachers do not view the authoritative discourses of digital pedagogical design as completely impassable. Such defeatist outlooks will only serve to reinforce mainstream social hegemony and deterministic, means-end approaches with digital technologies. As educators, we can accept our current narratives and succumb to the dialogue of historically-fueled power structures; or, we can change the narrative and make our internally persuasive discourse (Britzman, 2003) more explicitly and actively external. This dialogue needs to happen in active pedagogical reflection, conversations of advocacy and appeal, and most importantly, in the daily decisions and design choices of classroom teaching.

\section{Implications of the Research}

The findings from this study carry implications for several education stakeholders, including federal and state policymakers, teacher education programs, and elementary classroom teachers.

\section{Policymakers}

Pedagogy is not immune to the authoritative discourses (Britzman, 2003) of politics and educational reforms that flow from federal and state legislatures down to districts, schools, and individual classrooms (Cuban, 1990; Penuel \& O’Connor, 2018). Nora and Iris shared their ongoing dialogue with district curricula in how they designed digitally-mediated instruction. In Iris's district, the content area of social studies has been deemphasized and the social studies curricular program was incredibly outdated. Iris integrated learning activities to supplement the 
curriculum, including digitally sharing primary source materials on her blog and having students conduct online research.

Nora designed assessment blueprints to effectively design instruction and meet the rigorous standards and objectives of district curricula (with the intension of eventually aligning digital learning activities). Nora noted that she felt more freedom to design engaging, authentic learning experiences in which students used digital technologies in the STEM camp setting where she was not bound to a paced curriculum.

Technologies have been subject to educational reforms focused primarily on the transmission of academic content (Armstrong, 1929; Bundy, 1968; Riley, 1940; Thomas, 1980), propagating educational approaches in the 'banking' tradition (Freire, 2009). Currently, elementary teachers like Iris and Nora constantly dialogue with curricular demands that stem from federally- and state-mandated standards and assessments. Many of the participants utilized their digital classroom boards to implement transmission approaches as they teach required math and language arts content.

Technology access was a key dialogic factor for some of the participants. Felicity had to bring personal devices to her first grade classroom and eventually appealed to her district to gain access to additional iPads. Thea was unable to fully utilize her knowledge and approaches with SMART technologies during her time in Memphis due to lacking access to a fully functional SMART Board. Nora had similar struggles in terms of the types of zSpace activities she could design in her class, in which she only had one available, compared to the STEM camp, where she and her learners could access many.

To support educators in leveraging digital technologies in ways that promote students' authentic learning and equitable digital participation, policymakers must pass legislation that not 
only increases technology access but also provides teachers the freedom to exercise critical, student-centered pedagogical approaches. This may involve reconsidering political efforts that prioritize capitalist and economic goals over educational parity.

For example, to promote equity for schools and students, it is critical that federal regulations such as net neutrality be restored and maintained. At the time of this writing, the federal courts just upheld the FCC's decision to repeal net neutrality regulations established during the Obama administration (Reardon, 2019). Internet service providers can now increase charges to customers to access specific types of media, likely creating new access and participation gaps (Selyuhk, 2018; Snider, 2018).

\section{Teacher Education and Professional Development}

The participants in this study were in dialogue with past teacher education and professional development experiences. Thea utilizes SMART Board resources in her instructional design today, a technology she first learned as an undergraduate and student teacher during her college years. In addition to technology-focused graduate coursework, Nora regularly engages in professional development opportunities offered by her district.

Teacher education programs and designers of professional development must prepare teaching candidates and support practice teachers in adopting critical pedagogical perspectives and approaches with digital technologies. By creating counter-narratives in which elementary teachers more actively respond to the authoritative discourses of practice, generational ideas about how digital technologies can be leveraged with elementary students can begin to be superseded (Mintzes et al., 2012; Roberts, 2007).

Some teacher education programs attempt to foster candidates' development of technological pedagogical content knowledge (Mishra \& Koehler, 2006) in single course 
offerings (Angeli \& Valanides, 2013; Beschorner \& Kruse, 2016); however, it may be more effective and pragmatic to support future elementary teachers' development of critical digital pedagogy throughout an entire program coursework experience as an embedded tenet that is continually revisited (Gill et al., 2015).

In a similar fashion, effective professional development must be sustained (Desimone, 2009; Guskey, 2002; Norman, 1999) and focused on specific goals (Wolf \& Peele, 2019) related to technologies and critical pedagogy. Given the dialogic factors with which future elementary teachers will engage as full time professionals, it is important to foster their development of critical mindsets to negotiate between authoritative and internally persuasive discourses (Britzman, 2003) and emphasize transformative components in their instructional design (New London Group, 1996).

Some participants also found collaboration and coaching opportunities to be particularly helpful in their development of pedagogical design with digital technologies. Felicity developed a high regard for primary grade students to engage in daily independent reading, a tenet that carried over to her facilitation of digital recording experiences in recent years. Laurel and Iris shared stories of how they developed knowledge and teaching approaches with digital technologies through their coaching relationships with Oliver a few years ago. Likewise, Nora has developed a mentee relationship with her school's media specialist to whom she turns to ask technology questions regularly.

The formal coaching relationships Laurel and Iris has with Oliver were successful partnerships in which each teacher was supporting in designing and reflecting on their instruction and integration of digital technologies (Knight, 2007). Like Laurel and Iris, Nora met with her school's media specialist regularly (Desimone \& Pak, 2017) with the goal of solving problems of 
practice and applying digital technologies and approaches to her instructional design (Kurz et al., 2017). Practicing elementary teachers would benefit from formal coaching and/or informal collaborative partnerships that are goal-oriented toward developing and enacting critical digital pedagogy, providing the guidance and support (Frank et al., 2011; Freeman et al., 2017) needed to negotiate the dialogue between authoritative and internal discourses (Britzman, 2003).

Formal coaching programs require district commitment and subsequently, consistent funding, which was why Laurel and Iris eventually stopped regularly meeting with Oliver. If coaching programs are too challenging to fund, districts can still support the coordination of professional learning communities (PLCs) with goals centered around effective technology integration (Thoma, Hutchison, Johnson, Johnson, \& Stromer, 2017). Professional learning networks can also be established around professional goals in digital forums (Maraldo, 2014).

\section{Elementary Teachers}

Elementary teachers negotiate much institutional dialogue as they design instruction that incorporates digital technologies (Cope, Kalantzis, \& Smith, 2018). Schools are vulnerable to politics and mainstream social hegemony (Penuel \& O'Connor, 2018; Thomas, 1980) in which theoretical innovations can be challenging to practically implement (Roberts, 2007). School districts have heavily invested in digital technologies, often as part of one-to-one implementations, with means-end effectiveness assumptions (Chandler, 2012) and overemphasis on tools (Cristia et al., 2017) and/or mandated restrictions (Seglem, 2015).

The school context is an arena where core identities and associated beliefs or principles may clash with dominant norms and barriers to critical perspectives and pedagogies (Gee, 2017b). Historically, the role of technologies in the education sector has been subject to redefinition and debate, especially with regards to how they impact social power dynamics 
(Davies \& Schwen, 1971) as well as equitable access and participation (Jesson et al., 2015; Van Deurson \& Helsper, 2015). Furthermore, digital technologies have changed what comprises literacy (Leu et al., 2013) and have impacted the ways humans as social beings participate in a literate society (Gee, 2009a, 2015c; Steffen et al., 2019; Street, 1993, 2003).

Navigating beliefs, informed by past experience, can present challenges in which teachers must actively decide whether to align their teaching with mainstream, hegemonic values or break stride with Redesigned (New London Group, 1996) conceptions what effective digitallymediated (or non-digital) teaching and learning can be (Alsup, 2006; Elbaz-Luwisch, 2007; Rogers, 2007).

In spite of these challenges and dialogic factors, teachers must design instruction with a critical mindset to promote social justice and meaningful change (Luke, 2012b), leveraging digital technologies to empower students to successfully participate in socioculturally authentic Discourses (Gee, 2015a). Given the incredibly dialogic nature of pedagogy illuminated by the narratives constructed and disseminated in this study, other elementary teachers should maintain mindfulness of the dialogue they engage in as part of their ongoing Designing (New London Group, 1996) with digital technologies (Schein, 1972).

In considering the countless needs of their young students, elementary teachers must find ways to exercise critical pedagogy to promote equitable digital participant and effective, meaningful learning experiences (Tabb, 2008; Eng, 2016). Engaging in consistent self-reflection and practicing mindfulness routines or rituals can be helpful to the social-emotional well-being of classroom teachers, better preparing them to confront the challenges of authoritative and internally persuasive discourses (Britzman, 2003) and make optimal daily teaching decisions (Birchinall, Spendlove, \& Buck, 2019; Jennings \& Greenberg, 2009). 


\section{Recommendations for Future Research}

Future research must seek to further describe the dialogic nature of digital pedagogy and how teachers develop their pedagogical design with digital technologies, particularly those practicing in elementary classrooms. Teachers engage in dialogue within and between authoritative and internally persuasive discourses (Britzman, 2003) as they develop and enact their pedagogies.

To better conceptualize the abstract nature of Designing (New London Group, 1996) with digital technologies, it would be helpful to conduct additional narrative research with other elementary teachers beyond the specific times and places depicted in this study. Specifically, this study illuminated the incredibly dialogic nature of the digital pedagogies of elementary teachers and how critical framing and transformed practice may be elusive for some teachers.

Research questions that emerge from this study are What can be learned from the life stories of teachers who consistently integrate critical digital approaches? and What dialogic factors do elementary teachers perceive as impactful on their transformative pedagogical design with digital technologies? To answer these questions, I would utilize narrative methods to coconstruct the life stories of teachers who not only consistently integrate digital technologies but also utilize regularly enact critical teaching approaches to facilitate transformative learning experiences for students. Exploring the dialogic nature of transformative digital pedagogy at the elementary level is vital for pushing forward conceptual understanding of teaching approaches that can promote equitable digital participation and learning (Eng, 2016; Tabb, 2008).

Additionally, by increasing understanding of the dialogic nature of digital pedagogical design, I would like to apply to the design of a dialogic digital pedagogy framework of sorts. Such a framework could illuminate the "tipping points" (Novoa, 2018, p. 146) educators 
perceive internally and/or experience externally that inspire their design of transformative learning experiences for elementary students.

Exploring elementary students' perspectives of teachers who consistently integrate digital technologies would also be a natural next proceeding from this study. Students are the most immediate stakeholders in elementary education; therefore, it is important to understand their perceptions of transformative, socioculturally-relevant learning experiences mediated by digital technologies (and those that may have been less transformative). Considering this alternative pool of participants who are close to the issue of digital pedagogical design, research questions that emerge are How do the transformative digital pedagogical design choices of elementary teachers affect their students' classroom learning experiences? and How do the transformative digital pedagogical design choices of elementary teachers affect their students' digital literacy practices outside of the formal school context? In considering students perspectives and experiences, it is important to examine their in-school learning as well as their digital participation outside of school (Jenkins, 2006; Ito et al., 2013; Robinson, 2009; Van Dijk, 2012, 2017). I would design a longitudinal case study (Hays \& Singh, 2012; Plano Clark \& Creswell, 2010) to conduct this research over several years, defining the case within one or more elementary classrooms (Stake, 2003) in which the teacher(s) regularly used transformative digital pedagogical approaches (New London Group, 1996). 


\section{EPILOGUE}

I began formally conceptualizing this study in August 2018, but from a dialogic perspective, as depicted in the Prologue of this dissertation, my pedagogical narrative began long before that. Narrating the life stories and pedagogical dialogue of Felicity, Iris, Laurel, Nora, and Thea only seemed to amplify the dialogue of my own ongoing journey as an educator. As I have worked to attend academic conferences, conduct research, and implement teaching approaches with my current third grade class this year, I have been met with stifling administrative obstacles. I was informed by our administration this spring that my research and pursuits to share my work with other educators do not align with district goals and will not be formally supported.

At the time of this writing, I am preparing for a campus visit interview in pursuit of a position on a university teacher education faculty; just today, I finished preparing a teaching demonstration about design-based approaches to solving problems of practice in elementary mathematics instruction. In this new career, I consider it my charge to promote the principles and dispositions of critical pedagogical design and transformative teaching and learning. I intend to integrate student-centered digital approaches with my future pre-service and graduate students firsthand to share how they may do the same with their elementary students. It will be integral that I prepare these future and practicing teachers to critically respond to the dialogue of this profession. They must reflect on their current circumstances of practice and how their past resounds in the present.

Through narration, this study highlighted the dialogic nature of digital pedagogical design. However, illuminating the path and successfully traversing it are two different things. Transformative teaching and learning are not elusive by happenstance, but rather, because they 
are challenging to implement and facilitate amidst the cacophony of pedagogical dialogue across one's biography and career. It is time to use the light to begin walking forward. 


\section{REFERENCES}

Abshire, S. R., Cummings, C. D., Mason, D. R., \& Abernathy, L. K. (2014). Building literacy with popular Web 2.0 tools. In M. Gura (Ed.), Teaching literacy in the digital age: Inspirations for all levels and literacies (pp. 161-178). Eugene, OR: International Society for Technology in Education.

Abu Al Rub, M. F. (2015). Teachers' beliefs and technology use in kindergarten and elementary classrooms. World Journal on Educational Technology, 7(3), 149-156.

Ahmed, S. (2010). Happy objects. In G. J. Seigworth \& M. Gregg (Eds.), The affect theory reader (pp. 29-51). Durham, NC: Duke University Press.

Ahwee, S., Chiappone, L., Cuevas, P., Galloway, F., Hart, J., Lones, J., . . Tate, B. (2004). The hidden and null curriculums: An experiment in collective educational biography. Educational Studies, 35(1), 25-43.

Airhihenbuwa, C. O. (2007). Healing our differences: The crisis of global health and the politics of identity. Lanham, MD: Rowman \& Littlefield.

Alcalá, J. C., Austin, M., Granroth, M., \& Hewitt, B. (2016). Online inclusive pedagogy: A calland-response dialogue on digital storytelling. Education for Information, 32, 71-85.

Allen, T. (2008). Philosophy in red, philosophy in purple: Lebenswelt given, Weltanschauung achieved, lifeworld contra worldview. Analytic Teaching, 28(1), 9-17.

Alsup, J. (2006). Teacher identity discourses: Negotiating personal and professional spaces. Mahwah, NJ : Lawrence Erlbaum Associates, Inc. 
Amador, J. M., Kimmons, R., Miller, B. G., Desjardins, C. D., \& Hall, C. (2015). Preparing preservice teachers to become self-reflective of their technology integration practices. In M. L. Niess \& H. Gillow-Wiles (Eds.), Handbook of research on teacher education in the digital age (p. 81-107). Hershey, PA: IGI Global.

Andrews, M., Sclater, S. D., Squire, C., \& Tamboukou, M. (2004). Narrative research. In C. Seale, G, Gobo, J. F., Gubrium, \& D. Silverman (Eds.), Qualitative research practice (pp. 97-112). Thousand Oaks, CA: SAGE Publications, Inc.

Angay-Crowder, T., Choi, J., \& Yi, Y. (2013). Putting multiliteracies into practice: Digital storytelling for multilingual adolescents in a summer program. TESL Canada Journal, $30(2), 36-45$.

Angeli, C., \& Valanides, N. (2013). Technology mapping: An approach for developing technological pedagogical content knowledge. Journal of Educational Computing Research, 48(2), 199-221.

Anyon, J. (1994). The retreat of Marxism and socialist feminism: Postmodern and poststructural theories in education. Curriculum Inquiry, 24(2), 115-133.

Apple, M. (2013). Controlling the work of teachers. In D. J. Flinders \& S. J. Thornton (Eds.), The curriculum studies reader (4th ed., pp. 167-182). New York, NY: Routledge.

Archambault, L., Kennedy, K., \& Freidhoff, J. R. (2016). Accountability for students in K-12 online learning: Perspectives from Michigan stakeholders and beyond. Online Learning, 20(3), 126-139.

Armstrong, P. (1929). Radio in education; the Ohio School of the Air, and other experiments. New York, NY: The Payne Fund. 
Arendt, H. (2006) Between past and future: Eight exercises in political thought. New York, NY: Penguin Books Ltd. (Original work published 1954).

Aristotle. (1999). Nicomachean ethics (W. D. Ross, Trans.). Kitchener, ON, Canada: Batoche Books. (Original work published 350 B.C.E.).

Association for Educational Communications and Technology. (1977). The definition of educational technology. Washington, D.C.: Association for Educational Communications and Technology.

Atkinson, R. (2007). The life story interview as a bridge in narrative inquiry. In D. J. Clandinin (Ed.), Handbook of narrative inquiry: Mapping a methodology (pp. 224-245). Thousand Oaks, CA: SAGE Publications, Inc.

Aydarova, E. (2017). "I want a beautiful life": Divergent chronotopes in English language teacher education. Critical Inquiry in Language Studies, 14(4), 263-293.

Bach, H. (2007). Composing a visual narrative inquiry. In D. J. Clandinin (Ed.), Handbook of narrative inquiry: Mapping a methodology (pp. 280-307). Thousand Oaks, CA: SAGE Publications, Inc.

Bakhtin, M. (1981a). Discourse in the novel. (C. Emerson \& M. Holquist, Trans.). In M. Holquist (Ed.), The dialogic imagination: Four essays (pp. 269-422). Austin, TX: University of Austin Press.

Bakhtin, M. (1981b). Forms of time and chronotope in the novel. (C. Emerson \& M. Holquist, Trans.). In M. Holquist (Ed.), The dialogic imagination: Four essays (pp. 84-258). Austin, TX: University of Austin Press.

Bakhtin, M. (1984). Rabeleis and his world. (H. Iswolsky). Bloomington, IN: Indiana University Press. (Original work published 1965). 
Bakhtin, M. (1990). Author and hero in aesthetic activity (V. Liapunov, Trans.). In M. Holquist \& V. Liapunov (Eds.), Art and answerability: Early philosophical essays by M. M. Bakhtin (pp. 4-256). Austin, TX: University of Austin Press. (Original work published 1923).

Bakhtin, M. (1999a). Problems of Dostoevsky's poetics. (C. Emerson, Trans.). Minneapolis, MN: University of Minnesota Press. (Original work published 1963).

Bakhtin, M. (1999b). Toward a philosophy of the act (V. Liapunov, Trans.). In V. Liapunov \& M. Holquist (Eds.), Toward a philosophy of the act (3rd ed., pp. 1-76). Austin, TX: University of Texas Press.

Bakhtin, M. (2004). Dialogic origin and dialogic pedagogy of grammar: Stylistics in teaching Russian language in secondary school. (L. R. Stone, Trans.) Journal of Russian and East European Psychology, 42(6), 12-49. (Original work published 1994).

Baldauf, R. B., Jr. (1981). Educational television, enculturation, and acculturation: A study of change in American Samoa. International Review of Education, 27(3), 227-245.

Bamberg, M. (2012). Why narrative? Narrative Inquiry, 22(1), 202-210.

Bandura, A. (1977). Social learning theory. Englewood Cliffs, NJ: Prentice-Hall, Inc.

Bandura, A. (1997). Self-efficacy: The exercise of control. New York, NY: W.H. Freeman and Company.

Banks, J. A. (1996). Teaching strategies for ethnic studies (6th ed.). Boston, MA: Allyn \& Bacon, Inc. 
Barnes, N., Brighton, C. M., Fives, H., \& Moon, T. R. (2019). Literacy teachers' beliefs about data use at the bookends of elementary school. The Elementary School Journal, 119(3), 511-533.

Barton, D. (2012). Participation, deliberation learning and discourses of learning online. Language and Education, 26(2), 139-150.

Barton, D., \& Hamilton, M. (1998). Local literacies: Reading and writing in one community. New York, NY: Routledge.

Bazalgette, C., \& Buckingham, D. (2013). Literacy, media, and multimodality: A critical response. Literacy, 47(2), 95-102.

Bell, J. S. (2011). Reporting and publishing narrative inquiry in TESOL: Challenges and rewards. TESOL Quarterly: A Journal for Teachers of English to Speakers of Other Languages and of Standard English as a Second Dialect, 45(3), 575-584.

Bennett, S., Maton, K., \& Kervin, L. (2008). The 'digital natives' debate: A critical review of the evidence. British Journal of Educational Technology, 39(5), 775-786.

Beschorner, B., \& Kruse, J. (2016). Pre-service teachers' use of a technology integration planning cycle: A case study. International Journal of Education in Mathematics, Science and Technology, 4(4), 258-271.

Bethke Wendell, K., \& Rogers, C. (2013). Engineering design-based science, science content performance, and science attitudes in elementary school. Journal of Engineering Education, 102(4), 513-540. 
Birchinall, L., Spendlove, D., \& Buck, R. (2019). In the moment: Does mindfulness hold the key to improving the resilience and wellbeing of pre-service teachers? Teaching and Teacher Education, 86.

Black, R. W., \& Steinkuehler, C. (2014). Literacy in virtual worlds. In L. Christenbury, R. Bomer, \& P. Smagorinsky (Eds.), Handbook of adolescent literacy (pp. 271-286). New York, NY: Guilford Press.

Blewett, C., \& Hugo, W. (2016). Actant affordances: A brief history of affordance theory and a Latourian extension for education technology research. Critical Studies in Teaching and Learning, 4(1), 55-73.

Blommaert, J. (2015). Chronotopes, scales, and complexity in the study of language in society. Annual Review of Anthropology, 44, 105-116.

Blumer, H. (1969). Symbolic interactionism: Perspective and method. Englewood Cliffs, NJ: Prentice-Hall, Inc.

Bobbitt, F. (2013). Scientific method in curriculum-making. In Flinders, D. J., \& Thornton, S. J. (Eds.), The curriculum studies reader (4th ed., pp. 11-18). New York, NY: Routledge.

Borke, H. (1971). Interpersonal perception of young children: Egocentrism or empathy? Developmental Psychology, 5(2), 263-269.

Bostad, F., Brandist, C., Evensen, L. S., \& Faber, C. H. (2004). Introduction: Thinking culture dialogically. In F. Bostad, C. Brandist, L. S. Evensen, \& H. C. Faber (Eds.), Bakhtinian perspectives on language and culture: Meaning in language, art and new media (pp. 117). London, England: Palgrave MacMillan. 
Bourdieu, P. (1986). The forms of capital. In Richardson, J. (Ed.), Handbook of theory and research for the sociology of education (pp. 241-258). Westport, CT: Greenwood.

Bower, M., Highfield, K., Furney, P., \& Mowbray, L. (2013). Supporting pre-service teachers' technology-enabled learning design thinking through whole of programme transformation. Educational Media International, 50(1), 39-50.

Brader, A., \& Luke, A. (2013). Re-engaging marginalized youth through digital music production: Performance, audience and evaluation. Pedagogies: An International Journal, 8(3), 197-214.

Brettschneider, A. W. (2004). Dialoguing about dialogism: Form and content as a Bakhtinian dialogue. In A. F. Ball \& S. W. Freedman (Eds.), Bakhtinian perspectives on language, literacy, and learning (pp. 99-103). Cambridge, UK: Cambridge University Press.

Britzman, D. P. (2003). Practice makes practice: A critical study of learning to teach. Albany, NY: State University of New York Press.

Brown, R., \& Renshaw, P. (2006). Position students as actors and authors: Chronotopic analysis of collaborative learning activities. Mind, Culture, and Activity, 13(3), 247-259.

Brown, S. A. (2017). Digital initiatives for literacy development in elementary classrooms. Hershey, PA: IGI Global.

Brown v. Board of Education of Topeka, 347 U.S. 483 (1955). 
Bruce, C. (2015). Information literacy: Understanding peoples' information and learning experiences. In Knezevic, R. (Ed.) 12th International Scientific Conference: Western Balkan information literacy, 18-20 June 2015, Bihac, Bosnia and Herzegovina. Retrieved from https://eprints.qut.edu.au/95696/3/95696.pdf

Bruner, J. (1979). On knowing: Essays for the left hand. Cambridge, MA: Harvard University Press.

Bruner, J. (1986). Actual minds, possible worlds. Cambridge, MA: Harvard University Press.

Bruner, J. (2004). Life as narrative. Social Research, 71(3), 691-710.

Bundy, R. F. (1968). Computer-assisted instruction: Where are we? The Phi Delta Kappan, 49(8), 424-429.

Burke, E. F. (1939). An experimental study of the educational use of the typewriter in second grade (Master's thesis). Loyola University, Chicago, IL.

Bush, E. J. (1995, June). Internet publishing: An introduction and discussion of basics. Paper presented at the Annual Meeting of the Air \& Waste Management Association, San Antonio, TX.

Butin, D. W. (2009). The education dissertation: A guide for practitioner scholars. Thousand Oaks, CA: Corwin.

Cain, V. (2018). From Sesame Street to Prime Time School Television: Educational media in the wake of the Coleman Report. History of Education Quarterly, 57(4), 590-601. 
Canuel, M. J., \& White, B. J. (2014, July). Modeling pedagogy for teachers transitioning to the virtual classroom. Paper presented at the International Conference e-Learning 2014, Lisbon, Portugal.

Cassidy, M. (1998). Historical perspectives on teaching with technology in k-12 schools. The New Jersey Journal of Communication, 6(2), 170-184.

Cazden, C.B. (2006, January). Connected learning: "Weaving” in classroom lessons. Paper presented at the Pedagogy in Practice 2006 Conference, University of Newcastle, New South Wales, Australia.

Chandler, J. A. (2012). "Obligatory technologies": Explaining why people feel compelled to use certain technologies. Bulletin of Science, Technology \& Society, 32(4), 255-264.

Charon, R. (2007). What to do with stories: The sciences of narrative medicine. Canadian Family Medicine, 53(8), 1265-1267.

Chase, S. E. (1995). Ambiguous empowerment: The work narratives of women school superintendents. Amherst, MA: University of Massachusetts Press.

Chase, S. E. (2005). Narrative inquiry: Multiple lenses, approaches, voices. In N. K. Denzin \& Y. S. Lincoln (Eds.), The SAGE handbook of qualitative research (3rd ed., pp. 651-679). Thousand Oaks, CA: SAGE Publications, Inc.

Checkland, P. (1981). Systems thinking, systems practice. Chichester, West Sussex, UK: John Wiley \& Sons Ltd.

Clandinin, D. J., \& Connelly, F. M. (1988). Teachers as curriculum planners: Narratives of experience. New York, NY: Teachers College Press. 
Clandinin, D. J., \& Connelly, F. M. (1995). Competing and conflicting stories on the landscape. In D. J. Clandinin \& F. M. Connelly (Eds.), Teachers' professional knowledge landscapes (pp. 125-133). New York, NY: Teachers College Press.

Clandinin, D. J., \& Connelly, F. M. (2000). Narrative inquiry: Experience and story in qualitative research. San Francisco, CA: Josey-Bass.

Clandinin, D. J., \& Huber, J. (2010). Narrative inquiry. In B. McGaw, E. Baker, \& P. P. Peterson (Eds.), International encyclopedia of education (3rd ed., pp. 436-441). New York, NY: Elsevier.

Clouse, R. W., \& Nelson, H. E. (2000). School reform, constructed learning, and educational technology. Educational Technology Systems, 28(4), 289-303.

Coleman, J. S., Campbell, E. Q., Hobson, C. J., McPartland, J., Mood, A. M., Weinfeld, F. D., \& York, R. L. (1966). Equality of educational opportunity. Washington, D.C.: United States Department of Health, Education \& Welfare.

Connelly, F. M., \& Clandinin, D. J. (1990). Stories of experience and narrative inquiry. Educational Researcher, 19(5), 2-14.

Connelly, F. M., \& Clandinin, D. J. (1999). Borders of space and time. In F. M. Connelly \& D. J. Clandinin (Eds.), Shaping a professional identity (pp. 103-113). New York, NY: Teachers College Press.

Cope, B., \& Kalantzis, M. (1997). White noise: The attach on political correctness and the struggle for the Western canon. Interchange, 28(4), 283-329.

Cope, B., \& Kalantzis, M. (2009). "Multiliteracies": New literacies, new learning. Pedagogies 4(3), 164-195. 
Cope, B., Kalantzis, M., \& Smith, A. (2018). Pedagogies and literacies, disentangling the historical trends: An interview with Bill Cope and Mary Kalantzis. Theory Into Practice, $57(1), 5-11$.

Cornett, J., \& Knight, J. (2009). Research on coaching. In Knight, J. (Ed.), Coaching: Approaches and perspectives, (192-216). Thousand Oaks, CA: Corwin Press.

Cothran, A., \& Mason, G. E. (1978). The typewriter: Time-tested tool for teaching reading and writing. The Elementary School Journal, 78(3), 170-173.

Counts, G. S. (1930). The American road to culture: A social interpretation of education in the United States (2nd. ed.). New York, NY: The John Day Company, Inc.

Creswell, J. W. (2012). Educational research: Planning, conducting, and evaluating quantitative and qualitative research (4th ed.). Boston, MA: Pearson Education, Inc.

Cristia, J., Ibarrarán, P., Cueto, S., Santiago, A., \& Severín, E. (2017). Technology and child development: Evidence from the one laptop per child program. American Economic Journal: Applied Economics, 9(3), 295-320.

Cuban, L. (1990). Reforming again, again, and again. Educational Researcher, 19(1), 3-13.

D'Andrade, R. (1995). The development of cognitive anthropology. Cambridge, England: Cambridge University Press.

Dall'Alba, G. (2009). Learning professional ways of being: Ambiguities of becoming. In G. Dall'Alba (Ed.), Exploring education through phenomenology: Diverse approaches (pp. 41-52). Chichester, West Sussex, UK: Wiley-Blackwell.

Dallacqua, A. K., Kersten, S., \& Rhoades, M. (2015). Using Shaun Tan's work to foster multiliteracies in 21st-century classrooms. Reading Teacher, 69(2), 207-217. 
DaMatta, R. (1994). Some biased remarks on interpretivism: A view from Brazil. In R. Borofsky (Ed.), Assessing cultural anthropology (119-131). New York, NY: McGraw-Hill, Inc.

Daniel, L. G., \& Onwuegbuzie, A. J. (2002, November). Reliability and qualitative data: Are psychometric concepts relevant within an interpretivist research paradigm. Paper presented at the Annual Meeting of the Mid-South Educational Research Association, Chattanooga, TN.

Darling-Hammond, L., Hammerness, K., Grossman, P., Rust, F., \& Shulman, L. (2007). The design of teacher education programs. In L. Darling-Hammond \& J. Bransford (Eds.), Preparing teachers for a changing world: What teachers should learn and be able to do (pp. 390-441). New York, NY: The Guilford Press.

Darling-Hammond, L., Hyler, M. E., \& Gardner, M. (2017). Effective teacher professional development. Palo Alto, CA: Learning Policy Institute. Retrieved from https://learningpolicyinstitute.org/sites/default/files/productfiles/Effective_Teacher_Professional_Development_REPORT.pdf

Darling-Hammond, L., \& Rothman, R. (2015). Teaching in the flat world. New York, NY: Teachers College Press.

Davies, I, K., \& Schwen, T. M. (1971, March). Toward a definition of instructional development. Paper presented to the Association for Educational Communications and Technology Annual Convention, Washington, D.C.

Davis, F. D. (1989). Perceived usefulness, perceived ease of use, and user acceptance of information technology. MIS Quarterly, 13(3), 319-340. 
Delamont, S. (2004) Ethnography and participant observation. In C. Seale, G. Gobo, J. F. Gubrium, \& D. Silverman (Eds.), Qualitative research practice (pp. 205-217). Thousand Oaks, CA: SAGE Publications, Inc.

Demski, J. (2012). The hard(ware) choice. T.H.E.Journal, 39(9), 28-35.

Deng, F., Chai, C. S., So., H, Qian, Y., \& Chen, L. (2017). Examining the validity of the technological pedagogical content knowledge (TPACK) framework for preservice chemistry teachers. Australasian Journal of Educational Technology, 33(3), 1-14.

Depalma, R. (2010). Toward a practice of polyphonic dialogue in multicultural teacher education. Curriculum Inquiry, 40(3), 436-453.

Derrida, J. (1981). The law of genre. In W. J. T. Mitchell (Ed.), On narrative (pp. 51-78). Chicago, IL: The University of Chicago Press.

Derrida, J., Porter, C., \& Morris, E. P. (1983). The principle of reason: The university in the eyes of its pupils. Diacritics, 13(3), 2-20.

Desimone, L. M. (2009). Improving impact studies of teachers' professional development: Toward better conceptualizations and measures. Educational Researcher, 38(3), 181-199.

Desimone, L. M., \& Pak, K. (2017). Instructional coaching as high-quality professional development. Theory Into Practice, 56(1), 3-12.

Devedžic, V., \& Jovanović, J. (2015). Developing open badges: A comprehensive approach. Educational Technology Research \& Development, 63(4), 603-620.

Dewey, J. (1896). Interest in relation to training of the will. In C. A. McMurry (Ed.), Second supplement to the Herbart yearbook for 1895 (2nd ed., pp. 5-38). Chicago, IL: University of Chicago Press. 
Dewey, J. (1897). Criticisms wise and otherwise on modern child study. In Journal of proceedings and addresses of the thirty-sixth annual meeting of the National Education Association (pp. 867-868). Chicago, IL: The University of Chicago Press.

Dewey, J. (1966). Lecture XIX: February 15, 1899. In R. D. Archumbault (Ed.), Lectures in the philosophy of education: 1899 by John Dewey (1st ed., pp. 187-199). New York, NY: Random House, Inc.

Dewey, J. (1972). Plan of organization of the university primary school. In J. A. Boydston (Ed.), The early works of John Dewey, 1882-1888: Vol. 5 1895-1888: Early essays (pp. 223243). Carbondale, IL: Southern Illinois University Press. (Original work published 1895).

Dewey, J. (1994). Art as experience. In D. J. Flinders \& S. J. Thornton (Eds.), Art and its significance (3rd ed., pp. 204-220). Albany, NY: State University of New York Press.

Dewey, J. (1997). Experience and education. New York, NY: Simon \& Schuster. (Original work published 1938).

DeWitt, S. J. (1996). The current nature of hypertext research in computers and composition studies. An historical perspective. Computers and Composition, 13(1), 69-84.

Dietrich, T, \& Balli, S. J. (2014). Digital natives: Fifth-grade students' authentic and ritualistic engagement with technology. International Journal of Instruction, 7(2), 21-34.

Dilthey, W. (1985). The imagination of the poet: Elements for a poetics. (L. Agosta \& R. A. Makkreel, Trans.). In R. A. Makkreel \& F. Rodi (Eds.), Selected works volume V: Poetry and experience (pp. 299-160). Princeton, NJ: Princeton University Press. (Original work published 1887). 
Donovan, L., Green, T., \& Hansen, L. E. (2012). One-to-one laptop teacher education: Does involvement affect candidate technology skills and dispositions? Journal of Research on Technology in Education, 44(2), 121-139.

Dooley, C. M., Ellison, T. L., Welch, M. M., Allen, M., \& Bauer, D. (2016). Digital participatory pedagogy: Digital participation as a method for technology integration in curriculum. Journal of Digital Learning in Teacher Education, 32(2), 52-62.

Dressman, M. (2004). Dewey and Bakhtin in dialogue: From Rosenblatt to a pedagogy of literature as social, aesthetic practice. In A. F. Ball \& S. W. Freedman (Eds.), Bakhtinian perspectives on language, literacy, and learning (pp. 34-52). Cambridge, UK: Cambridge University Press.

Dweck, C. S., \& Legget, E. L. (1988). A social-cognitive approach to motivation and personality. Psychological Review, 95(2), 256-273.

Eagleton, T. (2003). Literary theory: An introduction (2nd edition). Minneapolis, MN: University of Minnesota Press.

Eglash, R. (2004). Appropriating technology: An introduction. In R. Eglash, J. L. Croissant, G. Di Chiro, \& R. Fouché (Eds.), Appropriating technology: Vernacular science and social power (pp. vii-xxi). Minneapolis, MN: University of Minnesota Press.

Eisner, E. W. (1979). The educational imagination: On the design and evaluation of school programs. New York, NY: Macmillan Publishing Co., Inc.

Eisner, E. W. (1990). The meaning of alternative paradigms for practice. In E. G. Guba (Ed.), The paradigm dialog (pp. 88-102). Thousand Oaks, CA: SAGE Publications, Inc. 
Elbaz-Luwisch, F. (2007). Studying teachers' lives and experience: Narrative inquiry into K-12 teaching. In D. J. Clandinin (Ed.), Handbook of narrative inquiry: Mapping a methodology (pp. 357-382). Thousand Oaks, CA: SAGE Publications, Inc.

Eliot, C. W., \& Robinson, O. D. (1894). The work of the Committee of Ten. The School Review, 2(6), 366-372.

Elmore, R. F. (1993) School decentralization: Who gains? Who loses? In J. Hannaway \& M. Carnoy (Eds.), Decentralization and school improvement: Can we fulfill the promise? (pp. 33-54). San Francisco, CA: Josey-Bass

Ely, D. P. (1963). The changing role of the audiovisual process in education: A definition and glossary of related terms. Washington, D.C.: National Education Association.

Ely, D. P. (1972). Defining the field of educational technology. Audiovisual Instruction, 18(3), $52-53$.

Ely, D. P. (1976, January). The current status of audiovisual definitions and terminology: An international perspective. Paper presented to the International Symposium on AudioVisual Materials, Strasbourg, France.

Ely, M., Vinz, R., Downing, M., \& Anzul, M. (1997). On writing qualitative research: Living by words. London, England: The Falmer Press.

Emerson, R. M., Fretz, R. I., \& Shaw, L. L. (2011). Writing ethnographic fieldnotes (2nd ed.). University of Chicago Press: Chicago, IL.

Eng, N. (2016). Education inequality: Broadening public attitudes through framing. Journal of Social Issues, 72(4), 676-695.

Fairclough, N. (2010). Critical discourse analysis: The critical study of language (2nd ed.). New York, NY: Routledge. 
Federal Communications Commission. (2018). E-rate: Universal service program for schools and libraries. Retrieved from https://www.fcc.gov/consumers/guides/universal-serviceprogram-schools-and-libraries-e-rate

Fiese, B. H., Tomcho, T. J., Douglas, M., Josephs, K., Poltrock, S., \& Baker, T. (2002). A review of 50 years of research on naturally occurring family routines and rituals: Cause for celebration? Journal of Family Psychology, 16(4), 381-390.

Finn, J. D. (1953). Professionalizing the audio-visual field. Audio Visual Communication Review, 1(1), 6-17.

Flick, U. (2007). Designing qualitative research. Thousand Oaks, CA: SAGE Publications, Inc. Forzani, E., \& Leu, D. J. (2012). New literacies for new learners: The need for digital technologies in primary classrooms. The Educational Forum, 76(4), 421-424.

Foucault, M. (1978). The history of sexuality volume I: An introduction. (R. Hurley, Trans.). New York, NY: Pantheon Books. (Original work published 1976).

Foucault, M. (1991). Governmentality. In G Burchell, C. Gordon, \& P. Miller (Eds.), The Foucault effect: Studies in governmentality (pp. 87-104). Chicago, IL: The University of Chicago Press. (Original work published 1978).

Frank, A. W. (2005). What is dialogical research, and why should we do it? Qualitative Health Research, 15(7), 964-974.

Frank, K. A., Zhao, Y., Penuel, W. R., Ellefson, N., \& Porter, S. (2011). Focus, fiddle, and friends: Experiences that transform knowledge for the implementation of innovations. Sociology of Education, 84(2), 137-156.

Freebody, P., \& Luke, A. (1990). Literacies programs: Debates and demands in cultural context. Prospect: An Australian Journal of TESOL, 5(3), 7-16. 
Freeman, J., Sugai, G., Simonsen, B., \& Everett, S. (2017). MTSS coaching: Bridging knowing to doing. Theory Into Practice, 56(1), 29-37.

Freire, P. (2009). Pedagogy of the oppressed. In A. Darder, M. P. Baltodano, \& R. D. Torres (Eds.), The critical pedagogy reader (2nd ed., pp. 52-60). New York, NY: Routledge.

Friesen, N. (2008). Critical theory: Ideology critique and the myths of e-learning. Ubiquity, 2008(June). Retrieved from http://ubiquity.acm.org/article.cfm?id=1386860

Fry, K. (2015). Developing media literacy: Managing fear and moving beyond. Journal of Media Literacy Education, 6(3), 65-70.

Fulara, A. (2013). The model of counterpoint improvisation and the methods of improvisation in popular music. Avant: Journal of Philosophical-Interdisciplinary Vanguard, 4(1), 417454.

Futrell, M., \& Geisert, P. (1985). A call to action to improve the design of microcomputer instructional courseware. Educational Technology, 25(5), 13-15.

Gamage, S. N., \& Tanwar, T. (2018). Factors affecting teachers' use of ICTs in the classroom: A systematic review of the literature. Information Technologies \& International Development, 14, 105-115.

Garcia, A., \& O’Donnell-Allen, C. (2015). Pose, wobble, flow: A cultural proactive approach to literacy instruction. New York, NY: Teachers College Press.

Gasson, S. (2004). Rigor in grounded theory research: An interpretive perspective on generating theory from qualitative field studies. In M. E. Whitman, \& A. B. Woszczynski (Eds.), The handbook of information systems research (pp. 79-102). Hershey, PA: Idea Group

Gee, J. P. (2005a). An introduction to discourse analysis: Theory and method (2nd edition). London, UK: Routledge. 
Gee, J. P. (2005b). Pleasure, learning, video games, and life: The projective stance. E-Learning, 2(3), 211-223.

Gee, J. P. (2008). Social linguistics and literacies: Ideology in discourses (3rd ed.). New York, NY: Routledge.

Gee, J. P. (2009a). A situated sociocultural approach to literacy and technology. In E. A. Baker (Ed.), The new literacies: Multiple perspectives on research and practice (pp. 165-193). New York, NY: The Guilford Press.

Gee, J. P. (2009b). Semiotic social spaces and affinity spaces: From the age of mythology to schools today. In D. Barton, \& K. Tusting (Eds.), Beyond communities of practice: Language, power, and social context (pp. 214-232). New York, NY: Cambridge University Press.

Gee, J. P. (2013). Reading as situated language: A sociocognitive perspective. In R. B. Ruddell, N. Unrau, \& D. E. Alvermann (Eds.), Theoretical models and processes of reading (136151). Newark, DE: International Reading Association.

Gee, J. P. (2014). Decontextualized language: A problem, not a solution. International Multilingual Research Journal, 8(1), 9-23.

Gee, J. P. (2015a). Discourse, small-d, big D. In K. Tracy, T. Sandel, \& C. Ilie (Eds.), The international encyclopedia of language and social interaction (1-5). Hoboken, NJ: Wiley-Blackwell.

Gee, J. P. (2015b). Games and comprehension: The importances of specialist language. In C. C. Block, \& S. R. Parris (Eds.), Comprehension instruction: Research-based best practice (2nd edition) (356-366). New York, NY: Guilford Press. 
Gee, J. P. (2015c). Reflections on understanding, alignment, the social mind, and language in interaction. Language and dialogue, 5(2), 300-311.

Gee, J. P. (2015d). The vexed nature of language learning and teaching. In R. H. Jones \& J. C. Richards (Eds.), Creativity in language teaching: Perspectives from research and practice (pp. 63-76). London, UK: Routledge.

Gee, J. P. (2016). Video games, design, and aesthetic experience. Rivista di estetica, (63), 149160.

Gee, J. P. (2017a). Educational linguistics. In M. Arnoff \& J. R. Miller (Eds.), The handbook of linguistics (2nd ed., pp. 603-616). Hoboken, NJ: Wiley-Blackwell.

Gee, J. P. (2017b). Identity and diversity in today's world. Multicultural Education Review, 9(2), 83-92.

Gee, J. P. (2018). Affinity spaces: How young people live and learn online and out of school. Phi Delta Kappan, 99(6), 8-13.

Geertz, C. (1973). The interpretation of cultures. New York, NY: Basic Books.

Geertz, C. (1995). After the fact: Two countries, four decades, one anthropologist. Cambridge, MA: Harvard University Press.

Geertz, C. (2005). Deep play: Notes on the Balinese cockfight. Daedalus, 134(4), 56-86.

Gibson, J. J. (1986) The ecological approach to visual perception. New York, NY: Psychology Press.

Gierhart, A. R. (2016). Curriculum mapping to meet state standards. New Teacher Advocate, $23(3), 2-3$ 
Gierhart, A. R. (2018). Using Blogger with elementary students to construct, publish, and connect. In ISTE 2018 recorded sessions. Washington, D.C.: ISTE. Retrieved from https://conference.iste.org/2018/program/search/detail_session.php?id=111021034

Gierhart, A. R., Bonner, S., Smith, A., \& Seglem, R. (2020). Fostering ethical engagement through digital collaboration. In K. H. Turner (Ed.), The ethics of digital literacy: Developing knowledge and skills across grade levels (pp. 89-100). Lanham, MD: Rowman \& Littlefield.

Gierhart, A. R., \& Brown, R. (2018). Developing technological literacy: Third graders use Google Classroom. Children's Technology and Engineering, 22(4), 22-25.

Gill, L., Dalgarno, B., \& Carlson, L. (2015). How does pre-service teacher preparedness to use ICTs for learning and teaching develop through their degree program? Australian Journal of Teacher Education, 40(1), 35-60.

Glesne, C. (2010). Becoming qualitative researchers: An introduction (4th ed.). New York, NY: Longman.

Gracia, J. J. E. (2012). Painting Borges: Philosophy interpreting art interpreting literature. Albany, NY: State University of New York Press.

Greene, M. (1984). "Excellence," meanings, and multiplicity. Teachers College Record, 86(2), 283-297.

Greene, M. (1995). Releasing the imagination. San Francisco, CA: Josey-Bass Inc., Publishers. Greene, M. (2009). In search of a critical pedagogy. In A. Darder, M. P. Baltodano, \& R. D. Torres (Eds.), The critical pedagogy reader (2nd. ed., pp. 84-96). New York, NY: Routledge. 
Greener, S., \& Wakefield, C. (2015). Developing confidence in the use of digital tools in teaching. Electronic Journal of E-Learning, 13(4), 260-267.

Groenewald, T. (2004). A phenomenological research design illustrated. International Journal of Qualitative Methods, 3(1), 42-55.

Groys, B. (2017). Between Stalin and Dionysus: Bakhtin's theory of the carnival. Dialogic Pedagogy: An International Online Journal, 5, 1-5.

Guala, E., \& Boero, P. (2017). Cultural analysis of mathematical content in teacher education: The case of elementary arithmetic theorems. Educational Studies in Mathematics, 96(2), 207-227.

Guba, E. G., \& Lincoln, Y. S. (1994). Competing paradigms in qualitative research. In N. K. Denzin \& Y. S. Lincoln (Eds.), Handbook of qualitative research (pp. 105-117). Thousand Oaks, CA: SAGE Publications, Inc.

Gubrium J. F. (2003). What is a good story? Generations, 27(3), 21-24.

Gubrium, J. F., \& Holstein, J. A. (2009). Analyzing narrative reality. Thousand Oaks, CA: SAGE Publications, Inc.

Guskey, T. (2002). Professional development and teacher change. Teachers and Teaching: Theory and Practice, 8(3/4), 381-391.

Guthrie, J. W. (1985). The educational policy consequences of economic instability: The emerging political economy of American education. Educational Evaluation and Policy Analysis, 7(4), 319-332.

Ha, C, \& Lee, S. (2019). Elementary teachers' beliefs and perspectives related to smart learning in South Korea. Smart Learning Environments, 6(3). 
Haefner, R. (1932). The typewriter in the primary and intermediate grades; a basic educational instrument for younger children. New York, NY: The Macmillan Company.

Haefner, R. (1936). The influence of the typewriter on reading in the elementary school. The Elementary English Review, 13(8), 291-294.

Hall, G. S. (1904). Adolescence: Its psychology and its relations to physiology, anthropology, sociology, sex, crime, religion and education - Volume II. New York, NY: D. Appleton and Company.

Han, H. S., \& Kemple, K. L. (2006). Components of social competence and strategies of support: Considering what to teach and how. Early Childhood Education Journal, 34(3), 241-246.

Hansen, D. T. (2010). Cosmopolitanism and education: A view from the ground. Teachers College Record, 112(1), 1-30.

Hargittai, E. (2002). Second-level digital divide: Differences in people's online skills. First Monday, 7(4). Retrieved from http://firstmonday.org/ojs/index.php/fm/issue/view/144

Harris, J. L., Al-Bataineh, M., \& Al-Bataineh, A. (2016). One to one technology and its effect on student academic achievement and motivation. Contemporary Educational Technology, 7(4), 368-381.

Harris, J. L., Mishra, P., \& Koehler, M. (2009). Teachers' technological pedagogical content knowledge and learning activity types: Curriculum-based technology integration reframed. Journal of Research on Technology in Education, 41(4), 393-416.

Harris, J., Phillips, M., Koehler, M., \& Rosenberg, J. (2017). TPCK/TPACK research and development: Past, present, and future directions. Australasian Journal of Educational Technology, 33(3), i-viii. 
Hays, D. G., \& Singh, A. A. (2012). Qualitative inquiry in clinical and educational settings. New York, NY: The Guilford Press.

Hecht, B. (1997). Net loss: Clinton's internet delusion. The New Republic, 216(7), 15-18.

Heidegger, M. (2001). Being and time. (J. Macquarrie \& E. Robinson, Trans.). Oxford, UK: Blackwell Publishers, Ltd. (Original work published 1962).

Heitink, M., Voogt, J., Verplanken, 1., van Braak, J., \& Fisser, P. (2016). Teachers' professional reasoning about their pedagogical use of technology. Computers \& Education, 101, 7083.

Henry, L. A., Castek, J., Roberts, L., Coiro, J., \& Leu, D. J. (2004). Case technologies to enhance literacy learning. Knowledge Quest, 33(2), 26-29.

Hensiek, S., DeKorver, B. K., Harwood, C. J., Fish, J., O’Shea, K., \& Towns, M. (2017). Digital badges in science: A novel approach to the assessment of student learning. Journal of College Science Teaching, 46(3), 28-33.

Herbert, M. (2012). Why all the chatter about \#EdChat? District Administration, 48(4), 51-54.

Herold, B. (2016, February 5). Technology in education: An overview. Education Week. Retrieved from https://www.edweek.org/ew/issues/technology-in-education/index.html Hess, J. (2018). A “discomfortable” approach to music education: Re-envisioning the "strange encounter." Philosophy of Music Education Review, 26(1), 24-45.

Hobbs, R. (2013). Improvization and strategic risk-taking in informal learning with digital media literacy. Learning, Media and Technology, 38(2), 182-197.

Höckert, J., \& Ljung, M. (2009). When extension system fails to connect with the farmers' lifeworld. In C. Paffarini, \& F. M. Santucci (Eds.), XIX ESEE European seminar of 
extension education: Theory and practice of advisory work in a time of turbulences (pp. 159-163). Perugia, Italy: Ali\&No Editrice.

Höckert, J., \& Ljung, M. (2013). Advisory encounters towards a sustainable farm developmentinteraction between systems and shared lifeworlds. The Journal of Agricultural Education and Extension: Competence for Rural Innovation and Transformation, 19(3), 291-309.

Holdway, J., \& Hitchcock, C. H. (2018). Exploring ideological becoming in professional development for teachers of multilingual learners: Perspectives on translanguaging in the classroom. Teaching and Teacher Education, 75, 60-70.

Hollingworth, S., Mansaray, A., Allen, K., \& Rose, A. (2011). Parents' perspectives on technology and children's learning in the home: Social class and the role of the habitus. Journal of Computer Assisted Learning, 27(4), 347-360.

Holmberg, J., Fransson, G., \& Fors, U. (2017, July). Teachers' reframing of practice during a design-based research project. Paper presented at the International Conference on Information, Communication Technologies in Education, Rhodes, Greece.

Holmberg, J., Fransson, G., \& Fors, U. (2018). Teachers' pedagogical reasoning and reframing of practice in digital contexts. The International Journal of Information and Learning Technology, 35(2), 130-142.

Holquist, M. (2002). Dialogism (2nd ed.). New York, NY: Routledge.

Huber, J., Caine, V., Huber, M., \& Steeves, P. (2016). Narrative inquiry as pedagogy in education: The extraordinary potential of living, telling, retelling, and reliving stories of experience. Review of Research in Education, 37(1), 212-242. 
Hughes, J., \& Lang, K. R. (2004). Issues in online focus groups: Lessons learned from an empirical study of peer-to-peer filesharing system users. European Journal of Business Research Methods, 2(2), 95-110.

Hull, G. A., \& Stornaiuolo, A. (2010). Literate arts in a global world: Reframing social networking as cosmopolitan practice. Journal of Adolescent \& Adult Literacy, 54(2), 8597.

Hunter, J. L. (2015). High possibility classrooms: A new model for technology integration. In M. Niess \& H Gillow-Wiles (Eds.), Handbook of research on teacher education in the digital age (pp. 466-492). Hershey, PA: IGI Global.

Husbye, N. E., Buchholz, B., Coggin, L. S, Powell, C. W., \& Wohlwend, K. E. (2012). Critical lessons and playful literacies: Digital media in PK-2 classrooms. Language Arts, 90(2), $82-92$.

Iannone, P. V. (1998). Exploring literacy on the internet. The Reaching Teacher, 51(5), 438-443. Ito, M., Gutierrez, K., Livingstone, S., Penuel, B., Rhodes, J., Salen, K., ... Watkins, S. C. (2013). Connected learning: An agenda for research and design. Retrieved from the Digital Media and Learning Research Hub website: https://dmlhub.net/publications/connected-learning-agenda-for-research-anddesign/

Jacobs, G. (1992). Hypermedia and discovery-based learning: A historical perspective. British Journal of Educational Technology, 23(2), 113-121.

Jacobs, G. (2005). Hypermedia and discovery based learning: What value? Australasian Journal of Educational Technology, 21(3), 355-366. 
James, M. (2015). On carnival and context: A response to Bridget Storrie. International Journal of Transitional Justice, 9(3), 486-493.

Janghorban, R., Roudsari, R. L., \& Taghipour, A. (2014). Skype interviewing: The new generation of online synchronous interview in qualitative research. International Journal of Qualitative Studies on Health and Well-being, 9(1), 1-2.

Janks, H. (2013). Critical literacy in teaching and research. Education Inquiry, 4(2), 225-242.

Januszewski, A. (2001). Educational technology: The development of a concept. Englewood, CO: Libraries Unlimited, Inc.

Jenkins, H. (2006). Confronting the challenges of participatory culture: Media education for the 21st century. Chicago, IL: The MacArthur Foundation.

Jennings, P. A., \& Greenberg, M. T. (2009). The prosocial classroom: Teacher social and emotional competence in relation to student and classroom outcomes. Review of Educational Research, 79(1), 491-525.

Jesson, R., McNaughton, S., \& Wilson, A. (2015). Raising literacy levels using digital learning: A design-based approach in New Zealand. The Curriculum Journal, 26(2), 198-223.

Joan Ganz Cooney Center at Sesame Workshop. (2016). Opportunity for all? Technology and learning in lower-income families. New York, NY: V. Rideout \& V. S. Katz. Retrieved from https://www.joanganzcooneycenter.org/wp-content/uploads/2016/01/jgcc_ opportunityforall.pdf

Johnson, M., \& Liber, O. (2008). The personal learning environment and the human condition: From theory to teaching practice. Interactive Learning Environments, 16(1), 3-15. 
Jones, A., \& Bennett, R. (2017). Reaching beyond an online/offline divide: Invoking the rhizome in higher education course design. Technology, Pedagogy, \& Education, 26(2), 193-210.

Jones, R. H., \& Hafner, C. A. (2012). Understanding digital literacies: A practical introduction. New York, NY: Routledge.

Josselson, R. (2007). The ethical attitude in narrative research. In D. J. Clandinin (Ed.), Handbook of narrative inquiry: Mapping a methodology (pp. 537-566). Thousand Oaks, CA: SAGE Publications, Inc.

Kabat, K. J. (2014). Time, space, and dialogue in a distance-learning class discussion board. ELearning and Digital Media, 11(2), 162-175.

Kac, E. (2004). Negotiating meaning: The dialogic imagination in electronic art. In F. Bostad, C. Brandist, L. S. Evensen, \& H. C. Faber (Eds.), Bakhtinian perspectives on language and culture: Meaning in language, art and new media (pp. 199-212). London, England: Palgrave MacMillan.

Kafyulilo, A., Fisser, P., Pieters, J., \& Voogt, J. (2015). ICT use in science and mathematics teacher education in Tanzania: Developing technological pedagogical content knowledge. Australasian Journal of Educational Technology, 31(4), 381-399.

Kalantzis, M., \& Cope, B. (2004). Multiliteracies: The story so far. (A. Cloonan, Interviewer). Australian Screen Education, 35, 47-51.

Kalantzis, M., \& Cope, B. (2010). Learning by design. E-Learning and Digital Media, 7(3), 198199.

Kalantzis, M., Cope, B., \& Harvey, A. (2003). Assessing multiliteracies and the new basics. Assessment in Education: Principles, Policy \& Practice, 10(1), 15. 
Kalmbach, J. (1996). From liquid paper to typewriters: Some historical perspectives on technology in the classroom. Computers and Composition, 13(1), 57-68.

Kang, H. S. (2014). Bruner's educational theory since structure of knowledge: Narrative turn. Advance Science and Technology Letters, 47, 258-260.

Kannellopoulos, P. A. (2011). Freedom and responsibility: The aesthetics of free musical improvisation and its educational implications - a view from Bakhtin. Philosophy of Music Education Review, 19(2), 113-135.

Kant, I. (1998). Critique of pure reason (P. Guyer \& A. W. Wood, Trans.). Cambridge, UK: Cambridge University Press. (Original work published 1781).

Kasson, F. H. (1895). The typewriter: A coming necessity in schools. Education, 15(10), 615622.

Katz, M. B. (2001). The irony of early school reform: Educational innovation in mid-nineteenth century Massachusetts. New York, NY: Teachers College Press. (Original work published 1968).

Kerkhoff, S. N. (2017). Designing global futures: A mixed methods study to develop and validate the teaching for global readiness scale. Teaching and Teacher Education, 65, 91106.

Keunen, B. (2010). The chronotopic imagination in literature and film: Bakhtin, Bergson, and Deleuze on forms of time. In N. Bemong, P. Borghart, M. De Dobbeleer, K. Demoen, K. De Temmerman, \& B. Keunen (Eds.), Bakhtin's theory of the literary chronotope: Reflections, applications, perspectives (pp. 35-56). Lebanon, NH: Academia Press.

Killi, C., Laurinen, L., Marttunen, M., \& Leu, D. J. (2012). Working on understanding during collaborative online reading. Journal of Literacy Research, 44(4), 448-483. 
Kim, J. H. (2008). A romance with narrative inquiry: Toward an act of narrative theorizing. Curriculum and Teaching Dialogue, $10(1 \& 2), 249-265$.

Kim, J. H. (2015). Understanding narrative inquiry. Thousand Oaks, CA: SAGE Publications, Inc.

Kim, J. H., \& Macintyre Latta, M. (2010). Narrative inquiry: Seeking relations as modes of interactions. The Journal of Educational Research, 103(3), 69-71.

Kim, M. S., \& Xing, X. (2019). Appropriation of affordances of multiliteracies for Chinese literacy teaching in Canada. Research and Practice in Technology Enhanced Learning, 14(1), 1-14.

Kimmons, R., Miller, B. G., Amador, J., Desjardins, C. D., \& Hall, C. (2015). Technology integration coursework and finding meaning in pre-service teachers' reflective practice. Educational Technology Research and Development, 63(6), 809-829.

Kincheloe, J. L. (2009). No short cuts in urban education: Metropedagogy and diversity. In S. R. Steinberg (Ed.), Diversity and multiculturalism: A reader (pp. 379-410). New York, NY: Peter Lang Publishing, Inc.

Kingsley, T. L., Cassady, J. C., \& Tancock, S. M. (2015. Successfully promoting 21st century online research skills: Interventions in 5th-grade classrooms. Reading Horizons, 54(2), 91-134.

Klapwijk, R., \& Van Doorn, F. (2015). Contextmapping in primary design and technology education: A fruitful method to develop empathy for and insight in user needs. International Journal of Technology and Design Education, 25(2), 151-167. 
Kliebard, H. M. (2004). The struggle for the American curriculum, 1893-1958 (3rd ed.). New York, NY: Routledge.

Knight, J. (2007). Instructional coaching: A partnership approach to improving instruction. Thousand Oaks, CA: Corwin Press.

Knupfer, N. N. (1993). Teachers and educational computing: Changing roles and changing pedagogy. In R. Muffoletto \& N. N. Knupfer (Eds.), Computers in education: Social, political, \& historical perspectives (pp. 163-179). Cresskill, NJ: Hampton Press, Inc.

Koehler, M. J., \& Mishra, P. (2003). Teachers learning technology by design. Journal of Computing in Teacher Education, 21(3), 94-102.

Koehler, M. J., Mishra, P., Hershey, K., \& Peruski, L. (2004). With a little help from your students: A new model for faculty development and online course design. Journal of Technology and Teacher Education, 12(1), 25-55.

Koehler, M. J., Mishra, P., Kereluik, K., Shin, T. S., \& Graham, C. R. (2014). The technological pedagogical content knowledge framework. In J. M. Spector, M. D. Merrill, J. Elen, \& M. J. Bishop (Eds.), Handbook of research on educational communications and technology (4th ed., pp. 101-111). New York, NY: Springer. .

Koehler, M. J., Mishra, P., \& Cain, W. (2013). What is technological pedagogical content knowledge (TPACK)? Journal of Education, 193(3), 13-19.

Koetting, J. R. (1996). On the importance of historical understanding within our own work. Educational Media and Technology Yearbook, 21, 23-26.

Koltko-Rivera, M. E. (2004). The psychology of worldviews. Review of General Psychology, $8(1), 3-58$. 
Kristeva, J. (1980). The bounded text. (T. Gora, A. Jardine, \& L. S. Roudiez, Trans.). In L. S. Roudiez (Ed.), Desire in language: A semiotic approach to literature and art (pp. 36-63). New York, NY: Columbia University Press.

Krumer-Nevo, M. (2012). Researching against othering. In N. K. Denzin \& M. D. Giardina (Eds.), Qualitative inquiry and the politics of advocacy (pp. 185-204). Walnut Creek, CA: Left Coast Press, Inc.

Kurz, A., Reddy, L. A., \& Glover, T. A. (2017). A multidisciplinary framework of instructional coaching. Theory Into Practice, 56(1), 66-77.

Lankshear, C., \& Knobel, M. (2003). New literacies: Changing knowledge and classroom learning. Maidenhead, Berkshire, England: Open University Press.

Lankshear, C., \& Knobel, M. (2006). New literacies: Everyday practices and classroom learning (2nd ed.). Maidenhead, Berkshire, England: Open University Press.

Lankshear, C., \& Knobel, M. (2007). Knobel and Lankshear on the new literacies. In M. Knobel, M. \& Lankshear, C. (Eds.), A new literacies sampler (pp. 2-17). New York, NY: Peter Lang. Retrieved from http://newlearningonline.com/literacies/chapter-2/knobel-andlankshear-on-the-new-literacies

Lanterman, C. S., \& Applequist, K. (2018). Pre-service teachers' beliefs: Impact of training in universal design for learning. Exceptionality Education International, 28(3), 102-121.

Lapan, S. D., Quartaroli, M. T., \& Reimer, F. J. (2012). Introduction to qualitative research. In S. D. Lapan, M. T. Quartaroli, \& F. J. Reimer (Eds.), Qualitative research: An introduction to methods and designs (pp. 3-18). Hoboken, NJ: Wiley-Blackwell.

Lather, P. (1986). Issues of validity in openly ideological research: Between a rock and a soft place. Interchange, 17(4), 63-84. 
Leander, K. M., \& Boldt, G. (2018). Design, desire, and difference. Theory Into Practice, 57(1), 29-37.

Lee, K., \& Brett, C. (2015). Dialogic understanding of teachers' online transformative learning: A qualitative case study of teacher discussions in a graduate-level online course. Teaching And Teacher Education, 46, 72-83.

Lei, J. (2009). Digital natives as preservice teachers: What technology preparation is needed?. Journal of Computing in Teacher Education, 25(3), 87-97.

Leighton, C. M., Ford-Conners, E., Robertson, D. A., Wyatt, J., Wagner, C. J., Proctor, C. P., \& Paratore, J. R. (2018). “Let's FaceTime tonight:” Using digital tools to enhance coaching. Reading Teacher, 72(1), 39-49.

Lemke, J. L. (2013). Thinking about feeling: Affect across literacies and lives. In O. Erstad \& J. Sefton-Green (Eds.), Identity, community, and learning lives in the digital age (pp. 5769). New York, NY: Cambridge University Press.

Lemley, C. K., \& Mitchell, R. W. (2012). Narrative inquiry: Stories lived, stories told. In Lapan, S. D., Quartaroli, M. T., \& Reimer, F. J. (Eds.), Qualitative research: An introduction to methods and designs (pp. 215-242). Hoboken, NJ: Wiley-Blackwell.

Lensmire, T. J. (1994). Writing workshop as carnival: Reflections on an alternative learning environment. Harvard Educational Review, 64(4), 371-391.

Lenters, K. (2016). Telling "a story of somebody" through digital scrapbooking: A fourth grade multiliteracies project takes an affective turn. Literacy Research and Instruction, 55(3), 262-283. 
Leu, D. J., Castek, J., Henry, L. A., Coiro, J., McMullan, M. (2004). Children's books: The lessons that children teach us: Integrating children's literature and the new literacies of the internet. The Reading Teacher, 57(5), 496-503.

Leu, D. J., Castek, J., Hartman, D. K., Coiro, J., \& Henry, L. A. (2005). Evaluating the development of scientific knowledge and new forms of reading comprehension during online learning. Napervllle, IL: North Central Regional Educational Laboratory/Learning Point Associates

Leu, D. J., Forzani, E., \& Kennedy, C. (2015). Income inequality and the online reading gap: Teaching our way to success with online research and comprehension. The Reaching Teacher, 68(6), 422-427.

Leu, D. J., Forzani, E., Rhoads, C., Maykel, C., Kennedy, C., \& Timbrell, N. (2014). The new literacies of online research and comprehension: Rethinking the achievement gap. Reading Research Quarterly, 50(1), 37-59.

Leu, D. J., Kinzer, C. K., Coiro, J., Castek, J., \& Henry, L. A. (2013). New literacies: A duallevel theory of the changing nature of literacy, instruction, and assessment. In D. E. Alvermann, N. J. Unrau, \& R. B. Ruddell (Eds.), Theoretical models and processes of reading (6th ed., pp. 1150-1181). Newark, DE: International Reading Association.

Leu, D. J., \& Maykel, C. (2016). Thinking in new ways and in new times about reading. Literacy Research and Instruction, 55(2), 122-127.

Leu, D. J., O’Byrne, W. I., Zakalinski, L., McVerry, J. G., \& Everett, Everett-Cacopardo, H. (2009). Expanding the new literacies conversation. Educational Researcher, 38(4), 264269. 
Leu, D. J., \& Zawalinski, L. (2007). The new literacies of online reading. The NERA Journal, $43(1), 1-7$.

Li, J., Snow, C., \& White, C. (2015). Urban adolescent students and technology: Access, use and interest in learning language and literacy. Innovation in Language Learning and Teaching, 9(2), 143-162.

Li, X., Chu, S. K. W., Ki, W. W., \& Woo, M. (2012). Using a wiki-based collaborative process writing pedagogy to facilitate collaborative writing among Chinese primary school students. Australasian Journal of Educational Technology, 28(1), 159-181.

Li, Y., Garza, V., Keicher, A., \& Popov, V. (2019). Predicting high school teacher use of technology: Pedagogical beliefs, technological beliefs and attitudes, and teacher training. Technology, Knowledge, and Learning, 24(3), 501-518.

Lieberman, A., \& Wood, D. (2003). Inside the National Writing Project: Connecting network learning and classroom teaching. New York, NY: Teachers College Press.

Limberg, L., Sundin, O., \& Talja, S. (2011). Three theoretical perspectives on information literacy. Human IT, 11(2), 93-130.

Linde, C. (1987). Explanatory systems in oral life stories. In D. Holland \& N. Quinn (Eds.), Cultural models in language and thought (pp. 343-368). Cambridge, England: Cambridge University Press.

Lindorff, A., \& Sammons, P. (2018). Going beyond structured observations: Looking at classroom practice through a mixed method lens. ZDM: The International Journal on Mathematics Education, 50(3), 521-534. 
Lizárraga, J. R., \& Gutiérrez, K. D. (2018). Centering Neplanta literacies from the borderlands:

Leveraging "in-betweenness" toward learning in the everyday. Theory Into Practice, $57(1), 38-47$

Lloyd, R., Elizabeth, M., \& Howell, M. (2019). Positioning pre-service teacher beliefs along the traditional-reform continuum: An examination of normative beliefs and discursive claims. Mathematics Enthusiast, 16(1-3), 155-210.

Lohnes Watulak, S., \& Kinzer, C. K. (2013). Beyond technology skills: Toward a framework for critical digital literacies in pre-service technology education. In Ávila, J., \& Pandya, J. Z. (Eds.), Critical digital literacies as social praxis: Intersections and challenges (127153). New York, NY: Peter Lang Publishing, Inc.

Lorimer Leonard, R. (2013). Traveling literacies: Multilingual writing on the move. Research in the Teaching of English, 48(1), 13-39.

Losh, E. (2018). Beyond the techno-missionary narrative. In K. A. Mills, A. Stornaiuolo, A. Smith, \& J. Z. Pandya (Eds.), Handbook of writing, literacies, and education in digital cultures (pp. 76-87). New York, NY: Routledge.

Lowther, D. L., Inan, F. A., Strahl, J. D., \& Ross, S. M. (2008). Does technology integration "work" when key barriers are removed? Educational Media International, 45(3), 195213.

Luke, A. (2004). Literacy and educational fundamentalism: A conversation with Dr. Allan Luke (H. Attarian, \& X. L. Curdt-Christiansen, Interviewers). English Quarterly, 36(4), 2-9. Luke, A. (2012b). Critical literacy: Foundational notes. Theory Into Practice, 51(1), 4-11. Luke, A. (2018). Looking at the next 20 years of multiliteracies: A discussion with Allan Luke (A. Garcia \& R. Seglem, Interviewers). Theory Into Practice, 57(1), 72-78. 
Luke, A., Cadzen C., Lin, A., \& Freebody, P (2004). The Singapore classroom coding scheme. National Institute of Education, Singapore, Core Research Program of the Centre for Research in Pedagogy and Practice:

Luke, A., Sefton-Green, J., Graham, P. W., Kellner, D., \& Ladwig, J. G. (2018). Digital ethics, political economy, and the curriculum: This changes everything. In K. A. Mills, A. Stornaiuolo, A. Smith, \& J. Z. Pandya (Eds.), Handbook of writing, literacies and education in digital culture (251-262). New York, NY: Routledge.

Lyle, J. (2003). Stimulated recall: A report on its use in naturalistic research. British Educational Research Journal, 29(6), 861-878.

Lyotard, J. (1984). The postmodern condition: A report on knowledge. (G. Bennington \& B. Massumi, Trans.). Manchester, UK: Manchester University Press. (Original work published 1979).

Mahiri, J. (2004). New teachers for new times: The dialogical principle in teaching and learning electronically. In A. F. Ball \& S. W. Freedman (Eds.), Bakhtinian perspectives on language, literacy, and learning (pp. 213-231). Cambridge, UK: Cambridge University Press.

Maraldo, J. (2014). Tweeting in the Agora: An historical documentary of educational structures and discourse in ancient Greece and in modern social media (Doctoral dissertation). Loyola University, Chicago, IL.

Marsh, J. (2014). Purposes for literacy in children's use of the online virtual world "Club Penguin." Journal of Research in Reading, 37(2), 179-195.

Martin, J., \& Merrotsy, P. (2006). Portfolio of artefacts: Promising data for qualitative research. Australasian Journal of Gifted Education, 15(1), 39-43. 
Matusov, E. (2009). Journey into dialogic pedagogy. New York, NY: Nova Science Publishers, Inc.

Matusov, E. (2015). Chronotopes in education: Conventional and dialogic. Dialogic Pedagogy, 3, A65-A97.

Matusov, E., \& Marjanovic-Shane, A. (2017). Bakhtin's mystical organic holism and its consequences for education. Dialogic Pedagogy: An International Online Journal, 5, 6174.

McAllum, K., Fox, S., Simpson, M., \& Unson, C. (2019). A comparative tale of two methods: How thematic narrative analyses author the data story differently. Communication Research and Practice, 5(4), 358-375.

McGuinn, P. (2016). From No Child Left Behind to the Every Student Succeeds Act: Federalism and the education legacy of the Obama administration. The Journal of Federalism, 46(3), $392-415$

McLaren, P. (2009). Critical pedagogy: A look at the major concepts. In A. Darder, M. P. Baltodano, \& R. D. Torres (Eds.), The critical pedagogy reader (2nd ed. pp. 61-83). New York, NY: Routledge.

Merchant, G. (2013). The trashmaster: Literacy and new media. Language and Education, 27(2), $144-160$.

Meredith, J. C. (1971). The CAI author/instructor. Englewood Cliffs, NJ: Educational Technology Publication.

Merleu-Ponty, M. (2002). Phenomenology of perception. (C. Smith, Trans.). New York, NY: Routledge. (Original work published 1945). 
Mertova, P., \& Webster, L. (2012). Critical event narrative inquiry in higher education quality. Quality Approaches in Higher Education, 3(2), 15-21.

Meyer, M. W. (1979). Organizational structure as signaling. The Pacific Sociological Review, 22(4), 481-500.

Mills, C. W. (2000). The power elite. Oxford, England: Oxford University Press. (Original work published 1956).

Mills, H., \& Jennings, L. (2011). Talking about talk: Reclaiming the value and power of literature circles. The Reading Teacher, 64(8), 590-598.

Mills, K. A., \& Levido, A. (2011). iPed: Pedagogy for digital text production. The Reading Teacher, 65(1), 80-91.

Milman, N. B., Carlson-Bancroft, A., \& Vanden Boogart, A. (2014). Examining differentiation and utilization of iPads across content areas in an independent, preK-4th grade elementary school. Computers in the Schools, 31(3), 119-133.

Mintzes, J. J., Marcum, B., Messerschmidt-Yates, C, \& Mark, A. (2012). Enhancing self-efficacy in elementary science teaching with professional learning communities. Journal of Science Teacher Education, 24(7), 1201-1218.

Mirra, N. Morrell, E., \& Filipak, D. (2018). From digital consumption to digital invention: Toward a new critical theory and practice of multiliteracies. Theory Into Practice, 57(1), 12-19.

Mishler, E. G. (1999). Storylines: Craftarists' narratives of identity. Cambridge, MA: Harvard University Press. 
Mishra, P., \& Koehler, M. J. (2003). Not "what" but "how": Becoming design-wise about educational technology. In Y. Zhao (Ed.), What should teachers know about technology: Perspectives and practices (pp. 99-122). Greenwich, CT: Information Age Publishing Inc.

Mishra, P., \& Koehler, M. J. (2006). Technological pedagogical content knowledge: A framework for teacher knowledge. Teachers College Record, 108(6), 1017-1054.

Mishra, P., Koehler, M. J., \& Henriksen, D. (2011). The seven trans-disciplinary habits of mind: Extending the TPACK framework towards 21 st century learning. Educational Technology, 51(2), 22-28.

Mitchell, R. (2008). 'Soft ears' and hard topics: Race, disciplinarity, and voice in higher education. In A. Y. Jackson \& L. A. Mazzei (Eds.), Voice in qualitative inquiry: Challenging conventional, interpretive, and critical conceptions in qualitative research (pp. 77-96). New York, NY: Routledge.

Miyazaki, K. (2017). Comment on Groys’ essay “between Stalin and Dionysus: Bakhtin’s theory of the carnival. Dialogic Pedagogy: An International Online Journal, 5, 47-52.

Morehead, H. (1955). Television and learning. Educational Leadership, 13, 167-171.

Moreno de Diezmas, E. N., \& Manzano, P. D. (2016). PLEs in primary school: The learners' experience in the PIPLEP project. Digital Education Review, (29), 45-61.

Morgan, A. (2011). Investigating our experience in the world: A primer on qualitative inquiry. Knoxville, TN: University of Tennessee Press.

Morris, R. V. (2018). Student research: Documentaries made in the community. Social Studies, $109(1), 34-44$. 
Morrissey, C. (1987). The two-sentence format as an interviewing technique in oral history fieldwork. Oral History Review, 15(1), 43-53.

Morrow, S. L. (2005). Quality and trustworthiness in qualitative research in counseling psychology. Journal of Counseling Psychology, 52(2), 250-260.

Morson, G. P. (2010). The chronotope of humanness: Bakhtin and Dostoevsky. In N. Bemong, P. Borghart, M. De Dobbeleer, K. Demoen, K. De Temmerman, \& B. Keunen (Eds.), Bakhtin's theory of the literary chronotope: Reflections, applications, perspectives (pp. 93-110). Lebanon, NH: Academia Press.

Muñoz, M. A., \& Guskey, T. R. (2015). Standards-based grading and reporting will improve education. Phi Delta Kappan, 96(7), 64-68.

Nance, K. A. (2004). Let us say that there is a human being before me who is suffering: Empathy, exotopy, and ethics in the reception of Latin American collaborative testimonio. In V. Z. Nollan (Ed.), Bakhtin: Ethics and mechanics (pp. 57-73). Evanston, IL: Northwestern University Press.

Naot-Ofarim, Y., \& Solomonic, S. (2016). Educational polyphony. Studies in Philosophy and Education, 35(1), 385-397.

National Commission on Excellence in Education (1983). A nation at risk: The imperative for educational reform. Washington, D.C.: United States Department of Education.

National Council for the Social Studies. (2013). Technology position statement and guidelines. Retrieved from http://www.socialstudies.org/positions/technology

National Council of Teachers of English. (2013). The NCTE definition of 21 st century literacies. Retrieved from http://www.ncte.org/positions/statements/21stcentdefinition 
National Council of Teachers of Mathematics. (2011). Strategic use of technology in teaching and learning mathematics. Retrieved from http://www.nctm.org/Standards-andPositions/Position-Statements/Strategic-Use-of-Technology-in-Teaching-and-LearningMathematics/

National Education Association for the United States. (1894). Report of the Committee of Ten on secondary school studies: With the reports of the conferences arranged by the committee. New York, NY: American Book Co.

National Education Association of the United States: Commission on the Reorganization of Secondary Education. (1918). Cardinal principles of secondary education: A report of the Commission on the Reorganization of Secondary Education, appointed by the National Education Association. Washington, D.C.: Government Printing Office.

National Governors Association Center for Best Practices \& Council of Chief State School Officers. (2010). Common Core State Standards for English language arts and literacy in history/social studies, science, and technical subjects. Washington, D. C. Retrieved from http://www.corestandards.org/wp-content/uploads/ELA_Standards1.pdf

National Science Teachers Association. (2016). The role of e-learning in science education. Retrieved from http://www.nsta.org/about/positions/e-learning.aspx

Naughton, C. (2016). A reflection on Bakhtin's 'epic and novel' in the context of early childhood student teachers' practicum. Studies in Philosophy and Education, 35(1), 93-101.

Negroponte, N. (2006). No lap un-topped: Digital inclusion from the bottom up. Public Sector Technology and Management, 3(6), 25-29.

Neumann, K. L., \& Kopcha, T. J. (2019). Using Google Docs for peer-then-teacher review on middle school students' writing. Computers and Composition, 54, 1-16. 
New London Group. (1996). A pedagogy of multiliteracies: Designing social futures. Harvard Educational Review, 66(1), 60-92.

Newman, I., Newman, D, \& Newman, C. (2011). Writing research articles using mixed methods. In T. S. Rocco \& T. Hatcher (Eds.), The handbook of scholarly writing and publishing (pp. 191-208). San Francisco, CA: Jossey-Bass.

Niederhauser, D. S., \& Stoddart, T. (2001). Teachers' instructional perspectives and use of educational software. Teaching and Teacher Education, 17, 15-31.

Niemeyer, D. J., \& Gerber, H. R. (2015). Maker culture and "Minecraft": Implications for the future of learning. Educational Media International, 52(3), 216-226.

Nolen, S. B., \& Koretsky, M. D. (2018). Affordances of virtual and physical laboratory projects for instructional design: Impacts on student engagement. IEEE Transactions on Education, 61(3), 226-233.

Norman, D. A. (1999). Affordance, conventions, and design. Interactions, 6(3), 38-43.

Novoa, M. (2018). Industrial design education as innovation broker through making, pivot thinking, autopoiesis and expansive learning. Design \& Technology Education, 23(3), $120-153$.

O'Hara, M. (2011). Young children's ICT experiences in the home: Some parental perspectives. Journal of Early Childhood Research, 9(3), 220-231.

O’Neal, L. J., Gibson, P., \& Cotten, S. R. (2017). Elementary school teachers' beliefs about the role of technology in 21st-century teaching and learning. Computers in the Schools, 34(3), 192-206. 
Office of Educational Technology. (2017). Reimagining the role of technology in education: 2017 National Education Technology Plan Update. Washington, D.C.: United States Department of Education.

Opfer, V. D., \& Pedder, D. (2011). Conceptualizing teacher professional learning. Review of Educational Research, 81(3), 376-407.

Ornstein, A. C. (1990). Philosophy as a basis for curriculum decisions. The High School Journal, 74(2), 102-109.

Overby, A., \& Jones, B. L. (2015). Virtual LEGOs: Incorporating Minecraft into the art education curriculum. Art Education, 68(1), 21-27.

Pangrazio, L. (2016). Reconceptualising critical digital literacy. Discourse: Studies in the Cultural Politics of Education, 37(2), 163-174.

Patterson, M. M., Kravchenko, N., Chen-Bouck, L., \& Kelley, J. A. (2016). General and domainspecific beliefs about intelligence, ability, and effort among preservice and practicing teachers. Teaching and Teacher Education, 59, 180-190.

Penuel, W. R., \& O’Connor, K. (2018). From designing to organizing new social futures: Multiliteracies pedagogies for today. Theory Into Practice, 57(1), 64-71.

Penuel, W. R., \& Shepard, L. A. (2016). Assessment and teaching. In D. H. Gitomer \& C. A. Bell (Eds.), Handbook of research on teaching (5th ed., pp. 787-850). Washington, D.C.: American Educational Research Association.

Pereira, S., \& Pereira, L. (2015). Digital media in primary schools: Literacy or technology? analyzing government and media discourses. Educational Policy, 29(2), 316-341. Peshkin, A. (1988). In search of subjectivity—one's own. Educational Researcher, 17(7), 17-21. 
Petty, J., Jarvis, J., \& Thomas, R. (2018). Core story creation: Analysing narratives to construct stories for learning. Nurse Researcher, 25(4), 47-51.

Pinch, T. J., \& Bijker, W. E. (1984). The social construction of facts and artefacts: Or how the sociology of science and the sociology of technology might benefit each other. Social Studies of Science, 14(3), 399-441.

Pinnegar, S., \& Daynes J. G. (2007). Locating narrative inquiry historically: Thematics in the turn to narrative. In D. J. Clandinin (Ed.), Handbook of narrative inquiry: Mapping a methodology (pp. 3-34). Thousand Oaks, CA: SAGE Publications, Inc.

Plano Clark, V. L., \& Creswell, J. W. (2010). Understanding research: A consumer's guide. Upper Saddle River, NJ: Pearson Education, Inc.

Plato (1941). The republic. (B. Jowett, Trans.). New York, Y: The Modern Library. (Original work published 360 B. C.).

Polkinghorne, D. E. (1988). Narrative knowing and the human sciences. Albany, NY: University of New York Press.

Polkinghorne, D. E. (1995). Narrative configuration in qualitative analysis. Qualitative Studies in Education, 8(1), 5-23.

Ponterotto, J. G. (2005). Qualitative research in counseling psychology: A primer on research paradigms and philosophy of science. Journal of Counseling Psychology, 52(2), 126-136.

Popkewitz, T. S., \& Shutkin, D. S. (1993). Social science, social movements, and the production of educational technology in the U.S. In R. Muffoletto \& N. N. Knupfer (Eds.), Computers in education: Social, political, \& historical perspectives (pp. 11-36). Cresskill, NJ: Hampton Press, Inc. 
Posthuma, D. (2010). The impact of at-risk students enrolled in advanced placement courses on a high school culture (Doctoral dissertation). California State University, Fullerton, CA.

Prensky, M. (2001). Digital natives, digital immigrants: A new way to look at ourselves and our kids. On the Horizon, 9(5), 1-6.

Prior, P., \& Shipka, J. (2003). Chronotopic lamination: Tracing the contours of literate activity. In C. Bazerman \& D. R. Russell (Eds.), Writing selves, writing societies (pp. 180-238). Fort Collins, CO: The WAC Clearinghouse.

Public Law 89-10 - Elementary and Secondary Education Act of 1965. Signed into public law April 11, 1965, 89th U.S. Congress. Retrieved from Government Publishing Office website: https://www.gpo.gov/fdsys/pkg/STATUTE-86/pdf/STATUTE-86-Pg235.pdf

Public Law 92-318 - Education Amendments of 1972. Signed into public law June 23, 1972, 92nd U.S. Congress. Retrieved from Government Publishing Office website: https://www.gpo.gov/fdsys/pkg/STATUTE-86/pdf/STATUTE-86-Pg235.pdf

Public Law 93-438 - National Research Act. Signed into public law July 12, 1974, 93rd U.S. Congress. Retrieved from National Institutes of Health: Office of History website: https://history.nih.gov/research/downloads/PL93-348.pdf

Public Law 94-142 - Education for All Handicapped Children Act. Signed into public law November 29, 1975, 94th U.S. Congress. Retrieved from Government Publishing Office website: https://www.gpo.gov/fdsys/pkg/STATUTE-89/pdf/STATUTE-89-Pg773.pdf Public Law 107-110 - No Child Left Behind Act of 2001. Signed into public law Jan. 8, 2002, 107th U.S. Congress. Retrieved from U.S. Department of Education website: https://www2.ed.gov/policy/elsec/leg/esea02/107-110.pdf 
Public Law 114-95 - Every Student Succeeds Act. Signed into public law Dec. 10, 2015, 114th U.S. Congress. Retrieved from U.S. Congress website: https://www.congress.gov/114/plaws/pub195/PLAW-114pub195.pdf

Puentedura, R. (2014). SAMR: A contextualized introduction [Powerpoint slides]. Retrieved from http://hippasus.com/rrpweblog/archives/2014/01/15/SAMRABriefContextualized Introduction.pdf

Quantz, R. A., \& O’Connor, T. W. (1988). Writing critical ethnography: Dialogue, multivoicedness, and carnival in cultural texts. Educational Theory, 38(1), 95-109.

Rabbat, S. (2014). Designing inquiry for upper elementary students: Lessons learned from driver's ed. Knowledge Quest, 43(2), 34-37.

Raby, D. (2012). 'My heart can't do what it wants': Sadness and learned empathy in a Nahua community. Anthropology \& Humanism, 37(2), 201-213.

Ravitch, S. M., \& Riggan, M. (2011). Reason \& rigor: How conceptual frameworks guide research (2nd ed.). Thousand Oaks, CA: SAGE Publications, Inc.

Reardon, M. (2019, October 7). Trump calls net neutrality court decision a 'great win.' CNET. Retrieved from https://www.cnet.com/news/trump-calls-net-neutrality-court-decision-agreat-win/

Rešić, S., \& Čukle, N. (2013). Influence of interactive boards in improving teaching of mathematics in high school. In M. Pavleković, Z. Kolar-Begović, \& R. Kolar-Šuper (Eds.), Mathematics teaching for the future (pp. 127-142). Zagreb, Croatia: Element.

Rico, R., \& Ertmer, P. A. (2015). Examining the role of the instructor in problem-centered instruction. TechTrends: Linking Research \& Practice to Improve Learning, 59(4), 96103. 
Riley, D. W. (1940). Conclusions drawn from the institutes for education by radio. Quarterly Journal of Speech, 26, 575-579.

Roberts, J. (2007). Education, eco-progressivism and the nature of school reform. Educational Studies, 41(3), 212-229.

Robinson, J. A., \& Hawpe, L. (1986). Narrative thinking in a heuristic process. In T. R. Sarbin (Ed.), Narrative psychology (pp. 111-125). New York, NY: Praeger Publishers.

Robinson, L. A taste for the necessary: A Bordeauian approach to digital inequality. Information, Communication, and Society, 12(4), 488-507.

Rocco, T. S., \& Plakhotnik, M. S. (2011). Increasing the odds of publishing a qualitative manuscript. In T. S. Rocco \& T. Hatcher (Eds.), The handbook of scholarly writing and publishing (pp. 161-178). San Francisco, CA: Jossey-Bass.

Rogers, A. G. (2007). The unsayable, Lacanian psychoanalysis, and the art of narrative interviewing. In D. J. Clandinin (Ed.), Handbook of narrative inquiry: Mapping a methodology (pp. 81-98). Thousand Oaks, CA: SAGE Publications, Inc.

Ronksley-Pavia, M., \& Grootenboer, P. (2017). Insights into disability and giftedness: Narrative methodologies in interviewing young people identified as twice exceptional. In R. Dwyer, I. Davis, \& E. Emerald (Eds.), Narrative research in practice: Stories from the field (pp. 183-208). Singapore: Springer.

Roose, I., Vantieghem, W., Vanderlinde, R., \& Van Avermaet, P. (2019). Beliefs as filters for comparing inclusive classroom situations: Connecting teachers' beliefs about teaching diverse learners to their noticing of inclusive classroom characteristics in videoclips. Contemporary Educational Psychology, 56, 140-151. 
Roozen, K. (2009). "Fan Fic-ing” English studies: A case study exploring the interplay of vernacular literacies and disciplinary engagement. Research in the Teaching of English, 44(2), 136-169.

Roozen, K., Woodard, R., Kline, S., \& Prior, P. A. (2015). The transformative potential of laminating trajectories of pedagogical practice: Three teachers' developing practices and identities. In T. Lillis, K. Harrington, M. Lea, \& S. Mitchell (Eds.), Working with academic literacies: Research, theory, design (pp. 205-215). Fort Collins, CO: The WAC Clearinghouse.

Ross, E. A. (1896). Social control. American Journal of Sociology, 1(5), 513-535.

Roswell, J., Kosnik, C., \& Beck, C. (2008). Fostering multiliteracies pedagogy through preservice teacher education. Teaching Education, 19(2), 109-122.

Rousseau, J. J. (1889). Émile; or, concerning education. (E. Worthington, Trans.). Boston, MA: D. C. Heath \& Company.

Rust, J. (2017). Pedagogy meets digital media: A tangle of teachers, strategies, and tactics. Contemporary Issues in Technology \& Teacher Education, 17(2), 168-193.

Saettler, P. (1990). The evolution of American educational technology. Englewood, CO: Libraries Unlimited, Inc.

Sassen, S. (2002). Towards a sociology of information technology. Current Sociology, 50(3), $365-388$.

Sauer, M. P. (2012). Storytelling by adults diagnosed with terminal illness: Narrative identifying through dialogical research (Doctoral dissertation). The Pennsylvania State University, State College, PA. 
Scheffler, I. (1964). The language of education. Springfield, IL: Charles C. Thomas. (Original work published 1960).

Schein, E. (1972). Professional education: Some new directions. New York, NY: McGraw-Hill Book Company.

Schensul, J. J. (2012). Methodology, methods, and tools in qualitative research. In Lapan, S. D., Quartaroli, M. T., \& Reimer, F. J. (Eds.), Qualitative research: An introduction to methods and designs (pp. 243-270). Hoboken, NJ: Wiley-Blackwell.

Schlesinger, A. M., Jr. (1986). The cycles of American history. Boston, MA: Houghton Mifflin Company.

Schön, D. A. (1983). The reflective practitioner. New York, NY: Basic Books, Inc.

Schroeter, S. (2019). Embodying difference: A case for anti-racist and decolonizing approaches to multiliteracies. Studies in Social Justice, 13(1), 142-158.

Schuller, C. J. (1985). Some historical perspectives on the instructional technology field. Journal of Instructional Development, 8(3), 3-6.

Schutz, A. (1945). On multiple realities. Philosophy and Phenomenological Research, 5(4), 533576.

Schutz, A. (1967) The phenomenology of the social world (G. Walsh \& F. Lehnert). Evanston, IL: Northwestern University Press. (Original work published 1932).

Schwandt T. (1998). Constructivist, interpretivist approaches to human inquiry. In N. K. Denzin \& Y. S. Lincoln (Eds.), The landscape of qualitative research: Theories and issues (pp. 221-259). Thousand Oaks, CA: SAGE Publications, Inc.

Schwandt, T. A. (2015). The SAGE dictionary of qualitative inquiry (4th edition). Thousand Oaks, CA: SAGE Publications, Inc. 
Schweder, R. A. (1991). Thinking through cultures: Expeditions in cultural psychology. Harvard University Press: Cambridge, MA.

Scollon, R. (1998). Mediated discourse as social interaction: A study of news discourse. New York, NY: Routledge.

Scollon, R. (2001). Mediated discourse: The nexus of practice. New York, NY: Routledge.

Scollon, R., Scollon, S. W., \& Jones, R. H. (2012). Intercultural communication: A discourse approach (3rd ed.). Chichester, West Sussex, UK: Wiley-Blackwell.

Seels, B. B., \& Richey, R. C. (1994). Instructional technology: The definition and domains of the field. Bloomington, IN: Association for Educational Communications and Technology.

Seglem, R. (2015). Driving into the gap: Decision-making for infusing technology in schools. In Keengwe, J., Mbae, J. G., \& Ngigi S. K. (Eds.), Promoting global literacy skills through technology-infused teaching and learning (63-85). Hershey, PA: IGI Global.

Seglem, R., \& Garcia, A. (2018). Changing literacies and civic pathways: Multiliteracies in inquiry-driven classrooms. Theory Into Practice, 57(1), 56-63.

Selyuhk, A. (2018, February 22). FCC takes another step toward repeal of net neutrality. NPR. Retrieved from https://www.npr.org/sections/thetwo-way/2018/02/22/587896608/fccsrepeal-of-net-neutrality-on-track-to-go-into-efffect

Shing, C. L., Saat, R. M., \& Loke, S. H. (2015). The knowledge of teaching - pedagogical content knowledge (PCK). The Malaysian Online Journal of Educational Science, 3(3), $40-55$

Shulman, L. S. (1986). Those who understand: Knowledge growth in teaching. Journal of Education- Boston University School of Education, 193(3), 1-12. 
Shulsky, D. D., Baker, S. F., Chvala, T., \& Willis, J. M. (2017). Cultivating layered literacies: Developing the global child to become tomorrow's global citizen. International Journal of Development Education and Global Learning, 9(1), 49-63.

Sidorkin, A. M. (1997). Carnival and domination: Pedagogies of neither care nor justice. Educational Theory, 47(2), 229-238.

Sidorkin, A. M. (2002). Learning relationship: Impure education, deschooled schools, and dialogue with evil. New York, NY: Peter Lang Publishing, Inc.

Sinks, T. A., \& Thurston, J. F. (1972). Effect of typing on school achievement in elementary grades. Educational Leadership, 29(4), 344-348.

Skinner, B. F. (1954). The science of learning and the art of teaching. Harvard Educational Review, 24(2), 86-97.

Skrtic, T. M. (1990). Social accommodation: Toward a dialogical discourse in educational inquiry. In E. G. Guba (Ed.), The paradigm dialog (pp. 125-138). Thousand Oaks, CA: SAGE Publications, Inc.

Slavin, R. E. (1989). PET and the pendulum: Faddism in education and how to stop it. The Phi Delta Kappan, 70(10), 752-758.

Smith, A., Cope, B., \& Kalantzis, M. (2018). The quantified writer: Data traces in education. In K. A. Mills, A. Stornaiuolo, A. Smith, \& J. Z. Pandya (Eds.), Handbook of writing, literacies, and education in digital cultures (pp. 235-247). New York, NY: Routledge.

Smith, A., \& Hull, G. (2013). Critical literacies and social media: Fostering ethical engagement with global youth. In J. Ávila \& J. Z. Pandya (Eds.), Critical digital literacies as social praxis: Intersections and challenges (pp. 63-84). New York, NY: Peter Lang Publishing, Inc. 
Smith, D. E. (1987). Women's perspective as a radical critique of sociology. In S. Harding (Ed.), Feminism and methodology: Social science issues (pp. 84-96). Bloomington, IN: Indiana University Press.

Smith, J. S. (2017). Assessing creativity: Creating a rubric to effectively evaluate mediated digital portfolios. Journalism and Mass Communication Educator, 72(1), 24-36.

Snedden, D. S. (1933). Valuing of learnings. Journal of Educational Sociology, 7, 105-116.

Snedden, D. S. (1934). Some sociological foundations. Journal of Educational Sociology, 7 , 420-423.

Snider, M. (2018, February 23). 22 states and DC are suing the FCC in a last-ditch effort to preserve net neutrality. USA Today. Retrieved from https://www.usatoday.com/story/tech/news/2018/02/22/net-neutrality-clock-tickingthose-who-want-old-rules-back/357985002/

Sohn, B. K., Thomas, S. P., Greenberg, K. H., \& Pollio, H. R. (2017). Hearing the voices of students and teachers: A phenomenological approach to educational research. Qualitative Research in Education, 6(2), 121-148.

Spector-Mersel, G. (2010). Narrative research: Time for a paradigm. Narrative Inquiry, 20(1), 204-224.

Stake, R. E. (2010). Qualitative research: Studying how things work. New York, NY: The Guilford Press.

Steffen, J. H., Gaskin, J. E., Meservy, T. O., Jenkins, J. L., \& Wolman, I. (2019). Framework of affordances for virtual reality and augmented reality. Journal of Management Information Systems, 36(3), 683-729. 
Stornaiuolo, A., Smith, A., \& Phillips, N. C. (2017). Developing a transliteracies framework for a connected world. Journal of Literacy Research, 49(1), 68-91.

Street, B. (1993). Introduction: The new literacy studies. In B. Street (Ed.), Cross-cultural approaches to literacy (pp. 1-21). Cambridge, England: Cambridge University Press.

Street, B. (2003). What's "new" in new literacy studies? Critical approaches to literacy in theory and practice. Current Issues in Comparative Education, 5(2), 77-91/

Stulman, J. (1974). The third industrial revolution. Management Review, 63(6), 52-55.

Sullivan, P., Smith, M. \& Matusov, E. (2009). Bakhtin, Socrates, and the carnivalesque in education. New Ideas in Psychology, 27(3), 326-342.

Sylvester, A., Tate, M., \& Johnstone, D. (2013). Beyond synthesis: Re-presenting heterogeneous research literature. Behaviour \& Information Technology, 32(12), 1199-1215.

Tabb, L. S. (2008). A chicken in every pot; one laptop per child: The trouble with global campaign promises. E-Learning, 5(3), 337-351.

Tawfik, A. A., \& Kolodner, J. L. (2016). Systematizing scaffolding for problem-based learning: A view from case-based reasoning. Interdisciplinary Journal of Problem-Based Learning, 10(1). Retrieved from https://docs.lib.purdue.edu/ijpbl/vol10/iss 1/6/

Tedlock, B. (1991). From participant observation to the observation of participation: The emergence of narrative ethnography. Journal of Anthropological Research, 47(1), 69-94.

Thibaut, P., \& Curwood, J. S. (2018). Multiliteracies in practice: Integrating multimodal production across the curriculum. Theory Into Practice, 57(1), 48-55.

Thoma, J., Hutchison, A., Johnson, D., Johnson, K., \& Stromer, E. (2017). Planning for technology integration in a professional learning community. Reading Teacher, 71(2), $167-175$. 
Thomas, M. (1980). The rise and decline of an educational technology: Television in America Samoa. Educational Communication and Technology, 28(3), 155-167.

Thorndike, E. L. (1912). Education, a first book. New York, NY: The Macmillan Company. Tinnell, J. (2018). Actionable media: Digital communication beyond the desktop. New York, NY: Oxford University Press.

Tonbuloğlu, I., \& Kiyici, M. (2018). Opinions of preservice teachers on their acceptance of the use of mobile technologies for teaching purposes. Journal of Education and Training Studies, 6(6), 94-110.

Tondeur, J., Roblin, N. P., van Braak, J., Fisser, P., \& Voogt, J. (2013). Technological pedagogical content knowledge in teacher education: In search of a new curriculum. Educational Studies, 39(2), 239-243.

Tondeur, J., van Braak, J., Ertmer, P. A., \& Ottenbreit-Leftwich, A. (2017). Understanding the relationship between teachers' pedagogical beliefs and technology use in education: A systematic review of qualitative evidence. Educational Technology Research and Development, 65(3), 555-575.

Torre, D., \& Murphy, J. (2015). A different lens: Using photo-elicitation interviews in education research. Education Policy Analysis Archives, 23(110/111), 1-23.

Tour, E. (2015). Digital mindsets: Teachers' technology use in personal life and teaching. Language Learning \& Technology, 19(3), 124-139.

Tracy, S. J. (2013). Qualitative research methods: Collecting evidence, crafting analysis, communicating impact. Chichester, West Sussex, UK: Wiley-Blackwell. 
Tyack, D. (1993). School governance in the United States: Historical puzzles and anomalies. In J. Hannaway \& M. Carnoy (Eds.), Decentralization and school improvement: Can we fulfill the promise? (pp. 1-32). San Francisco, CA: Josey-Bass

Valcke, M., Sang, G., Rots, I., \& Hermans, R. (2010). Taking prospective teachers' beliefs into account in teacher education. International Encyclopedia of Education, 7, 622-628.

van Deurson, A. J. A. M., \& Helsper, E. J. (2015). The third-level digital divide: Who benefits most from being online? In L. Robinson, S. R. Cotten, J. Schulz, T. M. Hale, \& A. Williams (Eds.), Communication and information technologies annual (studies in media and communications, volume 10) (pp. 29-52). Bingley, UK: Emerald Group Publishing Limited.

Van Dijk, J. A. G. M. (2012). The evolution of the digital divide: The digital divide turns to inequality of skills and usage. In J. Bus, M. Crompton, M. Hildebrandt, \& G. Metakides (Eds.), Digital enlightenment yearbook 2012 (pp. 57-75). Amsterdam: IOS Press.

Van Dijk, J. A. G. M. (2017). Digital divide: Impact of access. In P. Rössler, C. A. Hoffner, \& L. Zoonen (Eds.), The international encyclopedia of media effects (pp. 1-8). Hoboken, NJ: Wiley-Blackwell.

van Manen, M. (2016). Researching lived experience: Human science for action sensitive pedagogy (2nd ed.). New York, NY: Routledge.

Van Patten, J. J. (2000, July). New delivery systems for the 21st century. Paper presented to the World Futures Society Future Focus, Houston, TX.

Varier, D., Dumke, E. K., Abrams, L. M., Conklin, S. B., Barnes, J. S., \& Hoover, N. R. (2017). Potential of one-to-one technologies in the classroom: Teachers and students weigh in. Educational Technology Research And Development, 65(4), 967-992. 
Vigdor, J. L., Ladd, H. F., \& Martinez, E. (2014). Scaling the digital divide: Home computer technology and student achievement. Economic Inquiry, 52(3), 1103-1119.

Vlieghe, J. (2016). Education, digitization and literacy training: A historical and cross-cultural perspective. Educational Philosophy and Theory, 48(6), 549-562.

Vojak, C., Kline, S., Cope, B., McCarthey, S., \& Kalantzis, M. (2011). New spaces and old places: An analysis of writing assessment software. Computers and Composition, 28, 97111.

Voogt, J., Fisser, P., Pareja Roblin, N., Tondeur, J., \& van Braak, J. (2012). Technological pedagogical content knowledge - a review of the literature. Journal of Computer Assisted Learning, 29(2), 109-121.

Wang, G. (2009). The chronotopes of encounter and emergence. Journal of Curriculum Theorizing, 25(1), 1-5.

Warschauer, M. (2012). The digital divide and social inclusion. Americas Quarterly, 6(2), 130135.

Warschauer, M., \& Tate, T. (2018). Digital divides and social inclusion. In K. A. Mills, A. Stornaiuolo, A. Smith, \& J. Z. Pandya (Eds.), Handbook of writing, literacies, and education in digital cultures (pp. 63-75). New York, NY: Routledge.

Webster, L., \& Mertova, P. (2007). Using narrative inquiry as a research method: An introduction to using critical event narrative analysis in research on learning and teaching. New York, NY: Routledge. 
Wertz, F. L., Charmaz, K., McMullen, L. M., Josselson, R., Anderson, R., \& McSpadden, E. (2011). Five ways of doing qualitative analysis: Phenomenological psychology, grounded theory, discourse analysis, narrative research, and intuitive inquiry. New York, NY: The Guilford Press.

Whelan, K. (1999). Traveler on a journey. In F. M. Connelly \& D. J. Clandinin (Eds.), Shaping $a$ professional identity: Stories of educational practice (pp. 20-31). New York, NY: Teachers College Press.

White, E. J. (2014). 'Are you 'avin a laff?': A pedagogical response to Bakhtinian carnivalesque in early childhood education. Educational Philosophy and Theory, 46(8), 898-913.

Whitney, A. (2008). Teacher transformation in the National Writing Project. Research in the Teaching of English, 43(2), 144-187.

Wiggins, G. P., \& McTighe, J. (2005). Understanding by design (2nd ed.). Alexandria, VA: Association for Supervision and Curriculum Development.

Wolf, S., \& Peele, M. E. (2019). Examining sustained impacts of two teacher professional development programs on professional well-being and classroom practices. Teaching and Teacher Education, 86.

Woodard, R. (2015). The dialogic interplay of writing and teaching writing: Teacher-writers' talk and textual practices across contexts. Research in the Teaching of English, 50(1), 3559.

Xu, H., \& Ko, P. Y. (2019). Enhancing teachers' knowledge of how to promote self-regulated learning in primary school students: A case study in Hong Kong. Teaching and Teacher Education, 80, 106-114. 
Yelland, N., Cope, B., \& Kalantzis, M. (2008). Learning by design: Creating pedagogical frameworks for knowledge building in the twenty-first century. Asia-Pacific Journal of Teacher Education, 36(3), 197-213.

Yin, R. K. (2010). Qualitative research from start to finish. New York, NY: Guilford Press.

Zheng, B., Arada, K., Niiya, M., \& Warschauer, M. (2014). One-to-one laptops in K-12 classrooms: Voices of students. Pedagogies: An International Journal, 9(4), 279-299. 


\section{APPENDIX A: LIFE STORY INTERVIEW PROTOCOL}

This narrative research study is primarily focused on the pedagogical design of elementary teachers with digital technologies in current and past educational settings. I intend to present

elementary teachers' development and evolution of digital pedagogy across a lifetime of experiences by co-constructing the stories that you feel are pertinent and critical toward this end.

General Life Story Interview Questions:

- What are your first memories of using technology in your life?

- What experiences or examples of teaching with technology do you recall from your preservice teacher education program (in college)?

- At what point of your career did you start integrating digital technologies in your instruction consistently (three days per week or more)? 


\section{APPENDIX B: ONLINE FOCUS GROUP INTRODUCTION}

Thank you for joining the focus group tonight (or today). Please display your artifact on the screen using the Zoom screen share function when you are sharing. This activity is not meant to be evaluative, but rather, an opportunity to engage in dialogue with other elementary teachers about your instructional practices with digital technologies. When it is your turn to share, please introduce your artifact and discuss the lesson, situation, or context from which it was obtained. Please briefly explain how it relates to your teaching with digital technologies. After you share, other members of the group will have an opportunity to ask clarifying questions and/or share non-evaluative reactions. 


\section{APPENDIX C: OBSERVATION PROTOCOL}

When I observe, I will look for examples of the following:

- Student-centered uses of technology

- Teacher-centered uses of technology

- Interactions between teacher and students

- Interactions between students

- Classroom environment 


\section{APPENDIX D: SEMI-STRUCTURED INTERVIEW PROTOCOL}

These general questions were used in each semi-structured interview:

- What do you feel were one or two moments prior to your teaching career that were

influential on how you viewed technology during your teaching career, either now or in the past?

- In what ways have your uses of technology in your personal life impacted your uses of it in your teaching practices?

- What challenges have you faced in teaching with technology?

- Do you feel you have overcome these challenges?

- Are there challenges that you feel you have yet to overcome?

- What have been your biggest motivations for integrating technology in learning activities with students? 


\section{APPENDIX E: INFORMED CONSENT FORM}

\section{Introduction}

This research study is being conducted by Aaron R. Gierhart at Illinois State University to tell the life stories of elementary teachers who consistently integrate digital technologies in their teaching practices. For the purposes of this study, "consistently"is defined as using digital technologies within classroom contexts for teaching and/or student learning purposes at least three days per school week.

\section{Participant Criteria}

You must be a current full time elementary (K-5) classroom teacher to participate. You are ineligible to participate if you are currently within the European Economic Area.

\section{Procedures}

If you choose to take part in this research study you will be asked to complete two interviews, each lasting approximately 30-45 minutes. You will also be asked to permit one classroom observation lasting approximately 2-4 hours during which students will be present, engaging in normal learning activities with no intervention by the researcher. Finally, you will be asked to take photographs of your classroom environment and collect other teaching artifacts (e.g., lesson plans) that you feel are relevant to your pedagogy and teaching practices with technology. You will be able to share the artifacts in a series of three focus group discussions held online using the video conferencing service Zoom, which can be accessed by a privately shared link. The other participants and Mr. Gierhart will be part of these discussions. It is anticipated that this study will involve 5-6 participants. All participants should maintain the confidentiality of the other participants who attend the focus groups. The focus group discussions will last for approximately 40-60 minutes each. If you are unable to participate in the focus groups due to scheduling conflicts, you can elect to share your artifacts in a one-on-one interview instead.

\section{Findings}

The following findings from the study may be published or otherwise disseminated at public symposiums, academic conferences, academic journals, and Illinois State University's research website: direct quotations, shared images, and photos or scans of shared teaching artifacts.

\section{Risks/Discomforts}

The risks associated with this research includes the potential revelation of information in stories that compromises professional standing. To reduce these risks, participants will have the opportunity to review the written research text and interpretations and request any details be removed or interpretations be revised as needed with no penalty or loss of benefits.

\section{Benefits}

You can benefit from participating in this study by potentially gaining greater self-understanding about your pedagogy and teaching practices. You will be able to engage in dialogue with other elementary teachers in a series of three focus group discussions held online. Your stories will increase social understanding of the development and evolution of pedagogy and teaching with technology at the elementary level across a career and lifetime. 


\section{Confidentiality}

All information provided will remain confidential and will be reported with no identifying information. All data collected will be stored in a password-protected cloud account to which Mr. Gierhart, Dr. Robyn Seglem, and Dr. Kyle Miller will have access.

\section{Participation}

Participating in this study is voluntary. Refusal to participate at any time during the study involves no penalty of any kind. You may discontinue participation at any time without penalty or loss of benefits. You can also skip interview questions you do not feel like answering.

\section{Questions about the Research}

For questions about this research, Aaron R. Gierhart can be contacted at 815-499-6095 or argierh@ilstu.edu. The study is being overseen by Dr. Robyn Seglem, who can be contacted at 309-438-3969 or rseglem@ilstu.edu.

You will be given a copy of this consent form for your records.

I consent to participating in the study detailed in this form.

Signature

Date

If you have any questions about your rights as a subject/participant in this research, or if you feel you have been placed at risk or have experienced any adverse effects as a result of your participation, you can contact the Research Ethics \& Compliance Office at Illinois State University at (309) 438-5527 or via email at rec@ilstu.edu. 